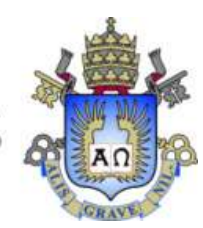

André Alonso Fernandes

\title{
Modelagem e avaliação de controladores não-lineares para perfuração de poços com gerenciamento de pressão
}

\section{Dissertação de mestrado}

Dissertação apresentada como requisito parcial para obtenção do grau de Mestre pelo Programa de PósGraduação em Engenharia Mecânica do Departamento de Engenharia Mecânica da PUC-Rio.

Orientador: Prof. Marco Antonio Meggiolaro 


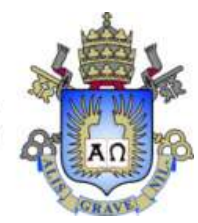

\title{
André Alonso Fernandes
}

\section{Modelagem e avaliação de controladores não-lineares para perfuração de poços com gerenciamento de pressão}

\begin{abstract}
Dissertação apresentada como requisito parcial para obtenção do grau de Mestre pelo Programa de PósGraduação em Engenharia Mecânica do Departamento de Engenharia Mecânica da PUC-Rio. Aprovada pela Comissão Examinadora abaixo assinada.
\end{abstract}

Prof. Marco Antonio Meggiolaro Orientador Departamento Engenharia Mecânica - PUC-Rio

Prof. João Carlos Ribeiro Plácido Departamento Engenharia Mecânica - PUC-Rio

Prof. Mauro Speranza Neto Departamento Engenharia Mecânica - PUC-Rio

Dr. Antonio Carlos Vieira Martins Lage Petróleo Brasileiro

Prof. José Eugenio Leal Coordenador Setorial do Centro Técnico Científico PUC-Rio 
Todos os direitos reservados. É proibida a reprodução total ou parcial do trabalho sem autorização da universidade, do autor e do orientador.

\section{André Alonso Fernandes}

Graduou-se em Engenharia Mecânica pela Universidade de São Paulo em 2001.

Ficha Catalográfica

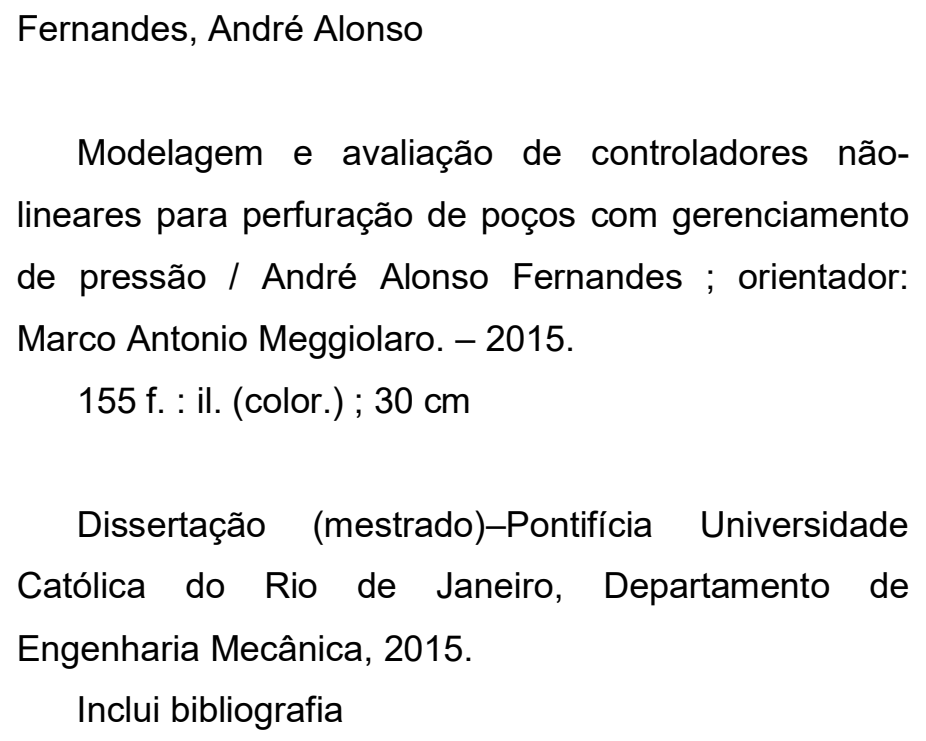

1. Engenharia mecânica - Teses. 2. MPD. 3. Perfuração de poços. 4. Modelagem. 5. Controle nãolinear. I. Meggiolaro, Marco Antonio. II. Pontifícia Universidade Católica do Rio de Janeiro. Departamento de Engenharia Mecânica. III. Título. 
Aos meus pais pelos exemplos e valores passados. A minha esposa Erica pelo incentivo e companheirismo.

Ao meu filho Martin. 


\section{Agradecimentos}

Agradeço aos colegas de trabalho e de universidade que contribuíram no meu desenvolvimento durante o curso de pós-graduação.

Aos professores da PUC pela disponibilidade e atenção dispensados.

Ao meu orientador Professor Marco Antonio Meggiolaro, pela orientação cientifica e conhecimentos compartilhados durante o desenvolvimento de minha dissertação.

À Pontifícia Universidade Católica de Rio de Janeiro e ao Curso de PósGraduação em Engenharia Mecânica, pelos auxílios concedidos, sem os quais este trabalho não poderia ter sido realizado. 


\section{Resumo}

Fernandes, André Alonso; Meggiolaro, Marco Antonio. Modelagem e avaliação de controladores não-lineares para Perfuração com gerenciamento de pressão. Rio de Janeiro, 2015. 155p. Dissertação de Mestrado - Departamento de Engenharia Mecânica, Pontifícia Universidade Católica do Rio de Janeiro.

Para acesso aos reservatórios portadores de hidrocarbonetos é necessária a perfuração de poços de petróleo. Entre as várias funções do fluido de perfuração podem se destacar o transporte do cascalho gerado pela broca, a função de primeira barreira para inibição de influxo das formações expostas no poço e a manutenção da pressão do poço dentre os limites de resistência das formações atravessadas (janela operacional). Alguns novos campos petrolíferos, bem como campos depletados sofrem restrições operacionais devido a pequenas janelas operacionais. A variação da pressão no poço aberto devido a perdas por atrito no anular, em alguns casos é maior do que a janela operacional, impedindo a perfuração do poço. Managed Pressure Drilling (MPD) é uma tecnologia alternativa à perfuração convencional. $\mathrm{O}$ anular do poço é vedado, possibilitando a retenção de pressão no anular. $\mathrm{O}$ ajuste da pressão no anular do poço possibilita compensar a variação da perda de atrito e perfurar poços com janelas operacionais estreitas. Para manutenção da pressão da zona objetivo dentro da janela operacional é necessário o controle adequado da pressão na superfície. A definição do valor de pressão necessário é obtida através do conhecimento do comportamento da dinâmica do fluido de perfuração no poço. Este trabalho desenvolveu um modelo de um sistema de poço de petróleo com MPD, levando em conta os efeitos estáticos e dinâmicos envolvidos na perfuração MPD. Sobre o modelo desenvolvido foram propostas e aplicadas diferentes técnicas de controle linear e não-linear para avaliação do desempenho dos controladores e identificação de pontos-chave na aplicação da técnica MPD. Os controles nãolineares propostos foram bem sucedidos em compensar os efeitos altamente nãolineares do sistema, melhorando sua resposta em tarefas típicas.

\section{Palavras-chave}

MPD; perfuração; modelagem; controle não linear. 


\section{Abstract}

Fernandes, André Alonso; Meggiolaro, Marco Antonio. Modeling and nonlinear control evaluation for Managed Pressure Drilling of oil wells. Rio de Janeiro, 2015. 155p. MSc. Dissertation - Departamento de Engenharia Mecânica, Pontifícia Universidade Católica do Rio de Janeiro.

For access of hydrocarbon reservoirs, drilling oil wells is required.. Among the various functions the drilling fluid may provide are cutting transportation generated by the bit, a barrier function for inhibiting influx of exposed formations in the well and maintaining well pressure within the resistance limits of the formations exposed (operational window). Some new oil fields as well as some depleted fields are experiencing severe operational restrictions due to small operational windows. The open hole pressure variation due to friction losses on the annular in some cases is greater than the operational window, inhibiting the perforation of the well. Managed Pressure Drilling (MPD) is an alternative technology to conventional drilling. The annular of the well is sealed while pressure is contained within it. By adjusting annular pressure it is possible to compensate for friction loss variation on the annular and drill well sections with close operational windows. For the proper pressure maintenance on the target zone within the operating window, it is required adequate pressure control on the surface. The definition of the necessary pressure value is obtained through knowledge of the dynamic behavior of the drilling fluid in the well. This work has developed a model of an oil well system with MPD, taking into account the static and dynamic effects involved in MPD. To the developed model different linear and non-linear control techniques were proposed and applied for evaluating the performance of controllers and identifying key points in implementing the MPD technique. The proposed non-linear control techniques were able to compensate for the highly non-linear nature of the system, improving its response during typical tasks.

\section{Keywords}

MPD; Drilling; Modeling; Non-Linear Control. 


\section{Sumário}

1 Introdução 21

1.1. Perfuração convencional 24

1.2. Perfuração MPD 27

1.3. Geomecânica 29

2 Modelo Hidráulico 36

2.1. Pressão Hidrostática $\quad 37$

2.2. Perda de Carga 37

2.2.1. Fluidos Newtonianos 38

2.2.2. Fluidos não Newtonianos 39

2.2.3. Fluxo laminar e turbulento 40

2.2.4. Modelos de fluido de perfuração. 41

2.2.4.1. Newtoniano 41

2.2.4.2. Bingham 42

2.2.4.3. Potência 43

2.2.4.4. Herschell-Buckley 44

2.2.5. Cálculo das perdas de carga 45

2.2.6. Validação dos resultados do cálculo de perda de carga 49

2.2.7. Perda de carga na broca 53

2.3. Modelagem hidráulica do choke MPD 54

2.4. Simulação com um único fluido no sistema 57

2.5. Modelo hidráulico simplificado 58

2.6. Modelo hidráulico dinâmico 58

2.6.1. Modelo não linear discretizado no espaço 60

2.6.2. Modelo padrão de simulação 64

2.7. Linearização do modelo hidráulico 64

3. Análise em Malha Aberta 68

3.1. Avaliação inicial da atuação do controlador 68

3.2. Resposta em Degrau 70

3.3. Diagrama de Bode 73 
4. Controle do Sistema 81

4.1. Controlador PID 82

4.1.1. Calibragem por Ziegler-Nichols 84

4.1.1.1. Controlador $P \quad 88$

4.1.1.2. Controlador PI 91

4.1.1.3. Controlador PD 93

4.1.2. Ajuste empírico dos ganhos 95

4.1.2.1. Controlador $P \quad 95$

$\begin{array}{ll}\text { 4.1.2.2. Controlador PI } & 97\end{array}$

4.1.2.3. Controlador PD 99

4.1.2.4. Controlador PID 101

4.2. Mapa para o choke 104

4.3. Controlador Não Linear 109

4.3.1. Controlador NL compensado por $\alpha \mathrm{D} 2 \mathrm{~A} 2$

4.3.2. Controlador NL compensado por $\alpha \mathrm{D} 2 \mathrm{~A} \quad 113$

4.3.3. Controlador NL compensado por $\alpha \mathrm{D} 2 \quad 115$

4.3.4. Controlador NL compensado por $\alpha \mathrm{DA} \quad 119$

4.3.5. Controlador NL compensado por A 123

5 Análise dos Resultados e Robustez dos Controladores 128

5.1. Avaliação dos resultados 128

5.2. Avaliação dos controladores com perturbações 129

5.3. Comparação entre modelo dinâmico e modelo quase-estático 137

5.4. Avaliação dos controladores NL 140

6 Conclusões 146

6.1. Trabalhos Futuros 148

7 Referências Bibliográficas 149

8 Anexos 153

8.1. Dados para simulação 153

8.2. Matrizes linearizadas do sistema 154 


\section{Lista de figuras}

Figura 1.1 - Esquema de perfuração de um poço.

Figura 1.2 - Janela operacional normal (esquerda), Janela operacional estreita (direita).

Figura 1.3 - Visualização do perfil de pressão do poço com pressão na superfície.

Figura 1.4 - Comparação entre os gradientes de sobrecarga de poços offshore e onshore.

Figura 1.5 - Comparação entre a janela operacional de um poço offshore e onshore.

Figura 1.6 - Projeto de assentamento de revestimentos para um poço convencional.

Figura 1.7 - Projeto de assentamento de sapatas convencional. 34

Figura 1.8 - Projeto de assentamento de sapatas com MPD. 34

Figura 2.1 - Esquema de perfuração convencional (a) e MPD (b) 36

Figura 2.2 - Esquema qualitativo de comportamentos reológicos. 39

Figura 2.3 - Comportamento qualitativo de curva de fluxo do fluido newtoniano.

Figura 2.4 - Comportamento qualitativo curva de fluxo do fluido Binghamiano.

Figura 2.5 - Comportamento qualitativo curva de fluxo do fluido de potência dilatante (vermelho) e pseudoplástico (azul).

Figura 2.6 - Comportamento qualitativo curva de fluxo do fluido do modelo de Herschell-Buckley.

Figura 2.7 - Esquema de um poço representativo do pré-sal.

Figura 2.8 - Tela com resultado Simulação Simentar com fluido Newtoniano

Figura 2.9 - Broca de perfuração com jatos de broca instalados (destaque).

Figura 2.10 - Coeficiente de descarga do choke contra sua abertura 
relativa.

Figura 2.11 - Perda de carga localizada no choke em função da abertura, para uma vazão fixa.

Figura 2.12 - Perda de carga localizada no choke em função da abertura e vazão - Mapa de choke.

Figura 2.13 - Volumes de controle para o sistema discretizado.

Figura 2.14 - Esquema dos volumes de controle do poço.

Figura 3.1 - Circuito hidráulico do fluido de perfuração em sistema MPD

Figura 3.2 - Circuito hidráulico MPD com bomba auxiliar

Figura 3.3 - Reação das pressões para um degrau de posição do choke de MPD, iniciado em $\mathrm{t}=100 \mathrm{~s}$.

Figura 3.4 - Reação da vazão no sistema para um degrau de posição do choke de MPD, iniciado em $t=100 \mathrm{~s}$.

Figura 3.5 - Resposta da pressão do degrau de posição do choke, assumindo um fluido incompressível.

Figura 3.6 - Vazão para um degrau de posição do choke, assumindo um fluido incompressível.

Figura 3.7 - Ganho por frequência, para $\mathrm{Am}=35 \%$.

Figura 3.8 - Resposta da fase na frequência, para $\mathrm{Am}=35 \%$.

Figura 3.9 - Ganho por frequência, para $\mathrm{Am}=50 \%$.

Figura 3.10 - Resposta da fase na frequência, para $\mathrm{Am}=50 \%$. 76

Figura 3.11 - Ganho por frequência, para $\mathrm{Am}=65 \%$. 77

Figura 3.12 - Resposta da fase na frequência, para $A m=65 \%$. 77

Figura 3.13 - Ganho para estimulo em diversas frequências.

Figura 3.14 - Fase para estimulo em diversas frequências considerando período infinito $\quad 79$

Figura 4.1 - Variação da vazão imposta durante a simulação. 82

Figura 4.2 - Comportamento da Vazão nos vários volumes de controle $(\mathrm{kP}=10-3)$.

Figura 4.3 - Comportamento da pressão nos vários volumes de controle $(\mathrm{kP}=10-3)$.

Figura 4.4 - Posição do choke $(\mathrm{kP}=10-3)$. 
Figura 4.5 - Comportamento da vazão nos volumes de controle

Figura 4.6 - Comportamento da pressão nos volumes de controle

Figura 4.7 - Posição do choke (kcrit $=6 \cdot 10-8)$.

Figura 4.8 - Vazão nos volumes de controle, para um controlador $P$ calibrado por Ziegler-Nichols com $\mathrm{kP}=3 \cdot 10-8$.

Figura 4.9 - Pressão nos volumes de controle, para um controlador $P$ calibrado por Ziegler-Nichols com $\mathrm{kP}=3 \cdot 10-8$.

Figura 4.10 - Abertura do choke para um controlador $\mathrm{P}$ calibrado por Ziegler-Nichols com kP $=3 \cdot 10-8$.

Figura 4.11 - Vazão nos volumes de controle, para um controlador PI calibrado por Ziegler-Nichols com $\mathrm{kP}=2.7 \cdot 10-8$ e kI $=2 \cdot 10-9$.

Figura 4.12 - Pressão nos volumes de controle, para um controlador PI calibrado por Ziegler-Nichols com kP = 2.7 $\cdot 10-8$ e kI $=2 \cdot 10-9$.

Figura 4.13 - Abertura do choke para um controlador PI calibrado por Ziegler-Nichols com kP $=2.7 \cdot 10-8$ e kI $=2 \cdot 10-9$.

Figura 4.14 - Vazão nos volumes de controle, para um controlador PD calibrado por Ziegler-Nichols com kP = 4.8·10-8 e kD = 2.6 10-7.

Figura 4.15 - Pressão nos volumes de controle, para um controlador PD calibrado por Ziegler-Nichols com $\mathrm{kP}=4.8 \cdot 10-8$ e $\mathrm{kD}=2.6 \cdot 10-7$.

Figura 4.16 - Abertura do choke para um controlador PD calibrado por Ziegler-Nichols com kP $=4.8 \cdot 10-8$ e kD $=2.6 \cdot 10-7$.

Figura 4.17 - Comportamento da pressão nos volumes de controle para um controlador $\mathrm{P}$ com $\mathrm{kP}=2 \cdot 10-9$.

Figura 4.18 - Comportamento da vazão nos volumes de controle para um controlador $\mathrm{P}$ com $\mathrm{kP}=2 \cdot 10-9$.

Figura 4.19 - Posição do choke para um controlador $\mathrm{P}$ com kP= $2 \cdot 10-9$.

Figura 4.20 - Vazão nos vários volumes de controle para um controlador PI com kP = 1,8·10-9 e kI = 1,3·10-10.

Figura 4.21 - Pressão nos vários volumes de controle para um controlador PI com kP = 1,8·10-9 e kI = 1,3·10-10.

Figura 4.22 - Posição do choke para um controlador PI com kP= $1,8 \cdot 10-9$ e $\mathrm{kI}=1,3 \cdot 10-10$. 
Figura 4.23 - Vazão nos vários volumes de controle para um controlador PD com $\mathrm{kP}=1.5 \cdot 10-8$ e $\mathrm{kD}=1 \cdot 10-7$.

Figura 4.24 - Pressão nos vários volumes de controle para um controlador PD com $\mathrm{kP}=1.5 \cdot 10-8$ e $\mathrm{kD}=1 \cdot 10-7$.

Figura 4.25 - Posição do choke para um controlador PD com kP = $1.5 \cdot 10-8$ e $\mathrm{kD}=1 \cdot 10-7$.

Figura 4.26 - Pressão nos vários volumes de controle para um controlador PID com kP = 1.5 $10-8, \mathrm{kI}=1 \cdot 10-10$ e $\mathrm{kD}=1 \cdot 10-7$.

Figura 4.27 - Vazão nos vários volumes de controle para um controlador PID com kP = 1.5 $10-8, \mathrm{kI}=1 \cdot 10-10$ e $\mathrm{kD}=1 \cdot 10-7$.

Figura 4.28 - Posição do choke para um controlador PID com kP = $1.5 \cdot 10-8, \mathrm{kI}=1 \cdot 10-10 \mathrm{e} \mathrm{kD}=1 \cdot 10-7$.

Figura 4.29 - Mapa de injeção de combustível de um carro.

Figura 4.30 - Perda de carga localizada no choke em função da abertura e vazão - Mapa de choke.

Figura 4.31 - Vazões para controlador com mapa de choke.

Figura 4.32 - Pressões para controlador com mapa de choke.

Figura 4.33 - Posição do choke para controlador com mapa de choke.

Figura 4.34 - Vazões nos vários volumes de controle para um controlador NL compensado por $\alpha \mathrm{D} 2 \mathrm{~A} 2$.

Figura 4.35 - Pressões nos vários volumes de controle para um controlador NL compensado por $\alpha \mathrm{D} 2 \mathrm{~A} 2$.

Figura 4.36 - Posição do choke para um controlador NL compensado por $\alpha \mathrm{D} 2 \mathrm{~A} 2$.

Figura 4.37 - Vazões nos vários volumes de controle para um controlador NL compensado por $\alpha \mathrm{D} 2 \mathrm{~A}$.

Figura 4.38 - Pressões nos vários volumes de controle para um controlador NL compensado por $\alpha \mathrm{D} 2 \mathrm{~A}$.

Figura 4.39 - Posição do choke para um controlador NL compensado por $\alpha \mathrm{D} 2 \mathrm{~A}$.

Figura 4.40 - Vazões nos vários volumes de controle para um controlador NL compensado por $\alpha \mathrm{D} 2$. 
Figura 4.41 - Pressões nos vários volumes de controle para um controlador NL compensado por $\alpha \mathrm{D} 2$.

Figura 4.42 - Posição do choke para um controlador NL compensado por $\alpha \mathrm{D} 2$.

Figura 4.43 - Vazões nos vários volumes de controle para um controlador NL compensado por $\alpha \mathrm{D} 2$, para ganhos ampliados em 8 vezes.

Figura 4.44 - Pressões nos vários volumes de controle para um controlador NL compensado por $\alpha \mathrm{D} 2$, para ganhos ampliados em 8 vezes.

Figura 4.45 - Posição do choke para um controlador NL compensado por $\alpha \mathrm{D} 2$, para ganhos ampliados em 8 vezes.

Figura 4.46 - Vazões nos vários volumes de controle para um controlador NL compensado por $\alpha \mathrm{DA}$.

Figura 4.47 - Pressões nos vários volumes de controle para um controlador NL compensado por $\alpha \mathrm{DA}$.

Figura 4.48 - Posição do choke para um controlador NL compensado por $\alpha \mathrm{DA}$.

Figura 4.49 - Vazões nos vários volumes de controle para um controlador NL compensado por $\alpha \mathrm{DA}$, com ganhos ampliados em 3 vezes.

Figura 4.50 - Pressões nos vários volumes de controle para um controlador NL compensado por $\alpha \mathrm{DA}$, com ganhos ampliados em 3 vezes.

Figura 4.51 - Posição do choke para um controlador NL compensado por $\alpha \mathrm{DA}$, com ganhos ampliados em 3 vezes.

Figura 4.52 - Vazões nos vários volumes de controle para um controlador NL compensado por A.

Figura 4.53 - Pressões nos vários volumes de controle para um controlador NL compensado por A.

Figura 4.54 - Posição do choke para um controlador NL compensado por A.

Figura 4.55 - Vazões nos vários volumes de controle para um 
controlador NL compensado por A, com ganhos ampliados em 5 vezes.

Figura 4.56 - Pressões nos vários volumes de controle para um controlador NL compensado por A, com ganhos ampliados em 5 vezes.

Figura 4.57 - Posição do choke para um controlador NL compensado por A, com ganhos ampliados em 5 vezes.

Figura 5.1 - Elemento recolhido de um choke MPD após limpeza. 130

Figura 5.2 - Variação de vazão para controlador PD com perturbação no instante $\mathrm{t}=250 \mathrm{~s}$.

Figura 5.3 - Variação de pressão para controlador PD com perturbação no instante $\mathrm{t}=250 \mathrm{~s}$.

Figura 5.4 - Posição do choke do controlador PD com perturbação no instante $\mathrm{t}=250 \mathrm{~s}$.

Figura 5.5 - Variação de vazão para controlador com mapa de choke com perturbação em $\mathrm{t}=250 \mathrm{~s}$.

Figura 5.6 - Variação de pressão para controlador mapa de choke com perturbação em $\mathrm{t}=250$ s.

Figura 5.7 - Posição do choke do controlador mapa de choke com perturbação em $t=250$ s.

Figura 5.8 - Variação de vazão para o controlador NL compensado por A com perturbação em $t=250$ s.

Figura 5.9 - Variação de pressão para o controlador NL compensado por A com perturbação em $t=250$ s.

Figura 5.10 - Posição do choke para o controlador NL compensado por A com perturbação em $t=250$ s.

Figura 5.11 - Vazões para um simulador PD com kP= 1.5 $10-8$ e $\mathrm{kD}=1 \cdot 10-7$, assumindo comportamento quase-estático.

Figura 5.12 - Pressões para um simulador PD com kP= 1.5·10-8 e $\mathrm{kD}=1 \cdot 10-7$, assumindo comportamento quase-estático.

Figura 5.13 - Posição do choke para um simulador PD com kP= 1.5 $10-8$ e $\mathrm{kD}=1 \cdot 10-7$, assumindo comportamento quase-estático.

Figura 5.14 - Curvas da perda de carga compensada por fator no 
controlador não linear.

Figura 5.15 - Curvas comparativas da perda de carga do choke (DeltaP) e de fatores de compensação dos controladores NL baseados em $\mathrm{A}$ e em $\alpha \mathrm{d} 2$, em relação à abertura relativa.

Figura 5.16 - Curvas de respostas dos controladores NL e linear na velocidade de abertura do choke. 


\section{Lista de tabelas}

Tabela 2-1 - Dimensões dos elementos do poço ……...............................50

Tabela 2-2 - Resultados do modelo hidráulico desenvolvido ....................51

Tabela 2-3 - Reologia de cada fluido utilizada:......................................52

Tabela 2-4 - Dados geométricos para simulação. ...................................... 64

Tabela 4-1 - Ganhos sugeridos Ziegler-Nichols ....................................... 88

Tabela 4-2 - Equações e fatores dos controladores não lineares. ..........111

Tabela 5-1 - Resultados objetivos dos controladores............................128

Tabela 8-1 - Dimensões dos elementos do poço ....................................153 


\section{Lista de símbolos}

\begin{tabular}{|c|c|}
\hline A & Aberturas do choke \\
\hline$A_{a}$ & Amplitudes de variação da abertura do choke \\
\hline$A_{\text {choke }}$ & Área da seção transversal do choke \\
\hline$A_{m}$ & Aberturas médias de choke \\
\hline$A_{n}$ & Área de passagem dos jatos da broca \\
\hline $\mathrm{AR}_{\mathrm{N}}$ & Área da seção transversal N \\
\hline $\mathrm{B}$ & Perda de carga linearizada do choke \\
\hline $\mathrm{D}$ & Dimensão do canal de escoamento [m] \\
\hline $\mathrm{d}_{\mathrm{e}}$ & Diâmetro externo da tubulação ou BHA[m] \\
\hline $\mathrm{d}_{\text {externo }}$ & Diâmetro externo da seção [m] \\
\hline $\mathrm{d}_{\mathrm{h}}$ & Diâmetro hidráulico [m] \\
\hline $\mathrm{d}_{\text {interno }}$ & Diâmetro interno da seção [m] \\
\hline $\mathrm{d}_{\mathrm{i}}$ & Diâmetro interno do revestimento, poço ou riser [m] \\
\hline $\mathrm{f}$ & Fator de fricção \\
\hline $\mathrm{F}$ & Força aplicada no fluido \\
\hline $\mathrm{F}_{\text {bit }}$ & Perda de carga na broca \\
\hline$F_{i}$ & Perda de carga no volume de controle i \\
\hline g & Constante gravitacional $\left[\mathrm{m} / \mathrm{s}^{2}\right]$ \\
\hline$G_{f}$ & Gradiente de fratura \\
\hline $\mathrm{H}$ & Profundidade vertical [m] \\
\hline $\mathrm{He}$ & Número de Hedstrom \\
\hline $\mathrm{He}_{\mathrm{HB}}$ & Número de Hedstrom fluidos tipo Herschell-Buckley \\
\hline i & Índice do volume de controle \\
\hline$I A D C$ & Internacional Association of Drilling Contractor \\
\hline $\mathrm{K}$ & Índice de consistência \\
\hline $\mathrm{k}_{\mathrm{P}}$ & Ganho proporcional \\
\hline $\mathrm{k}_{\text {crit }}$ & Ganho proporcional crítico \\
\hline $\mathrm{k}_{\mathrm{I}}$ & Ganho integrativo \\
\hline $\mathrm{k}_{\mathrm{D}}$ & Ganho derivativo \\
\hline
\end{tabular}




\begin{tabular}{|c|c|}
\hline $\mathrm{K}$ & $\begin{array}{l}\text { Constante de proporcionalidade do inverso do } \\
\text { quadrado da abertura do choque }\end{array}$ \\
\hline $\mathrm{K}_{\mathrm{ajustado}}$ & $\begin{array}{l}\text { Derivada da reta tangente da curva de perda de carga } \\
\text { do choke }\end{array}$ \\
\hline 1 & Comprimento do volume de controle \\
\hline $\mathrm{L}$ & Comprimento do corpo do choke \\
\hline LE & Limite de escoamento \\
\hline MPD & Managed Pressure Drilling \\
\hline $\mathrm{n}$ & Índice de comportamento \\
\hline $\mathrm{P}$ & Controlador proporcional \\
\hline$\dot{\mathrm{p}}$ & Variação da pressão com tempo \\
\hline$P_{b}$ & Perda de carga nos jatos da broca $[\mathrm{Pa}]$ \\
\hline$P_{\text {fundo }}$ & Pressão no fundo do poço $[\mathrm{Pa}]$ \\
\hline$P_{\text {hidrostática }}$ & Pressão hidrostática [Pa] \\
\hline PI & Controlador proporcional-integral \\
\hline PID & Controlador proporcional-integral-derivativo \\
\hline$P_{p}$ & Pressão de poros \\
\hline Profundidade & Pressão em uma determinada profundidade [Pa] \\
\hline $\mathrm{P}_{\text {superfície }}$ & Pressão da superfície \\
\hline $\mathrm{p}(\mathrm{z})$ & Pressão de sobrecarga [Pa] \\
\hline Q & Vazão volumétrica \\
\hline$\dot{\mathrm{q}}$ & Variação da vazão com tempo \\
\hline$q_{b}$ & Vazão da bomba de lama \\
\hline $\operatorname{Re}$ & Número de Reynolds \\
\hline $\mathrm{Re}_{\frac{\mathrm{HB}}{\mathrm{POT}}}$ & $\begin{array}{l}\text { Número de Reynolds para fluidos do tipo potência e } \\
\text { Hershell-Buckley }\end{array}$ \\
\hline $\operatorname{Re}_{\mathrm{HB}}$ & Número de Reynolds para fluidos tipo \\
\hline & Herschell-Buckley \\
\hline S & Área de superfície exposta ao cisalhamento $\left[\mathrm{m}^{2}\right]$ \\
\hline $\mathrm{t}$ & Instante da simulação \\
\hline $\mathrm{T}$ & Tensão cisalhamento \\
\hline $\mathrm{U}$ & Vetor de entradas do sistema \\
\hline$\overline{\mathrm{v}}$ & Velocidade média do fluido \\
\hline
\end{tabular}




\begin{tabular}{|c|c|c|}
\hline & $\omega$ & Frequência do estímulo \\
\hline & $\mathrm{W}$ & Vazão mássica \\
\hline & $\dot{\mathrm{X}}$ & Vetor com derivadas das variáveis de estados \\
\hline & z & Cota das formações [m] \\
\hline & $\mathbb{A}, \mathbb{B}, \mathbb{C}, \mathbb{D}$ & Matrizes do sistema \\
\hline & $\alpha_{\mathrm{d}}$ & Coeficiente de descarga \\
\hline & $\beta$ & Módulo de bulk \\
\hline & $\Delta \mathrm{h}_{\mathrm{i}}$ & Diferença de altura \\
\hline & $\Delta \mathrm{p}$ & Perda de carga $[\mathrm{Pa}]$ \\
\hline & $\Delta \mathrm{P}_{\text {carga }}$ & Somatório das perdas de carga até a superfície [Pa] \\
\hline & $\Delta \mathrm{P}_{\text {choke }}$ & Perda de carga no Choke $[\mathrm{Pa}]$ \\
\hline & $\Delta \mathrm{P}_{\text {fricção anular }}$ & Perda de carga por fricção no anular [Pa] \\
\hline & $\Delta \mathrm{v}$ & Diferencial de velocidade entre planos [m/s] \\
\hline & $\Delta \mathrm{y}$ & Diferencial de distância entre planos vizinhos [m] \\
\hline & $\varepsilon$ & Rugosidade[m] \\
\hline & $\mu_{\mathrm{P}}$ & Viscosidade plástica do fluido \\
\hline & $\mu$ & Viscosidade dinâmica \\
\hline & $\rho$ & Densidade do fluido $\left[\mathrm{kg} / \mathrm{m}^{3}\right]$ \\
\hline & $\rho(\mathrm{z})$ & Massa específica das camadas sobrepostas \\
\hline & $\sigma_{\mathrm{v}}$ & Pressão de sobrecarga [Pa] \\
\hline & $\tau$ & Tensão de escoamento \\
\hline & $\tau_{0}$ & Tensão mínima de escoamento \\
\hline
\end{tabular}




\section{1 Introdução}

A indústria do petróleo realiza atividades de exploração e explotação de campos de petróleo em todo o mundo. Para acessar os reservatórios produtores é necessária a construção de poços de petróleo. A etapa de construção de poços se divide em duas fases: perfuração e completação.

A perfuração de um poço de petróleo consiste na etapa inicial da construção do poço. Durante a etapa de perfuração do poço todas as camadas entre o solo, ou leito marinho, até o reservatório objetivo são expostas em alguma fase da perfuração. Para que o poço seja perfurado com segurança é necessário que as formações expostas no decorrer da perfuração fiquem expostas a pressões dentro de sua chamada janela operacional. Caso contrário problemas operacionais e de segurança são possíveis, implicando em tempo não produtivo e custos operacionais.

$\mathrm{Na}$ exploração de poços de petróleo existe um componente de incerteza sobre as características das formações a serem atravessadas durante a perfuração. $\mathrm{Na}$ explotação, etapa de desenvolvimento, de poços de petróleo as características dos reservatórios atravessados durante a perfuração de poços podem sofrer alterações significativas de suas características ao longo do desenvolvimento do campo. O projeto e execução da perfuração de um poço deve seguir uma série de normas internacionais, relativas à segurança das operações e do meio ambiente. $\mathrm{O}$ projeto de perfuração de um poço deve ser robusto o suficiente para atender a todas as normas de segurança e incertezas sobre as condições do poço.

As características das formações atravessadas na trajetória do poço definem os limites mínimos e máximos de pressão possíveis em cada profundidade do poço. Estudos de geomecânica e estimativas de pressão de poros servem de referência para a definição do número de fases e o projeto de revestimentos do poço.

A perfuração de formações frágeis ou de reservatórios com depleção avançada apresentam estreitas janelas operacionais, em alguns casos com 
diferença inferior a 5\% entre a mínima e a máxima pressão admissíveis. Durante a perfuração com tecnologia convencional, a pressão no poço em cada profundidade é definida pela soma da pressão hidrostática na profundidade com as perdas de carga da profundidade considerada até o retorno na superfície. Nas paradas de bombeio pelo interior da coluna, as perdas de carga no espaço anular são eliminadas. Em algumas locações com janelas estreitas, a perda de carga no anular pode ser superior à janela operacional, impedindo o aprofundamento do poço com o uso de técnicas convencionais de perfuração.

Dado o alto investimento necessário para construção de um poço offshore, é necessário que o mesmo possua grande produtividade, ou injetividade para poços injetores. Um maior diâmetro final do poço gera uma menor perda de carga na coluna de produção, o que permite maior produtividade. Locações com janelas operacionais estreitas perfuradas com tecnologia convencional podem necessitar de um maior número de fases para atingir o objetivo. $\mathrm{O}$ aumento do número de fases de um poço reduz o diâmetro final do mesmo, além de encarecer a operação de perfuração, solução nem sempre aceitável para os poços de desenvolvimento, que necessitam de uma produção mínima para se tornarem econômicos.

A técnica de MPD - Managed Pressure Drilling - permite ajustar a pressão no anular do poço através do controle de uma contrapressão na superfície gerada pela restrição da área de passagem do fluxo na sáida do circuito hidráulico. A variação da área de passagem do fluxo é feita por um restritor de fluxo também conhecido como choke. O controle adequado da pressão no anular do poço para diferentes situações operacionais permite trabalhar dentro da janela operacional, mesmo em locações com janelas estreitas.

Para controle adequado da pressão no fundo do poço é necessário o conhecimento da sua dinâmica, assim como a transmissão da pressão ao longo dele. Assim, o ajuste da pressão na superfície pode ser feito de maneira adequada não causando eventos de sub-pressurização ou sobre-pressurização das formações expostas do poço aberto.

A indústria hoje usa diferentes abordagens para controle da pressão na superfície de um poço com MPD (Fosli 2006, Frink 2006, Godhavn 2009). O principal método de controle automático utilizado é o controlador PID e suas derivações, um dos objetos de estudo deste trabalho. 
Este trabalho se divide em duas partes principais: modelagem e controle. A primeira parte trata da construção de um modelo hidráulico da perfuração de um poço com componentes estáticos e dinâmicos. Como o fluido de perfuração pode ter diferentes propriedades, é feita uma análise sobre as características de diferentes tipos fluidos de perfuração. A literatura para caracterização dos fluidos de perfuração possui diversas fontes, (Bourgoyne 1985, Machado 2002, Rocha 2007 e Scheid 2011), não sendo limitada a uma única abordagem para definição do comportamento reológico de alguns tipos de fluidos de perfuração. Além da hidráulica de um poço convencional, é desenvolvida a hidráulica do choke MPD, responsável pelo controle da pressão de superfície na perfuração com gerenciamento de pressão, com base em um modelo derivado de Jelali e Kroll, (2003).

Com os componentes estáticos do modelo hidráulico, são desenvolvidas as equações dinâmicas do sistema. Landet (2012) desenvolveu um modelo dinâmico de um poço MPD com uma aproximação linear do modelo hidráulico do poço. Este trabalho desenvolve um modelo hidráulico dinâmico com base em um sistema não linear para uma geometria genérica de poço.

A segunda parte do trabalho é a análise e desenvolvimento de diferentes técnicas de controle. Um método de controle usado por diferentes companhias de serviço de MPD é o controlador PID. Tanto Saeed (2012), como Siahaam (2014), mencionam o uso de controladores PID e PI em aplicações reais do sistema MPD. O controlador PID e suas derivações são analisados para servir como referência no desenvolvimento de outros controladores. Além da revisão sobre os controladores já utilizados na indústria, neste de trabalho são analisadas novas propostas de técnicas alternativas de controle sobre o modelo hidráulico desenvolvido. O primeiro método alternativo proposto é o Mapa de Choke, que vem a ser uma forma de controle feed-foward. A outra proposta para técnica de controle são controladores não-lineares que visam compensar as não-linearidades do sistema, melhorando a resposta do controlador. São simuladas situações operacionais comuns em poços para análise de desempenho dos controladores e a resposta do sistema.

Este capítulo 1 da dissertação introduz alguns conceitos básicos de perfuração de poços de petróleo necessários para o entendimento do problema, explicando as diferenças entre a perfuração convencional e a perfuração MPD, e 
conceitos básicos de estudos de geomecânica. O segundo capítulo descreve a construção do modelo hidráulico de um poço com MPD para o cenário estático e para o cenário dinâmico. O capítulo 3 faz a análise do sistema desenvolvido em malha aberta, analisando a resposta para degrau, resposta em frequência e linearidade do sistema. O capítulo 4 faz a análise da aplicação de diferentes controladores no sistema, abrangendo técnicas de controle comuns (PID e derivações) e as diferentes técnicas de controle propostas neste trabalho, Mapa de Choke e controladores não-lineares. Para cada controlador analisado são discutidas as respostas do sistema. O capítulo 5 faz uma análise geral dos resultados obtidos e a verificação de robustez dos controladores. O capitulo 6 reúne as conclusões obtidas na dissertação e apresenta sugestões de trabalhos futuros.

\section{1.}

\section{Perfuração convencional}

A perfuração de poços de petróleo envolve basicamente a mesma tecnologia, desde o século 19. A perfuração de um poço consiste na descida de uma série de tubos denominados drillpipes (DP) conectados, e bombeio de fluido de perfuração (lama) através deles, enquanto o peso próprio e a rotação são transmitidos à broca. Entre os DP e a broca existe uma série de equipamentos de perfuração como drillcollars, drilling-jars, estabilizadores e diversos equipamentos eletrônicos (MWD, LWD, PWD) esse conjunto é denominado Bottom Hole Assembly (BHA). O fluido bombeado através da coluna de perfuração é responsável por trazer os cascalhos para a superfície, e também consiste na principal barreira de segurança do poço, sendo responsável pela estabilização de suas paredes abertas. A estabilização do poço aberto e a inibição de influxos da formação por parte do fluido é devida à densidade do fluido. A densidade de fluido é responsável pela pressão hidrostática no anular do poço. A diferença entre a mínima e máxima pressão admissível para uma determinada profundidade é chamada de janela operacional. Estando a pressão dentro da janela operacional, não são esperados problemas com os influxos e estabilidade do poço (nota: diversos outros problemas operacionais são possíveis, porém não são o foco desta dissertação). 
A figura 1.1 ilustra um esquema genérico de poço, onde uma broca conectada a DP e ao BHA aplica peso e rotação na formação para gerar cascalhos. As setas indicam o caminho percorrido pelo fluido de perfuração do interior do DP para o anular do poço. A linha de retorno do fluido de perfuração com cascalhos do poço que direciona o fluxo até as peneiras (para remoção dos cascalhos) é denominada como Flowline.

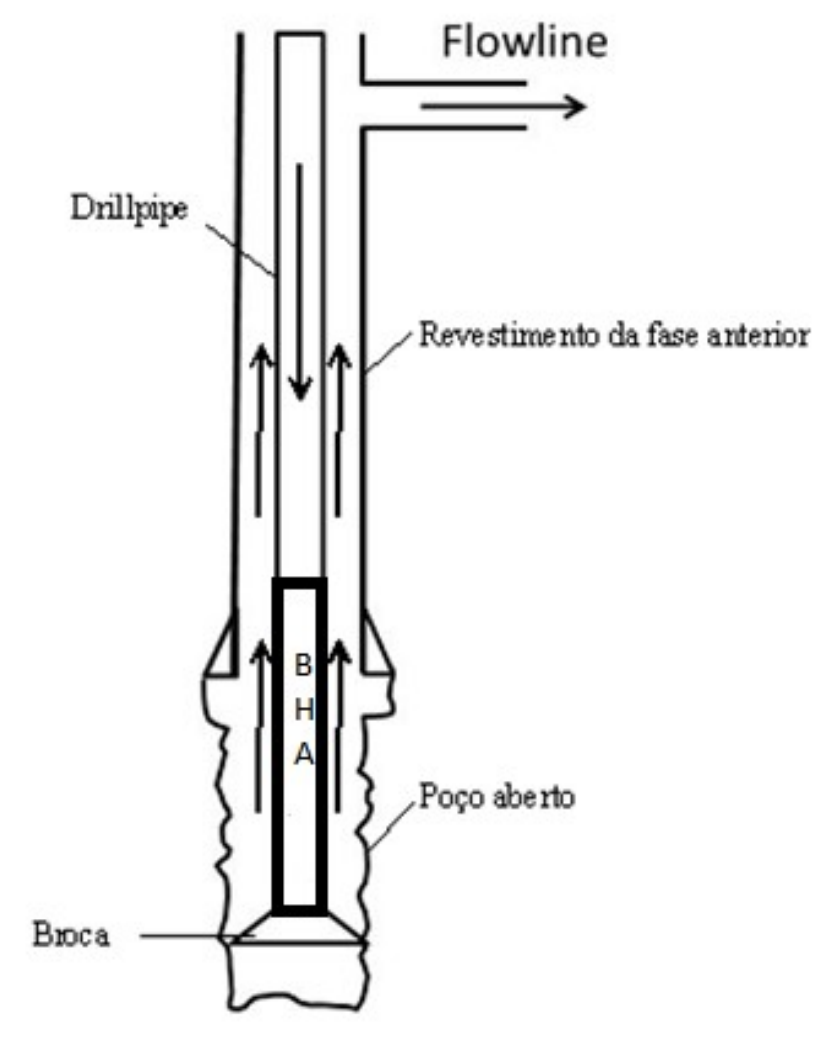

Figura 1.1 - Esquema de perfuração de um poço.

A extensão da fase de um poço é dependente da janela operacional e formações na sua trajetória. Um poço de petróleo é constituído de diversas fases concêntricas. A cada fase, um novo trecho do poço é perfurado para o seu aprofundamento, e isolado com revestimento (tubulação de aço que vai até a cabeça do poço) ou com liner (tubulação de aço que vai até o revestimento anterior). A fase seguinte é iniciada com um diâmetro inferior ao diâmetro interno da fase anterior. Esse processo é repetido até que o objetivo do poço seja alcançado, ou ocorra alguma inviabilidade técnica. Não será foco do trabalho a 
discussão sobre a etapa de revestimento e cimentação, que foge do escopo do trabalho de perfuração com gerenciamento da pressão (MPD).

O fluido bombeado pelo interior da coluna de perfuração possui diversas funções:

- Resfriar a broca;

- Transportar o cascalho para a superfície;

- Estabilizar as paredes do poço aberto;

- Impedir influxos indesejados das formações expostas no poço aberto.

A pressão no interior do poço aberto deve impedir o colapso e influxos indesejáveis sem extrapolar a resistência da formação ao qual ele está exposto. Uma dificuldade adicional com relação à manutenção da pressão dentro da janela operacional no poço é a variação da pressão com a variação na vazão. A cada conexão de DP (para poder aprofundar a broca), as bombas de lama são desligadas. Por conta das perdas de carga no anular do poço, a pressão no interior do mesmo varia com a oscilação da vazão de lama; esta variação por si só pode acarretar na inviabilidade de prosseguir a perfuração em um número mínimo de fases ou até mesmo o cumprimento dos objetivos propostos. A definição da pressão no fundo do poço para perfuração convencional é dada pela equação (1.1), devendo essa pressão estar dentro da janela operacional do poço.

$$
P_{\text {fundo }}=P_{\text {hidro }} \text { ática }+\Delta P_{\text {friç̧ão anular }}
$$

Alguns novos campos petrolíferos, bem como campos depletados, sofrem restrições operacionais devido a pequenas janelas operacionais. A variação da pressão no poço aberto devido a perdas por atrito no anular em alguns casos é maior do que a janela operacional, impedindo a sua perfuração. Managed Pressure Drilling (MPD) é uma tecnologia alternativa à perfuração convencional. O anular do poço é vedado, possibilitando a contenção (trapeamento) de pressão. O ajuste da pressão no anular do poço possibilita compensar a variação da perda de atrito e perfurar poços com janelas operacionais estreitas.

A figura 1.2 mostra um esquema da perfuração de uma nova fase do poço. $\mathrm{O}$ Termo ECD corresponde a Equivalent Circulating Density, significa qual seria a densidade equivalente de um fluido em condições estáticas para o ponto de 
medição. O Triângulo na ordenada dos gráficos representa a profundidade final do revestimento da fase anterior. Isolando as formações da fase anterior da fase atual, assim os limites de pressão da fase corrente não serão afetados pelos limites de pressão da(s) fase(s) anterior(es).

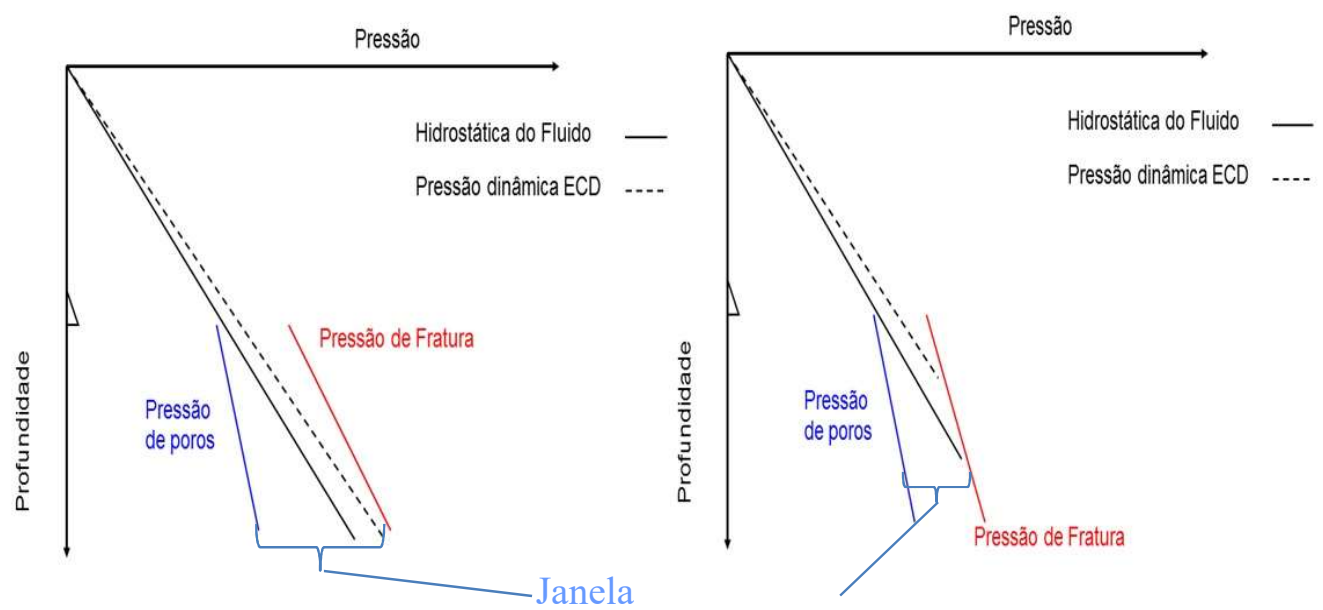

\section{Figura 1.2 - Janela operacional normal (esquerda), Janela operacional estreita (direita).}

Conforme mencionado anteriormente, a janela operacional do poço limita a faixa de pressão/profundidade dentro dele. O exemplo da esquerda na figura 1.2 mostra uma janela operacional mais ampla, o que permitiria aprofundar a fase do poço. No exemplo da direita, a janela operacional é mais estreita, o que impediria seguir perfurando até a mesma profundidade do caso anterior.

$\mathrm{O}$ aumento do número de fases para o mesmo poço acaba por limitar o diâmetro interno dele, o que acaba limitando o diâmetro da coluna de produção. Um diâmetro restrito da coluna de produção aumenta a perda de carga para o escoamento da produção, o que acaba gerando a necessidade de um maior diferencial de pressão para escoamento. Como a pressão do reservatório é limitada, uma maior perda de carga na coluna acaba por gerar uma menor produtividade por poço.

\section{2.}

Perfuração MPD

A IADC (International Association of Drilling Contractors) define Managed Pressure Drilling como um método de perfuração adaptável utilizado 
para controlar com precisão o perfil de pressão no anular no poço. Os objetivos principais do método são determinar o limite de variação da pressão de fundo de poço e controlar o perfil de pressão associado no anular do poço.

Como definido anteriormente, uma nova possibilidade na perfuração é o confinamento de pressão na superfície, feita pelo MPD, que pode ser traduzida como perfuração com gerenciamento de pressão. Desta forma, o perfil de pressão dentro do poço pode ser manipulado não apenas com a densidade do fluido de perfuração e outros fatores reológicos do mesmo.

O exemplo com janela operacional estreita é repetido na figura 1.3. Neste caso pode-se observar que uma aplicação de pressão na superfície permite que seja atingida uma maior profundidade final da fase do poço em comparação com o uso de tecnologia convencional.

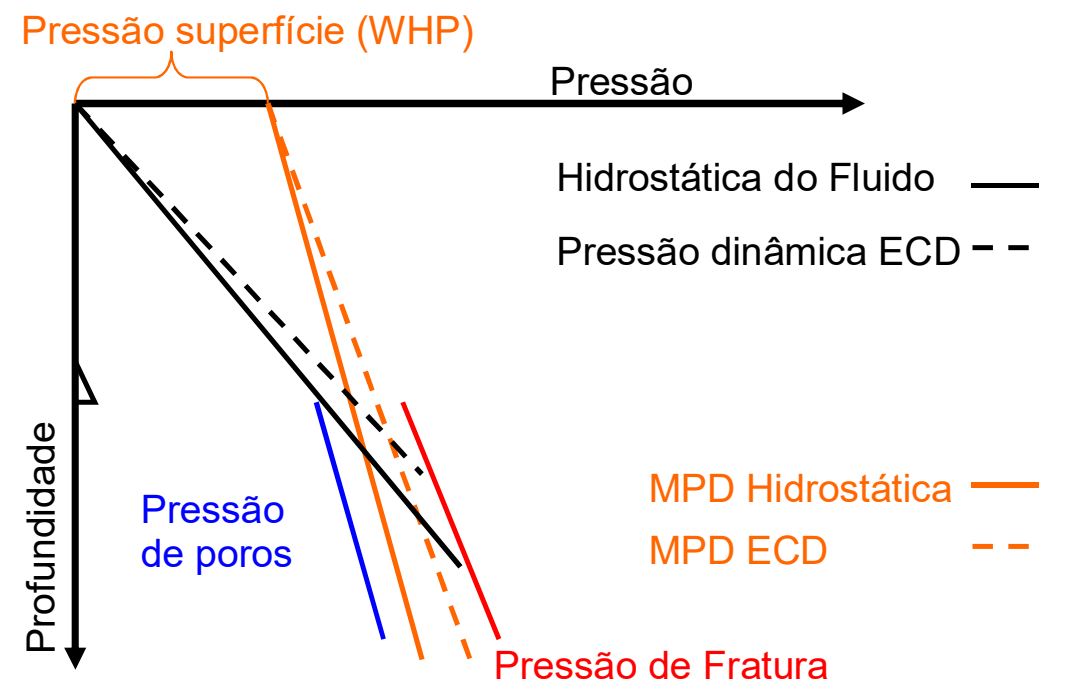

\section{Figura 1.3 - Visualização do perfil de pressão do poço com pressão na superfície.}

O controle adequado da pressão na superfície é feito pela restrição do fluxo da saída. O fluido de perfuração tem sua passagem forçada por chokes (restritores de fluxo), e dependendo da necessidade de pressão no poço a abertura dos chokes é alterada. A pressão no fundo passa a ser a soma da pressão hidrostática, perdas de carga no anular até a superfície e pressão na cabeça:

$$
P_{\text {fundo }}=P_{\text {hidro ática }}+\Delta P_{\text {fricção anular }}+\Delta P_{\text {choke }}
$$


O processo de controle da pressão é contínuo durante toda a operação de perfuração, e fundamental para o sucesso da técnica, visto que o erro na aplicação na correta pressão na superfície pode retirar a pressão de dentro do poço de sua janela operacional.

Para um adequado controle da pressão da superfície, e consequente perfil de pressão dentro do poço, são feitas duas abordagens, descritas a seguir. A primeira abordagem é pelo controle manual do choke, onde um operador aciona diretamente a válvula do choke e com isso varia a contrapressão no fundo do poço de acordo com a sua ação. Esta abordagem é mais simples e usada ainda em alguns poços de terra, porém está sendo abandonada pela indústria. A segunda abordagem faz uso de um controlador automático da posição do choke com base na situação operacional. Esta abordagem independe da atenção contínua e da resposta imediata do operador.

A perfuração com MPD permite a construção de poços com um menor número de fases, ou permite que cenários com janelas operacionais estreitas ou inexistentes sejam perfurados com menor quantidade de problemas operacionais. Apesar de ser uma operação mais complexa, o controle preciso da pressão no anular do poço permite a redução e até a eliminação do tempo perdido no controle de perdas e evento de controle de poço.

Na sessão de geomecânica é explicada a razão dos poços de lâmina de água ultraprofunda encontrar restrições na janela operacional. Em alguns casos, somente as perdas de cargas no anular, necessária para o mínimo funcionamento das ferramentas de perfuração e transporte dos cascalhos para a superfície, já impede o prosseguimento da perfuração. Formações carbonáticas tanto do pós-sal como do pré-sal também apresentam janelas operacionais reduzidas, fato agravado com a depleção dos reservatórios.

\section{3.}

\section{Geomecânica}

Para o projeto de perfuração de um poço é necessário um estudo de geopressões das formações a serem atravessadas por ele. O estudo de geopressões consiste no cálculo das pressões existentes no subsolo e das pressões que são impostas às formações, que podem inclusive levar à falha da rocha. As principais 
pressões em um estudo de geopressões, para perfuração de um poço, são: pressão de sobrecarga, pressão de poros, pressõea de colapso inferior e superior e pressão de fratura. As três últimas determinam a janela operacional do poço, que são os limites de pressão admissíveis dentro do poço aberto para uma determinada profundidade.

Definições:

- Pressão (tensão) de sobrecarga: é a pressão exercida pelo somatório do peso de todas as camadas sobrepostas ao elemento considerado. A equação (1.3) descreve a função para cálculo da tensão de sobrecarga:

$$
p(z)=p_{0}+g \int_{0}^{z} \rho(z) d z
$$

- Pressão de poros: Pressão dos fluidos contidos dentro do espaço poroso das rochas de subsuperfície. Esta pressão é função da massa específica do fluido da formação e de cargas que este esteja suportando. Para evitar a produção de hidrocarbonetos durante a perfuração, a pressão do interior do poço deve ser superior à pressão de poros, relevante aspecto de segurança.

- Pressões de colapso: é a pressão que leva à falha da rocha por cisalhamento. A ruptura por cisalhamento pode ocorrer tanto por excesso de pressão no interior do poço (colapso superior) como por falta de pressão no interior do poço (colapso inferior). A operação de perfuração com pressão fora dos limites das pressões de colapso pode induzir alteração no diâmetro do poço e até desmoronamento parcial ou total do poço aberto.

- Pressão de fratura: pressão que leva à fratura da formação por tração. Quando a pressão do poço excede a pressão de fratura, problemas operacionais como perda de circulação e instabilidade das paredes do poço podem ser verificados, causando transtornos operacionais e até impossibilidade de prosseguimento da perfuração.

O limite inferior de pressão é determinado pelo maior valor entre a pressão de poros e a pressão de colapso inferior. O limite superior é determinado pelo 
menor valor entre a pressão de fratura, pressão de sobrecarga e a pressão de colapso superior.

Considerando que a pressão de sobrecarga é definida como a soma do peso das formações em uma determinada profundidade, para uma mesma cota de reservatório um poço terrestre irá sofrer uma maior pressão de sobrecarga que um poço marítimo, visto que nos poços marítimos existe uma parcela de água.

A figura 1.4 ilustra a diferença do gradiente de sobrecarga para poços offshore com 1500m de LDA com o gradiente de sobrecarga verificado em poços terrestres. No exemplo foram consideradas as mesmas formações para as mesmas cotas, com a diferença do poço offshore ter água como componente de sobrecarga.

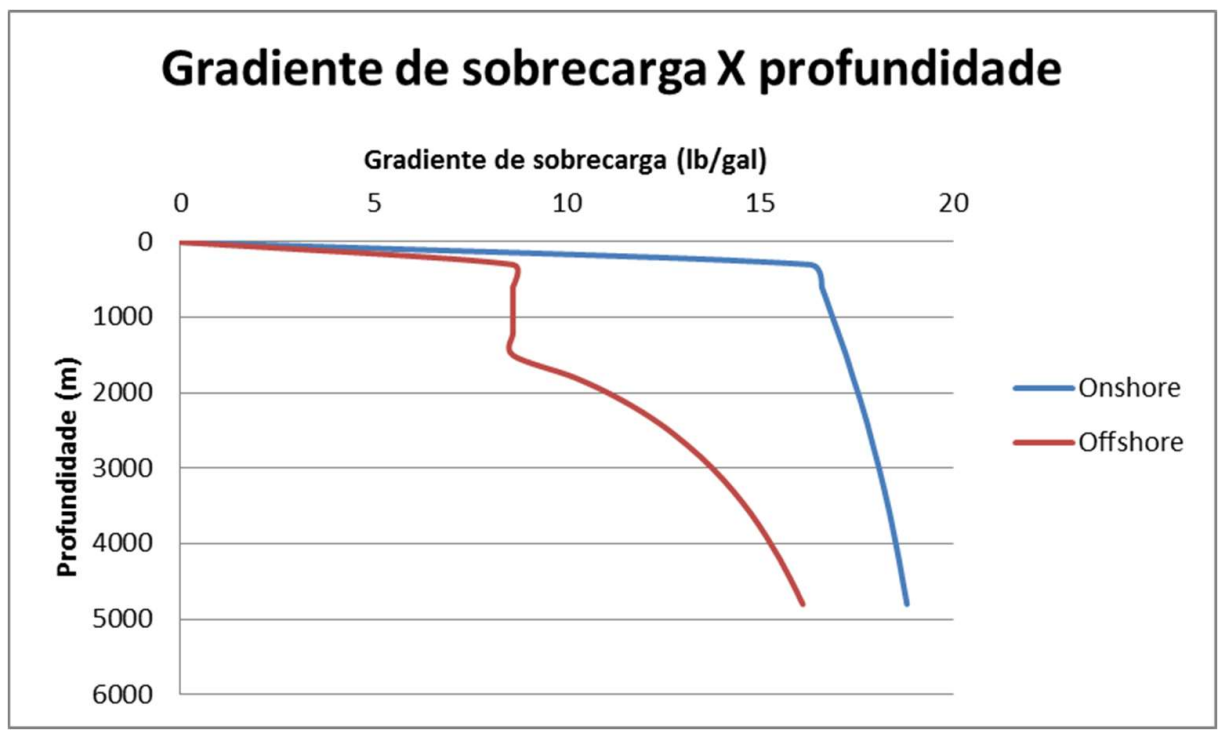

Figura 1.4 - Comparação entre os gradientes de sobrecarga de poços offshore e onshore.

A pressão de fratura é sensível às pressões de sobrecarga e de poros. A menor sobrecarga acaba por gerar uma janela operacional mais estreita, quando comparando um poço offshore com um poço terrestre. Considerando a mesma sedimentação, um poço offshore deve apresentar um cenário de perfuração mais restrito do que um cenário de poço terrestre. Existem diversas correlações para determinação do gradiente de fratura, um exemplo é o de Hubbert e Willis, indicado por Machado, 2002:

$$
G_{f}=\frac{1}{3}\left(\frac{\sigma_{v}}{Z}+2 \frac{P_{p}}{Z}\right)
$$


onde $G_{f}$ é o gradiente de fratura, $\sigma_{v}$ é a pressão de sobrecarga, $P_{p}$ é a pressão de poros e $z$ é a profundidade vertical da formação. A figura 1.5 mostra que a redução da sobrecarga reduz a janela operacional.

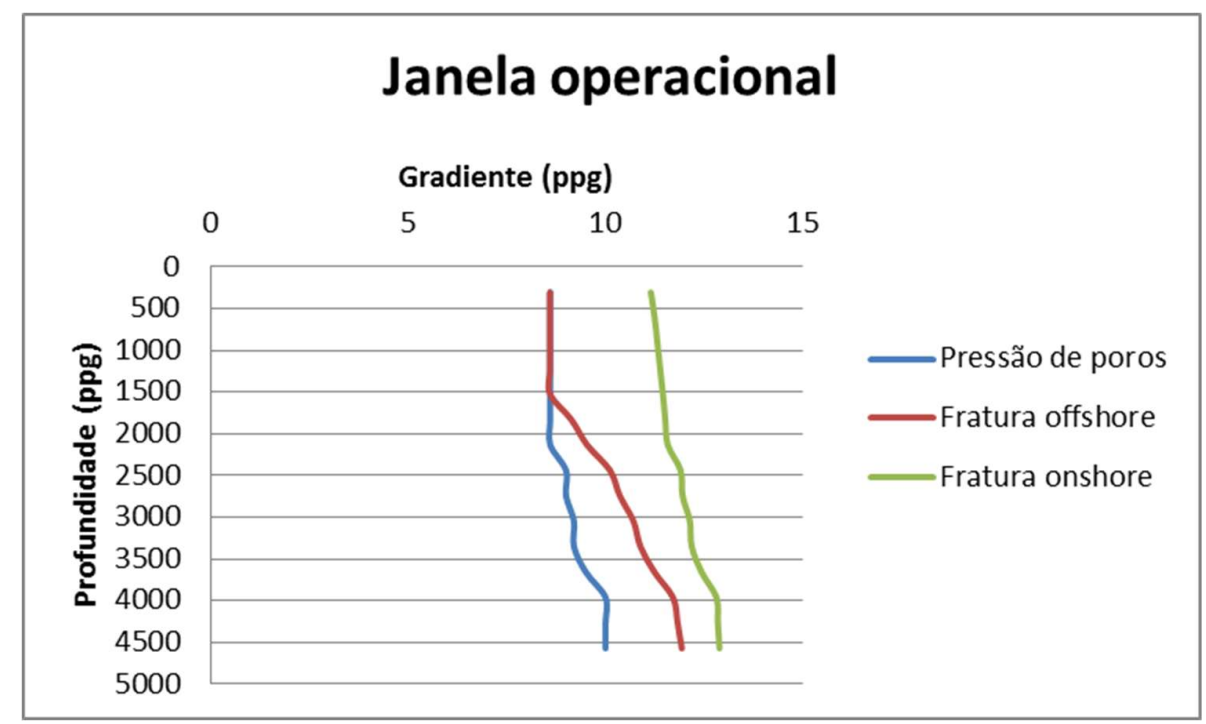

Figura 1.5 - Comparação entre a janela operacional de um poço offshore e onshore.

Outro ponto impactante na janela operacional de um poço de petróleo é a depleção dos reservatórios. Apesar de o limite inferior da janela operacional ser ampliado, o que se verifica na prática é que a janela operacional se reduz. O limite superior de pressão é reduzido em maior valor, pois a pressão de colapso superior passa a ser o limite de pressão superior do poço aberto.

A perfuração de regiões depletadas pode apresentar desafios não encontrados na perfuração de poços em regiões com pressões originais devido à menor janela operacional. Não é incomum verificar em campanhas de adensamento da malha de drenagem de reservatórios problemas operacionais (como perdas severas, prisão de coluna) não encontrados na primeira etapa de desenvolvimento do reservatório.

O gradiente de colapso também é função da pressão de poros e pressão de sobrecarga. Verificam-se os problemas operacionais semelhantes aos casos com o gradiente de fratura, com a redução da janela operacional para poços depletados e/ou offshore.

Em formações carbonáticas existe outro fenômeno que contribui para a redução da janela operacional, que é a pré-existência de fraturas naturais na 
formação, o que limita o valor superior de pressão dentro do poço pelo máximo diferencial de pressão entre a formação e o poço.

$\mathrm{Na}$ análise de novas locações ou no adensamento de malha de locações antigas, a análise da janela operacional acaba por determinar o projeto de assentamento de sapatas (profundidade final do revestimento de cada fase) de um poço. A figura 1.6 exemplifica o processo.

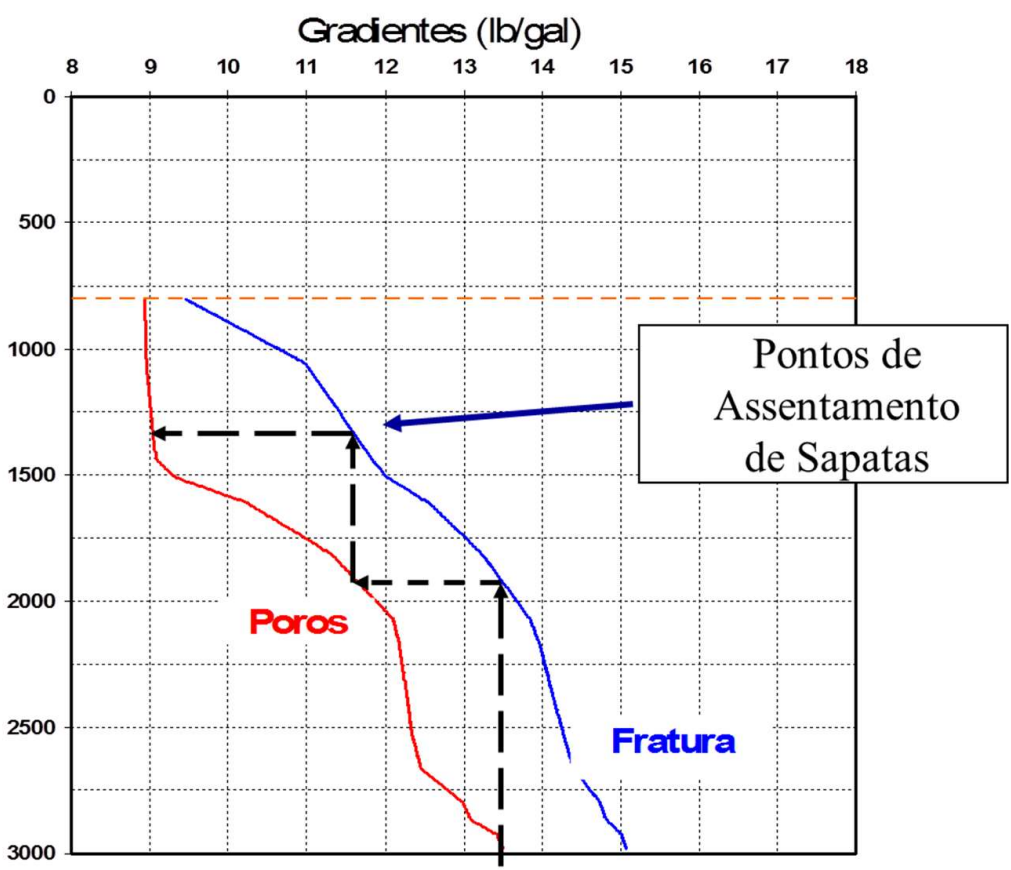

\section{Figura 1.6 - Projeto de assentamento de revestimentos para um poço convencional.}

O que se verifica é que algumas locações possuem janelas operacionais muito estreitas ou inexistentes, o que acaba por demandar um projeto de poço mais robusto, com maior número de fases e contingências. As figuras 1.7 e 1.8 possuem a mesma janela operacional, a diferença entre ambas é que na figura 1.7 é feito um projeto de assentamento de sapatas com base em técnicas de perfuração convencional enquanto na figura 1.8 se considera o uso da técnica de MPD. Ao se comparar as figuras 1.7 e 1.8, observa-se que o MPD dá uma maior flexibilidade operacional, pois é possível concluir a perfuração do poço em uma fase depois da sapata de $95 / 8$ ", permitindo a conclusão de poços com menor número de fases quando comparado com um poço convencional. 


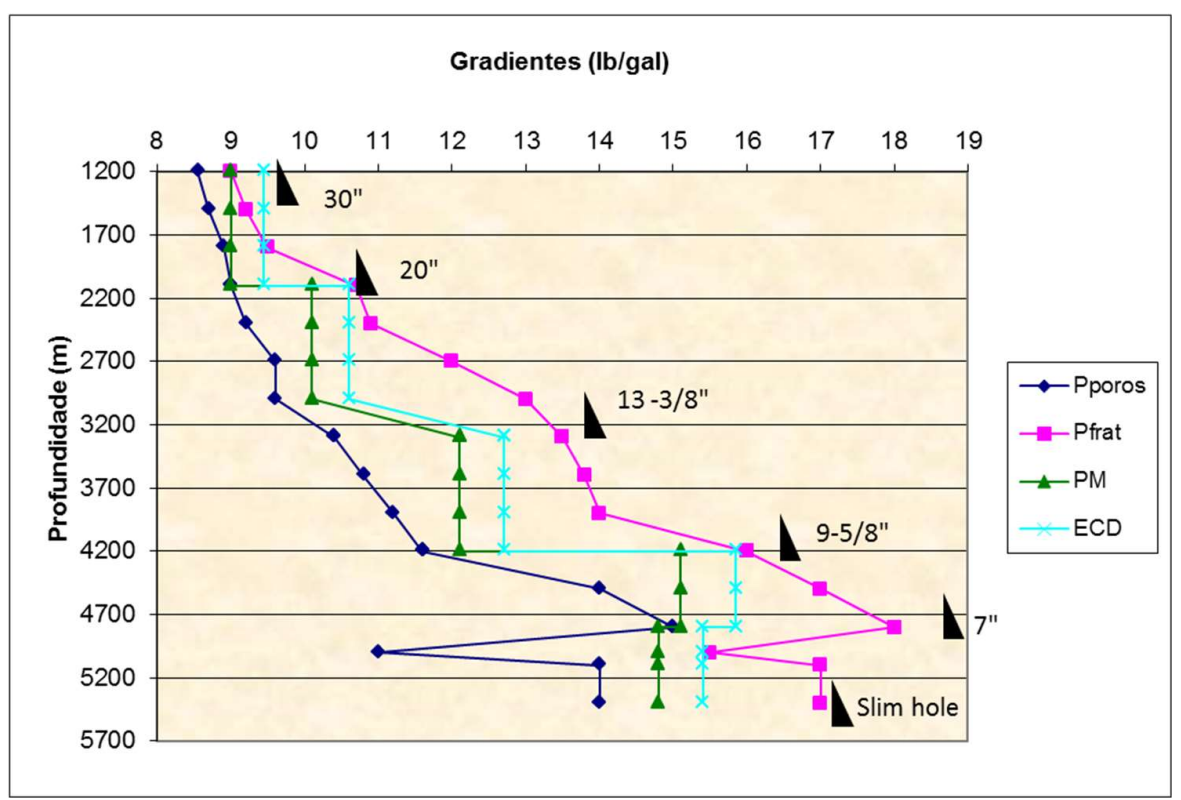

Figura 1.7 - Projeto de assentamento de sapatas convencional.

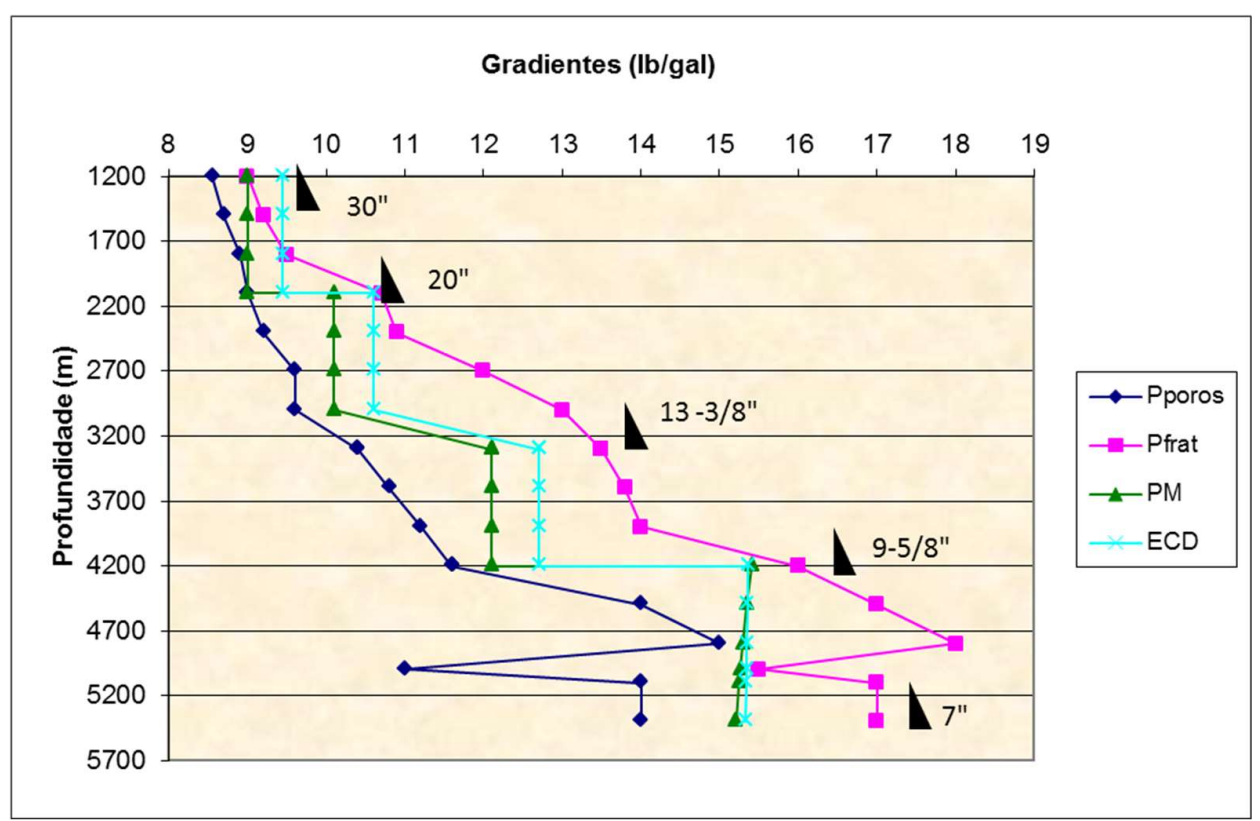

Figura 1.8 - Projeto de assentamento de sapatas com MPD.

Nas figuras anteriores, PM é a densidade do fluido, Pporos é a densidade equivalente da pressão de poros na profundidade, Pfrat é a densidade equivalente da pressão de fratura na profundidade, e ECD é Equivalent Circulation Density, que é a densidade equivalente no interior do poço para uma determinada profundidade considerando as perdas de cargas do sistema. 
Em uma perfuração MPD, a pressão dentro do poço é função do fluido e da contra-pressão na superfície. A estabilidade do poço aberto depende diretamente de a pressão aplicada no seu interior estar dentro da janela operacional referente à profundidade. Para sucesso na aplicação do MPD, o controle da pressão no anular do poço aberto deve ser adequado e dentro da janela operacional. Como a pressão na superfície possui capacidade de ser alterada muito mais rapidamente do que a pressão hidrostática e a perda de carga, o controle da pressão na superfície consegue ter resposta mais rápida para manter a pressão no poço dentro de sua janela operacional do que em uma perfuração convencional.

No próximo capítulo, o modelo hidráulico do sistema é desenvolvido, para posteriormente serem propostos e simulados controladores mais eficientes que os atuais. 


\section{2 \\ Modelo Hidráulico}

Conforme descrito no capítulo de introdução, durante a perfuração de um poço convencional o fluido de perfuração é bombeado pelo interior da coluna, seguindo no espaço anular e retornando pela linha de fluxo (flowline), conforme ilustrado na figura 2.1(a).
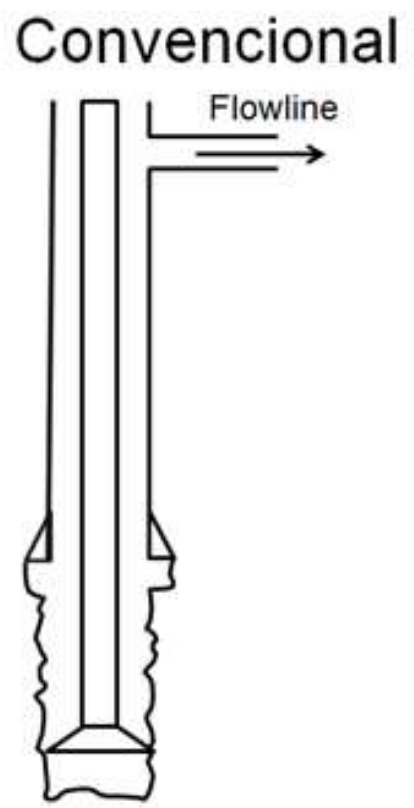
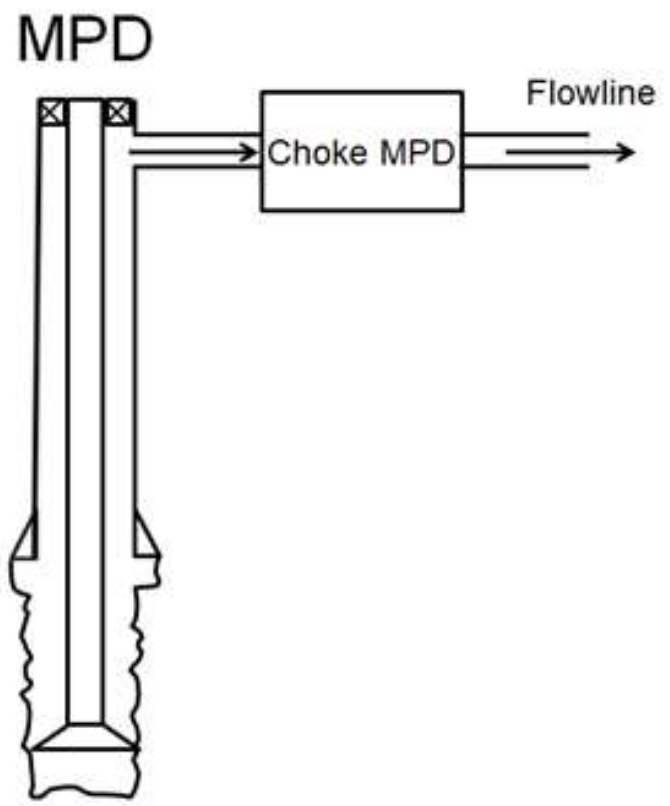

Figura 2.1 - Esquema de perfuração convencional (a) e MPD (b)

Considerando o ponto de início de bombeio na mesma cota do retorno de bombeio, a pressão de bombeio é devida à fricção do fluido ao longo de sua trajetória, que ocorre no interior da coluna, jato da broca e no espaço anular do poço. Por simplicidade, se considera o perfil médio de velocidade para uma dada profundidade e a pressão média na profundidade. Assim, a primeira abordagem para determinação da pressão em alguma profundidade no espaço anular irá considerar a pressão hidrostática e o somatório das perdas de carga da profundidade até a superfície:

$$
P_{\text {Profundidade }}=P_{\text {Hidrostática }}+\Delta P_{\text {carga }}
$$


A determinação da pressão é importante para verificar se a operação se encontra dentro da janela operacional, e quanto é o excesso de pressão no fundo com relação à pressão de poros.

Para uma perfuração MPD, novos componentes são adicionados, vide figura 2.1(b). O anular do poço é restrito por cabeças rotativas, que são elementos vedantes que permitem o giro dos drillpipes. Antes do fluido de perfuração ser liberado para a flowline, ele é restringido por um choke (restritor de fluxo), que irá gerar uma perda de carga localizada na região. A adição do choke acrescenta mais um componente na equação para determinação da pressão de uma dada profundidade do anular do poço:

$P_{\text {Profundidade }}=P_{\text {Hidrostática }}+\Delta P_{\text {carga }}+\Delta P_{\text {choke }}$

O modelo hidráulico deste trabalho considera somente um tipo de fluido no poço e desconsidera a presença de sólidos no anular.

\section{1. \\ Pressão Hidrostática}

A pressão hidrostática é função direta da densidade do fluido de perfuração. Sendo $H$ a profundidade vertical, $g$ a aceleração da gravidade e $\rho$ a densidade do fluido, a pressão hidrostática em uma profundidade vertical $H$ será definida como:

$$
P_{\text {Hidrostática }}=\rho * g * H
$$

O modelo hidráulico deste trabalho considera somente um tipo de fluido no poço, e desconsidera a presença de sólidos no anular, que serão lidados como sendo perturbações no sistema.

\section{2.}

\section{Perda de Carga}

Um fluido ideal se deforma de maneira contínua sob a ação de um sistema de forças, sendo esta deformação também conhecida como escoamento. Desta forma, para um fluido ideal o escoamento se apresenta quando qualquer tensão é aplicada, não podendo resistir à tensão sem deformação. Alguns fluidos exibem resistência ao escoamento, sendo necessária uma tensão mínima para o seu início. 
Nestes fluidos, caso a tensão aplicada sobre o mesmo seja inferior à sua resistência inicial, o escoamento não se inicia. Devido à resistência ao escoamento, a energia mecânica é convertida em calor.

A deformação de um fluido pode ser expressa em função de sua taxa de cisalhamento, definida como o deslocamento relativo das partículas ou planos de fluido; outras denominações comuns são grau de deformação ou gradiente de velocidade. A expressão para definição da taxa de cisalhamento, $\gamma$, relaciona a diferença de velocidade entre planos vizinhos com a distância entre os mesmos, conforme equação (2.4):

$$
\gamma=\frac{\Delta v}{\Delta y}
$$

onde $\Delta \mathrm{v}$ é a diferença de velocidades entre duas camadas de fluido adjacentes e $\Delta y$ é a distância entre elas. A unidade no S.I. de $\gamma$ é $\mathrm{s}^{-1}$.

A tensão de cisalhamento é a força por unidade de área cisalhante necessária para manter o escoamento do fluido, representando a resistência do escoamento. A tensão de cisalhamento pode ser expressa por:

$$
\tau=\frac{F}{S}
$$

onde $\mathrm{F}$ é a força aplicada na direção do escoamento e $\mathrm{S}$ é a área da superfície exposta ao cisalhamento. A unidade no S.I. desta tensão é Pascal $(\mathrm{Pa}$ ou N/m²).

\subsection{1.}

\section{Fluidos Newtonianos}

No escoamento de um fluido newtoniano, em regime laminar, existe uma proporcionalidade entre a tensão de cisalhamento e a taxa de cisalhamento, sendo uma reta cuja tangente é a viscosidade dinâmica. Uma única determinação experimental é suficiente para definir o comportamento da viscosidade com a taxa de cisalhamento. 


\subsection{2.}

\section{Fluidos não Newtonianos}

Os fluidos em que a relação entre a taxa de cisalhamento e a tensão de cisalhamento não é constante são denominados como não newtonianos. $\mathrm{Na}$ atividade de perfuração de poços de petróleo, os fluidos utilizados para perfuração muitas vezes se comportam como fluidos não newtonianos. Fluidos utilizados na perfuração de poço em muitos dos casos são compostos químicos, podendo ter diferentes composições. É comum o preparo dos fluidos em uma sonda de perfuração, sendo as propriedades do fluido adequadas para cada fase do poço e as formações expostas na fase. Desta forma, diferentes fluidos utilizados na perfuração podem apresentar diferentes comportamentos reológicos, não existindo um único modelo reológico para comportamento geral dos fluidos de perfuração.

A relação entre a tensão de cisalhamento e a taxa de cisalhamento define o comportamento reológico dos líquidos. Cada tipo de fluido possui uma curva de fluxo característica. São exemplos: Bingham, Newtoniano, Pseudoplástico, Dilatante, Herschell-Buckley.

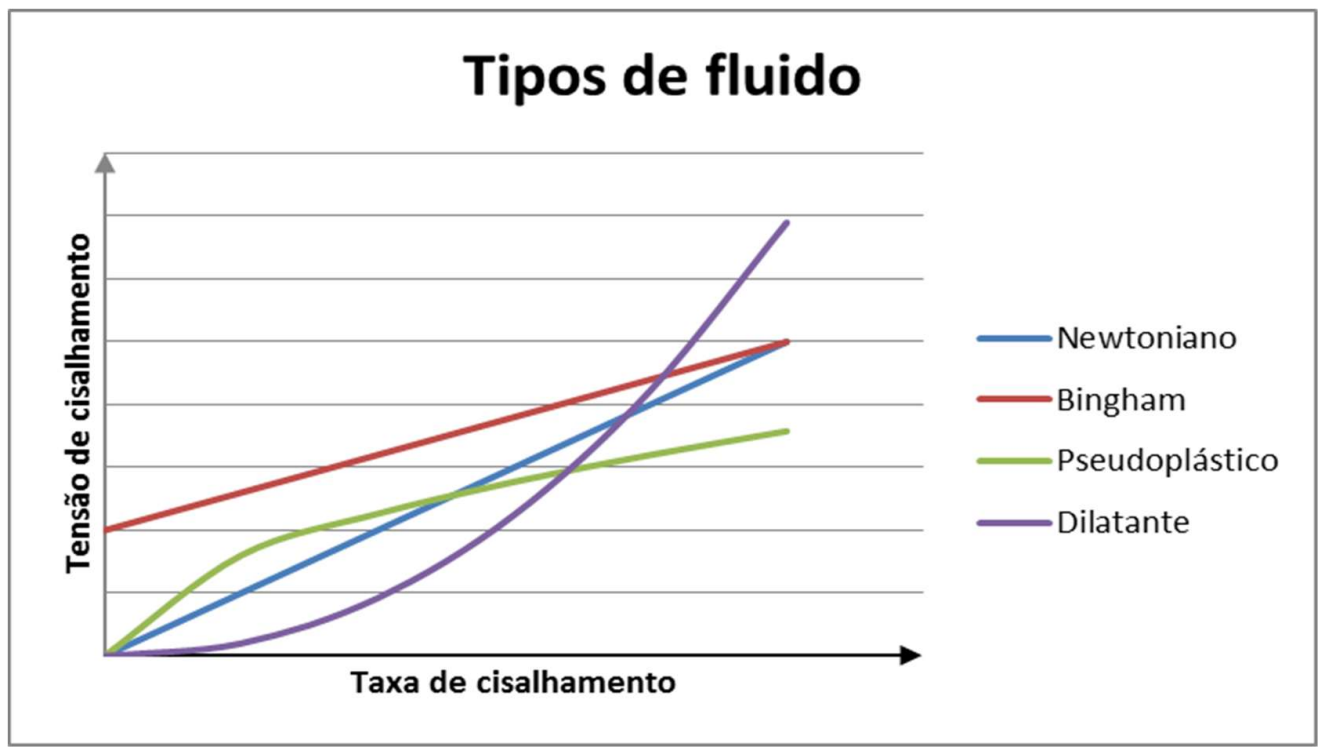

Figura 2.2 - Esquema qualitativo de comportamentos reológicos. 


\subsection{3.}

\section{Fluxo laminar e turbulento}

O regime de escoamento dos fluidos pode ser tanto laminar como turbulento. Para determinação do regime de escoamento do fluido, é utilizado o número de Reynolds, um número adimensional que correlaciona as forças viscosas com as forças inerciais. Para o fluido newtoniano e o do tipo Bingham, o número de Reynolds é representado por

$$
R e=\frac{\rho d \bar{v}}{\mu}
$$

onde Re é o número de Reynolds, $\rho$ a densidade do fluido, $d$ a dimensão do canal de escoamento, $\bar{v}$ a velocidade média de fluxo, e $\mu$ a viscosidade dinâmica. Para os fluidos do tipo potência e Herschell-Buckley, o cálculo do número de Reynolds segue

$$
R e_{H B / P O T}=\frac{8 d^{n} v^{(2-n)} \rho}{K\left[\frac{2(3 n+1)^{n}}{n}\right]}
$$

onde $n$ é o índice de comportamento, $\rho$ a densidade do fluido, $d$ a dimensão do canal de escoamento, $v$ a velocidade de fluxo, e $K$ o índice de consistência.

No escoamento laminar, as camadas de fluxo se deslocam de forma paralela com a direção do escoamento, não ocorrendo mistura entre camadas de fluxo. A distribuição de velocidades em um escoamento laminar possui perfil parabólico.

No escoamento turbulento, ocorre o deslocamento caótico de pequenas massas de fluido ao longo do canal de fluxo. Os turbilhões provocam misturas entre as camadas e mesmo para um fluxo plenamente desenvolvido a velocidade em um ponto varia em torno de um valor médio.

Em tubulações lisas, para números de Reynolds menores ou iguais a 2100 o fluxo será laminar. Valores de número de Reynolds acima de 2100 e menores do que 3000 são considerados como regime transiente, enquanto valores superiores a 3000 são considerados como regime de fluxo turbulento, (Bourgoyne et al, 1986, e Machado, 2002). Uma simplificação na modelagem considerada é que para número de Reynolds inferiores a 2100 o fluxo será considerado como Laminar e para valores superiores o fluxo será assumido como Turbulento. 
A determinação do regime de fluxo é importante para determinação do fator de atrito e o cálculo da perda de carga nas tubulações do poço. Assumindo um modelo sem perda de fluido ao longo do caminho do fluxo, a vazão em todas as seções será a mesma. Por possuírem diferentes dimensões, as velocidades médias de cada seção, ao longo do interior da coluna e do anular do poço, podem diferir. Consequentemente, o número de Reynolds de cada seção também pode diferir, gerando diferentes perdas de carga lineares para cada seção.

\subsection{4.}

Modelos de fluido de perfuração.

A determinação da perda de carga é dependente da reologia do fluido e do tipo de fluido. Na perfuração de poços de petróleo, diversos tipos de fluidos são utilizados. Serão analisados os tipos de modelos de fluidos mais comuns para perfuração: Newtoniano, Bingham, Potência, e Herschell-Buckley.

\subsubsection{1. Newtoniano}

O fluido newtoniano é utilizado na perfuração offshore em geral nas fases iniciais do poço, ou como fluido de sacrifício. São exemplos de fluidos newtonianos utilizados: água do mar e soluções salinas. Note que fluido de sacrifício são os fluidos utilizados quando a taxa de perdas é muito alta ou total, e a logística ou custo impedem a operação com fluidos de perfuração com reologia mais sofisticada. A figura 2.3 ilustra qualitativamente a curva de fluxo do fluido Newtoniano. 


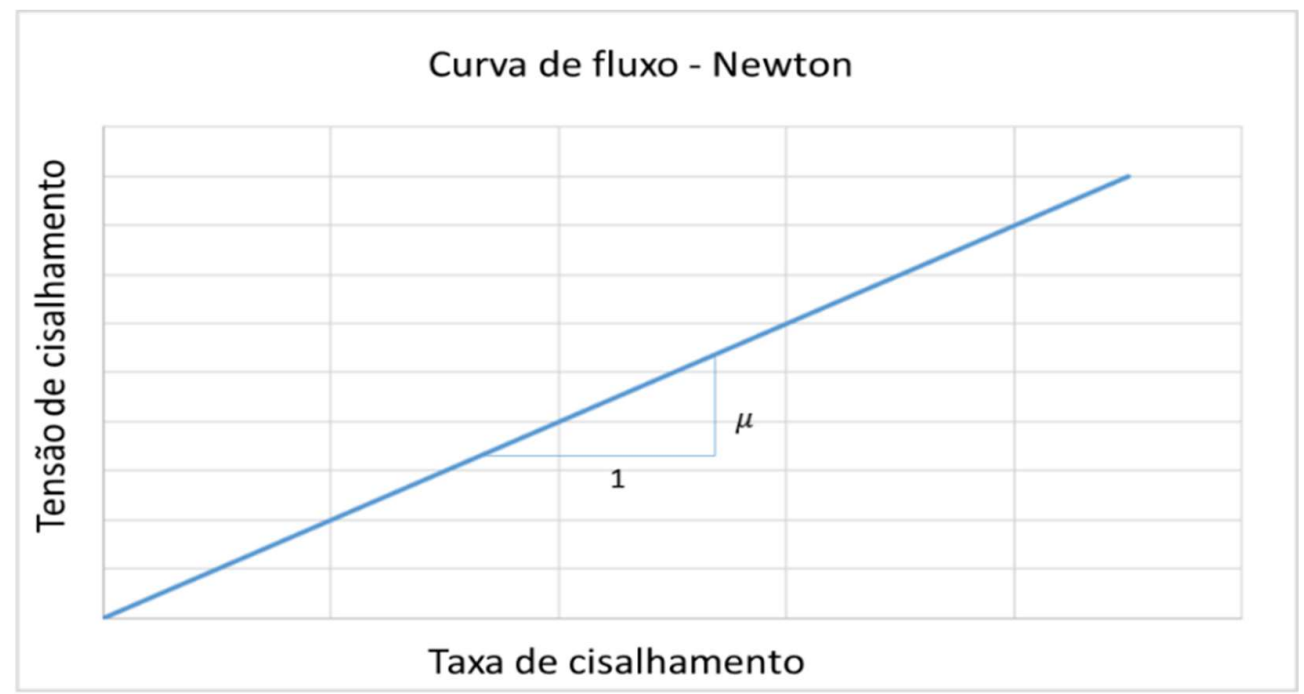

Figura 2.3 - Comportamento qualitativo de curva de fluxo do fluido newtoniano.

\subsubsection{2.}

Bingham

O fluido do modelo de Bingham requer a aplicação de uma tensão mínima $\tau_{0}$, também conhecida como limite de escoamento, para que haja deformação cisalhante. A equação da tensão de cisalhamento no fluido Binghamiano segue a equação:

$$
\tau=\mu_{P} * \gamma+\tau_{0}
$$

onde $\tau$ é a tensão de cisalhamento, $\mu_{P}$ a viscosidade plástica do fluido, $\gamma$ a taxa de cisalhamento, e $\tau_{O}$ limite de escoamento. A figura 2.4 ilustra qualitativamente a curva de fluxo do fluido Binghamiano. 


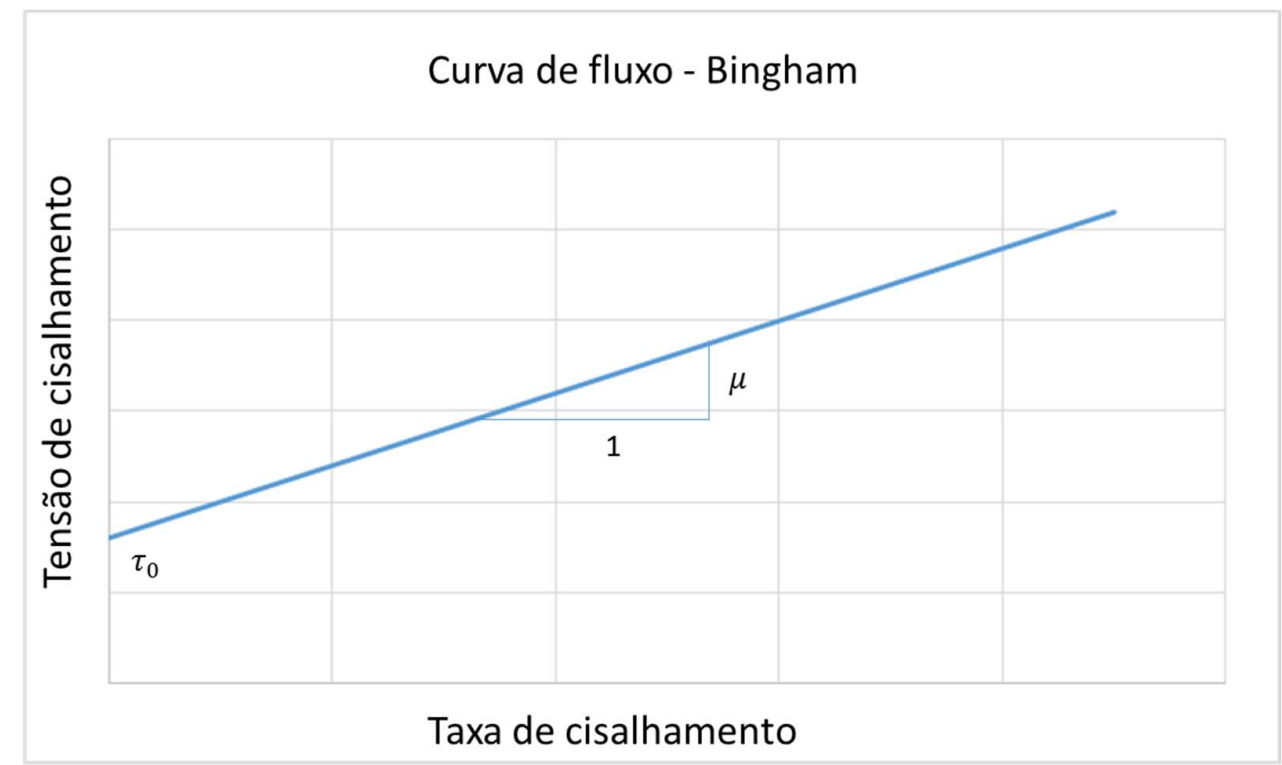

Figura 2.4 - Comportamento qualitativo curva de fluxo do fluido Binghamiano.

\subsubsection{3. \\ Potência}

No modelo de fluido de potência, o comportamento do fluido é definido com base no índice de consistência $K$ e no índice de comportamento $n$. Fluidos que possuem $n$ maior que zero e menor que 1,0 são chamados de pseudoplásticos, enquanto fluidos com $n$ maior do que 1,0 são chamados de dilatantes. A equação da tensão de cisalhamento segue o formato:

$\tau=K(\gamma)^{n}$

A figura 2.5 ilustra qualitativamente a curva de fluxo do fluido de Potência. 


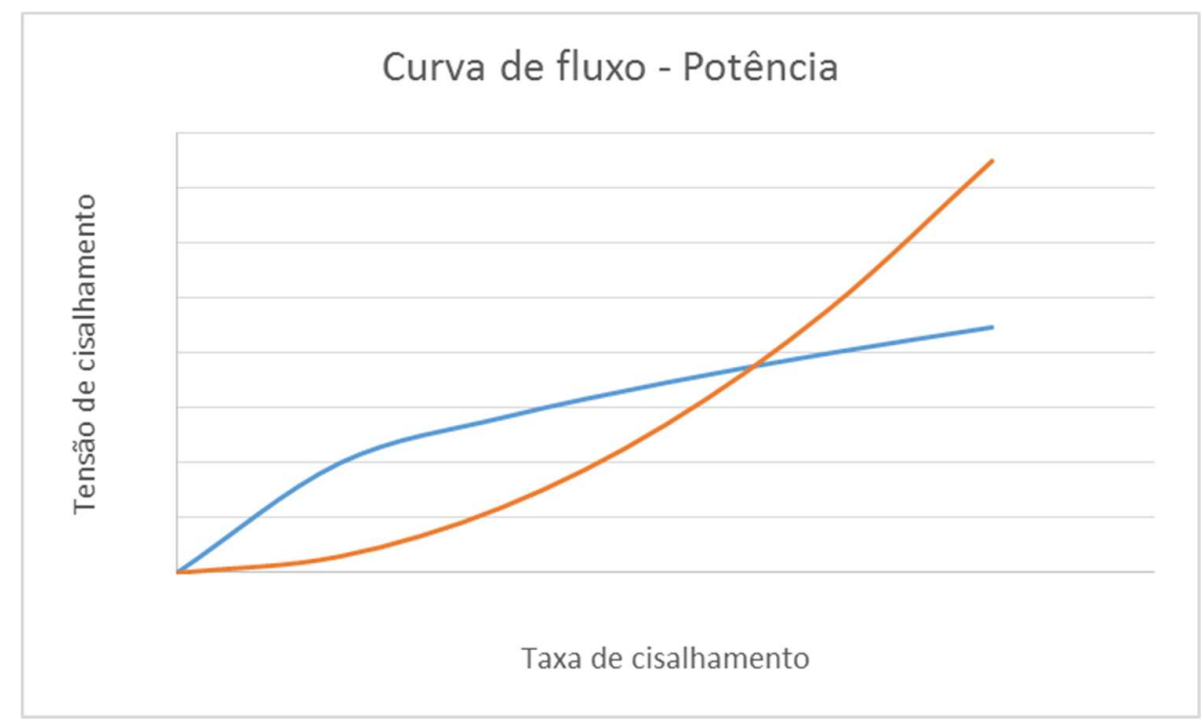

Figura 2.5 - Comportamento qualitativo curva de fluxo do fluido de potência dilatante (vermelho) e pseudoplástico (azul).

\subsubsection{4. \\ Herschell-Buckley}

O modelo de Herschell-Buckley também é conhecido como modelo de fluido de potência com limite de escoamento. A equação que define o comportamento do fluxo admite mais um componente que a equação do fluido de potência, este termo é o limite de escoamento $\tau_{O}$ :

$$
\tau=K(\gamma)^{n}+\tau_{O}
$$

A figura 2.6 ilustra qualitativamente a curva de fluxo do fluido do tipo Herschell-Buckley. 


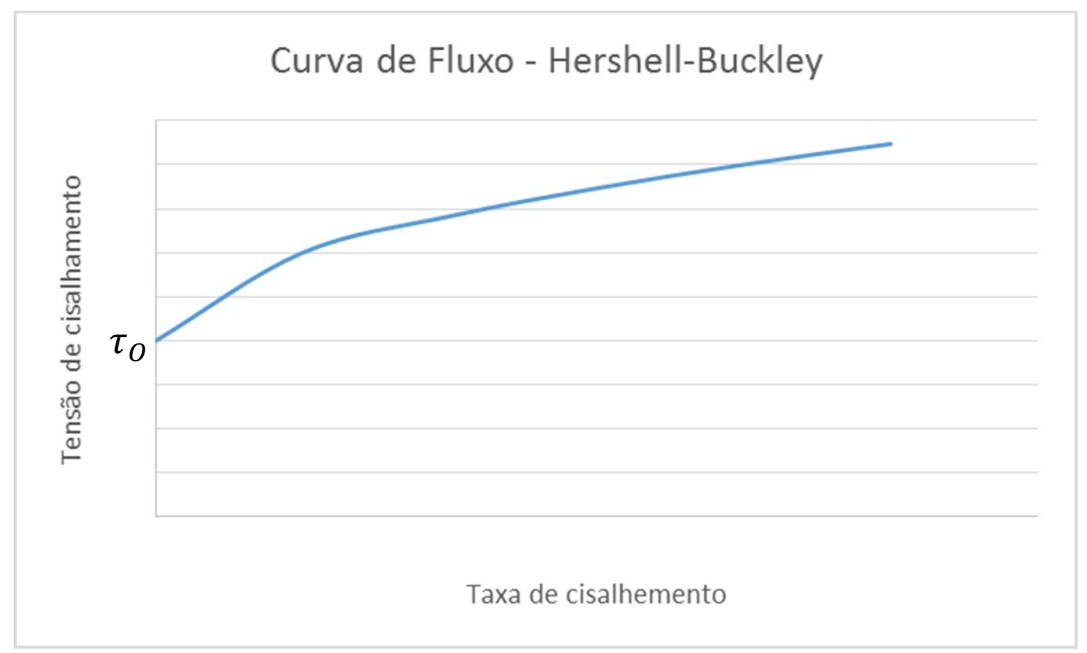

Figura 2.6 - Comportamento qualitativo curva de fluxo do fluido do modelo de Herschell-Buckley.

\subsection{5.}

\section{Cálculo das perdas de carga}

O cálculo da perda de carga de um fluido em um poço é dependente do tipo e reologia do fluido, geometria do poço, e vazão do fluido. A sua determinação não é direta, devendo seguir uma sequência de cálculos.

O regime de fluxo muda a forma de cálculo da perda de carga. A determinação do regime de fluxo, laminar ou turbulento, é feita com o número de Reynolds do escoamento no trecho considerado. O número de Reynolds é determinado com base na geometria do trecho, velocidade do fluido no trecho, e dados reológicos do fluido.

Para o interior da coluna de perfuração e BHA, a dimensão principal é o diâmetro interno desta tubulação. Para o anular do poço é necessário o cálculo do diâmetro hidráulico, com base no diâmetro externo da tubulação e BHA e diâmetro do poço ou diâmetro interno no revestimento ou riser de perfuração. Bourgoyne (1986) define o diâmetro hidráulico como:

$$
d_{H}=0,816 *\left(d_{\text {externo }}-d_{\text {interno }}\right)
$$

onde $d_{H}$ é Diâmetro hidráulico, $d_{\text {externo }}$ é o diâmetro externo na seção, e $d_{\text {interno }}$ o diâmetro interno da seção. 
Com o número de Reynolds definido para cada trecho, é possível definir o regime de fluxo e a forma de cálculo do fator de fricção do trecho.

O cálculo da perda de carga para os fluidos Binghamiano e de HerschellBuckley necessitam do cálculo do número de Hedstrom. Este passo é necessário em fluidos que apresentam limite de escoamento. A equações (2.12) e (2.13) mostram as definições utilizadas para fluido do tipo Bingham no interior da tubulação e no anular, respectivamente:

$$
\begin{aligned}
& H e=\frac{\rho D^{2} \tau_{0}}{\mu_{p}^{2}} \\
& H e=\frac{\rho\left(d_{\text {externo }}-d_{\text {interno }}\right)^{2} \tau_{0}}{\mu_{p}^{2}}
\end{aligned}
$$

Para o fluido do tipo Herschell-Buckley, o número de Hedstrom segue a equação (2.14):

$$
H e_{H B}=\frac{R e_{H B}^{2} \tau_{0}}{\rho v^{2}}
$$

Para regimes laminares, o fator de fricção $f$ de um fluido Newtoniano, ou de potência, é dado pela equação:

$$
f_{\text {Newton } / \text { Potência }}=\frac{16}{R e}
$$

Para os fluidos do tipo Bingham e Herschell-Buckley, o cálculo do fator de atrito laminar não é direto, sendo necessário fazer um cálculo recursivo.

Para o modelo de Herschell-Buckley, o fator de fricção é calculado seguindo as equações:

$$
\begin{gathered}
f=\frac{2 H e_{H B}}{R e_{H B}^{2}}+\frac{16 Z^{-n}}{R e_{H B}} \frac{16}{R e} \\
\frac{\tau_{0}}{\tau_{w}}=\frac{2 H e_{H B}}{f R e_{H B}^{2}} \\
Z=\left(1-\frac{\tau_{0}}{\tau_{w}}\right)^{3}+\frac{2(3 n+1)}{2 n+1}\left(\frac{\tau_{0}}{\tau_{w}}\right)\left(1-\frac{\tau_{0}}{\tau_{w}}\right)^{2}+\frac{3 n+1}{n+1}\left(1-\frac{\tau_{0}}{\tau_{w}}\right)\left(\frac{\tau_{0}}{\tau_{w}}\right)^{2}
\end{gathered}
$$


onde Re é o número de Reynolds, He é o número de Hedstrom, e $\frac{\tau_{0}}{\tau_{w}}$ é o coeficiente de tensões. O cálculo do fator de atrito depende de uma estimativa inicial de $Z$, na qual o fator calculado resulta em um coeficiente de tensões e em um novo valor de Z. Após algumas iterações o valor de $f$ converge, definindo-se assim o fator de atrito. $\mathrm{O}$ critério de parada adotado é quando o erro for menor que $10^{-4}$.

Para o modelo de Bingham, outro conjunto de equações é utilizado:

$$
\begin{aligned}
& f_{\text {inicial }}=\frac{0,00791}{R e^{0,25}} \\
& y=\frac{16}{R e_{B}}\left[1+\frac{H e_{B}}{R e_{B}}-\frac{H e_{B}^{4}}{3 f^{3} R e_{B}^{7}}\right]-f \\
& d y=\frac{16 H e^{4}}{f^{4} R e^{8}}-1 \\
& f=f_{\text {anterior }}-\frac{y}{d y}
\end{aligned}
$$

As iterações devem ser repetidas até que a diferença entre o fator de fricção calculado na iteração atual e o fator de atrito calculado na iteração anterior sejam desprezíveis. O critério de parada utilizado neste trabalho é o mesmo valor de critério de conversão adotado para Hershell-Buckley $\left(10^{-4}\right)$.

Para regime de fluxo turbulento, a metodologia utilizada para o cálculo do fator de fricção difere para do fluido de potência com relação aos demais fluidos utilizados. O fator de atrito para o fluido de potência considera a correlação proposta por Gomes (1987):

$$
f=0,069 n^{2 / 3} R e^{-0,235}
$$

Os fluidos do tipo Newtoniano, Bingham e Hershell-Buckley precisam de um modelo recursivo com base na equação de Colebrook, equação (2.24), sendo necessárias algumas iterações até definição do valor do fator de fricção.

$$
\frac{1}{\sqrt{f}}=-1,73716 \log \left(\frac{\frac{\varepsilon}{d_{h}}}{3,7}+\frac{1,255}{\operatorname{Re} \sqrt{f}}\right)
$$


onde $\varepsilon$ é a rugosidade da tubulação/revestimento, e $d_{h}$ o diâmetro hidráulico da tubulação, conforme apresentado na equação (2.11).

O cálculo da perda de carga $(\Delta p)$ é dependente do regime do fluxo e do tipo de fluido. Os fluidos dos modelos Newton, Bingham, Potência, e HerschellBuckley têm a perda de carga definida pela equação (2.25), para o interior da coluna, e pela equação (2.26), para espaço anular.

$$
\begin{aligned}
& \Delta p=2 f \rho^{2} \frac{l}{d} \\
& \Delta p=2 f \rho^{2} l / 0,816\left(d_{i}-d_{e}\right)
\end{aligned}
$$

onde $f$ é o fator de fricção, $\rho$ é a massa específica, $v$ é a velocidade média na seção, $l$ é o comprimento da seção, e $d$ o diâmetro da tubulação. Para o espaço anular, $d_{i}$ é o diâmetro interno do revestimento ou poço aberto e $d_{e}$ o diâmetro externo da tubulação ou BHA na seção.

Para o fluido do modelo de Bingham, quando o regime de fluxo é laminar, as equações (2.25) e (2.26) são substituídas pelas equações (2.27) para a perda de carga no interior da coluna, e (2.28) para cálculo das perdas de carga pelo anular.

$$
\begin{aligned}
& \Delta p=\left(\frac{32 \mu v}{d^{2}}+\frac{16 L E}{3 d}\right) * l \\
& \Delta p=\left(\frac{48 \mu v}{\left(d_{h}\right)^{2}}+\frac{6 L E}{\left(d_{h}\right)}\right) * l
\end{aligned}
$$

onde LE é o limite de escoamento, $\rho$ é a massa específica, $v$ é a velocidade média na seção, $l$ é o comprimento da seção, $\mu$ é a viscosidade plástica do fluido, e $d$ o diâmetro da tubulação. Para o espaço anular, $d_{h}$ é o diâmetro hidráulico do anular do revestimento/poço aberto e da tubulação ou BHA na seção.

Vale observar que tanto o cálculo do fator de fricção como o cálculo de perda de carga possuem diferentes modelos e equações na literatura. Existem diversas metodologias para definição dos valores. O trabalho de Scheid et al, 2009 serviu como referência para determinação das equações a serem utilizadas. Este trabalho selecionou as equações com melhores resultados com base em experimentos desenvolvidos com foco na perfuração de poços de petróleo. 


\subsection{6.}

\section{Validação dos resultados do cálculo de perda de carga}

Neste trabalho, a modelagem apresentada foi implementada em um simulador em MATLAB ${ }^{\circledR}$ (The MathWorks Inc., 2000). Uma maneira de validar o modelo hidráulico e a metodologia de cálculo de perda de carga é comparar os resultados do modelo com os resultados de um software de simulação hidráulico com resultados conhecidos e validados operacionalmente. O software escolhido para comparação foi o Simentar (Petrobras, 2010). O Simentar é um software de simulação hidráulica de cimentação, desenvolvido pelo centro de pesquisa da Petrobras, capaz de simular as perdas de carga de diversos tipos de fluido.

A verificação considerou a geometria típica de um poço do pré-sal: um poço vertical com $5000 \mathrm{~m}$ de profundidade e $2000 \mathrm{~m}$ de lámina de água. A coluna de perfuração é constituída por 4700m de drillpipe (tubulação de perfuração) e $300 \mathrm{~m}$ de BHA. O poço é constituído de um revestimento intermediário de diâmetro interno de 12,6 polegadas $(320,04 \mathrm{~mm})$ da profundidade do poço final do poço até a profundidade da cabeça do poço no leito marinho; do leito marinho até a superfície está localizado o riser de perfuração, com diâmetro interno de 19,25 polegadas $(488,95 \mathrm{~mm})$, que faz a conexão hidráulica da cabeça do poço no fundo do mar até a superfície, vide tabela 2-1. A figura 2.7 ilustra o esquema do poço. 


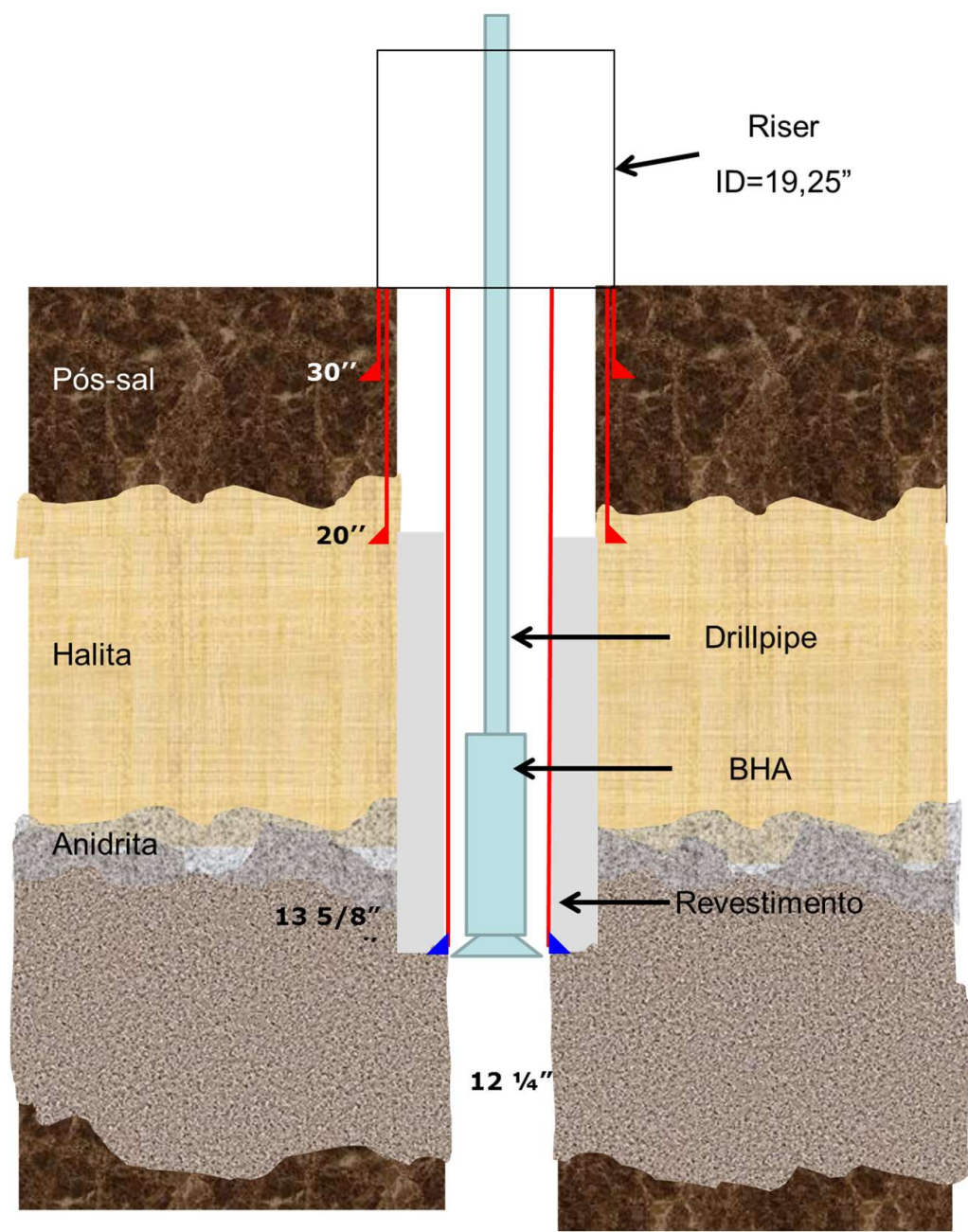

Figura 2.7 - Esquema de um poço representativo do pré-sal.

Tabela 2-1 - Dimensões dos elementos do poço

\begin{tabular}{|l|c|c|c|}
\hline Elemento & $\begin{array}{c}\text { ID } \\
\text { (polegadas) }\end{array}$ & $\begin{array}{c}\text { OD } \\
\text { (polegadas) }\end{array}$ & $\begin{array}{c}\text { Comprimento } \\
(\mathrm{m})\end{array}$ \\
\hline Drillpipe & 4,63 & - & 4700 \\
\hline BHA & 3 & - & 300 \\
\hline Anular poço revestido - BHA & 12,6 & 8 & 300 \\
\hline Anular poço revestido - drillpipe & 12,6 & 5,5 & 2700 \\
\hline Anular riser - drillpipe & 19,25 & 5,5 & 2000 \\
\hline
\end{tabular}

Foram utilizadas 3 vazões diferentes nas simulações de fluidos de perfuração dos 4 tipos modelados: $0.0318 \mathrm{~m}^{3} / \mathrm{s}, 0.0159 \mathrm{~m}^{3} / \mathrm{s}$, e $0,0079 \mathrm{~m}^{3} / \mathrm{s}$, que representam $100 \%, 50 \%$ e $25 \%$ da vazão de perfuração normal para um poço com estas características. A variação das vazões teve como objetivo mudar o regime de 
fluxo (laminar e turbulento) em diferentes seções do poço, para uma maior abrangência do comportamento do simulador. A figura 2.8 e tabelas $2-2$ e 2-3 mostram alguns resultados das simulações de perda de carga, tanto para o modelo desenvolvido nesta dissertação em MATLAB ${ }^{\circledR}$ (The MathWorks Inc., 2000), quanto para o software Simentar (Petrobras, 2010).

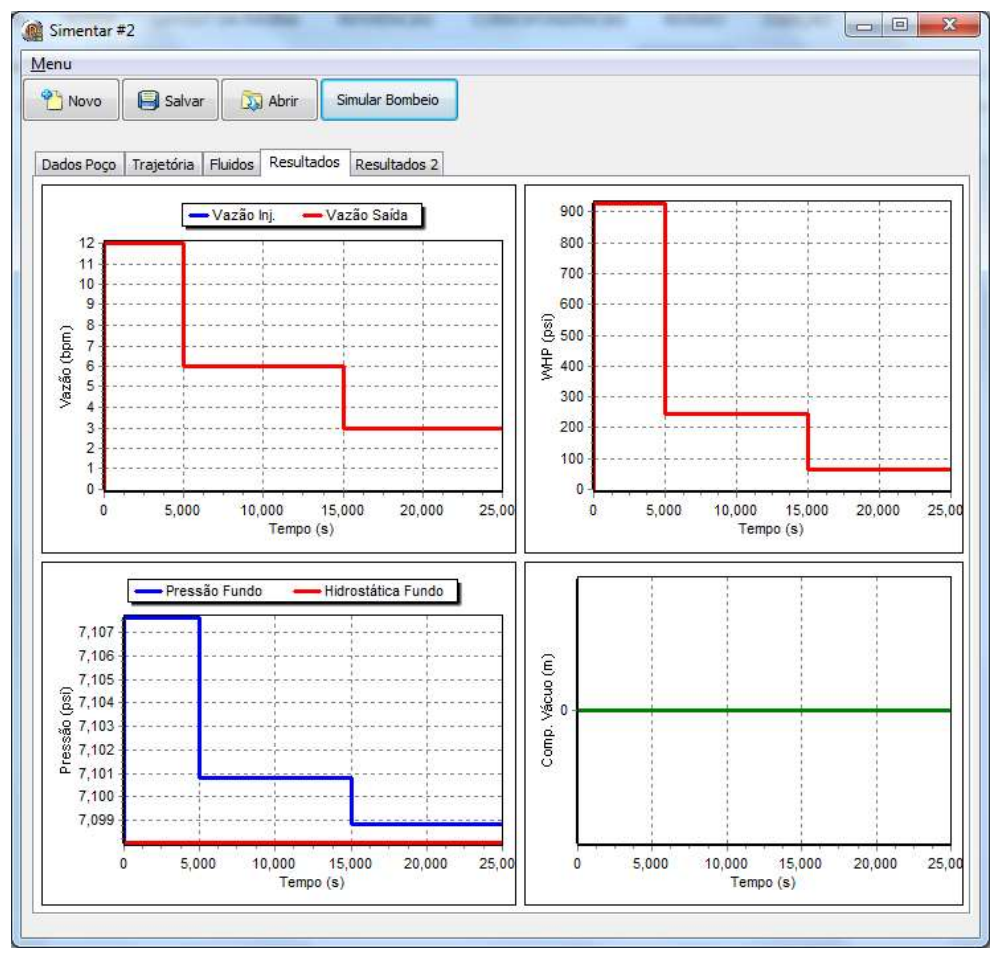

Figura 2.8 - Tela com resultado Simulação Simentar com fluido Newtoniano

Tabela 2-2 - Resultados do modelo hidráulico desenvolvido

\begin{tabular}{|l|l|l|l|l|l|l|}
\hline & \multicolumn{3}{|c|}{ Modelo desenvolvido } & \multicolumn{3}{c|}{ Simentar } \\
\hline $\begin{array}{l}\text { Tipo de } \\
\text { fluido }\end{array}$ & $\begin{array}{l}\text { Q100\% } \\
\text { (psi) }\end{array}$ & $\begin{array}{l}\text { Q50\% } \\
(\mathrm{psi})\end{array}$ & $\begin{array}{l}\text { Q25\% } \\
(\mathrm{psi})\end{array}$ & $\begin{array}{l}\text { Q100\% } \\
(\mathrm{psi})\end{array}$ & $\begin{array}{l}\text { Q50\% } \\
(\mathrm{psi})\end{array}$ & $\begin{array}{c}\text { Q25 } \\
\% \\
(\mathrm{psi})\end{array}$ \\
\hline Newton & 908 & 240 & 65 & 920 & 245 & 65 \\
\hline Potência & 430 & 139 & 45 & 420 & 140 & 45 \\
\hline Bingham & 2273 & 860 & 805 & 2320 & 880 & 790 \\
\hline $\begin{array}{l}\text { Hershell- } \\
\text { Buckley }\end{array}$ & 970 & 287 & 90 & 980 & 280 & 85 \\
\hline
\end{tabular}


Tabela 2-3 - Reologia de cada fluido utilizada:

\begin{tabular}{|c|c|c|c|c|c|}
\hline Tipo de fluido & $\rho(\mathrm{ppg})$ & $\mu(\mathrm{cP})$ & $\begin{array}{c}\mathrm{LE} \\
\left(\mathrm{lbf} / 100 \mathrm{ft}^{2}\right)\end{array}$ & $\mathrm{n}$ & $\begin{array}{c}\mathrm{k} \\
\left(\mathrm{lbf} . \mathrm{s} / 100 \mathrm{ft}^{2}\right)\end{array}$ \\
\hline Newton & 8.33 & 1 & - & - & - \\
\hline Bingham & 9 & 33 & 15 & - & - \\
\hline Potência & 9.1 & 73 & 22 & 0.44 & 0.0412 \\
\hline $\begin{array}{c}\text { Hershell- } \\
\text { Buckley }\end{array}$ & 9.1 & 26 & 12 & 0.44 & 0.0291 \\
\hline
\end{tabular}

Conforme pode ser observado na tabela $2-2$, os resultados do modelo hidráulico desenvolvido são semelhantes aos resultados obtidos pelo software Simentar. Entre os 4 tipos de fluido analisados, o que obteve os resultados mais próximos foi o fluido Newtoniano (erro próximo a $2 \%$ ). O maior erro encontrado foi com o fluido do tipo Bingham ( $\sim 3 \%)$; mesmo assim, o erro se encontra dentro da margem de erro verificada entre simuladores comerciais (Drill Bench, Olga, etc...), na qual uma variação na estimativa da perda de carga de diferentes simuladores hidráulicos não é incomum.

Um fato observado durante a simulação das perdas de carga para diferentes fluidos foi a não continuidade dos valores de perda de carga calculados na mudança do fluxo laminar para turbulento para os fluidos do tipo Bingham e Herschell-Buckley. No caso do fluido do tipo Herschell-Buclkley, a perda de carga para um Reynolds laminar, 1990, no trecho anular revestimento e drillpipe é de 48 psi, enquanto a perda de carga no mesmo trecho para um Reynolds turbulento, 2200, é de 1,2 psi. Esse comportamento descontínuo não é observado em circulações reais, na qual a pressão de bombeio possui um comportamento continuo (incremental com a vazão). Vale notar que durante a entrada de bombas se verifica um aumento de pressão inicial, relacionado com a quebra do gel, porém este pico de pressão não se mantém com a continuidade do bombeio. Do ponto de vista de controle, isso traria uma dificuldade adicional no choke, sem estar relacionado com um aumento da fidedignidade do modelo. Com isso considerado, foi optado continuar o desenvolvimento do modelo hidráulico e do controlador do choke trabalhando somente com fluido Newtoniano e fluido do tipo potência. 


\subsection{7. \\ Perda de carga na broca}

O fluido bombeado no interior da coluna passa pelos jatos da broca antes de seguir para o anular do poço. Como ocorre uma mudança brusca na seção transversal de fluxo, isso acaba gerando uma perda de carga localizada. O cálculo de perda de carga em jatos de broca é dado pela equação (2.29):

$$
P_{b}=\frac{(\rho) *\left(Q^{2}\right)}{(12032) *\left(A_{n}{ }^{2}\right)}
$$

onde $P_{b}$ corresponde à perda de carga nos jatos da broca, $(\rho)$ é a densidade do fluido, $(Q)$ a vazão pelos jatos da broca, e $\left(A_{n}\right)$ a área de passagem dos jatos da broca. As unidades consideradas na fórmula são unidades inglesas (psi, ppg, gpm e pol$^{2}$ respectivamente), ainda usadas pela maior parte da indústria do petróleo. Para sua aplicação no problema, que usa o SI, foi utilizado um fator de correção para adequação das unidades das variáveis da fórmula.

A equação utilizada para perda de carga nos jatos da broca é uma derivação da equação indicada por Bourgoyne (1986). Ela está consolidada e é praticamente a mesma utilizada em diversos softwares comerciais, salvo o uso de um fator de correção que varia em torno de 5\% a depender de cada software. Na figura 2.9 se observa uma vista frontal de uma broca de perfuração com destaque, seta vermelha, indicando a posição de um dos jatos de broca da broca.

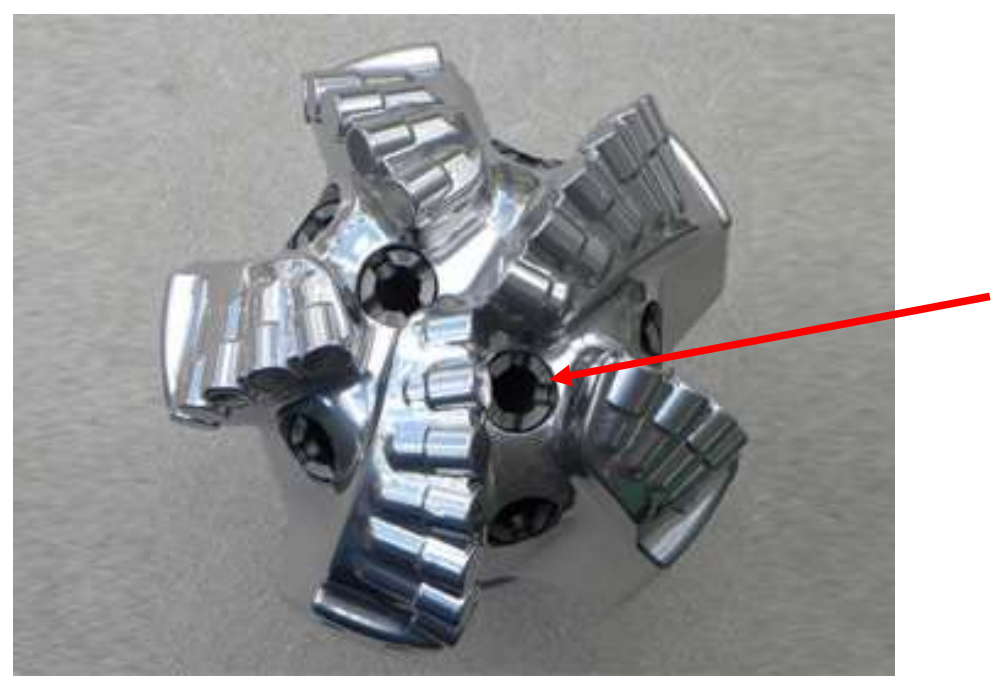

Figura 2.9 - Broca de perfuração com jatos de broca instalados (destaque). 


\section{3. \\ Modelagem hidráulica do choke MPD}

O choke para o sistema MPD é um restritor de fluxo variável instalado a montante da flowline, conforme figura 2.1(b). A função do choke MPD é gerar uma perda de carga localizada no retorno de fluido, com o objetivo de mudar o perfil de pressão do anular do poço, conforme discutido anteriormente e demonstrado na figura 1.3.

O modelo de restritor de fluxo considerado como referência para a modelagem do choke é o modelo de perda de carga localizada em placas de orifícios em tubulações circulares, desenvolvido por Jelali e Kroll (2003). Este modelo foi adaptado para o funcionamento do choke, onde a variável de abertura relativa do choke é considerada como diretamente proporcional à relação de áreas do fluxo de passagem.

Um outro modelo para choke, que não necessita de adaptação, seria o de válvula borboleta. O problema deste modelo é que, historicamente, de acordo com Sharma et al (2015), e nos trabalhos realizados em poços de terra em território nacional, tem-se verificado acúmulo de cascalho na válvula em suas aplicações como choke do manifold MPD durante a perfuração. Essa característica é ruim para o adequado controle da pressão do poço, visto que o acúmulo de cascalho no choke altera a resposta do mesmo. O modelo de choke com válvula borboleta não representa o que vem sendo utilizado pela indústria.

De forma geral, a vazão de um choke segue:

$$
Q=\alpha_{d} \mathrm{~A}_{\text {choke }} \sqrt{\frac{2}{\rho} \Delta p}
$$

onde $Q$ é a vazão pelo choke, $\alpha_{d}$ é o coeficiente de descarga, $A$ é a área de passagem do choke, $\rho$ é a densidade do fluido, e $\Delta p$ a perda de carga localizada no choke. Rearranjando-se a equação anterior, obtém-se

$$
\Delta p=\frac{Q^{2} \rho}{2 \alpha_{d}^{2} \mathrm{~A}_{\mathrm{choke}}{ }^{2}}
$$

O que define a característica de um choke é o comportamento do coeficiente de descarga com a vazão. Na modelagem hidráulica para placas de orifícios, o coeficiente de descarga segue as seguintes equações: 


$$
\begin{aligned}
& \alpha_{d}=\left(2,28+64 \frac{2 L}{d_{0} d}\right)^{-1 / 2} \text { para } \frac{d_{0} d}{2 L} \leq 50 \\
& \alpha_{d}=\left(1,5+13,74\left(\frac{2 L}{d_{0} d}\right)^{1 / 2}\right)^{-1 / 2} \text { para } \frac{d_{0} d}{2 L} \geq 50
\end{aligned}
$$

onde $d$ é o diâmetro da tubulação, $d_{0}$ o diâmetro do orifício, e $L$ é o comprimento, na direção do fluxo, do orifício. O choke considerado possui diâmetro interno $d$ de 4 polegadas, e espessura de 0,5 polegadas. Mesmo na condição de choke totalmente aberto, a relação entre $\frac{d_{0} d}{2 L}$ sempre ficará abaixo de 50. Logo, a equação (2.33) é descartada em favor da equação (2.32) no cálculo do coeficiente de descarga. A figura 2.10 mostra o comportamento do coeficiente de descarga com a abertura do choke.

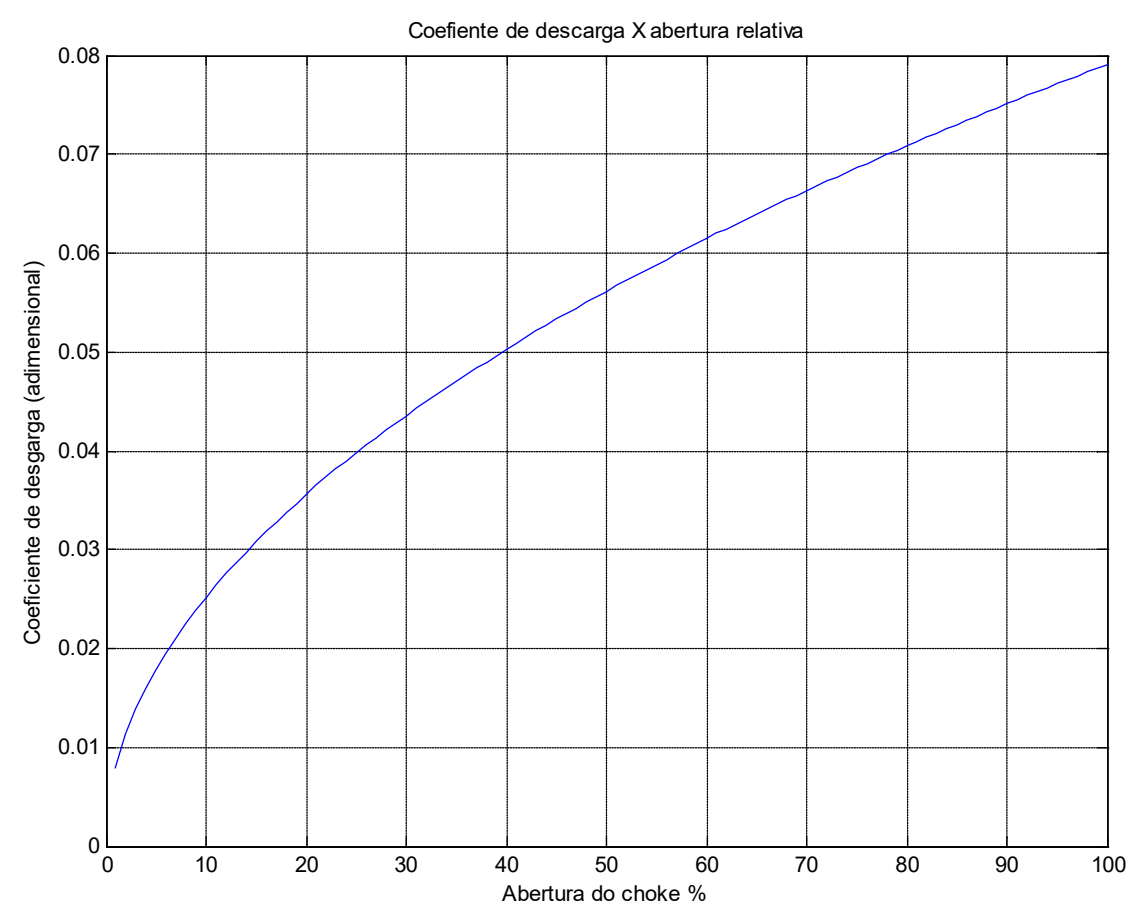

\section{Figura 2.10 - Coeficiente de descarga do choke contra sua abertura relativa.}

Vale notar que as equações (2.32) e (2.33) são indicadas para número de Reynolds superiores a 80. Como as vazões de perfuração não costumam operar abaixo deste número de Reynolds, o modelo do choke considerou o coeficiente de descarga descrito pela equação (2.32). Durante um pequeno intervalo de tempo no acionamento e desligamento das bombas de lama o número de Reynolds pode 
atingir estes valores, porém este cenário não é comum em uma operação MPD offshore, visto que a circulação no choke MPD é contínua. O fluxo pode ter origem pelo interior da coluna de perfuração ou pela da linha de booster que é uma linha com saída na base do riser de perfuração, em ambos casos o choke irá se deparar com vazão.

O ideal, quando considerada a aplicação de um choke MPD, é existir uma calibração prévia do seu coeficiente de descarga. Por não ter um comportamento linear, o conhecimento do comportamento da curva do coeficiente de descarga pode ajudar a calibrar o choke e os ganhos do controlador. A limitação da calibração prévia é que a mesma é feita normalmente com água, enquanto diferentes fluidos de perfuração podem alterar o comportamento do coeficiente de descarga, alterando o comportamento previsto do choke. A figura 2.11 mostra a perda de carga localizada no choke para diversas aberturas e uma mesma vazão. A figura (2-12) representa um mapa 3D da perda de carga localizada no choke para diferentes vazões e aberturas do choke.

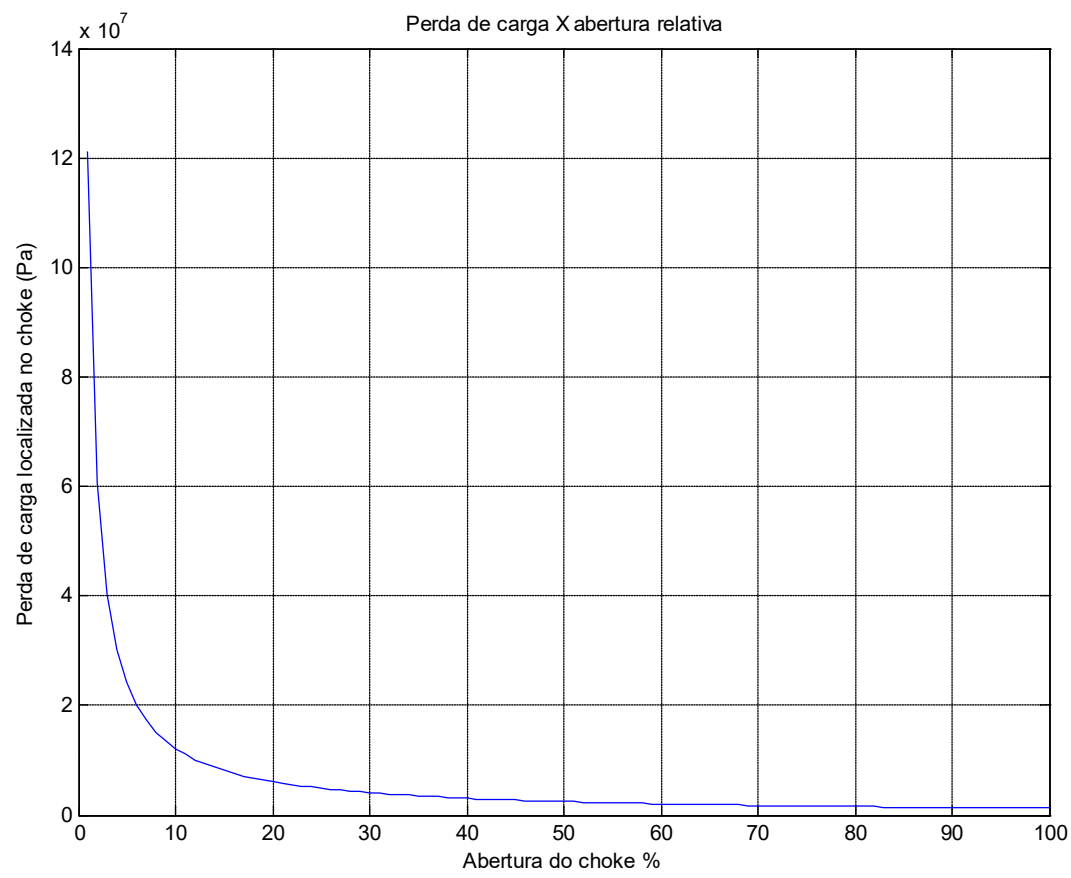

Figura 2.11 - Perda de carga localizada no choke em função da abertura, para uma vazão fixa. 


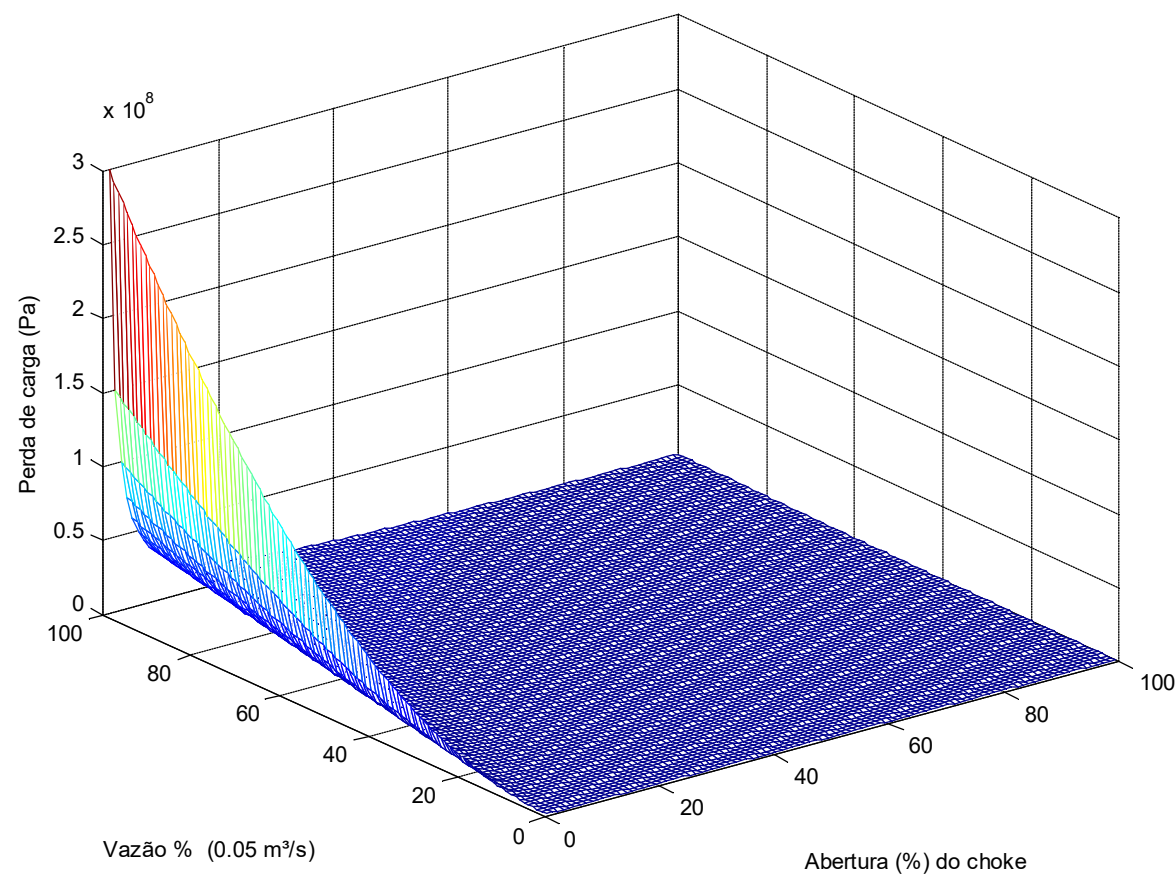

Figura 2.12 - Perda de carga localizada no choke em função da abertura e vazão - Mapa de choke.

Conforme pode ser observado nas figuras 2.11 e 2.12, o choke possui um comportamento altamente não linear, em especial na região em que a sua abertura equivale a menos de $10 \%$ da área total de passagem. Como durante uma operação de perfuração são diversas as possibilidades operacionais, o erro na linearização do choke deixa de ser desprezível.

\section{4 .}

\section{Simulação com um único fluido no sistema}

No desenvolvimento do trabalho foi considerado o sistema com somente um tipo de fluido. Apesar de situação possível, o desenvolvimento do modelo hidráulico considerando a existência de diferentes tipos de fluidos no poço não representa desafio adicional do ponto de vista de controle, visto que o modelo hidráulico do anular será regido pelo mesmo conjunto de regras, somente com um transiente lento da reologia do fluido no anular do poço. Em uma aplicação real com uma ferramenta de PWD (Pressure While Drilling) disponível, esse transiente é facilmente ajustável, visto que o intervalo de tempo de aquisição de 
sinal do PWD é muito menor do que o tempo de substituição do fluido anular de um poço offshore (segundos comparado com horas).

\section{5 .}

\section{Modelo hidráulico simplificado}

Conhecidos os fatores necessários para cálculo da pressão em qualquer profundidade do poço, é possível montar um modelo simplificado de controle MPD. Dada a pressão desejada na profundidade escolhida, o controlador deve adequar a abertura do choke de forma que a pressão na superfície chegue em um valor tal que a pressão na profundidade desejada atinja a pressão de referência. A equação 2.34 mostra como obter a pressão necessária na superfície:

$$
P_{\text {superfície }}=P_{\text {profundidade }}-P_{\text {hidrostática }}-\Delta P_{\text {fricção prof-sup }}
$$

Para este modelo, o ajuste do choke depende da reologia do fluido e da vazão. Como a reologia do fluido é considerada invariável, as perdas de carga serão função somente da vazão do fluido e posição do choke.

Como o fenômeno de compressibilidade é ignorado, a variação da vazão de fluido na entrada é propagada em todo o sistema de forma instantânea, e a pressão da perda de carga é propagada de forma direta com a variação da vazão de entrada. Para este cenário, a posição do choke irá provocar uma variação da perda de carga localizada no mesmo e consequentemente uma variação na pressão em todo o fluido a montante do mesmo. Com estas considerações, verifica-se que as respostas no modelo são instantâneas com a variação do choke e com a variação da vazão.

Um modelo simulado nestas condições não considera o fator tempo, visto a transmissibilidade instantânea da pressão e vazão. Ou seja, não é considerado o transiente do sistema, apenas seu regime permanente. Na análise das simulações será discorrido sobre o impacto desta hipótese para o controle da pressão no anular do poço.

\section{6.}

\section{Modelo hidráulico dinâmico}

Outra abordagem para modelagem hidráulica de um poço é considerar o sistema como uma linha de transmissão hidráulica, conforme elaborado por 
Landet et al (2012). O modelo de linha de transmissão hidráulica é derivado das equações de balanço de massa e momento para um volume de controle diferencial $\mathrm{AR} d x$, aonde $\mathrm{AR}$ é a seção transversal da área e $x$ é a coordenada no sentido do volume. Considera-se que o volume contenha um fluido compressível com densidade $\rho(x, t)$ (na posição $\mathrm{x}$ e no tempo $\mathrm{t}$ ). Dada a velocidade média do fluido, $\bar{v}$, através da seção transversal pode-se encontrar o balaço de massa para o volume. A vazão de massa, $w$, é:

$$
w(x, t)=\int_{A} \rho v d A R=\rho \bar{v} A R
$$

Assim, o balanço de massa é ser dado como:

$$
\frac{\partial \rho}{\partial t}=-\frac{1}{A} \frac{\partial w}{\partial x}
$$

Como a principal variável de controle desejada é a pressão, a equação acima será rearranjada para a variável de pressão com o tempo. Esta mudança considera a equação $d p=(\beta / \rho) d \rho$, onde $\beta$ é o módulo de bulk do fluido, também conhecido como compressibilidade, definido como a relação entre o acréscimo de pressão no material e o seu decréscimo de volume. A nova equação é dada também em função da vazão $q$, onde $q \cdot \rho=\omega$ :

$$
\frac{\partial p}{\partial t}=-\beta / A R \frac{\partial q}{\partial x}
$$

A função da vazão volumétrica é encontrada a partir do balanço de momento para o mesmo volume de controle. Sendo $\alpha$ o ângulo entre a direção do fluxo positivo, $g$ a gravidade, e $F_{d x}$ a força de atrito por comprimento diferencial, tem-se

$$
\frac{\partial \omega}{\partial t}=-A R \frac{\partial p}{\partial x}-\frac{\partial}{\partial x} \int_{A} \rho v^{2} d A-F_{d x}+A R \rho g \cos \alpha
$$

A equação (2.38) está em função da vazão mássica. Para convertê-la em função da vazão volumétrica, considera-se a densidade como constante. Além disso, a variação do termo $\frac{\partial}{\partial x} \int_{A} \rho v^{2} d A R$ é considerada desprezível. Assim, a equação simplificada fica:

$$
\frac{\partial q}{\partial t}=-\frac{A R}{\rho_{0}} \frac{\partial p}{\partial x}-\frac{F}{\rho_{0}}+A g \cos \alpha
$$


As equações diferencias do modelo de linha de transmissão hidráulica são então representadas pelas equações (2.37) e (2.39), para considerar os transientes do sistema, ao invés de apenas seu comportamento em regime permanente.

\subsection{1.}

Modelo não linear discretizado no espaço

A seção anterior definiu duas equações diferencias para o modelo a ser simulado. As equações são discretizadas no tempo e espaço, e resolvidas pelo método de volume finitos simples. Equações diferenciais são aplicadas à média de pressão e fluxo de cada volume de controle. Para a simulação, as pressões assumidas são do centro de cada volume de controle, enquanto as vazões são tomadas pelos extremos de cada. Como o modelo é basicamente unidimensional (ao longo da profundidade do poço), as vazões consideradas são as vazões de entrada e saída de cada volume de controle.

As condições de contorno do modelo são as diferentes entradas do sistema:

- Vazão da bomba de lama $q_{b}$;

- $\quad$ Abertura do choke A

Nas equações (2.37) e (2.39), os termos do lado direito precisam ser parametrizados em função da coordenada espacial $x$. Assim, o volume de controle $i$ tem sua própria seção transversal $A_{i}$, densidade $\rho_{i}$, módulo de bulk $\beta_{i}$, diferença de altura $\Delta h_{i}$, e perda de carga $F_{i}=F\left(q_{i}, d_{i}, l_{i}, \rho_{i}, \mu_{i}\right)$, onde $d_{i}$ é o diâmetro interno da coluna ou o diâmetro hidráulico do anular, $l_{i}$ é o comprimento do volume de controle $i$, e $\mu_{i}$ é a viscosidade plástica do fluido. A figura 2.13 mostra o ponto de referência de pressão e vazão para cada volume de controle. 


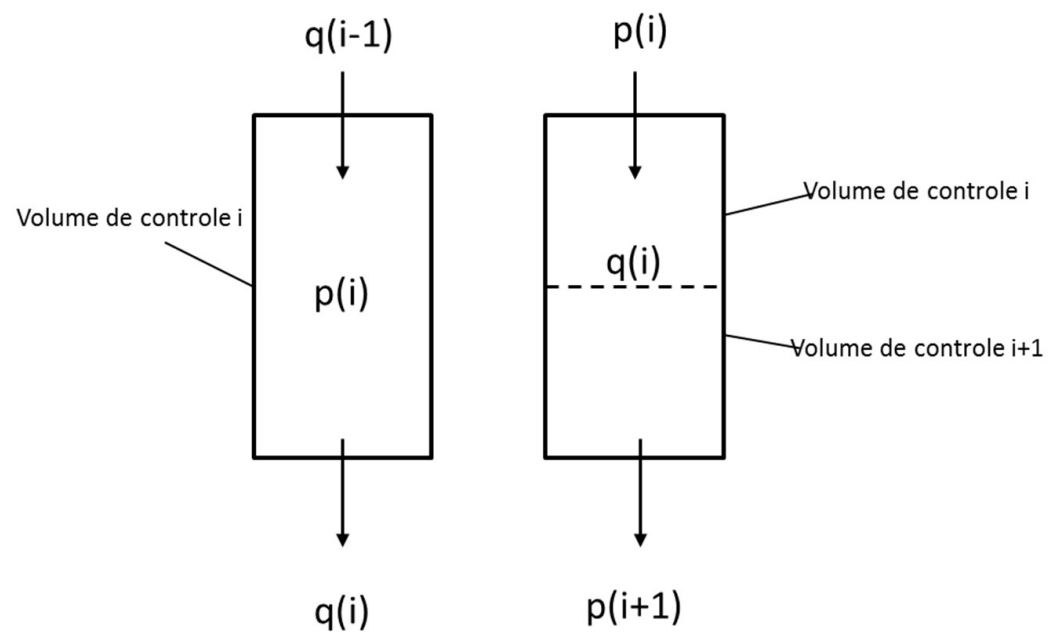

Figura 2.13 - Volumes de controle para o sistema discretizado.

Para servir de base para as simulações efetuadas nesta dissertação, foi considerado um modelo com cinco volumes de controle no poço ao longo de sua profundidade. Os cinco volumes de controle conseguem representar as características geométricas básicas de um poço offshore, i.e. DP, BHA, revestimento e riser de perfuração. A figura 2.14 mostra o esquema geral considerado para as simulações do poço de referência. 


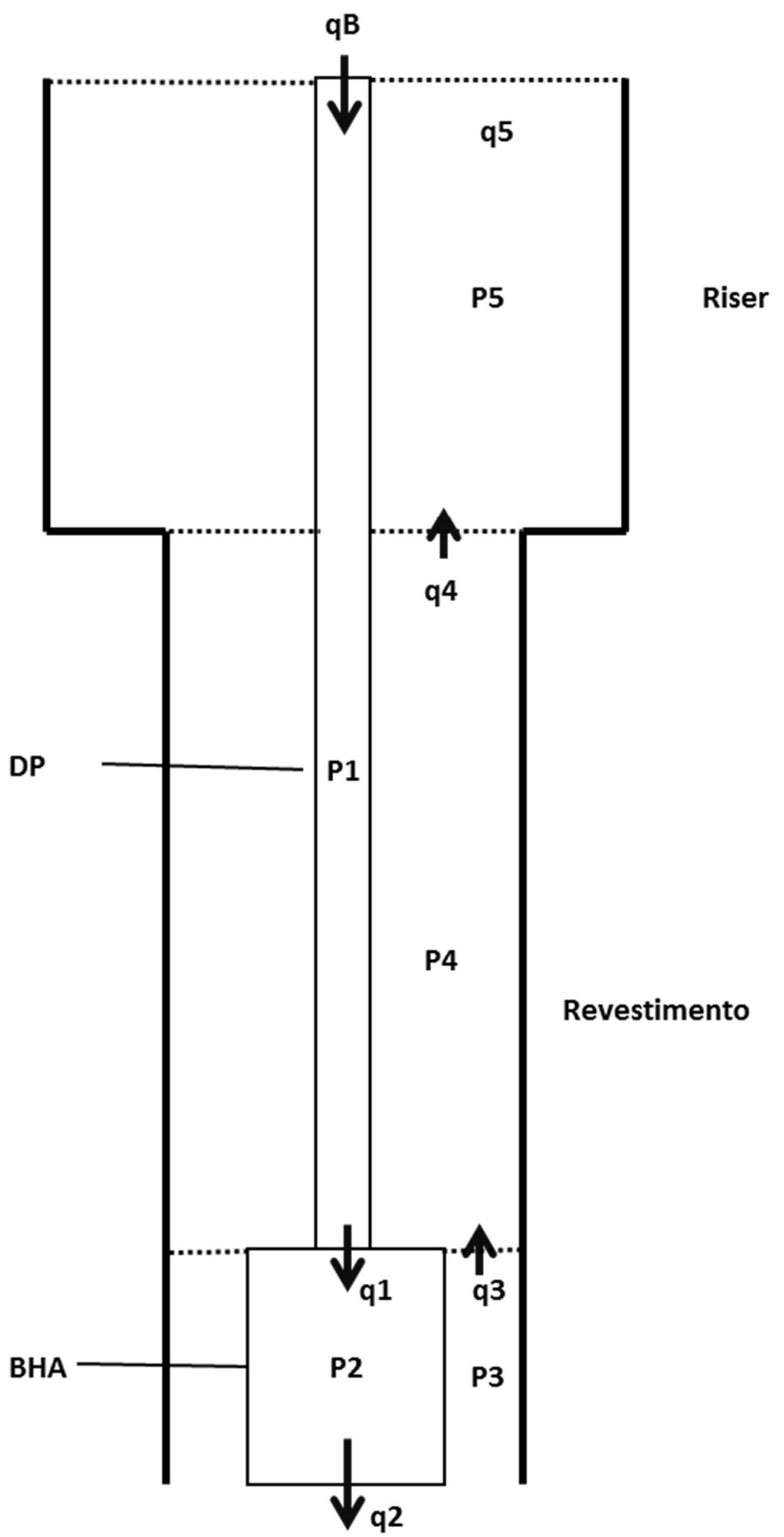

Figura 2.14 - Esquema dos volumes de controle do poço.

Combinando as equações para os 5 volumes de controle, sendo os dois primeiros referentes ao interior da coluna e o demais referentes ao anular, as equações dinâmicas do sistema são definidas nas equações (2.40) a (2.49). O termo $p$ representa a pressão média e $q$ a vazão de saída do volume de controle, conforme ilustrado nas figuras 2.13 e 2.14 . 


$$
\begin{aligned}
\dot{p}_{1} & =\frac{\beta_{1}}{A R_{1} l_{1}}\left(q_{b}-q_{1}\right) \\
\dot{p}_{2} & =\frac{\beta_{2}}{A R_{2} l_{2}}\left(q_{1}-q_{2}\right) \\
\dot{p}_{3}= & \frac{\beta_{3}}{A R_{3} l_{3}}\left(q_{2}-q_{3}\right) \\
\dot{p}_{4}= & \frac{\beta_{4}}{A R_{4} l_{4}}\left(q_{3}-q_{4}\right) \\
\dot{p}_{5}= & \frac{\beta_{5}}{A R_{5} l_{5}}\left(q_{4}-q_{5}\right) \\
\dot{q}_{1}= & \frac{A R_{1}}{l_{1} \rho_{1}}\left(p_{1}-p_{2}\right)-\frac{F_{1} A R_{1}}{\rho_{1} l_{1}}+A R g \frac{\Delta h_{1}}{l_{1}} \\
\dot{q}_{2}= & \frac{2 A R_{2} A R_{3}}{A R_{3} l_{2} \rho_{2}+A R_{2} l_{3} \rho_{3}}\left[\left(p_{2}-p_{3}\right)-F_{b i t}-F_{2}+g \frac{\left(\rho_{2} \Delta h_{2}-\rho_{3} \Delta h_{3}\right)}{2}\right. \\
\dot{q}_{3}= & \frac{A R_{3}}{l_{3} \rho_{3}}\left(p_{3}-p_{4}\right)-\frac{F_{3} A}{\rho_{3} l_{3}}-A R g \frac{\Delta h_{3}}{l_{3}} \\
\dot{q}_{4}= & \frac{A R_{4}}{l_{4} \rho_{4}}\left(p_{4}-p_{5}\right)-\frac{F_{4} A R_{4}}{\rho_{4} l_{4}}-A R g \frac{\Delta h_{4}}{l_{4}}\left(p_{5}-\Delta p_{C h o k e}\right)-\frac{F_{5} A R_{5}}{\rho_{5} l_{5}}-A R g \frac{\Delta h_{5}}{l_{5}} \\
& A R_{5}
\end{aligned}
$$

Nas equações acima, o termo $F_{b i t}$ representa a perda de carga na broca e o termo $\Delta p_{\text {Choke }}$ representa a perda de carga no choke. Vale observar que o número de trechos no anular e no interior da coluna não necessitam ser iguais.

A variação da vazão do segundo volume de controle adota uma diferente relação, pois este é o local onde o fluido sai do interior da coluna e entra no anular do poço. O termo de área por comprimento para $\dot{q}_{2}$ é uma média da resistência do último volume de controle do interior da coluna com o primeiro elemento do anular do poço. 


\subsection{2.}

Modelo padrão de simulação

A tabela 2-3 mostra as dimensões dos elementos do poço considerado nas simulações deste trabalho. Para gerar uma maior perda de carga por fricção no anular, e consequentemente um cenário onde o controle da pressão no fundo é mais dependente da atuação do choke, o diâmetro da fase do poço foi reduzido de um valor de 12,6 " para 8,6 ", que representa o valor do diâmetro interno de um revestimento de 9-5/8" (diâmetro comum na indústria do petróleo).

Tabela 2-4 - Dados geométricos para simulação.

\begin{tabular}{|l|c|c|c|}
\hline \multicolumn{1}{|c|}{ Elemento } & $\begin{array}{c}\text { ID } \\
\text { (polegadas) }\end{array}$ & $\begin{array}{c}\text { OD } \\
\text { (polegadas) }\end{array}$ & $\begin{array}{c}\text { Comprimento } \\
(\mathrm{m})\end{array}$ \\
\hline Drillpipe & 4,63 & - & 4700 \\
\hline BHA & 3 & - & 300 \\
\hline Anular poço revestido - BHA & 8,6 & 8 & 300 \\
\hline Anular poço revestido - drillpipe & 8,6 & 5,5 & 2700 \\
\hline Anular riser - drillpipe & 19,25 & 5,5 & 2000 \\
\hline
\end{tabular}

Note que o diâmetro externo das ferramentas do BHA de uma fase de 8,5" é de 6,75". Mantendo o objetivo de gerar maior perda de carga no anular e tornar o controle da pressão no poço pelo MPD mais crítico, foi considerado um BHA com diâmetro externo de 8".

O fluido escolhido foi o fluido do tipo de potência, que possui comportamento mais semelhante com os fluidos utilizados nas fases de perfuração em que o MPD é aplicado. Os dados do fluido do poço, em unidades no SI, são:

Densidade: $1092.4 \mathrm{~kg} / \mathrm{m}^{3}$;

Módulo de compressibilidade: $6,6 * 10^{9} \mathrm{~Pa}$;

Viscosidade plástica:0,057 Pa.s;

Limite de escoamento: 11,97 Pa;

Fator K: 0,04;

Fator N: 0,5.

\section{7.}

\section{Linearização do modelo hidráulico}

A linearização do sistema permite maiores possibilidades de aplicação de técnicas de controle linear, facilitando a calibração de ganhos. Conforme 
observado nas equações diferenciais do sistema, existem alguns termos não lineares. Uma proposta para o sistema é linearizar os termos para uma região de operação. Mais adiante, uma análise não linear será adotada para a proposta e verificação de controladores não lineares.

Para o cálculo da perda de carga, foi escolhida uma vazão de referência, e o sistema foi linearizado nesta perda de carga. Neste enfoque linearizado, o mesmo procedimento foi tomado para a perda de carga na broca.

Para a perda de carga no choke, além da escolha de uma vazão para linearização, é necessário escolher uma abertura média do choke para cálculo da perda de carga localizada. O coeficiente de descarga médio do choke também deve ser considerado. Como a perda de carga localizada no choke, vide equação (2.31), é inversamente proporcional ao quadrado da abertura do choke, vide equação (2.40), é necessário linearizar esta entrada para um ponto de abertura. A equação (2.41) mostra a forma linearizada da perda de carga do choke em função da abertura.

$$
\begin{aligned}
& \Delta p=K * \frac{1}{A^{2}} \\
& \Delta p=K_{\text {ajustado }} *(-A)+B
\end{aligned}
$$

onde $K$ é uma constante de proporcionalidade do inverso do quadrado da abertura do choke com sua perda de carga, para uma vazão média de referência, $K_{\text {ajustado }}$ é a derivada da reta tangente da curva de perda de carga, e $B$ é o valor da perda de carga linearizada na abertura média do choke multiplicada pela vazão.

Com a linearização de todos os termos das equações diferenciais, é possível representar o sistema no formato:

$$
\begin{aligned}
& \dot{X}=\mathbb{A} X+\mathbb{B} U \\
& Y=\mathbb{C} X+\mathbb{D} U
\end{aligned}
$$

onde $X$ é o vetor de variáveis de estado, $X=\left[p_{1} p_{2} p_{3} p_{4} p_{5} q_{1} q_{2} q_{3} q_{4} q_{5}\right]^{T}$, e $U$ o vetor de entradas do sistema, $U=\left[q_{b} A_{\text {Choke }} g \text { Constante choke }\right]^{T}$ devendo ser considerado, além da vazão das bombas de lama, a abertura do choke, a ação da gravidade, e a constante do choke. As matrizes/vetores $\mathbb{A}, \mathbb{B}, \mathbb{C}, \mathbb{D}$ representam o sistema linearizado (nos anexos se encontram as matrizes e vetores utilizados). 
Utilizando as ferramentas do ambiente MATLAB ${ }^{\circledR}$ (The MathWorks Inc., 2000) no sistema linearizado, é possível verificar que o sistema é observável nos diversos valores de linearização estudados. Uma vez que o sistema é observável em suas diferentes linearizações, em diferentes condições do poço, infere-se que o sistema original não linear também é observável.

Para o caso de realimentação de estado completo, seria necessário o uso de um observador no sistema linearizado, como um filtro de Kalman linear, uma vez que a pressão no fundo do poço não é medida em tempo real, e sim inferida a partir do modelo. Para o caso geral do sistema não linear, a implementação exigiria um observador não-linear, como um filtro de Kalman estendido. Neste trabalho, ao invés de um enfoque probabilístico com filtros de Kalman, os estados foram estimados usando um enfoque determinístico. Esta simplificação é justificada pela alta complexidade do sistema não linear, que dificultaria a aplicação de um filtro de Kalman estendido, e aos longos tempos de resposta envolvidos neste sistema, que apesar do uso de um enfoque dinâmico no controle permitem uma modelagem quase-estática do observador.

No entanto, modelos linearizados são deficientes no controle do sistema hidráulico de um poço com MPD, que é altamente não linear, conforme demonstrado neste capítulo. A linearização só funcionaria para uma situação específica de perfuração, na qual qualquer desvio da condição linearizada acarretaria em infidelidade do modelo hidráulico com a realidade do poço. Como a perfuração de um poço com MPD exige flexibilidade operacional, a linearização em um único ponto não é considerada como uma boa aproximação para o tratamento do problema, tendo sido analisada apenas para o estudo de observabilidade. Nas simulações apresentadas neste trabalho, o sistema não linear completo é considerado, sem nenhuma linearização.

Um melhor cenário para controle seria o registro direto da variável a ser controlada, a pressão no fundo do poço, que normalmente é obtida de forma indireta pelas equações apresentadas ou em observadores. Em aplicações de MPD em cenário offshore e poços de terra com maiores recursos, a ferramenta PWD é disponível durante a perfuração das principais fases do poço. A ferramenta PWD permite a medição da pressão no anular na profundidade do BHA, enquanto houver uma vazão mínima pelo seu interior para ativação e comunicação com a superfície. No entanto, o sensor de PWD fundo possui algumas limitações para o 
seu uso. A primeira limitação é a taxa de dados transmitidos, que costuma ser um registro por minuto em situações normais, e nos melhores casos 1 registro a cada 10 segundos (taxas relativamente baixas para serem usadas como realimentação de um controlador), com a penalidade de menor taxa de transmissão de outras ferramentas dos BHA. A segunda limitação é que a ferramenta se comunica por pulsos de pressão, não sendo incomum a corrupção de parte dos dados de pressão do fundo.

Para o uso da informação da densidade equivalente de circulação, ECD, do anular na perfuração convencional, esses fatos não possuem impacto significativo. Para controle automático da pressão, os dados do PWD não são usados diretamente, tendo seu uso limitado a calibração do modelo hidráulico. A frequência inferior a $0,1 \mathrm{~Hz}$ e a não confiabilidade dos dados impacta na correta atuação do controlador para ajuste da pressão no poço. Outro fator limitante no uso do dado de PWD é que a informação do mesmo nem sempre é gerada pela mesma empresa responsável pelo controle do choke MPD. Dada a importância do registro para o controle adequado da pressão no fundo e a dificuldade na transmissão de dados entre diferentes empresas em um ambiente de sonda offshore, as lógicas de controladores de choke MPD disponíveis não consideram o registro do PWD na lógica de controle. Desse modo, a realimentação dos controladores existentes, assim como os propostos nesse trabalho, usa estimativas (normalmente determinísticas ao invés de probabilísticas) da pressão no fundo do poço, ao invés de medições não confiáveis e com taxas de amostragem muito baixas.

No próximo capítulo, os modelos desenvolvidos serão simulados em malha aberta, para no capítulo 4 permitirem avaliar os controladores existentes e os propostos nesse trabalho. 


\section{3.}

\section{Análise em Malha Aberta}

\section{1.}

\section{Avaliação inicial da atuação do controlador}

Antes de se aplicar um controlador sobre o modelo hidráulico, é interessante observar o seu comportamento sob diferentes estímulos. Como as entradas do modelo hidráulico são a vazão total das bombas de lama e a posição do choke, vale a análise do uso de cada entrada para controle na pressão no fundo. Em outras palavras, é possível controlar a pressão no fundo do poço apenas atuando nas bombas, ou apenas atuando no choke, possibilidades que serão avaliadas a seguir.

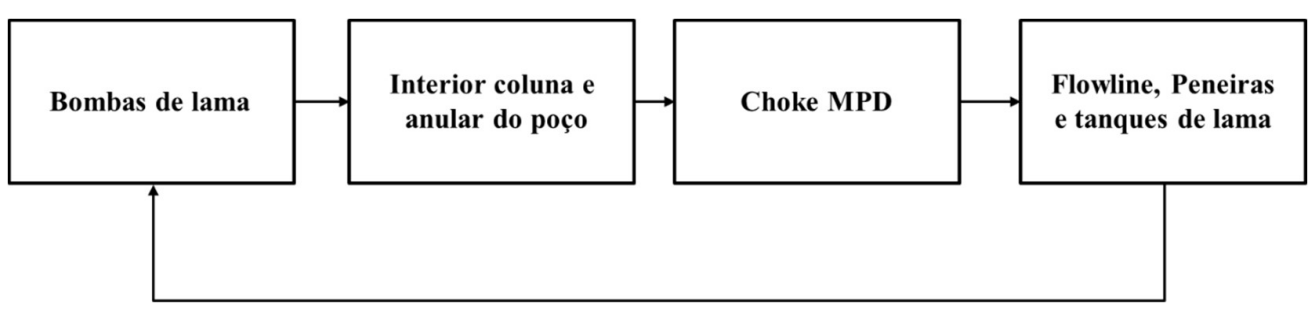

Figura 3.1 - Circuito hidráulico do fluido de perfuração em sistema MPD

As bombas de lama de uma sonda de perfuração offshore podem chegar a $1600 \mathrm{~kW}$ de potência, necessitando de grande espaço e alimentação de energia para sua utilização. O controle da pressão no fundo com uso de uma bomba de controle, além de inconveniente devido às grandes dimensões associadas, tem o efeito colateral de impactar na limitação de algumas ferramentas do BHA que possuem faixas de vazão para funcionamento adequado.

Uma alternativa para alteração da vazão na entrada do choke MPD seria uma bomba auxiliar, vide figura 3.2. Esta bomba possuiria menores dimensões que uma bomba de lama, e poderia bombear por um circuito menor com intenção de alterar a vazão na saída do sistema e consequentemente alterar a perda de carga localizada no choke. 


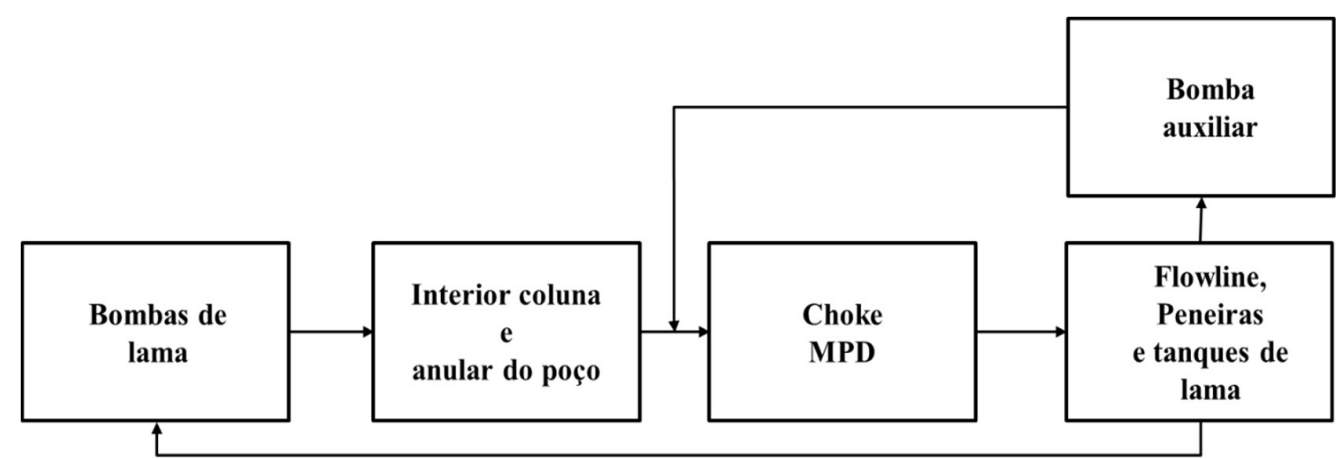

Figura 3.2 - Circuito hidráulico MPD com bomba auxiliar

Essa opção é usada em alguns poços terrestres em que o MPD é empregado, porém em sondas marítimas essa opção não é aplicada, por implicar em maiores alterações no esquema e nos equipamentos de uma sonda offshore, que na maioria das vezes possui restrições de espaço. Outro fato que limita o uso de uma bomba auxiliar na superfície é a existência da linha de booster no riser. Essa linha permite alimentar o retorno de fluido sem impactar na vazão de fluido que passa pelo interior da coluna. Como a bomba que alimenta a linha de booster é um equipamento da sonda que não é fabricado pela empresa fornecedora do controlador MPD, o uso da vazão de booster para controle da pressão no anular do poço não é utilizada pelo controlador. Os controladores MPD comerciais reagem à variação da vazão na linha de booster, não atuando sobre a vazão diretamente.

Ao invés de atuar nas bombas para controle de vazão e consequentemente de pressão, a alternativa mais prática consiste na atuação da válvula de choke para controle de pressão. Para a abertura e fechamento do choke, são necessários atuadores hidráulicos e um controlador PLC. Estes equipamentos se encontram no módulo acumulador (skid) do choke MPD. Comparativamente, a atuação da válvula de choke é mais simples e demanda menos energia do que o uso de bombas auxiliares para controle da pressão do sistema. Por gerar uma perda de carga localizada, uma pequena mudança na abertura do choke impacta todo o perfil de anular.

Com isso considerado, o controle da planta para atingir uma pressão desejada em uma determinada profundidade será concentrado através da abertura e fechamento do choke MPD. Os estímulos na planta foram simulados através de variações na posição de abertura do choke MPD. 


\section{2.}

\section{Resposta em Degrau}

O primeiro estimulo avaliado foi uma entrada em degrau do choke de uma posição $100 \%$ aberta para metade de seu curso, iniciado no instante $t=100$ s. $O$ sistema foi iniciado em repouso e a vazão das bombas de lama incrementadas entre os instantes $t=1 \mathrm{~s}$ e $\mathrm{t}=33 \mathrm{~s}$ de maneira constante até que $\mathrm{q}=0,032 \mathrm{~m}^{3} / \mathrm{s}$. Conforme a figura 3.3, pode-se observar que a pressão no ponto de controle (primeira célula do anular do poço, BHA-REV) não sobe imediatamente. Observando-se a figura 3.4 verifica-se que a vazão de todos volumes de controle são reduzidas momentaneamente, em especial no riser, último volume de controle. Este fato se explica devido à compressibilidade do fluido, visto que a pressão gerada no choke não é imediatamente transmitida para o restante do sistema.

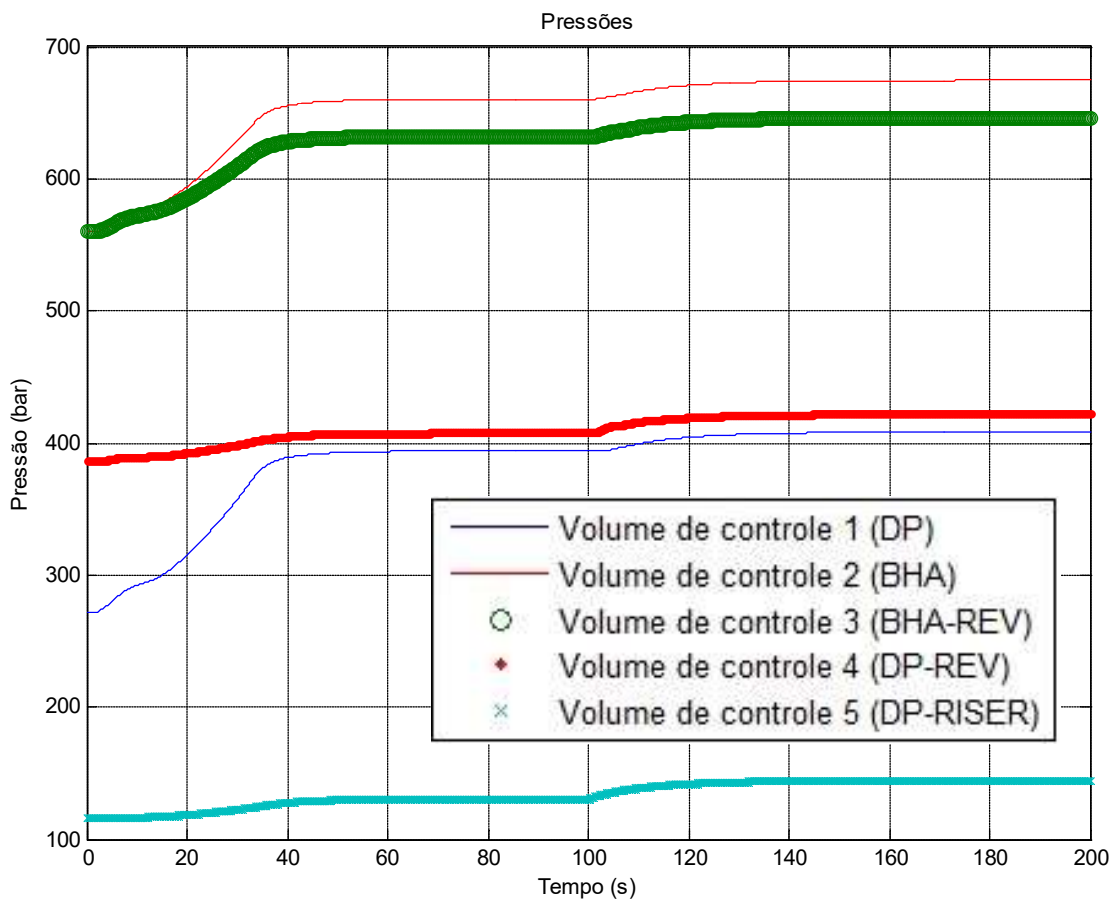

Figura 3.3 - Reação das pressões para um degrau de posição do choke de MPD, iniciado em $t=100 s$. 
Conforme visto no capítulo de modelagem hidráulica, uma redução na abertura do choke causa um aumento da perda de carga localizada nele. A equação (2.39) indica que o aumento da pressão na saída de um volume de controle irá acarretar na redução da vazão no volume de controle.

A figura 3.4 mostra o comportamento das vazões dos diversos volumes de controle, após a redução da abertura do choke no instante de tempo $t=100 \mathrm{~s}$. Os volumes de controle referentes ao interior da coluna, BHA, Anular-BHA e anular poço revestido-DP, sofrem uma redução de até $10 \%$ da vazão devido à restrição do choke. No volume de controle que representa o espaço anular do riser, se observa uma redução da vazão em torno de $25 \%$. A diferença entre a redução da vazão para cada volume de controle está associada com as dimensões e posição de cada volume de controle. $\mathrm{O}$ volume de controle do riser está imediatamente na montante do choke MPD, sendo a pressão diretamente transmitida neste volume de controle, reduzindo sua vazão diretamente. O aumento da pressão do choke é transmitido aos demais volumes de controle sequencialmente, conforme o sistema se pressuriza. $\mathrm{O}$ fato do anular do riser representar o maior volume de controle significa que uma maior quantidade de fluido tem que entrar no volume de controle até que o mesmo retorne ao regime permanente.

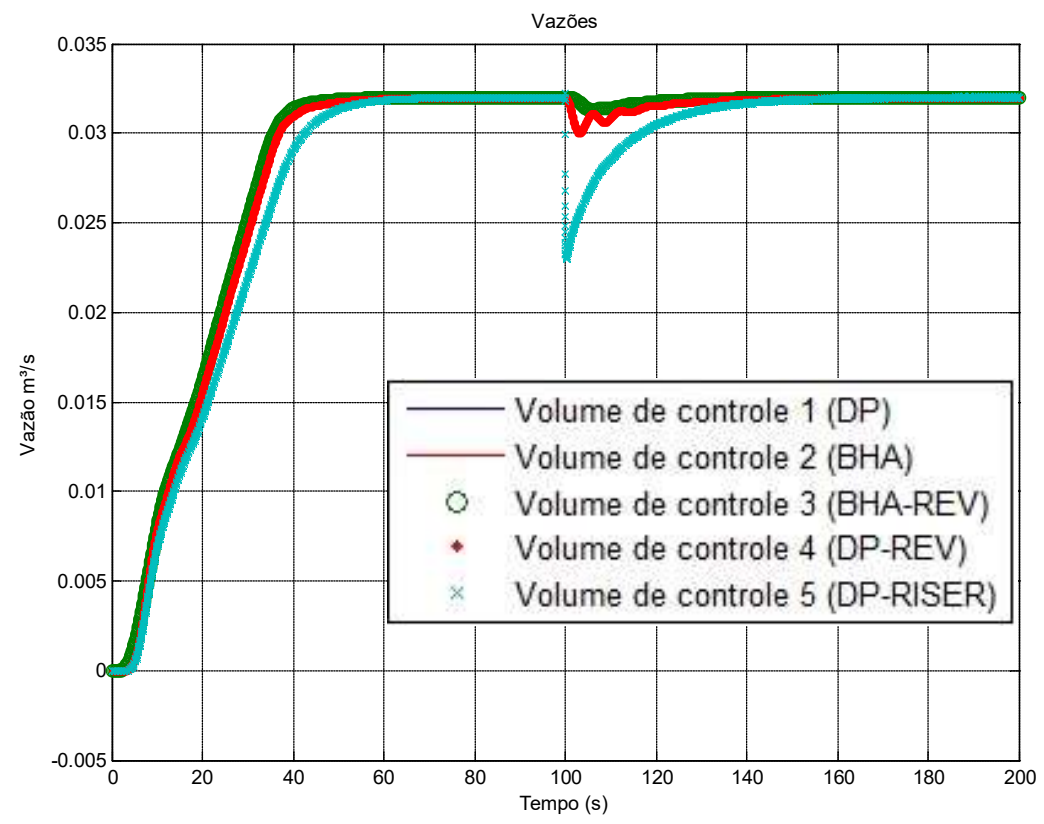

Figura 3.4 - Reação da vazão no sistema para um degrau de posição do choke de MPD, iniciado em $t=100 \mathrm{~s}$. 
Para avaliação do efeito da compressibilidade do fluido no sistema, foi simulado o mesmo degrau de posição do choke no mesmo cenário de variação da vazão e estímulo (i.e. iniciando em $\mathrm{t}=100 \mathrm{~s}$ ), porém alterando o módulo de bulk do fluido. A alteração do módulo de bulk utilizou um fator de 100, para simular um fluido incompressível. As figuras 3.5 e 3.6 mostram a reação do sistema para um fluido virtualmente incompressível. Como pode ser visto, a transmissão da pressão é feita em um menor período de tempo, quando comparada à simulação anterior. A vazão dos volumes de controle, salvo o anular do riser, praticamente não sofrem alteração. A vazão do volume de controle do anular do riser é afetada, sofrendo redução, porém por um período de tempo inferior ao observado em um fluido com compressibilidade normal. Se este fosse o comportamento dos fluidos de perfuração, a dinâmica do sistema poderia ser desprezada, facilitando a avaliação do problema de controle da pressão do choke. No entanto, este não é o caso, e portanto este trabalho precisa considerar a dinâmica do sistema para simular o sistema de forma fidedigna com a realidade.

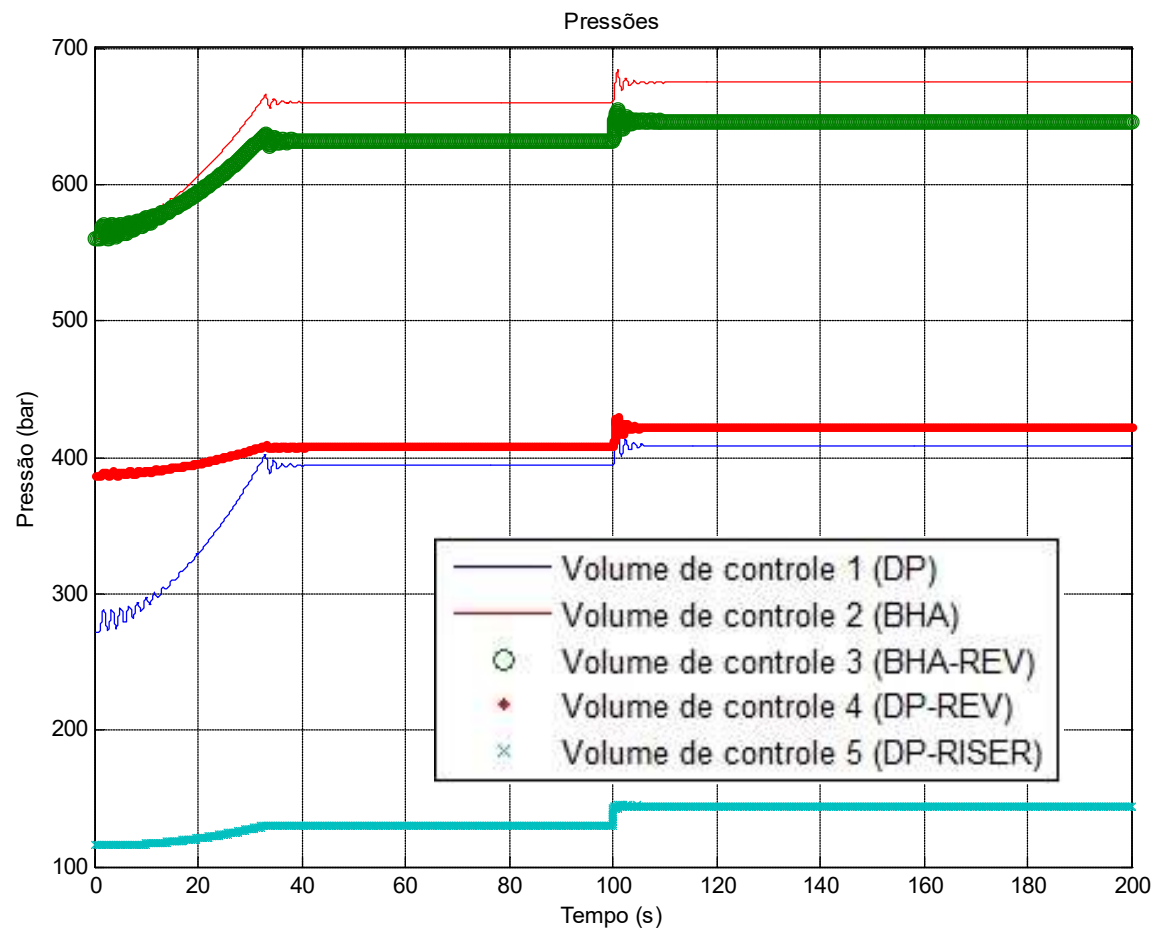

Figura 3.5 - Resposta da pressão do degrau de posição do choke, assumindo um fluido incompressível. 


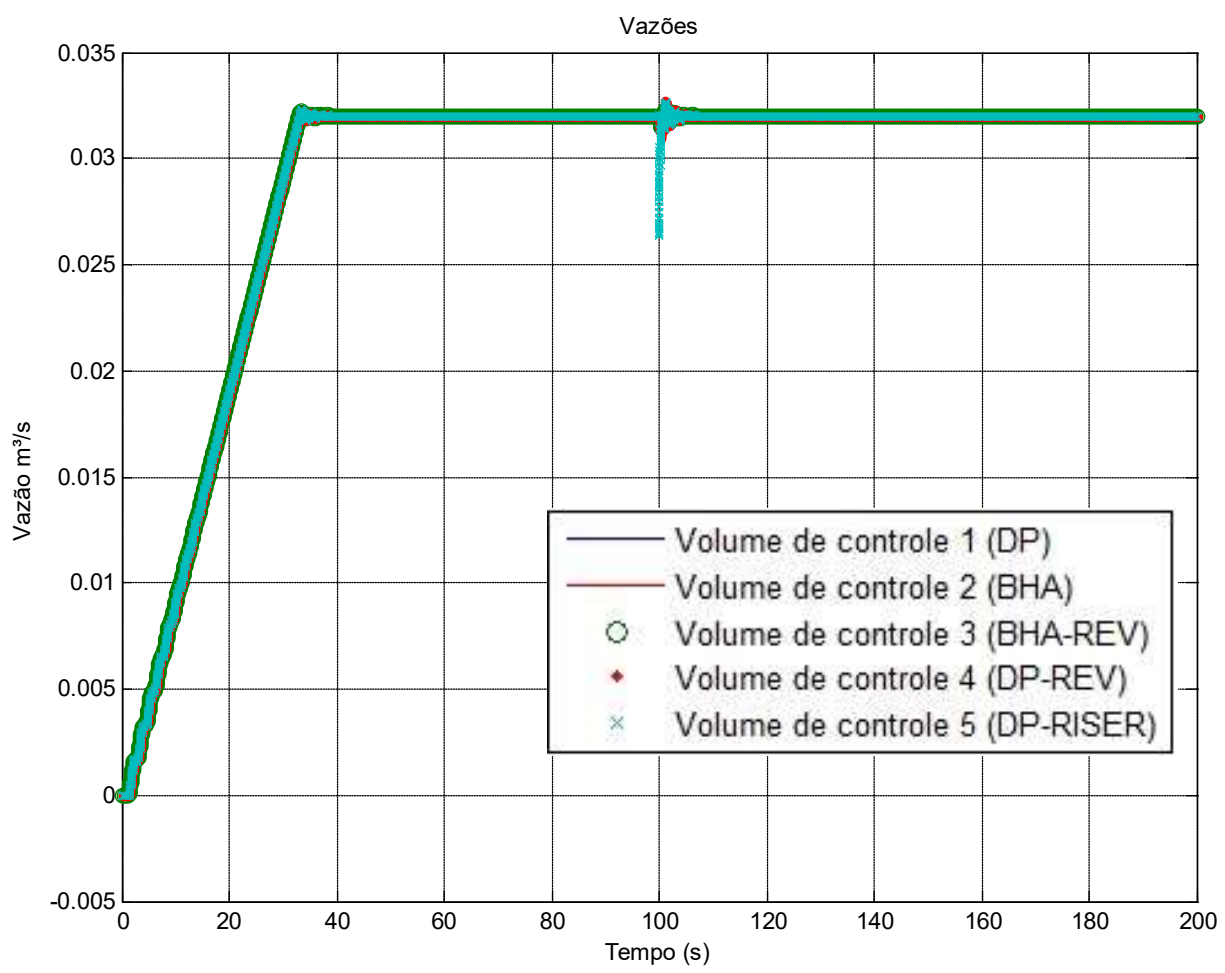

Figura 3.6 - Vazão para um degrau de posição do choke, assumindo um fluido incompressível.

\section{3. \\ Diagrama de Bode}

A segunda etapa na observação do sistema em malha aberta foi aplicar um estímulo senoidal para diversas frequências sobre o modelo de simulação padrão. A faixa de frequência analisada considerou a faixa prática operacional de um choke. Um estímulo em altas frequência não é factível para um choke hidráulico, logo frequências maiores que $1 \mathrm{~Hz}$ não foram analisadas. Frequências menores que $0,001 \mathrm{~Hz}$ também não foram analisadas, pois fogem do tempo de reação necessário para uma operação de perfuração. Para confirmar a validade da análise para frequências muito baixas, foi feita uma análise em regime permanente, simulando assim uma frequência zero.

Ao total foram feitas sete diferentes simulações não lineares para verificação da resposta em frequência do sistema quanto à variação da posição do choke. A variação da posição do choke para cada simulação foi em torno de uma abertura 
média. Foram feitas simulações com 3 aberturas médias $\left(A_{m}\right)$ de choke: 35\%, $50 \%$ e $65 \%$. Para as aberturas de $35 \%$ e $65 \%$ de choke, foram simuladas duas amplitudes de variação da abertura do choke $A_{a}$ para o estimulo em frequência, $15 \%$ e $30 \%$ (e.g. se $A_{m}=65 \%$ e $A_{a}=30 \%$, então o choke foi comandado a oscilar entre $35 \%$ e $95 \%$ ). Para uma abertura média de $50 \%$, foram feitas simulações com 3 amplitudes de variação: $15 \%$, 30\% e 45\%. O estímulo do sistema pela variação do choke seguiu a equação senoidal (3.1):

$$
A_{\text {choke }}=A_{m}+A_{a} \operatorname{sen}\left(\omega\left(t-t_{\text {inicial }}\right)\right)
$$

Aonde $t$ é o instante da simulação, $t_{\text {inicial }}$ é o instante em que o estímulo é iniciado no sistema, e $\omega$ é a frequência do estímulo. A análise de diversas aberturas médias e diversas amplitudes de variação de abertura do choke visou verificar o impacto da não linearidade da abertura do choke com a perda de carga localizada.

Cada uma das simulações realizadas para diferentes frequências, gerou uma curva de dados de oscilação da pressão no tempo. Através dos dados obtidos, pode-se fazer uma análise da resposta em frequência da fase e da magnitude da resposta do sistema para uma determinada abertura média e amplitude de variação do choke. Também simulada a resposta em regime permanente aonde o choke é mantido em posição constante para o valor mínimo e máximo de abertura do choke. A resposta em regime permanente foi considerada como uma reposta de baixa frequência.

A magnitude da resposta é definida como a diferença entre a pressão máxima e mínima verificadas para o estímulo do choke, após a estabilização da resposta, dividida por dois.

As figuras 3.7 a 3.12 mostram as resultados das diversas simulações. 


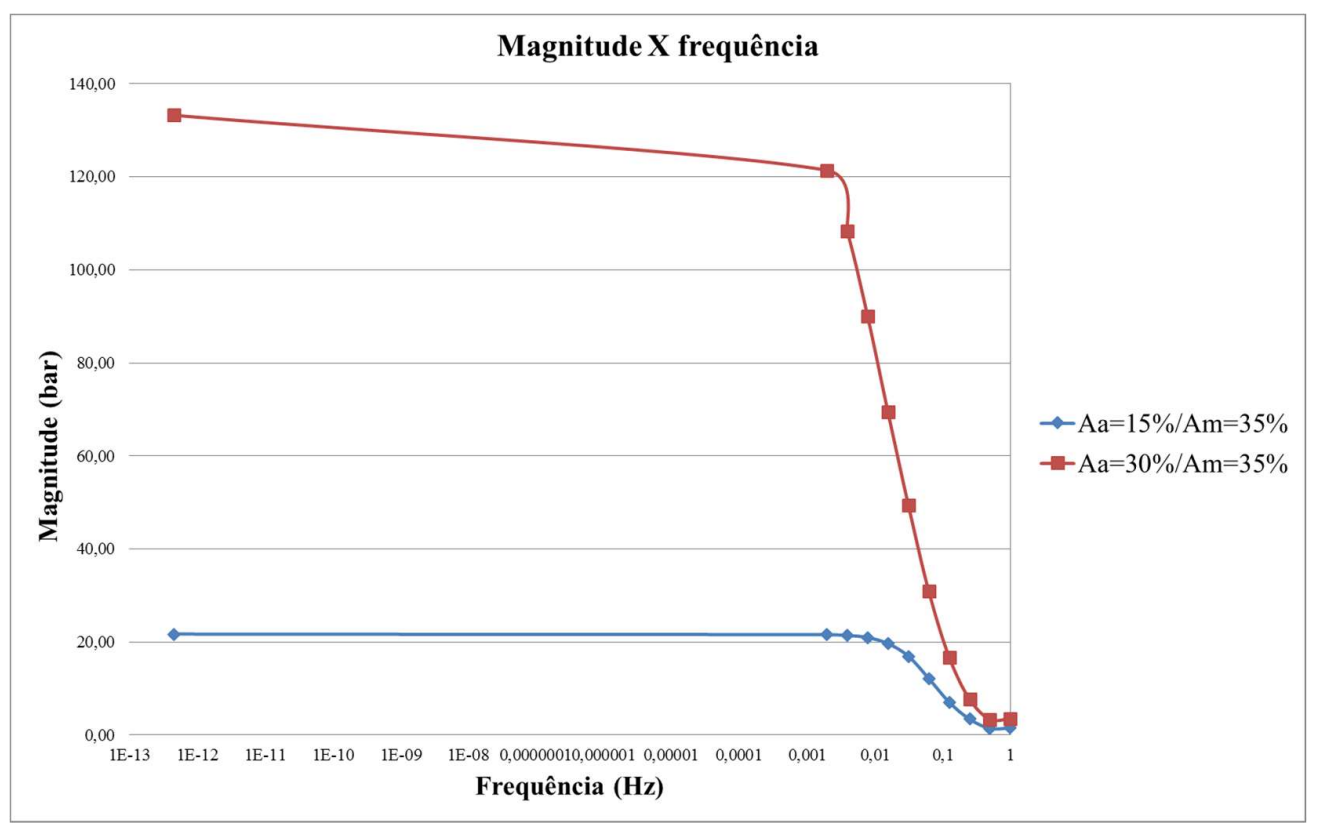

Figura 3.7 - Ganho por frequência, para $A_{m}=35 \%$.

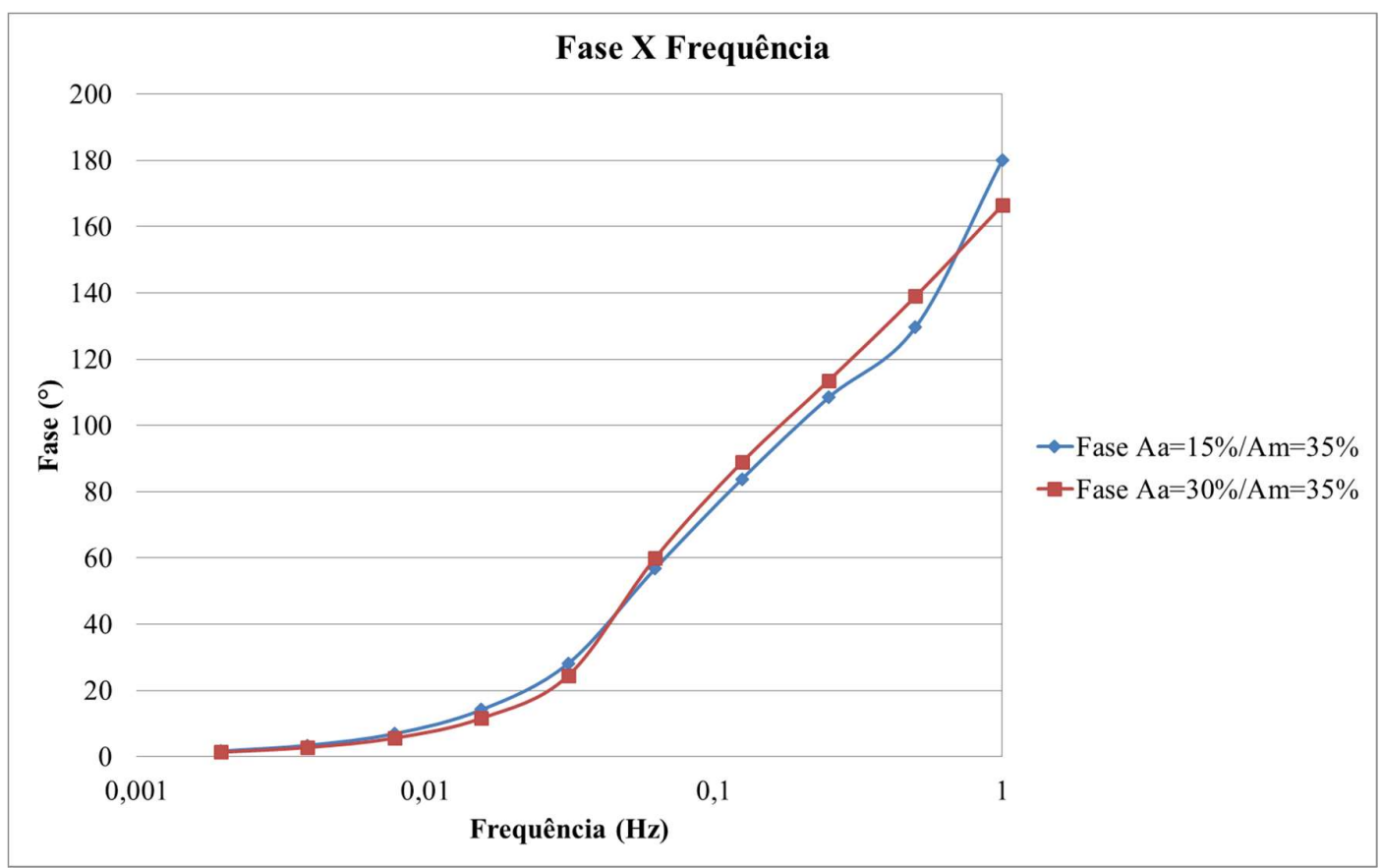

Figura 3.8 - Resposta da fase na frequência, para $A_{m}=35 \%$. 


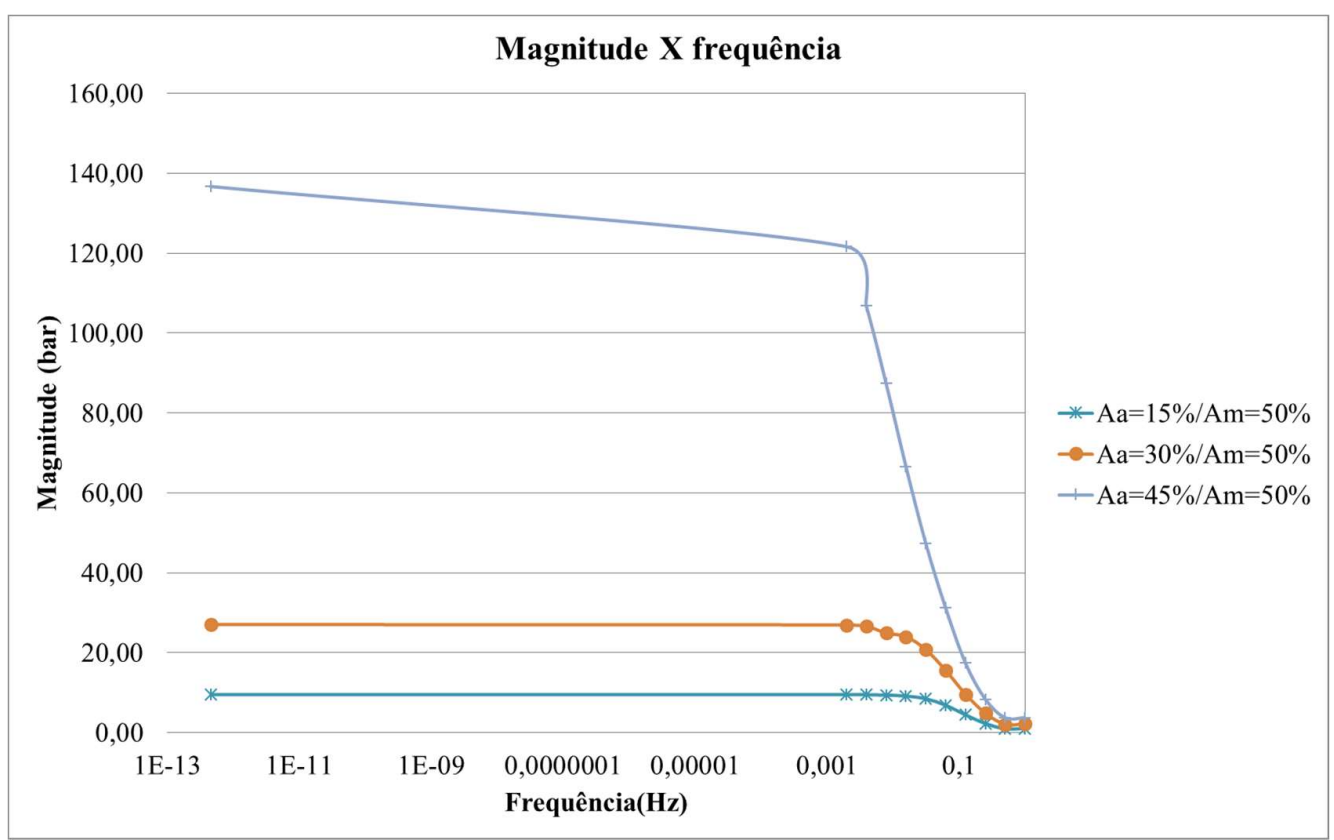

Figura 3.9 - Ganho por frequência, para $A_{m}=50 \%$.

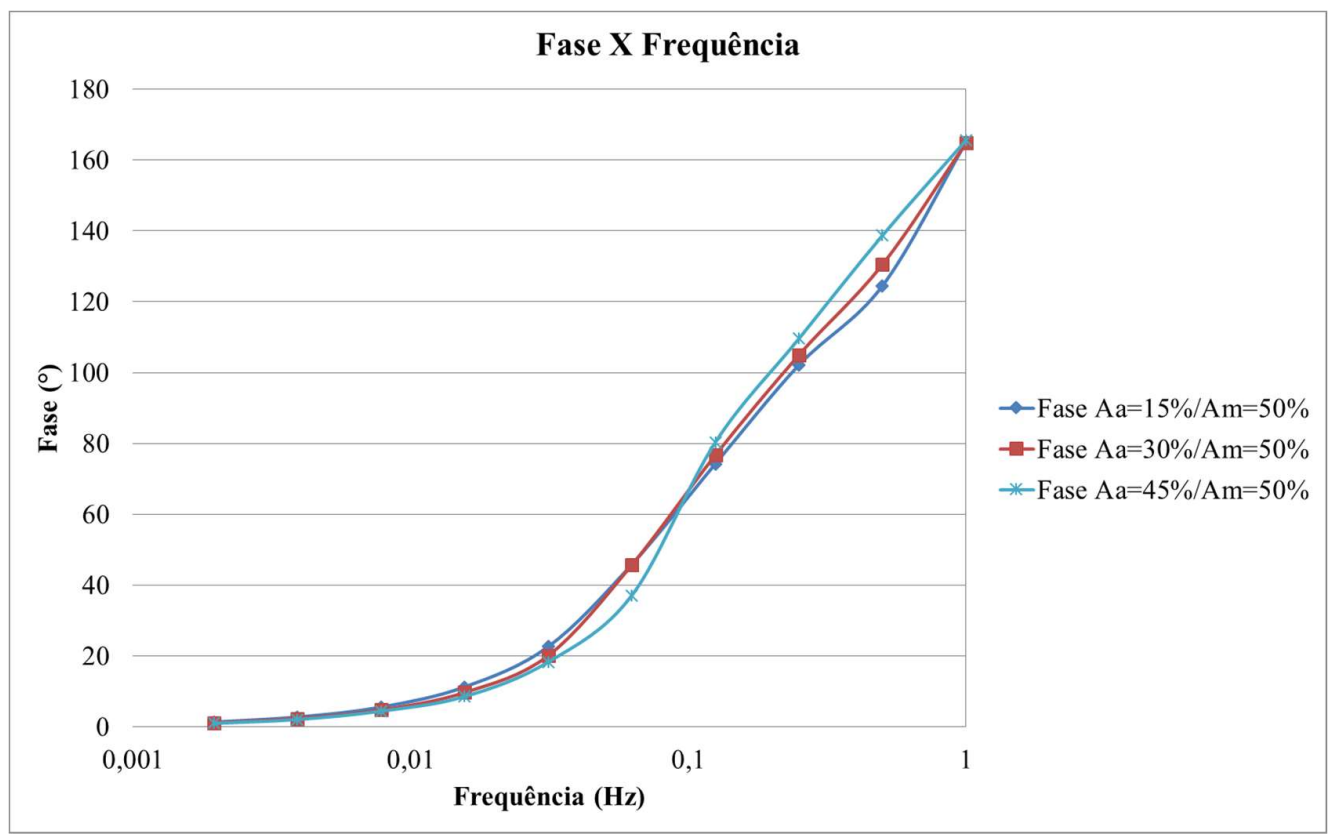

Figura 3.10 - Resposta da fase na frequência, para $A_{m}=50 \%$. 


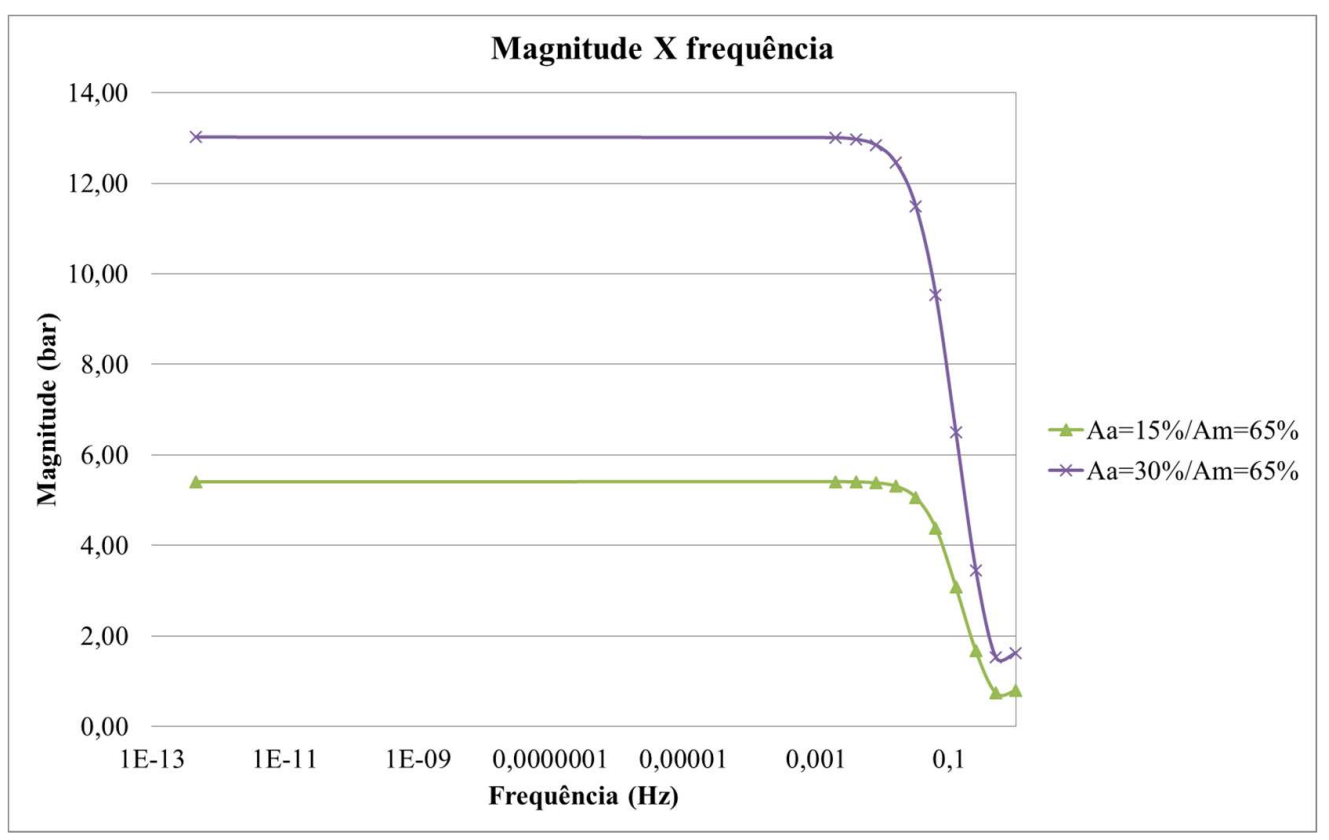

Figura 3.11 - Ganho por frequência, para $A_{m}=65 \%$.

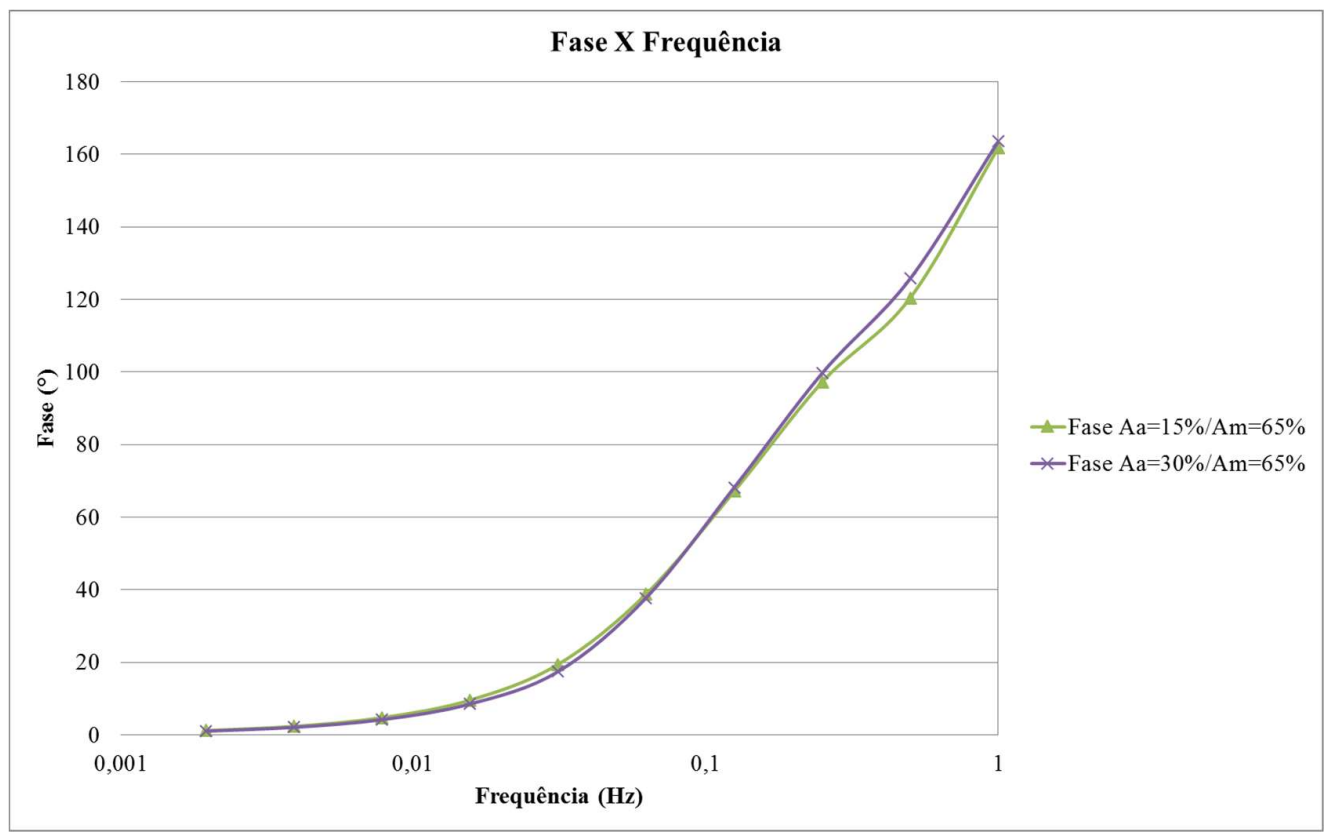

Figura 3.12 - Resposta da fase na frequência, para $A_{m}=65 \%$. 
Os resultados obtidos indicam que o sistema possui significativas não linearidades. Mesmo quando observada a resposta para pequenas amplitudes do choke, não se verifica um comportamento de primeira ordem no sistema. $\mathrm{O}$ comportamento da perda de carga, que não é linear, com as variações de pressão na abertura do choke, que por sua vez gera uma perda de carga localizada com comportamento não linear, podem explicar este comportamento em frequência.

A figura 3.13 agrega todos os resultados de magnitude de resposta devido ao estímulo em diferentes frequências. Pode-se observar que para um período tendendo a infinito, i.e. em regime permanente, não existe diferença significativa na amplitude da resposta e da fase com relação às frequências mais baixas simuladas. Isso indica que a faixa de frequência avaliada é representativa para o problema.

Outro ponto observado é que a zona de trabalho do choke (definida pela sua abertura média $A_{m}$ ) possui maior impacto na resposta do que a amplitude $A_{a}$ do estímulo. As maiores magnitudes observadas são para abertura média de 35\%, com $30 \%$ de amplitude de variação da abertura do choke, e com 50\% de abertura média com $45 \%$ de amplitude de variação da abertura. Somente no regime permanente é que se observa uma diferença na magnitude da resposta do estímulo. Para uma abertura média de $65 \%$ com $30 \%$ de amplitude de variação da abertura do choke, a magnitude da resposta é inferior ao verificado para uma abertura média de $35 \%$ com $15 \%$ de amplitude de variação, corroborando com o indício de que a posição média do choke tem maior impacto na dinâmica do sistema do que a amplitude e frequência de oscilação do choke.

$\mathrm{Na}$ faixa de maior frequência de estímulo, se observa que a magnitude da resposta é menor. Isso vem do fato de o sistema possuir uma inércia para resposta ao estímulo, e que o aumento ou diminuição da pressão necessita de tempo para alterar o estado do sistema. 


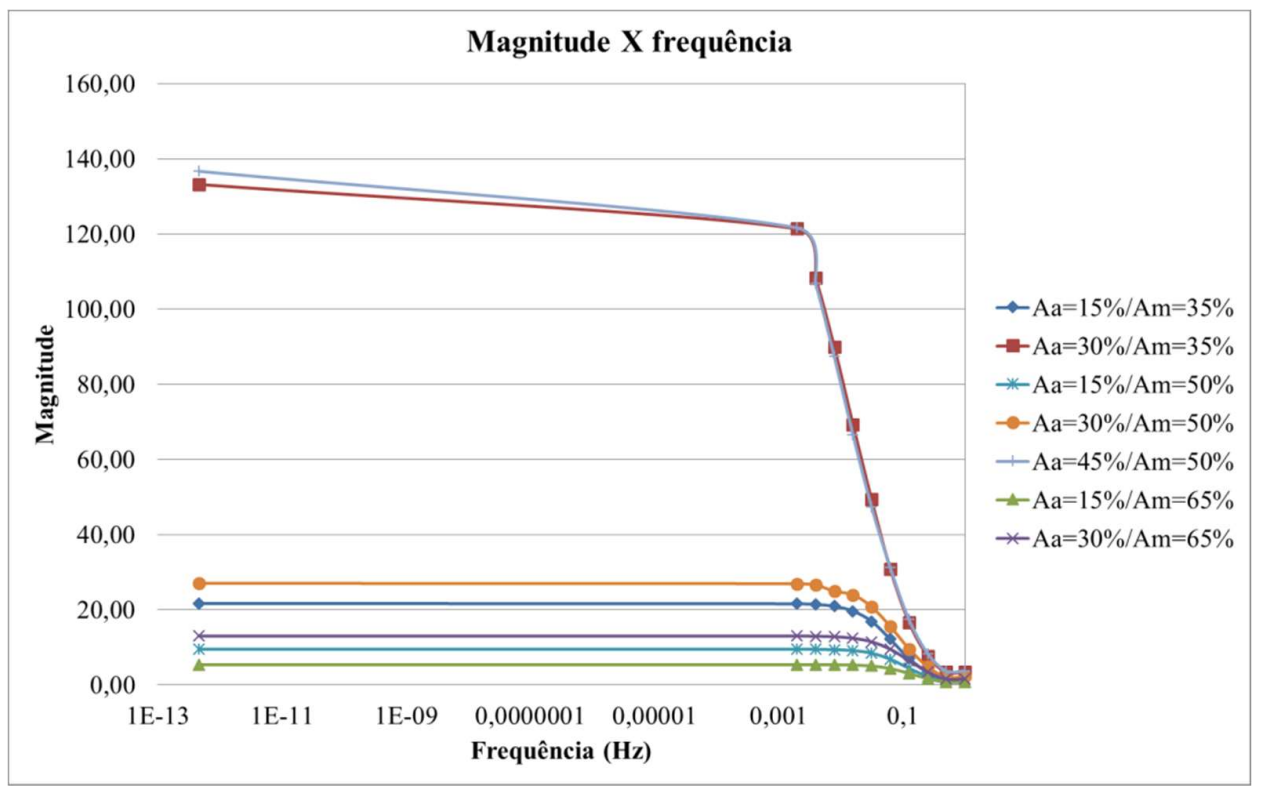

Figura 3.13 - Ganho para estimulo em diversas frequências.

A resposta em fase para os diversos estímulos mostrou comportamento semelhante em todas simulações. Quanto menor a frequência do estímulo, menor a fase entre o estímulo e a resposta do sistema. Para frequências mais altas, a inércia do sistema tem maior impacto do que a posição do choke, apresentando um atraso entre $160^{\circ}$ e $180^{\circ}$. A figura 3.14 resume em um gráfico todas avaliações para estimulo em frequência.

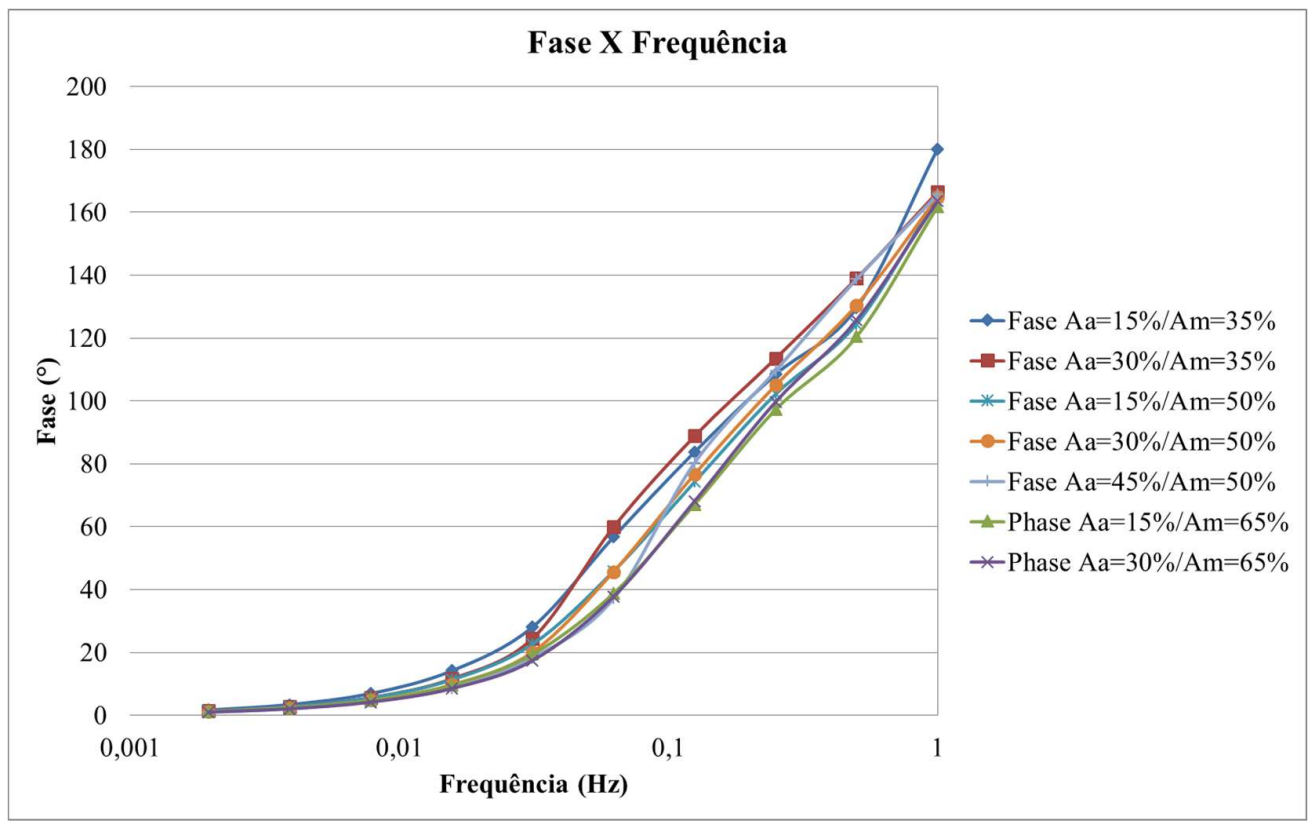

Figura 3.14 - Fase para estimulo em diversas frequências considerando período infinito 
Verifica-se que análise da resposta do sistema em frequência para o sistema não linear é mais trabalhosa do que a análise para um sistema linearizado. Sistemas linearizados permitem o uso de ferramentas automáticas para geração do diagrama de Bode, enquanto sistemas não-lineares demandam que cada ponto de análise em frequência seja feita uma simulação individual e colheta de dados da simulação. Isso acaba por gerar um tempo de simulação superior.

No próximo capítulo, controladores lineares e não lineares são estudados para compensar os significativos efeitos não lineares observados em malha aberta. 


\section{4. Controle do Sistema}

No controle no choke MPD, o atuador age progressivamente na sua abertura e fechamento. Ou seja, é impossível alterar instantaneamente a abertura do choke, cujo atuador provoca variações neste valor de forma incremental. Assim, o controlador passa a ter um efeito integral na resposta.

Do ponto de vista de modelagem, é irrelevante controlar a abertura do choke ou sua taxa, desde que se reconheça que um controlador proporcional da taxa de abertura seria equivalente a um controle integral da abertura. No entanto, para melhor reproduzir a física do atuador, a taxa de abertura do choke é utilizada como a saída do controlador, ao invés da abertura em si, a qual não poderia ser alterada instantaneamente. Desse modo, um controlador proporcional puro irá comandar uma variação na abertura do choke enquanto houver erro na variável controlada. Ao atingir o valor desejado, um comando zero do controlador significa que a abertura do choke será mantida constante, permitindo assim atingir um regime permanente.

Para as simulações de resposta dos diferentes controladores, foi utilizado um mesmo padrão de teste. A geometria e o fluido do poço simulado são os mesmos do modelo de poço offshore avaliado nas simulações de malha aberta do capítulo anterior. O padrão de teste utilizado teve como objetivo submeter o controlador a uma ampla variação da operação do choke, sem penalizar excessivamente o tempo de simulação.

Para garantir a estabilidade da simulação e evitar erros numéricos, as simulações são iniciadas a partir da condição de repouso. A vazão no interior da coluna é aumentada em rampa até a vazão de bombeio de perfuração (assumida com valor $\mathrm{q}=0,032 \mathrm{~m}^{3} / \mathrm{s}$ ), enquanto o sistema é mantido com choke $100 \%$ aberto neste regime até $\mathrm{o}$ instante $\mathrm{t}=100 \mathrm{~s}$, quando o controlador é ativado. Para o controlador, é passada a pressão de referência de 655 bar no primeiro volume de controle do anular. No instante $\mathrm{t}=300$ s é realizada uma redução em rampa na vazão de bombeio, para $\mathrm{q}=0,016 \mathrm{~m}^{3} / \mathrm{s}$, para verificar a reação do controlador a 
esta variação. A figura 4.1 ilustra a variação da vazão com o tempo durante a simulação.

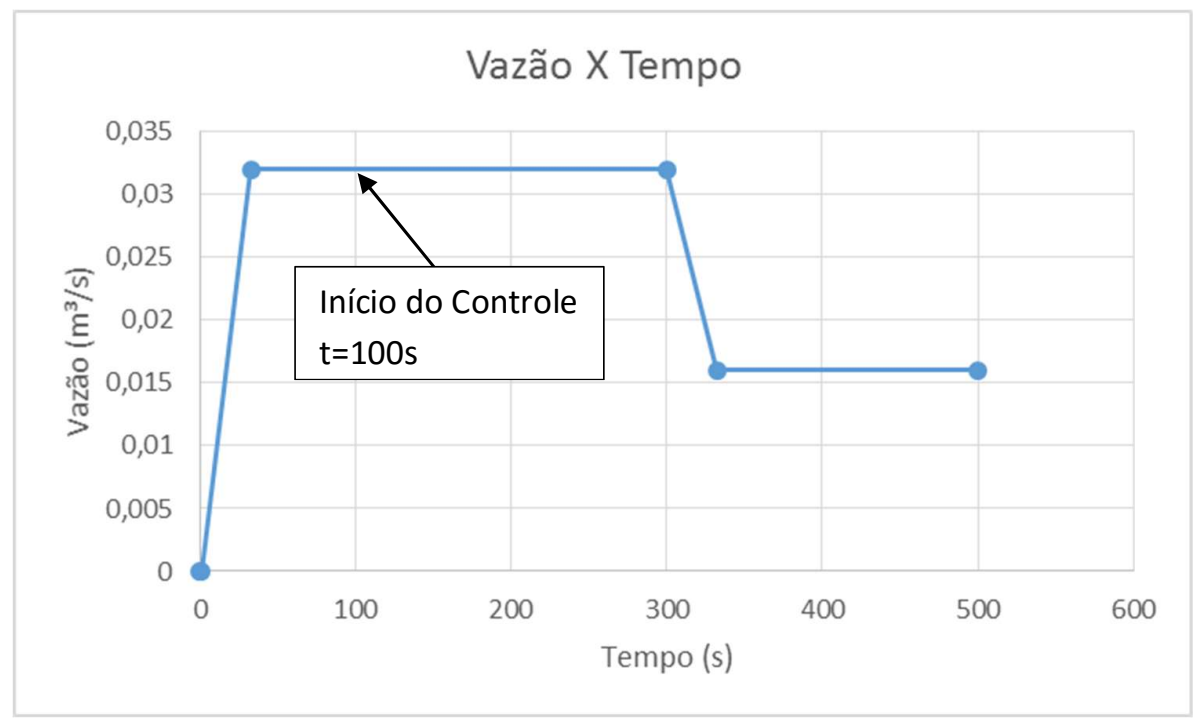

Figura 4.1 - Variação da vazão imposta durante a simulação.

Um critério inicial para avaliação do desempenho de controladores é o seu tempo de resposta. Caso o controlador leve menos do que 200s até a estabilização, após o distúrbio, o controlador será considerado apto para verificações sobre o desempenho do controle. Caso o controlador não se encontre estabilizado após 200s do distúrbio, é considerado que o mesmo não deve ser investigado mais profundamente, uma vez que não será suficientemente rápido para aplicações típicas. Vale notar que os parâmetros impostos ao controlador, i.e. degrau de pressão de 25 bar e redução rápida da vazão, devem ser considerados como rigorosos em relação a cenários típicos encontrados na prática. Em condições normais durante uma perfuração com MPD, os degraus de pressão e as taxas de variação da vazão costumam ser mais brandos do que os valores utilizados para referência dos testes.

\section{1.}

Controlador PID

O controlador proporcional-integral-derivativo (controlador PID) é um mecanismo de realimentação amplamente utilizado em sistemas de controle 
industrial. Um controlador PID calcula um valor de erro como a diferença entre uma variável do processo de medição e um ponto de ajuste desejado. O controlador tenta então minimizar esse erro.

O algoritmo controlador PID envolve três parâmetros constantes separados: proporcional, integral e derivativo, denotados P, I, e D, respectivamente. De forma simplificada, estes valores podem ser interpretados em termos de tempo: $\mathrm{P}$ depende do erro presente, I sobre a acumulação de erros no passado, e D é uma previsão de futuros erros, com base na taxa atual de mudança do erro. A soma ponderada destas três ações é utilizada para ajustar o processo através do controle de um elemento, tal como a posição de uma válvula de controle, um amortecedor, ou a potência fornecida a um elemento de aquecimento. No presente caso, o controlador irá atuar na velocidade (taxa) de abertura do choke MPD, $\dot{A}$. A equação (4.1) demonstra como a velocidade de abertura é afetada por cada um dos parâmetros do controlador PID:

$$
\dot{A}=K_{P} e(t)+K_{D} \frac{d}{d t} e(t)+K_{I} \int_{0}^{t} e(\tau) d \tau
$$

Através do ajuste dos três parâmetros (ganhos) no algoritmo de controle PID, o controlador pode buscar a ação de controle projetada para os requisitos específicos do processo. Alguns cenários podem ser atendidos com o uso de apenas uma ou duas ações para proporcionar o controle do sistema apropriado. Isto é conseguido pelo ajuste dos outros parâmetros para zero. Um controlador PID será chamado PI, PD, P ou controlador I na ausência de ações de controle dos demais termos. De forma geral, controladores PI são bastante comuns, já que a ação derivativa é sensível à medição de ruído, enquanto que a ausência de um termo integral pode impedir o sistema de atingir o seu valor-alvo devido a perturbações ou erros na modelagem.

A estratégia de controle mais utilizada na indústria do petróleo para controle de pressão no poço com chokes MPD é o controlador PID, i.e. com os 3 ganhos diferentes de zero. Como são diversas configurações de poço existentes com os mais diversos fluidos de perfuração, os ganhos do controlador (proporcional, integrativo e derivativo) são ajustados a cada fase para cada poço. Dependendo da situação operacional, é possível que os ganhos do poço precisem ser ajustados manualmente pelo operador MPD no decorrer da construção da fase do poço, 
assim como durante a transição entre conexão e perfuração, ou no caso entupimento parcial do choke.

\subsection{1.}

\section{Calibragem por Ziegler-Nichols}

Como estratégia inicial de controle foram aplicados controladores P, PI, PD e PID ao sistema não linear completo. A primeira abordagem para o cálculo dos ganhos do controlador foi a metodologia de Ziegler-Nichols (1942). Nesta metodologia, é necessário conhecer o ganho proporcional mínimo (ganho crítico) para uma oscilação constante da resposta do sistema. Com o valor do ganho crítico e o tempo de oscilação do sistema, são definidos os ganhos para os controladores P, PD e PI.

Em uma primeira tentativa, foi considerado um ganho proporcional $k_{P}=$ $10^{-3}$. A análise do comportamento da pressão e vazão nos diversos volumes de controle indica uma saturação do controlador, vide figuras 4.2 a 4.4. Desse modo, ganhos menores precisam ser considerados, como estudado a seguir.

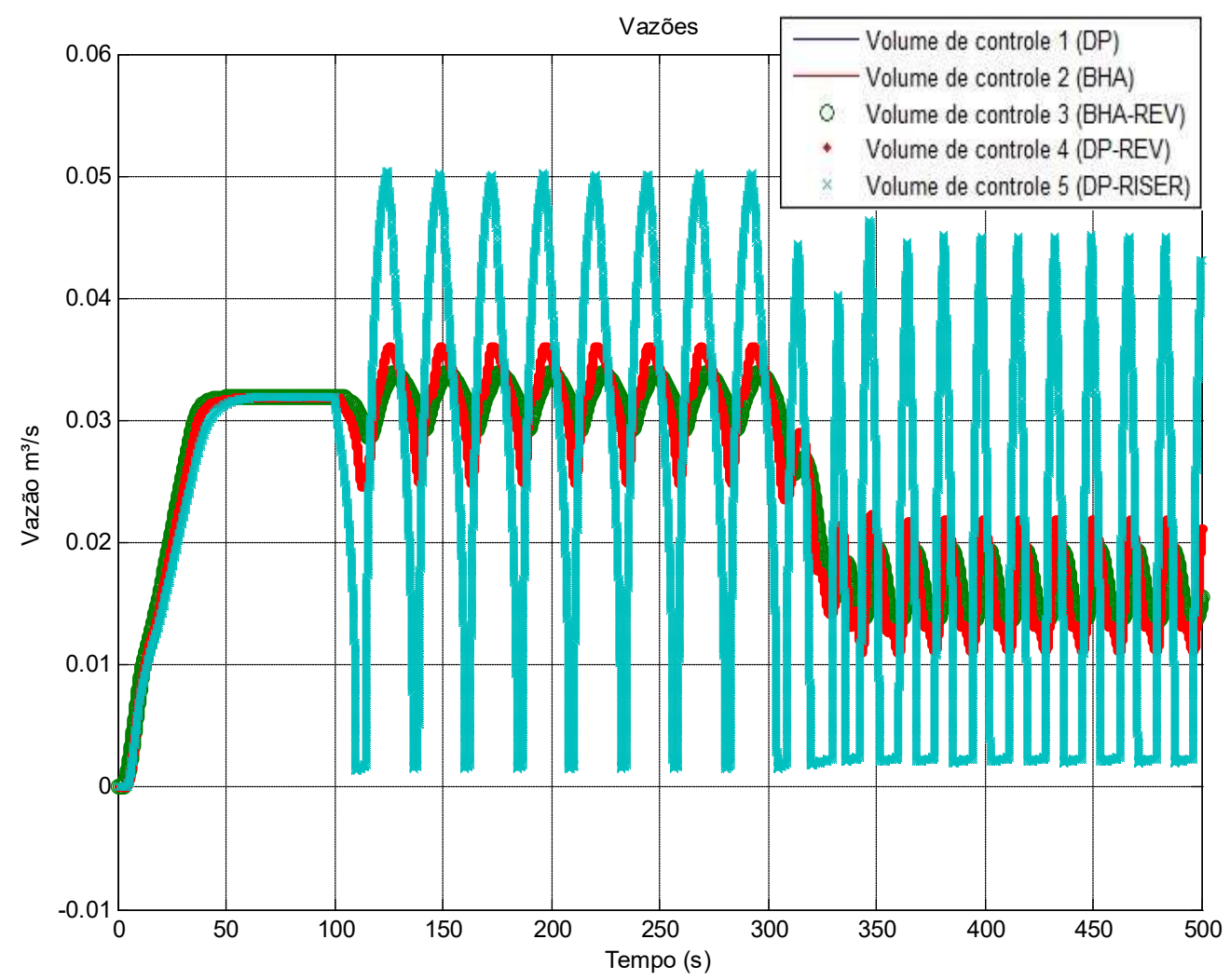

Figura 4.2 - Comportamento da Vazão nos vários volumes de controle $\left(k_{\mathrm{P}}=\right.$ $\left.10^{-3}\right)$. 


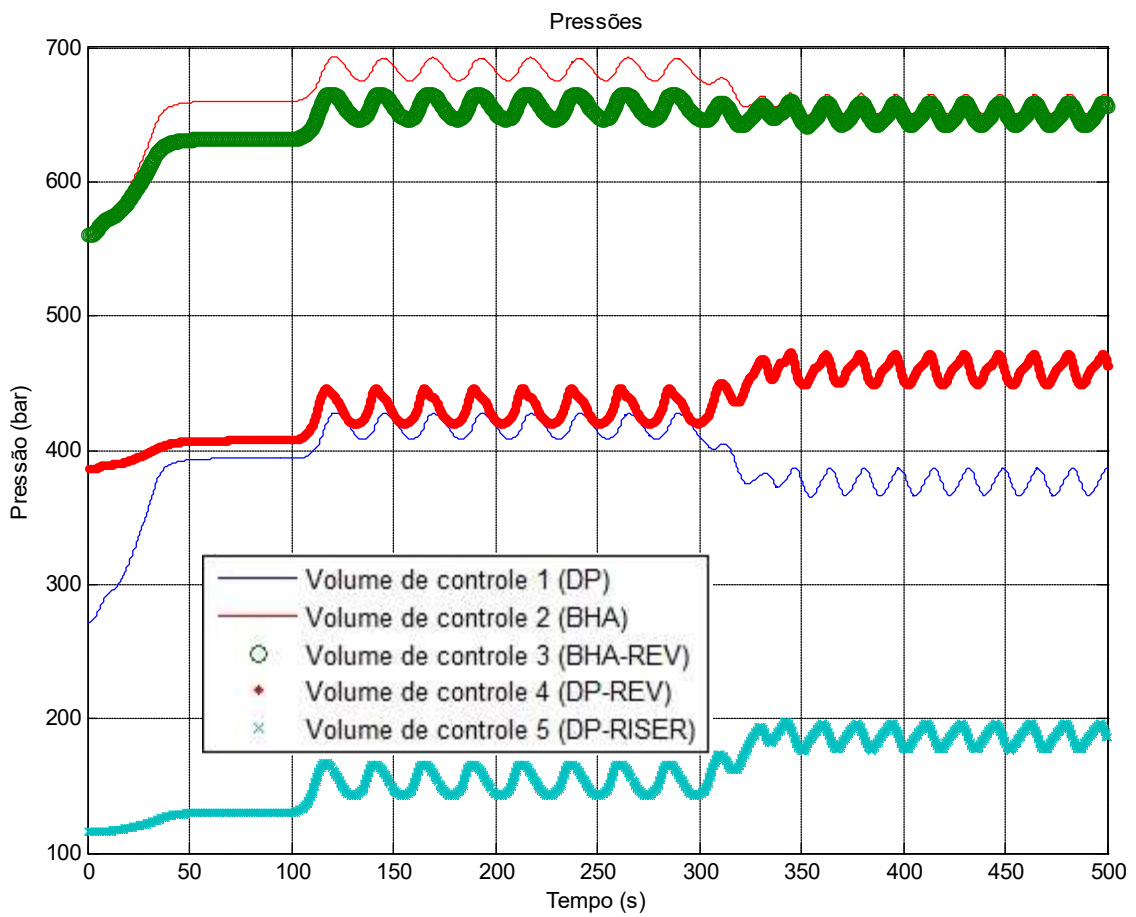

Figura 4.3 - Comportamento da pressão nos vários volumes de controle

$$
\left(\mathbf{k}_{\mathbf{P}}=10^{-3}\right) \text {. }
$$

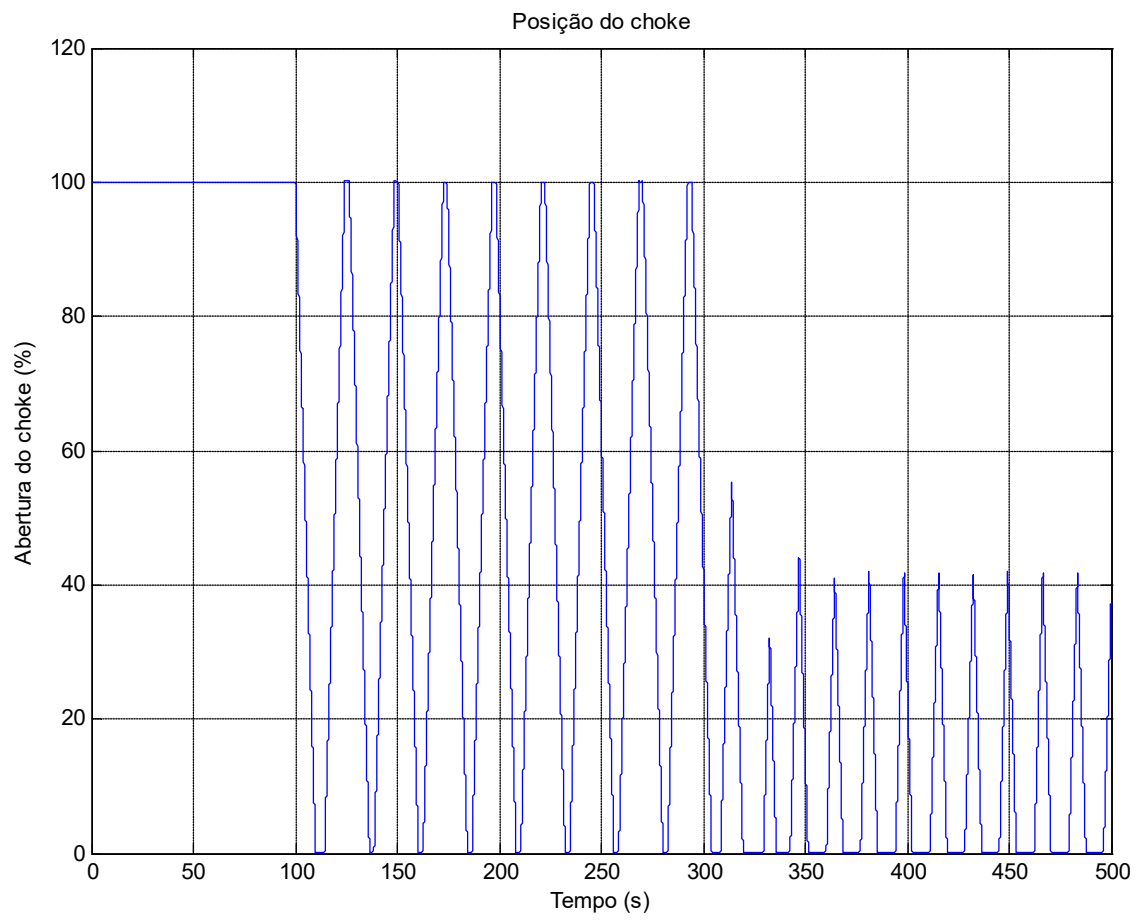

Figura 4.4 - Posição do choke $\left(k_{P}=10^{-3}\right)$. 
Antes de se prosseguir com outras tentativas para obtenção de ganho crítico, foi feita uma análise para estimativa do ganho proporcional. Uma referência para cálculo da ordem de grandeza dos ganhos do controlador se baseia em correlacionar a variação do choke com a variação da perda de carga localizada. No capítulo de modelagem hidráulica, a figura 2.14 mostrou a perda de carga localizada com a abertura do choke para uma vazão fixa. Considerando o trecho linear do gráfico, uma variação na perda de carga de $10^{7} \mathrm{~Pa}$ representa uma variação de $10 \%$ da abertura do choke. Como o erro é proporcional à pressão (ordem de grandeza $10^{7}$ ), a primeira estimativa de ordem grandeza para o ganho proporcional é obtida correlacionando o erro com uma taxa de abertura. A equação (4.2) correlaciona o erro (diferença entre a pressão atual e a pressão de referência) e o ganho com a taxa de variação, conforme seria a saída do controlador:

$$
\frac{d A}{d t}=k_{P} * \text { erro }
$$

Rearranjando a eq. (4.2) para a eq. (4.3) se obtém uma referência inicial de ganho proporcional desejado:

$$
k_{P}=\frac{d A}{d t} / \text { erro }
$$

Assumindo uma máxima taxa de mudança do choke de 10\%/s (abertura ou fechamento do choke de $10 \%$ em um segundo, valor dentro das faixas operacionais reais), a ordem de grandeza de referência para o ganho proporcional do controlador fica em $10^{-8}$. Vale notar que este ganho é referenciado ao SI; se outras unidades fossem utilizadas, por exemplo o sistema Imperial, os ganhos do controlador deveriam ser ajustados de acordo.

Após algumas simulações partindo do valor de ganho estimado, foi obtido o valor de ganho crítico de $\mathrm{P}$ como $k_{\text {crit }}=6 \cdot 10^{-8}$. O tempo de oscilação entre períodos observado foi de $35 \mathrm{~s}$, vide figuras 4.5 a 4.7 , a partir do qual ZieglerNichols pôde ser aplicado. 


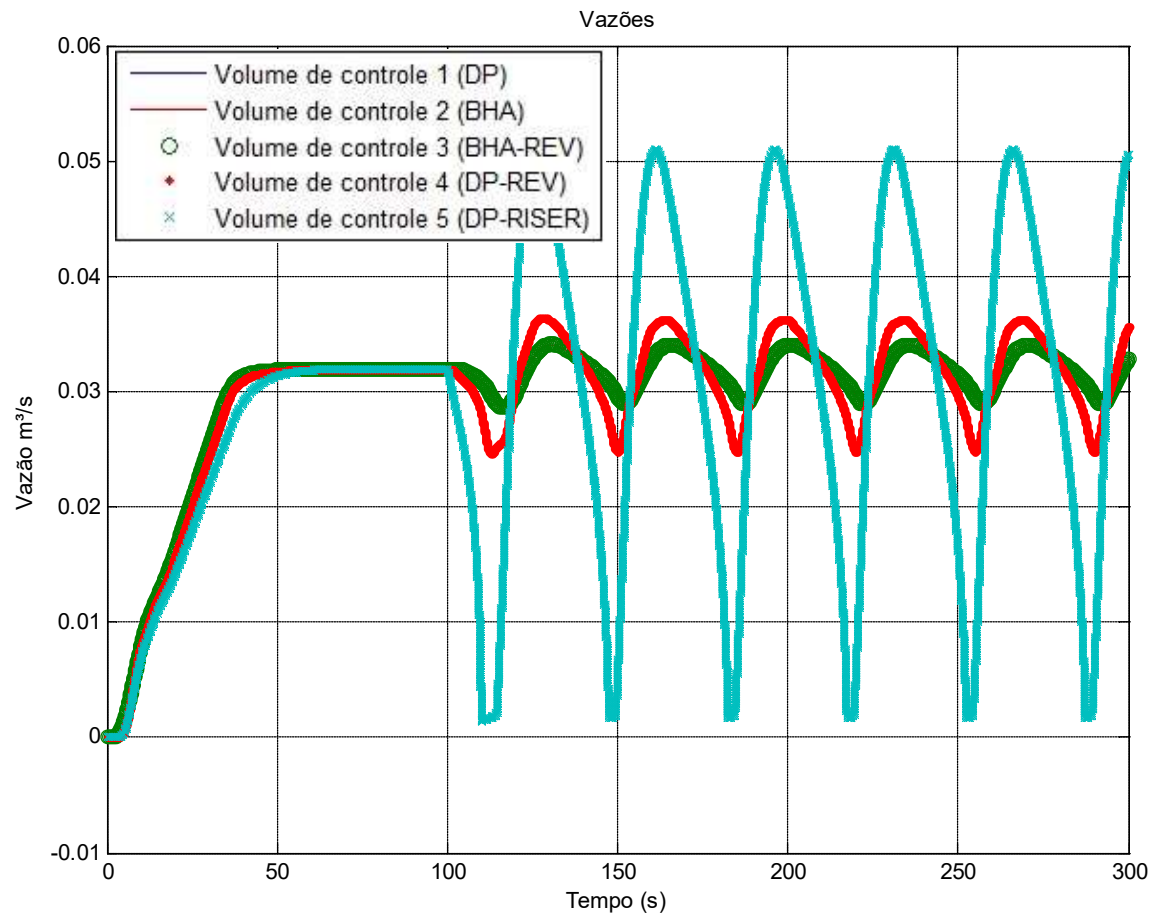

Figura 4.5 - Comportamento da vazão nos volumes de controle

$$
\left(k_{\text {crit }}=6 \cdot 10^{-8}\right) \text {. }
$$

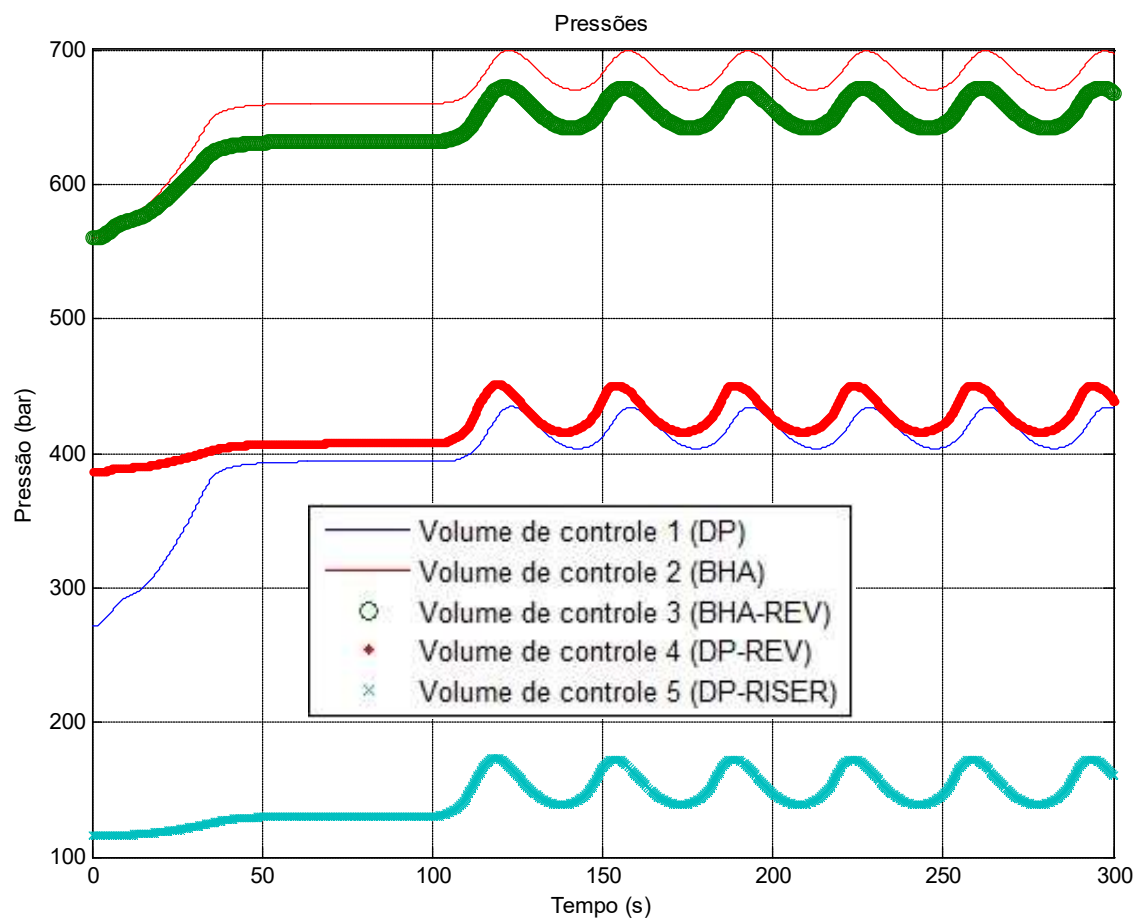

Figura 4.6 - Comportamento da pressão nos volumes de controle

$$
\left(k_{\text {crit }}=6 \cdot 10^{-8}\right) \text {. }
$$




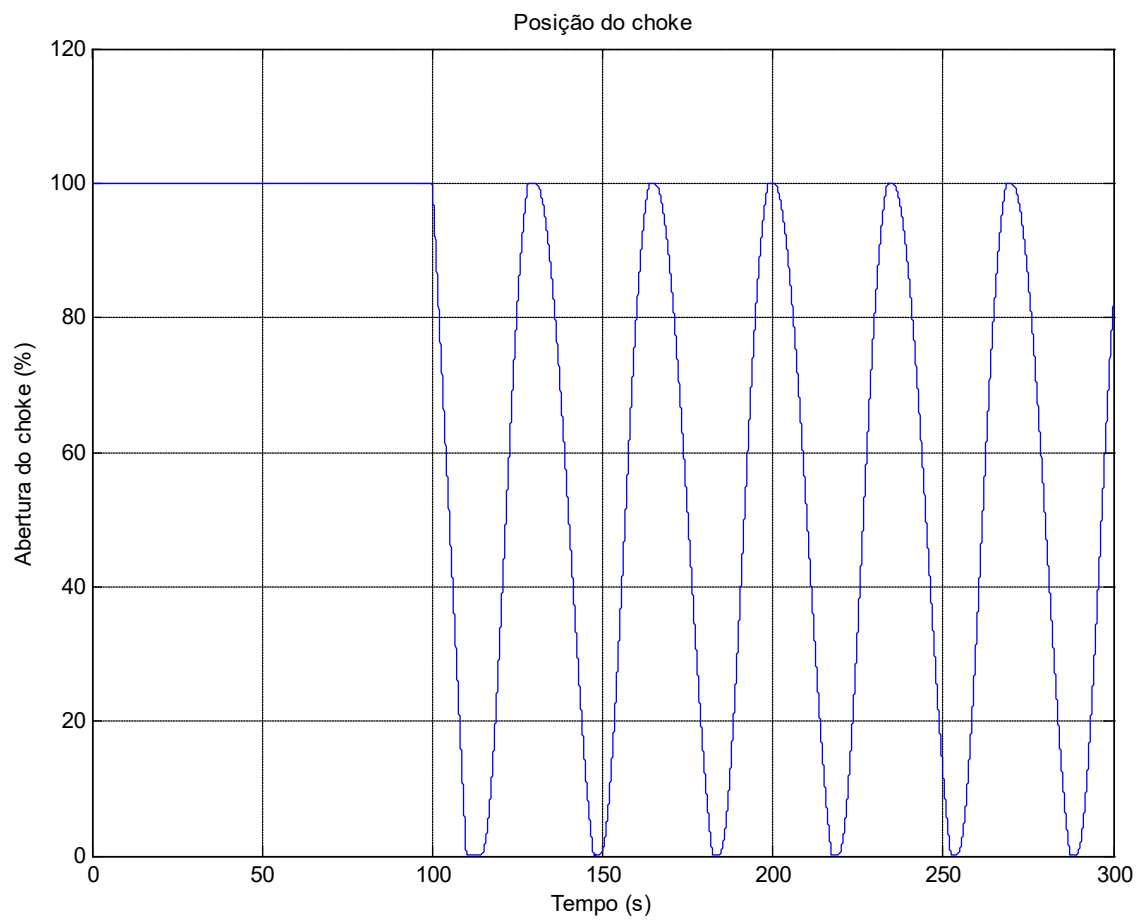

Figura 4.7 - Posição do choke $\left(k_{\text {crit }}=6 \cdot 10^{-8}\right)$.

A tabela 4.1 mostra os ganhos sugeridos pelo método heurístico de ZieglerNichols para os controladores P, PI e PD com base no valor de $k_{\text {crit }}=6 \cdot 10^{-8} \mathrm{e}$ $T_{\text {crit }}=35 \mathrm{~s}$ obtidos com as simulações. As figuras 4.8 a 4.16 mostram os resultados obtidos com os ganhos do controlador determinados com estas calibragens, discutidas nas seções a seguir.

Tabela 4-1 - Ganhos sugeridos Ziegler-Nichols

\begin{tabular}{|c|c|c|c|}
\hline Tipo de controle & $k_{P}$ & $k_{I}$ & $k_{D}$ \\
\hline $\mathrm{P}$ & $0,5 k_{\text {crit }}$ & - & - \\
\hline $\mathrm{PI}$ & $0,45 k_{\text {crit }}$ & $1,2 * k_{\text {crit }} / T_{\text {crit }}$ & - \\
\hline $\mathrm{PD}$ & $0,8 k_{\text {crit }}$ & - & $k_{\text {crit }} T_{\text {crit }} / 8$ \\
\hline
\end{tabular}

4.1.1.1.

Controlador P

Um controlador puramente proporcional, com ganho calculado pela Tabela 4-1, apresentou oscilação no controle da pressão de referência. O comportamento 
da abertura do choke MPD, e o comportamento das vazões dos volumes de controle, confirmam uma oscilação sobre o ponto de equilíbrio, vide figuras 4.8 a 4.10. Como a pressão não foi estabilizada até o momento de decremento da vazão, instante 300 s, a simulação foi interrompida, visto que o tempo de 200 s deveria ser suficiente para controle adequado do degrau de pressão dado ao controlador no instante de 100s. A inadequabilidade do controle P é justificada pela ausência de um termo derivativo para inibir as oscilações.

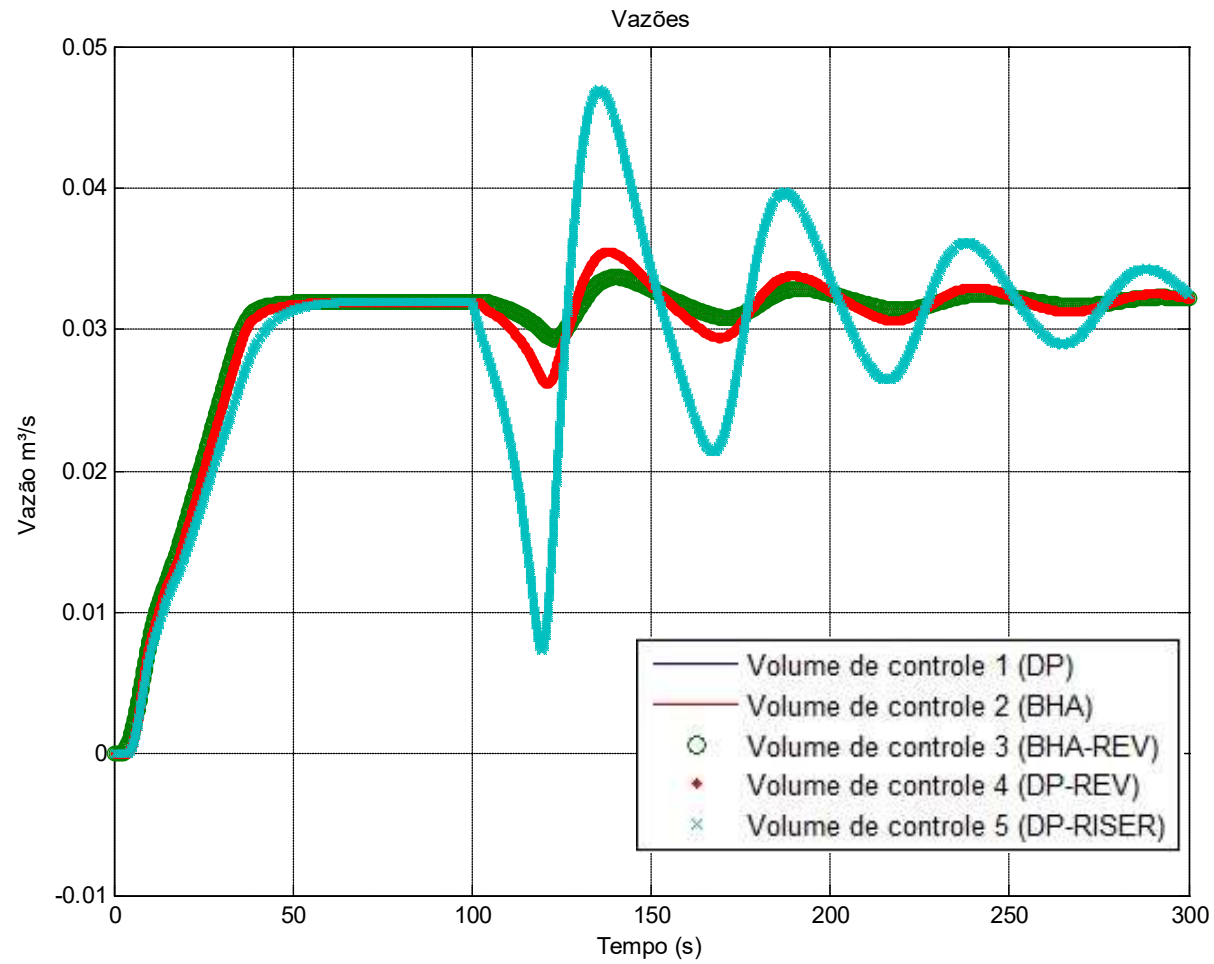

Figura 4.8 - Vazão nos volumes de controle, para um controlador $P$ calibrado por Ziegler-Nichols com $k_{P}=3 \cdot 10^{-8}$. 


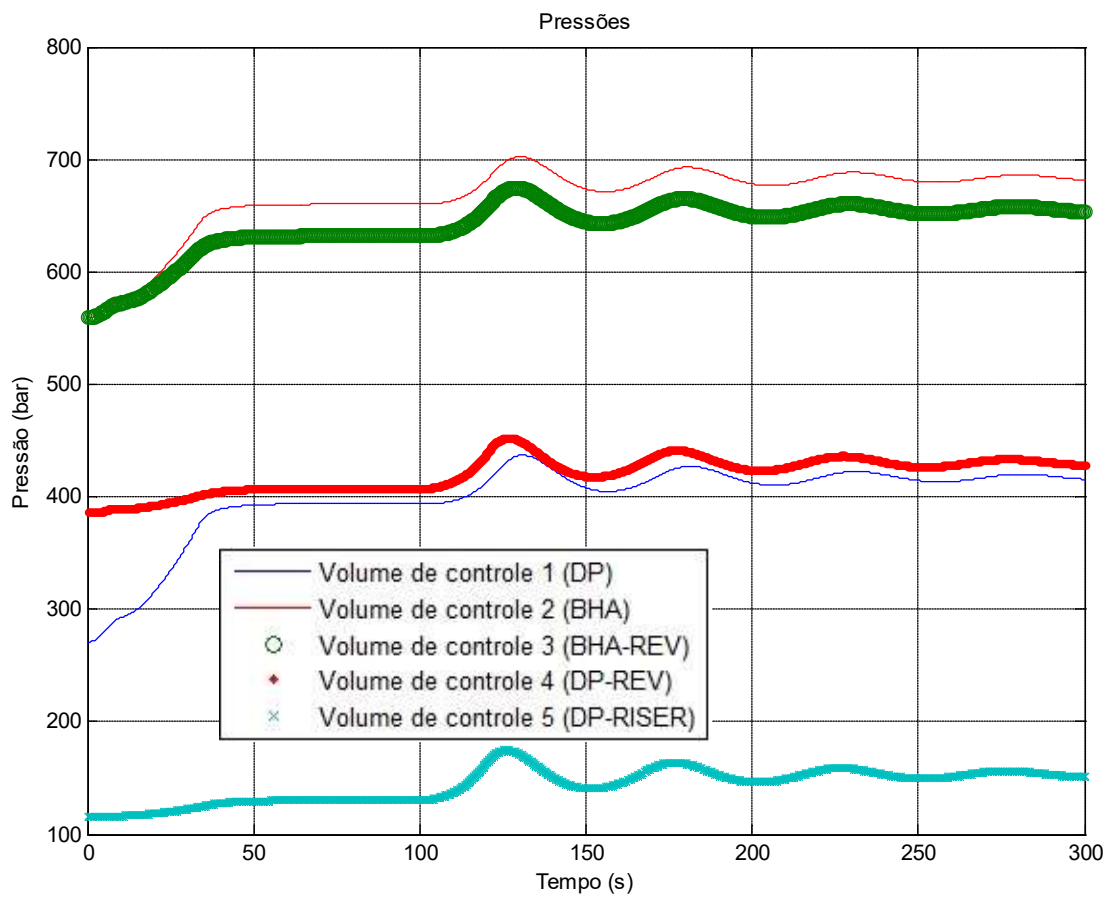

Figura 4.9 - Pressão nos volumes de controle, para um controlador $P$ calibrado por Ziegler-Nichols com $k_{P}=3 \cdot 10^{-8}$.

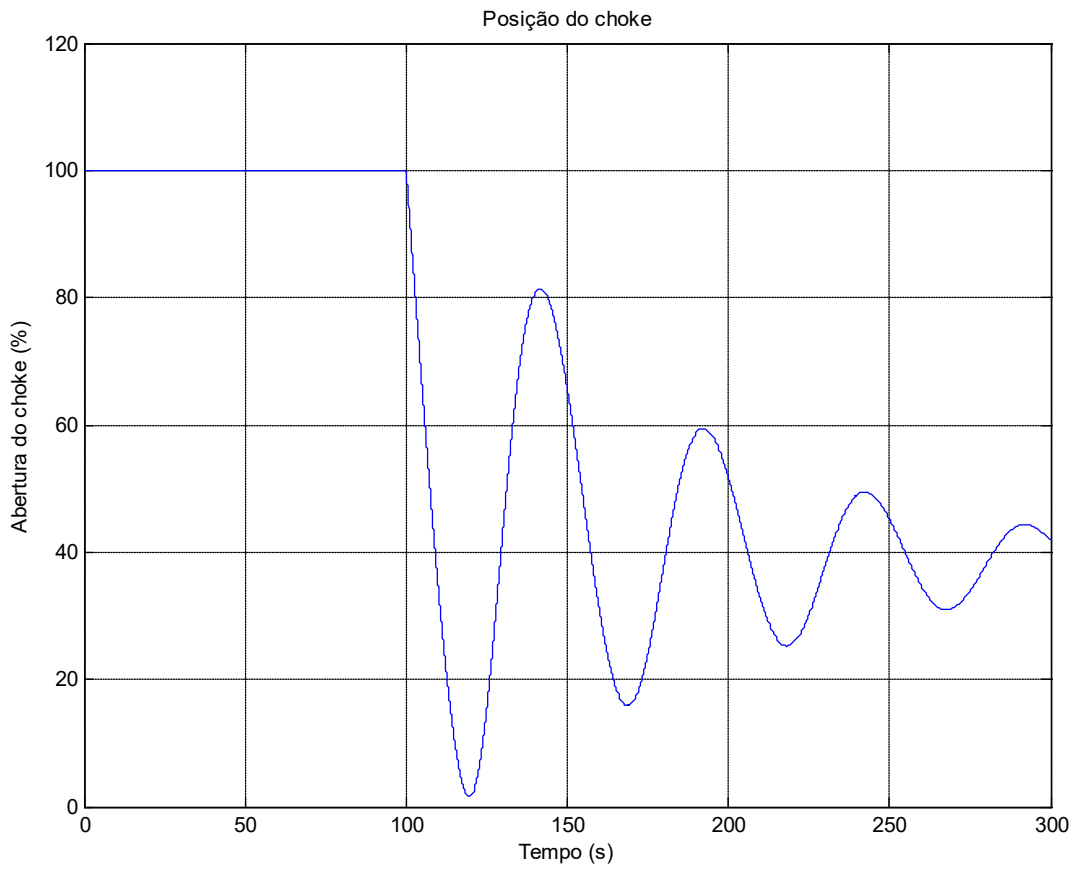

Figura 4.10 - Abertura do choke para um controlador $P$ calibrado por Ziegler-Nichols com $k_{P}=3 \cdot 10^{-8}$. 


\subsubsection{2.}

Controlador PI

O controlador proporcional integrativo (PI), calibrado por Ziegler-Nichols segundo a Tabela 4.1, mostra a saturação do choke MPD, conforme a figura 4.13. A vazão (figura 4.11), em especial do volume de controle do riser, indica uma atuação agressiva do choke, saturado, visto que a vazão neste volume de controle varia bruscamente, indicando compressão e descompressão abrupta do poço (vide figura 4.12). $\mathrm{O}$ comportamento da pressão acaba sendo semelhante ao comportamento do estímulo senoidal feito para análise em frequência do sistema. Como não houve convergência do valor da pressão até o instante $300 \mathrm{~s}$, o teste também foi interrompido. A inadequabilidade do controle PI é justificada pelo comportamento não linear do sistema, e pelos limites de operação do choke.

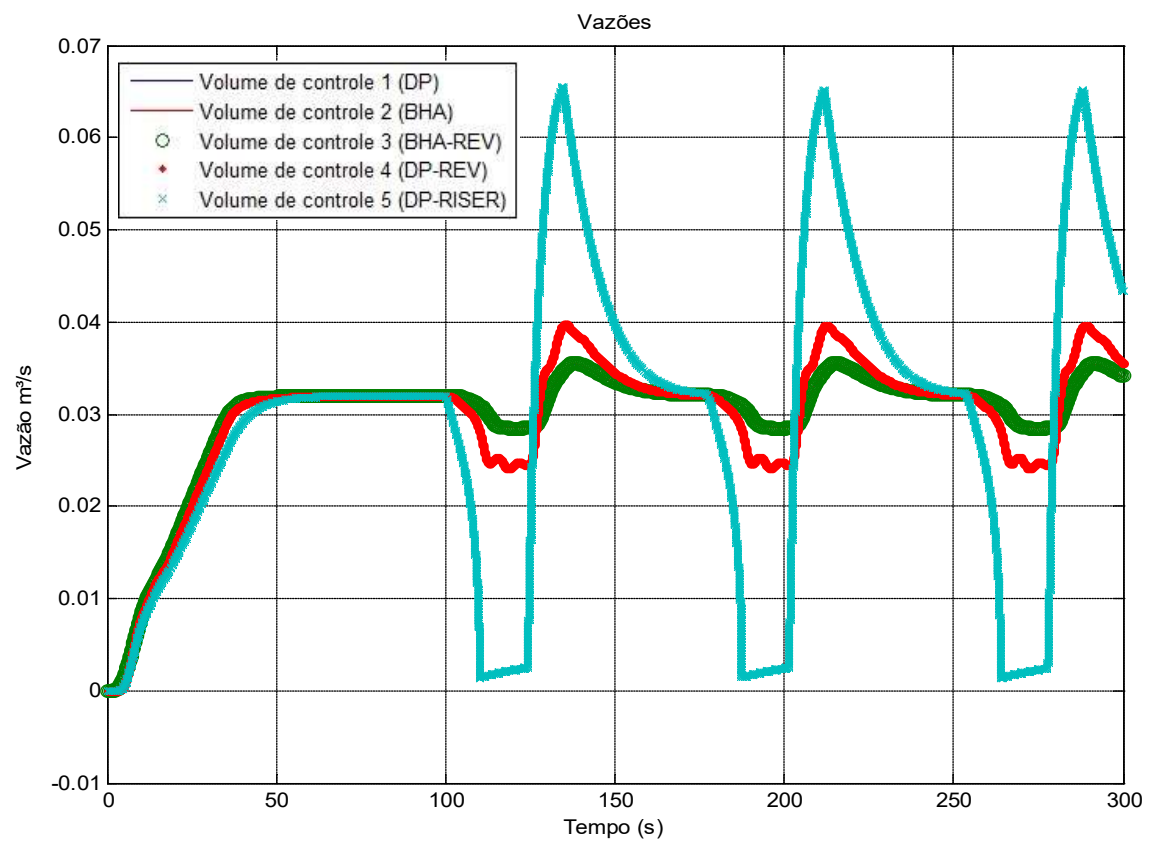

Figura 4.11 - Vazão nos volumes de controle, para um controlador PI calibrado por Ziegler-Nichols com $k_{P}=2.7 \cdot 10^{-8}$ e $k_{I}=2 \cdot 10^{-9}$. 


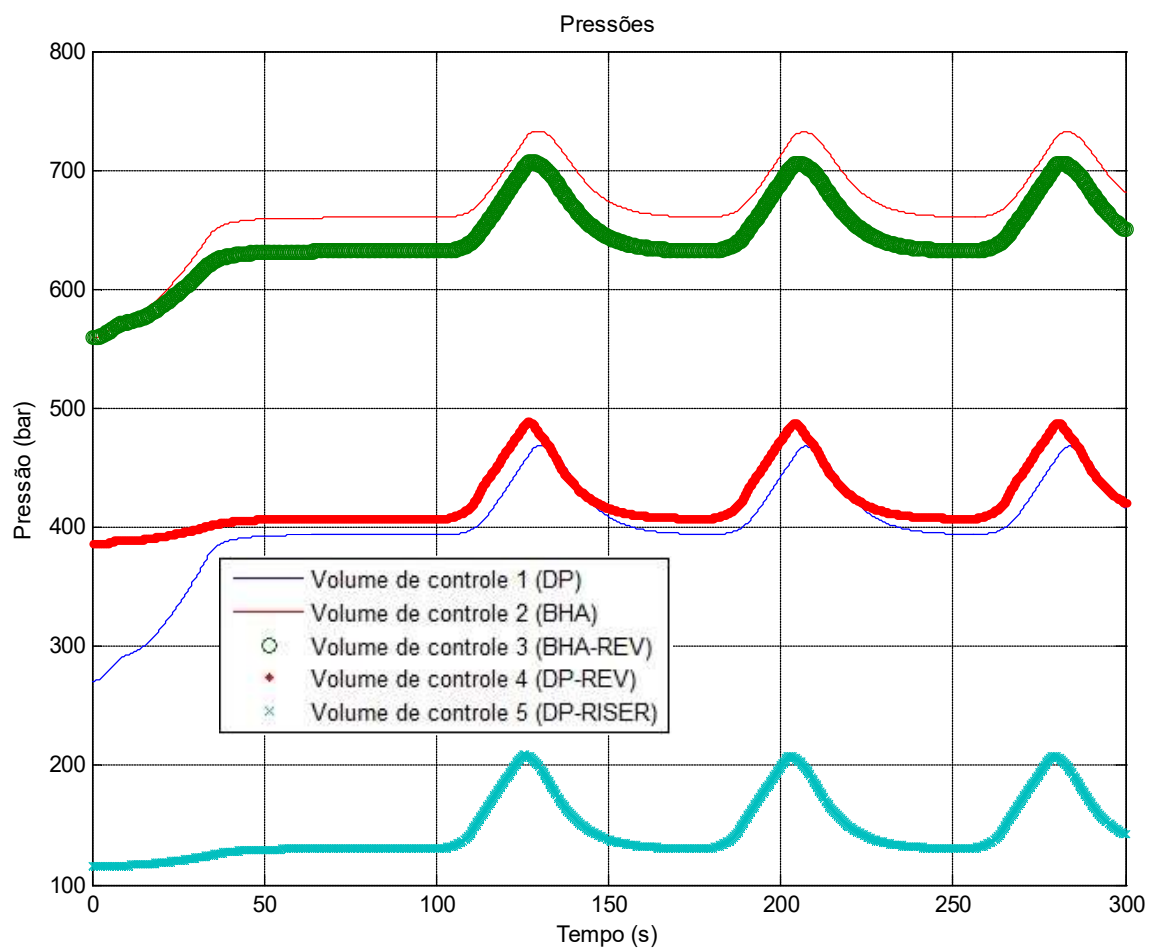

Figura 4.12 - Pressão nos volumes de controle, para um controlador PI calibrado por Ziegler-Nichols com $k_{P}=2.7 \cdot 10^{-8}$ e $k_{I}=2 \cdot 10^{-9}$.

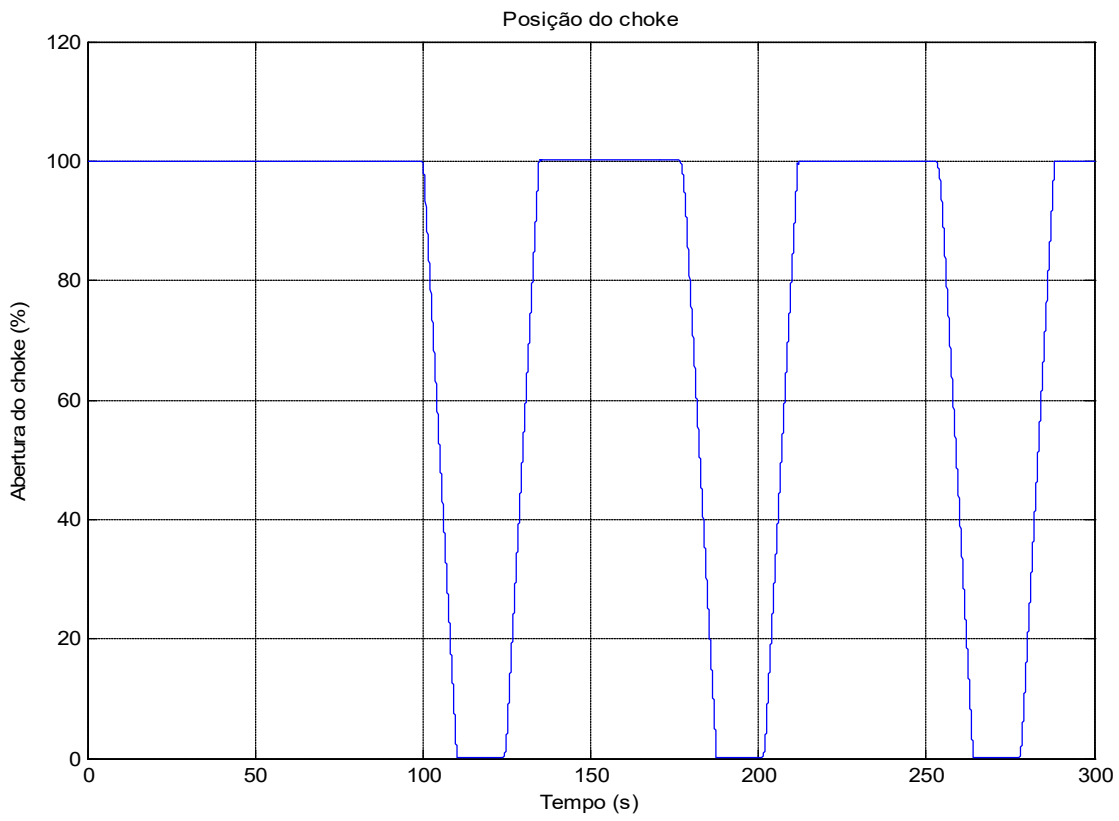

Figura 4.13 - Abertura do choke para um controlador PI calibrado por Ziegler-Nichols com $k_{P}=2.7 \cdot 10^{-8}$ e $k_{I}=2 \cdot 10^{-9}$. 
4.1.1.3.

Controlador PD

Entre os controladores simulados com ganhos de Ziegler-Nichols, o Controlador PD foi o único que atendeu ao primeiro objetivo da simulação, que é de estabilizar a pressão do primeiro elemento do anular com a pressão de referência na vazão de $0,032 \mathrm{~m}^{3} / \mathrm{s}$, vide figuras 4.14 a 4.16 . Na segunda etapa da simulação, no decremento da vazão, o controlador não conseguiu efetuar o controle adequado. Apesar de a oscilação se manter próxima ao valor de referência, nota-se que o choke fica oscilando continuamente. O comportamento do choke acaba por provocar repetidas pressurizações e descompressões do sistema, alterando a vazão de saída no poço. Em uma aplicação real, a resposta obtida, além do não cumprimento da meta de controle e desgaste do equipamento, provocaria uma situação de comprometimento da segurança da operação, visto que o monitoramento da vazão de saída é requisito de segurança na perfuração de poços de petróleo que operem com retorno de fluido na superfície.

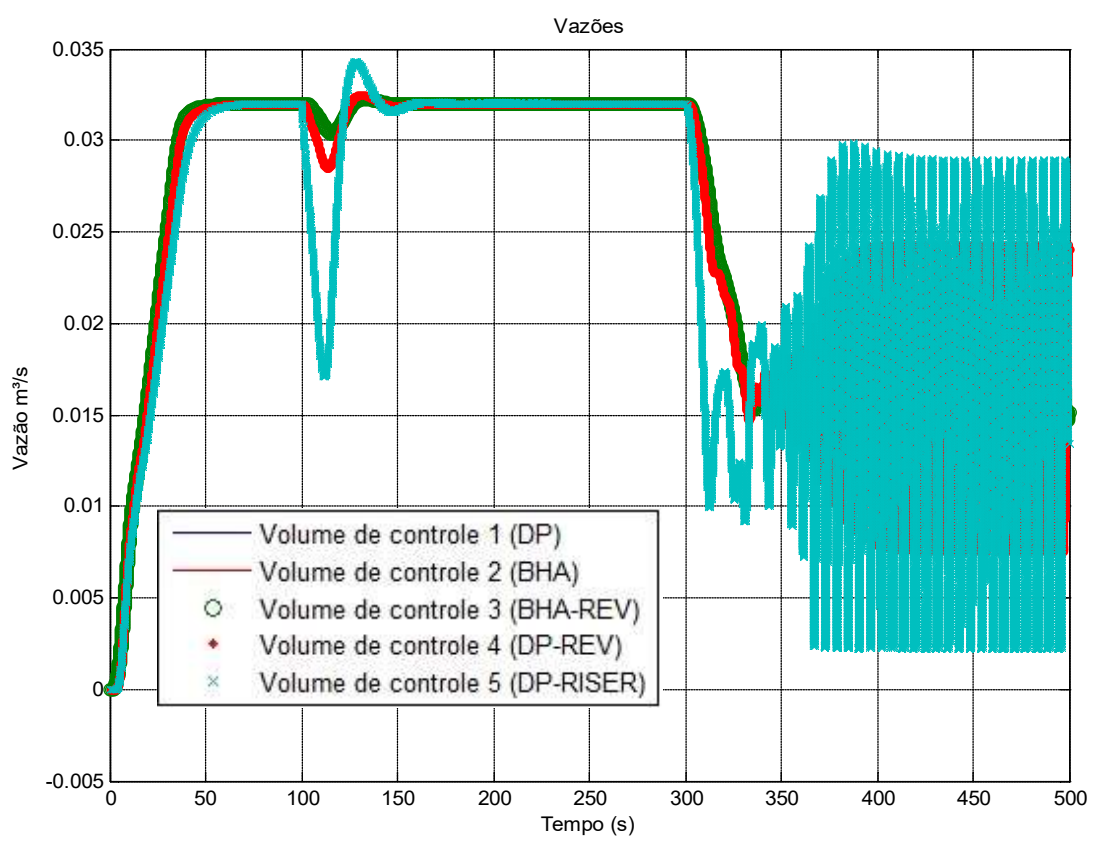

Figura 4.14 - Vazão nos volumes de controle, para um controlador PD calibrado por Ziegler-Nichols com $k_{P}=4.8 \cdot 10^{-8}$ e $k_{D}=2.6 \cdot 10^{-7}$. 


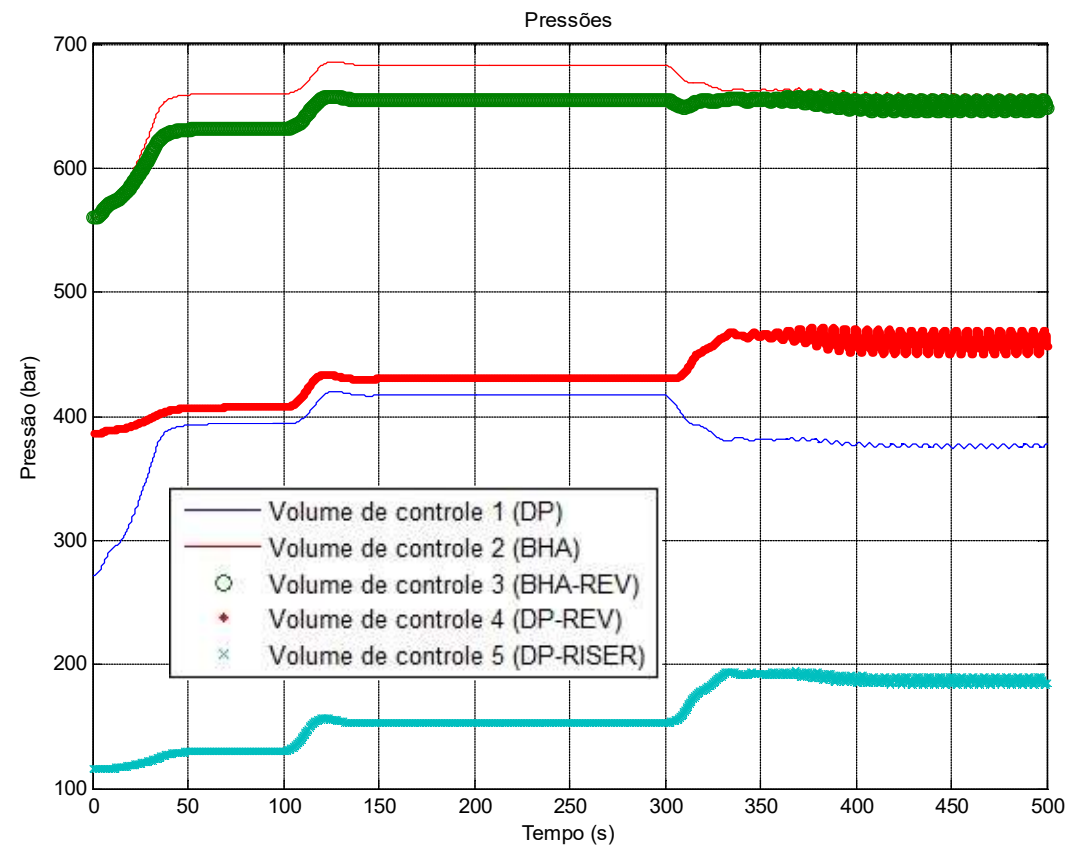

Figura 4.15 - Pressão nos volumes de controle, para um controlador PD calibrado por Ziegler-Nichols com $k_{P}=4.8 \cdot 10^{-8}$ e $k_{D}=2.6 \cdot 10^{-7}$.

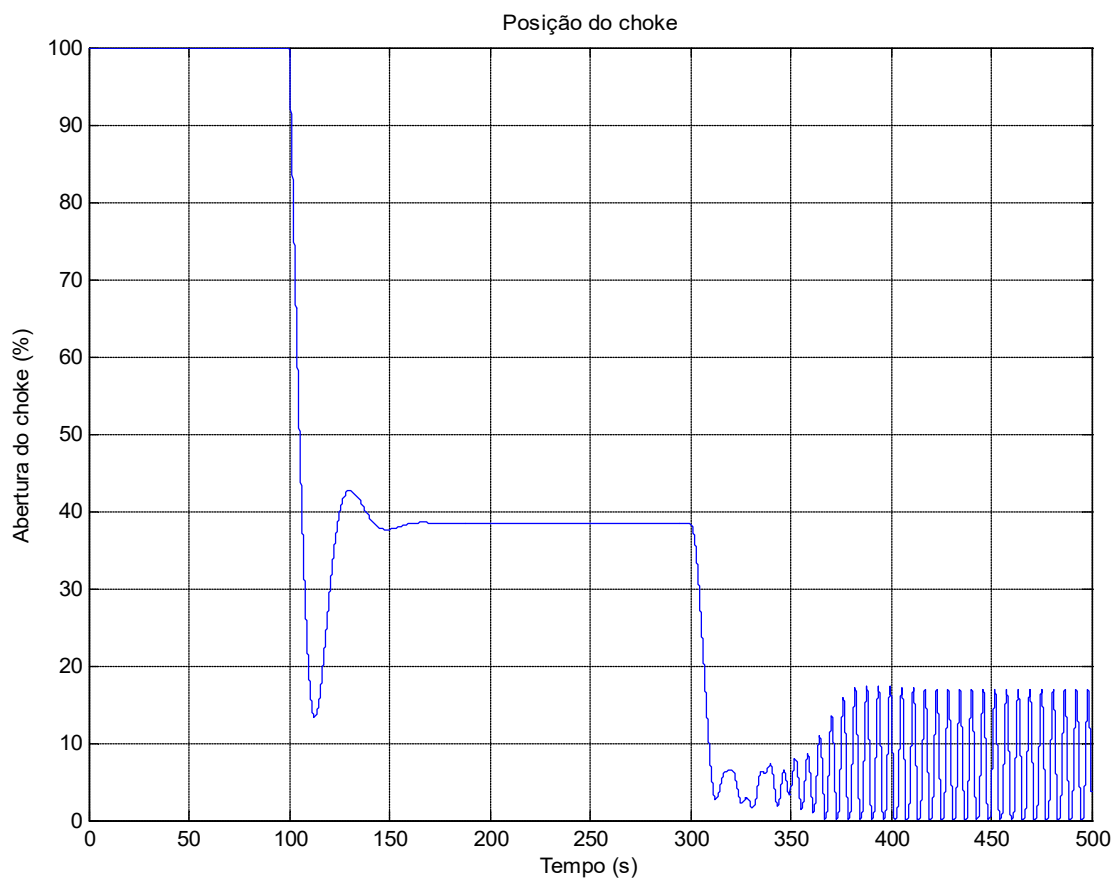

Figura 4.16 - Abertura do choke para um controlador PD calibrado por Ziegler-Nichols com $k_{P}=4.8 \cdot 10^{-8}$ e $k_{D}=2.6 \cdot 10^{-7}$. 
A inadequabilidade do controle PD é justificada pelo comportamento não linear do sistema: o ajuste de Ziegler-Nichols só é adequado para pequenas oscilações, cuja dinâmica possa ser considerada aproximadamente linear. As grandes oscilações verificadas nas figuras geram efeitos não lineares que controles lineares como o PD não consegue controlar de forma adequada.

De forma geral, os ganhos propostos aos três controladores P, PI e PD com a metodologia de Ziegler-Nichols indicam ter alto valor, dado o sobre-sinal no controle da pressão objetivo e saturação do atuador, acarretando em oscilações e não atingindo a meta de controle. O motivo do comportamento do sistema está relacionado com sua não linearidade. Tanto a perda de carga localizada no choke como a vazão do sistema são não lineares, requerendo o uso de controladores lineares com ganhos escalonados, ou controladores não lineares.

\subsection{2.}

Ajuste empírico dos ganhos

A dificuldade deste método é que além de necessitar interpretação do comportamento do sistema são necessárias diversas simulações para otimização do sistema. Como no controlador PID a resposta ao erro é linear, o ganho do controlador foi atenuado para que o mesmo pudesse trabalhar em diversas condições de operação sem causar saturação do atuador ou oscilações excessivas. Partindo dos ganhos indicados por Ziegler-Nichols, foram feitas outras simulações para encontrar ganhos (PID) com melhor desempenho. Com a estratégia de redução dos ganhos, a simulação indica que a pressão de referência é atingida na zona objetivo somente em alguns casos, como discutido a seguir.

\subsubsection{1.}

Controlador $\mathbf{P}$

As figuras 4.17 a 4.19 mostram os resultados da simulação com o controlador $\mathrm{P}$ com ganho $k_{P}=2 \cdot 10^{-9}$. Conforme pode ser observado, para que ocorra diminuição da oscilação na segunda etapa da simulação com tendência para convergência, o ganho do controlador proporcional deve ser bastante reduzido. A redução do ganho proporcional acaba por prejudicar o desempenho do controlador na primeira parte da simulação. Mesmo com ganho reduzido, na segunda parte da 
simulação não se verifica a estabilização da pressão até 200s após a redução da vazão. Uma maior redução do ganho do controlador iria prejudicar a resposta para a primeira parte da simulação. Vale notar que o ganho do controlador utilizado foi reduzido em 93\% em relação ao ganho indicado por Ziegler-Nichols, que havia sido calibrado para a primeira etapa da simulação.

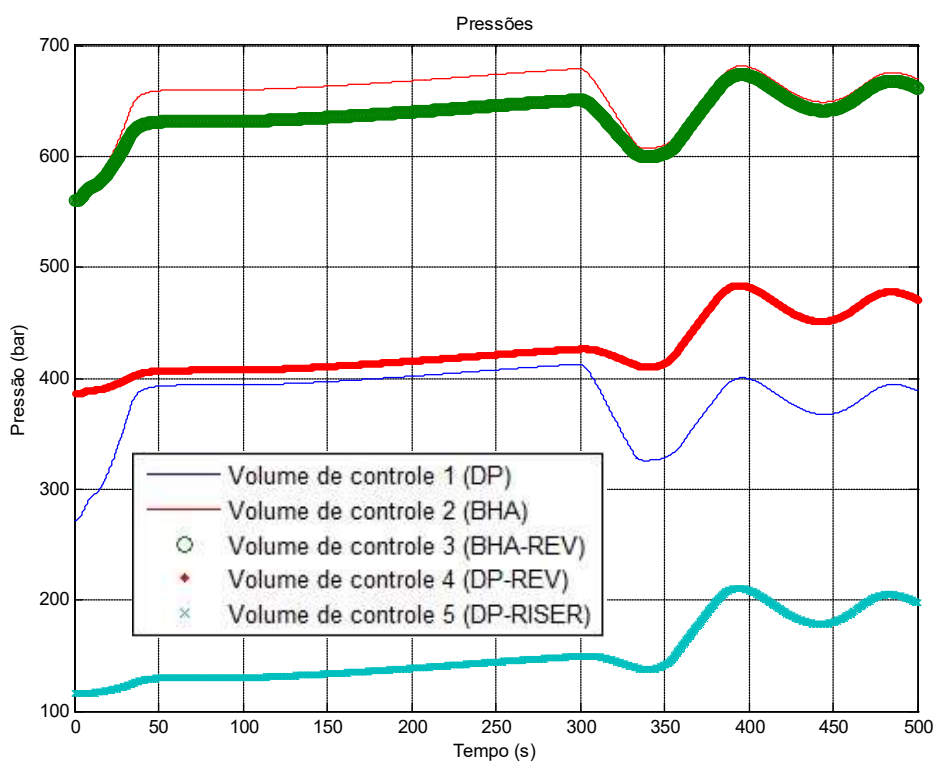

Figura 4.17 - Comportamento da pressão nos volumes de controle para um controlador $P \operatorname{com} k_{P}=2 \cdot 10^{-9}$.

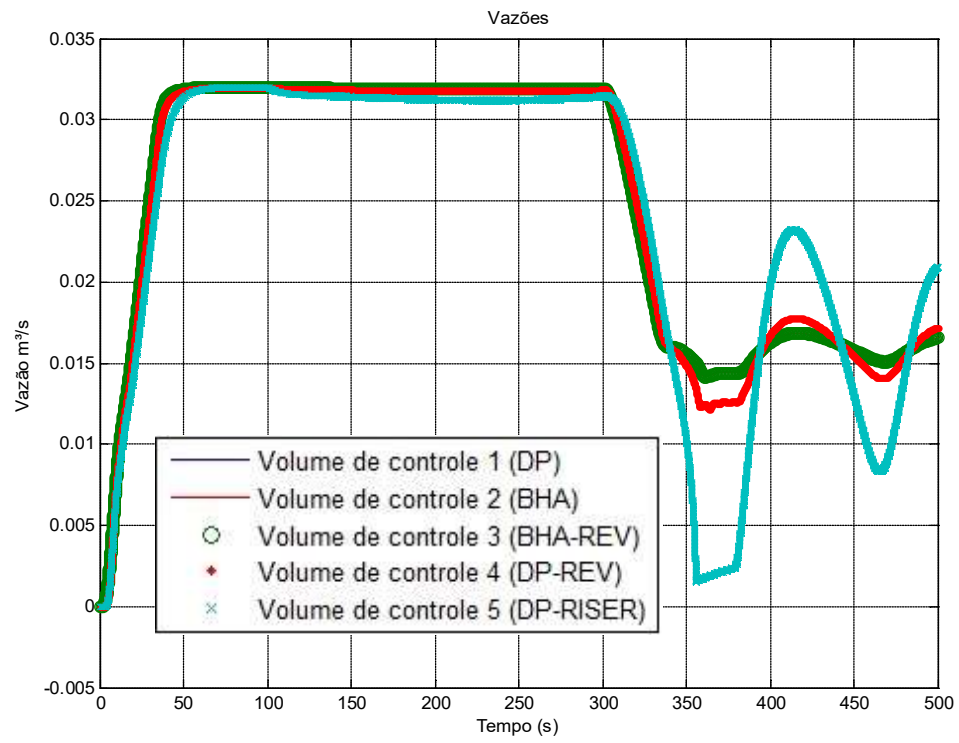

Figura 4.18 - Comportamento da vazão nos volumes de controle para um controlador $P \operatorname{com} k_{P}=2 \cdot 10^{-9}$. 


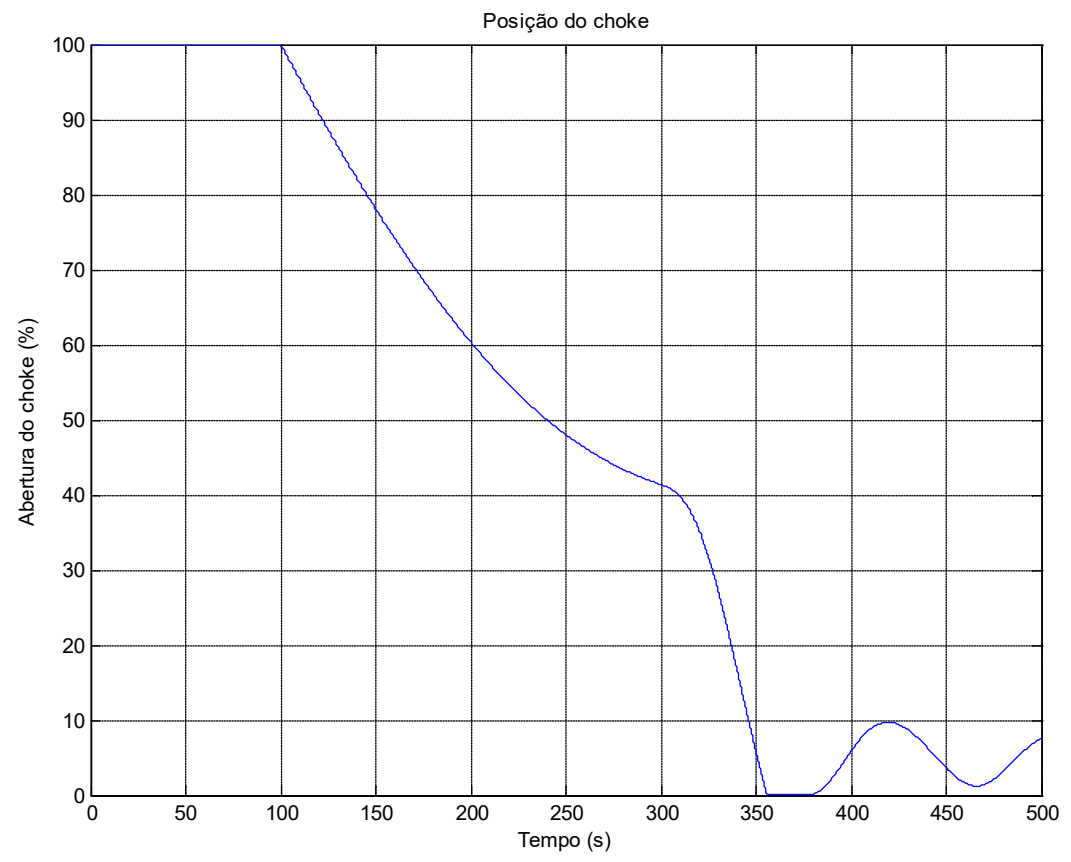

Figura 4.19 - Posição do choke para um controlador $P \operatorname{com} k_{P}=$ $\mathbf{2} \cdot 10^{-9}$

$\mathrm{O}$ ganho do controlador $\mathrm{P}$ serviu de partida para definição de ganho nos controladores PI, PD e PID. As figuras 4.20 a 4.28 das seções a seguir mostram o desempenho dos diversos controladores para o mesmo cenário de simulação. Vale observar que os ganhos foram obtidos empiricamente, uma vez que a linearização do sistema em diversas condições de operação resultaria em calibragens muito diferentes entre si segundo qualquer método linear.

\subsubsection{2.}

\section{Controlador PI}

Utilizando o valor de ganho proporcional da simulação anterior e a relação entre os ganhos do controlador proporcional e o controlador proporcional integrativo proposto por Ziegler-Nichols, foram buscados os ganhos do controlador PI. Mesmo com os novos valores, o controlador PI não se mostrou eficiente para manutenção da pressão no fundo, vide figuras 4.20 a 4.22. 


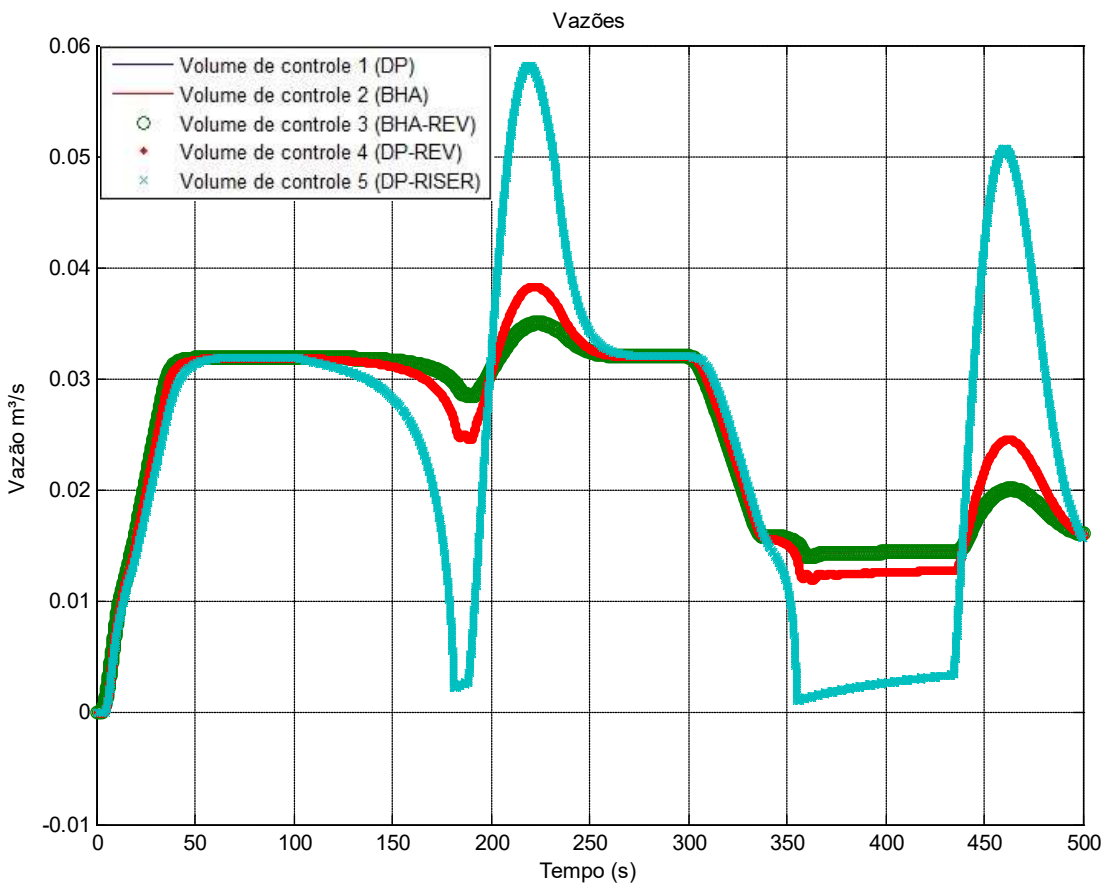

Figura 4.20 - Vazão nos vários volumes de controle para um controlador $P I \operatorname{com} k_{P}=1,8 \cdot 10^{-9}$ e $k_{I}=1,3 \cdot 10^{-10}$.

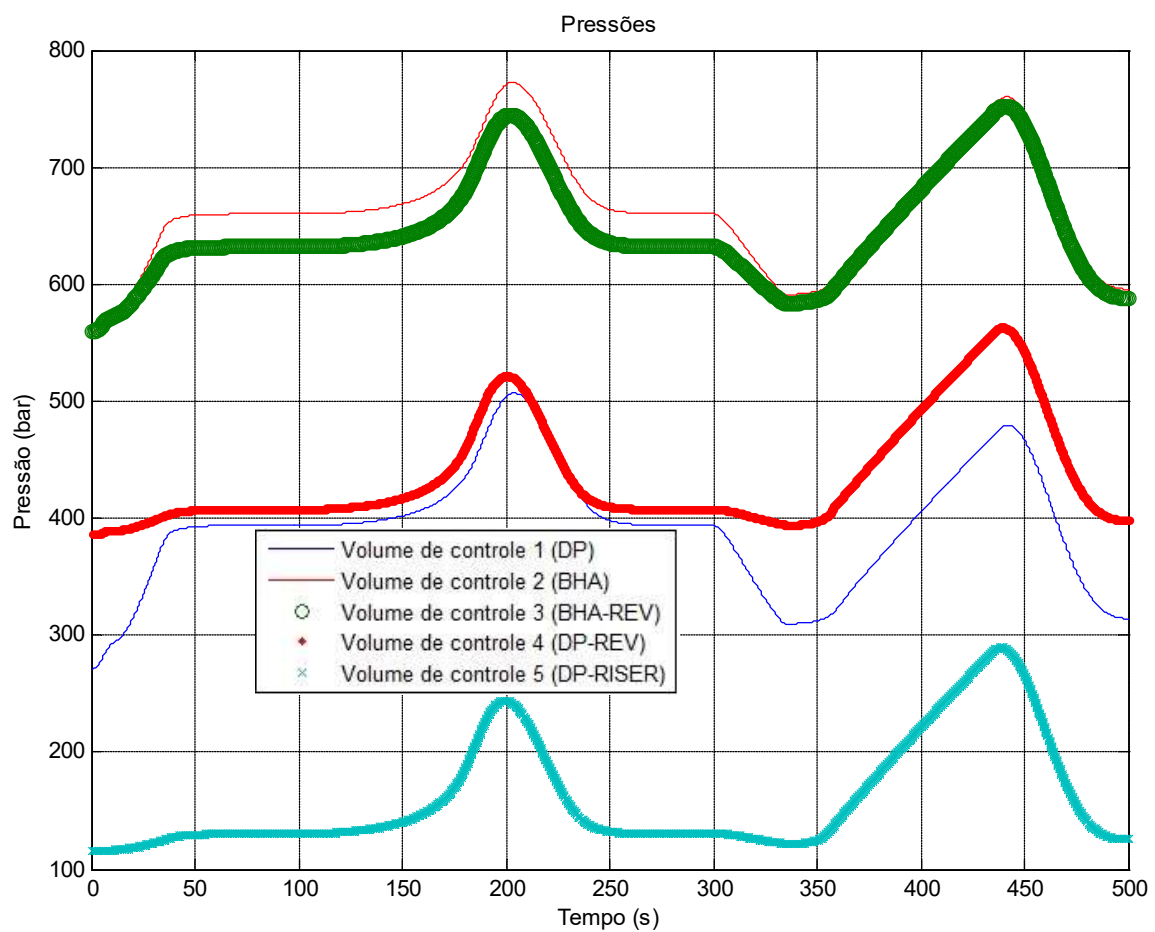

Figura 4.21 - Pressão nos vários volumes de controle para um controlador PI com $k_{P}=1,8 \cdot 10^{-9}$ e $k_{I}=1,3 \cdot 10^{-10}$. 


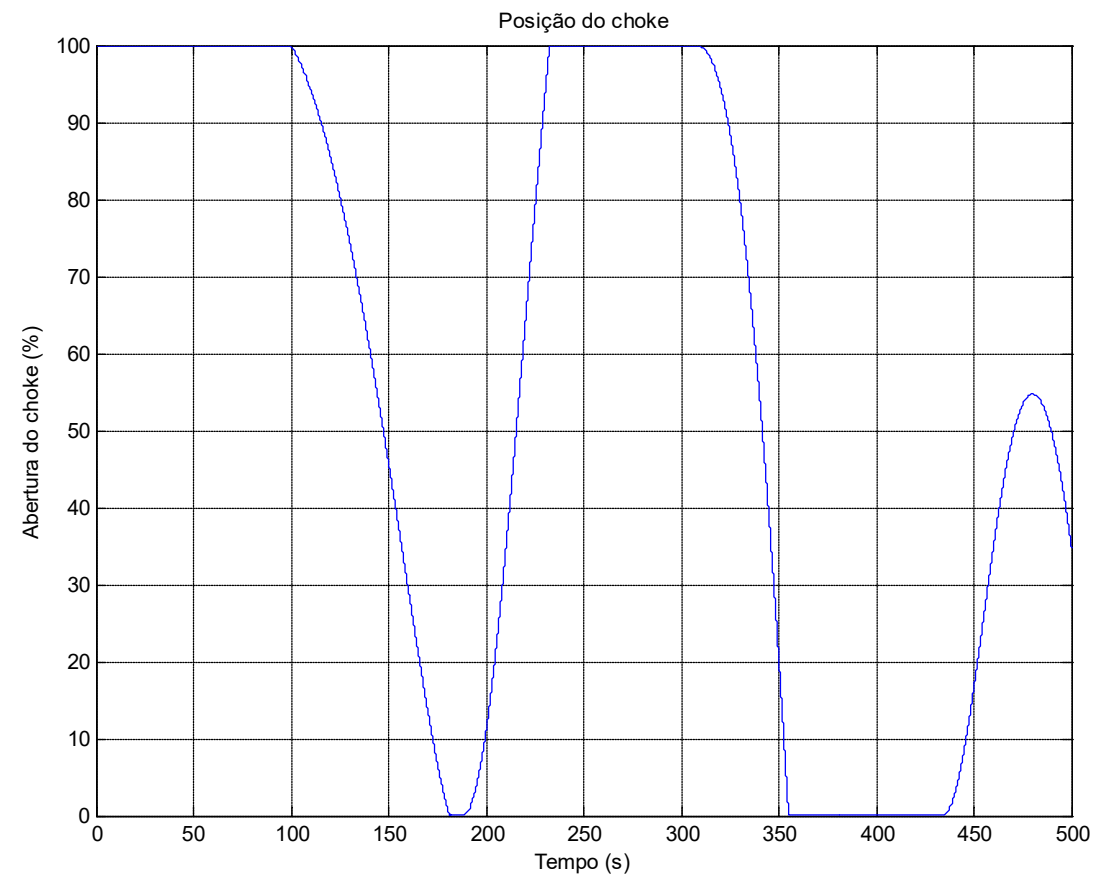

Figura 4.22 - Posição do choke para um controlador PI $\operatorname{com} k_{\mathrm{P}}=$ $1,8 \cdot 10^{-9}$ e $k_{I}=1,3 \cdot 10^{-10}$.

A atuação do controlador PI na primeira parte da simulação indica que o ganho proporcional se mostra lento na atuação do choke. Quando o valor do ganho integrativo passa a ter um maior impacto no controle, a movimentação do choke é acelerada gerando um sobre-sinal no controle da pressão no fundo. $\mathrm{Na}$ segunda parte da simulação, novamente o controlador tem uma resposta inicial lenta até a saturação do choke, fazendo com que a pressão na zona objetivo tenha variação superior àquela observada no controlador puramente proporcional. Foram realizadas algumas tentativas heurísticas para alteração dos ganhos, com o objetivo de se obter melhor velocidade na reposta, porém o ganho na velocidade do controlador PI acabava por acarretar em instabilidade, em especial na segunda parte da simulação.

\subsubsection{3.}

\section{Controlador PD}

Como terceira proposta de controlador, foi aplicado um PD no choke sobre o sistema para verificar o seu desempenho. Para referência inicial dos ganhos do controlador, também foi utilizada a relação entre o controlador puramente 
proporcional e os ganhos relativos dados pela metodologia de Ziegler-Nichols. Os resultados obtidos com o melhor par de ganhos, proporcional e derivativo, atendem ao objetivo principal do controlador, que é o controle da pressão com a do primeiro elemento anular do poço dentro do intervalo de tempo proposto.

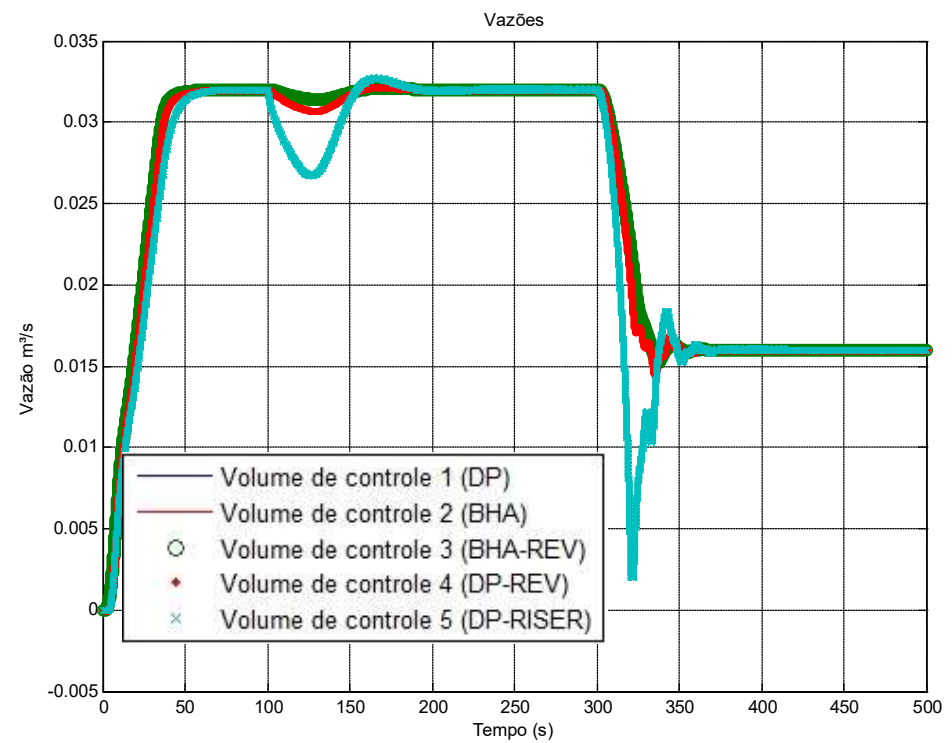

Figura 4.23 - Vazão nos vários volumes de controle para um controlador PD $\operatorname{com} k_{P}=1.5 \cdot 10^{-8}$ e $k_{D}=1 \cdot 10^{-7}$.

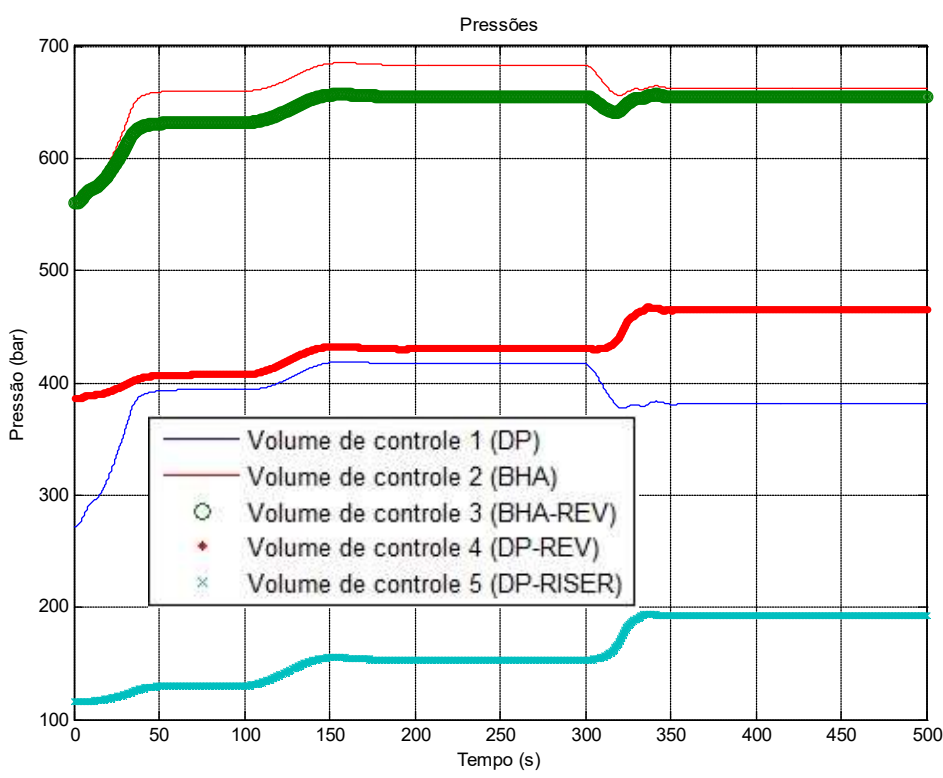

Figura 4.24 - Pressão nos vários volumes de controle para um controlador $P D \operatorname{com} k_{P}=1.5 \cdot 10^{-8}$ e $k_{D}=1 \cdot 10^{-7}$. 


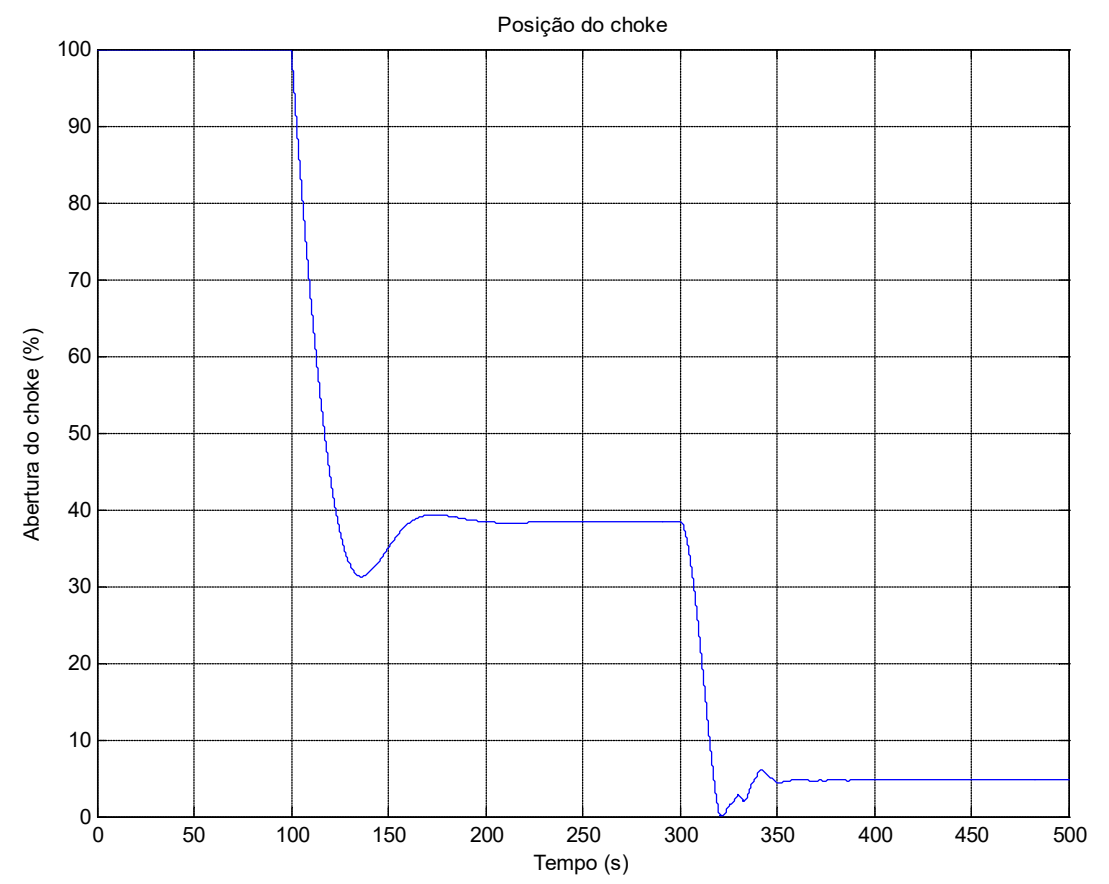

Figura 4.25 - Posição do choke para um controlador PD com $k_{P}=$ $1.5 \cdot 10^{-8}$ e $k_{D}=1 \cdot 10^{-7}$.

O tempo de subida de $42 \mathrm{~s}$ é adequado para uma aplicação real, onde um degrau de pressão de 25 bar usualmente é feito em maior tempo. O sobre-sinal de 1 bar e o tempo de acomodação de $70 \mathrm{~s}$ não impactariam a operação de perfuração em MPD. A simulação de diminuição da vazão obteve como resultado uma diminuição temporária da pressão no fundo do poço, indicando que a velocidade de atuação do controlador não consegue compensar a inércia do sistema com velocidade suficiente.

\subsubsection{4.}

\section{Controlador PID}

Em comparação com o controlador puramente proporcional e com o controlador proporcional integrativo, o controlador proporcional derivativo é que conseguiu melhores resultados. $\mathrm{O}$ controlador $\mathrm{PID}$, cujos resultados são mostrados nas figuras 4.26 a 4.28, conseguiu resultados próximos ao do PD, porém sem apresentar melhora significativa. Devido à ação derivativa, o ganho proporcional pode ser incrementado sem causar oscilações na resposta da pressão da zona de controle. Nas duas etapas da simulação, o controle conseguiu manter a 
pressão sem as oscilações verificadas nas simulações com os controladores P e PI. Como os controladores PID e PD atenderam ao primeiro objetivo de tempo e o controlador PID não apresentou melhora sobre o controlador PD, o controlador PD será considerado como controlador de referência para as demais simulações.

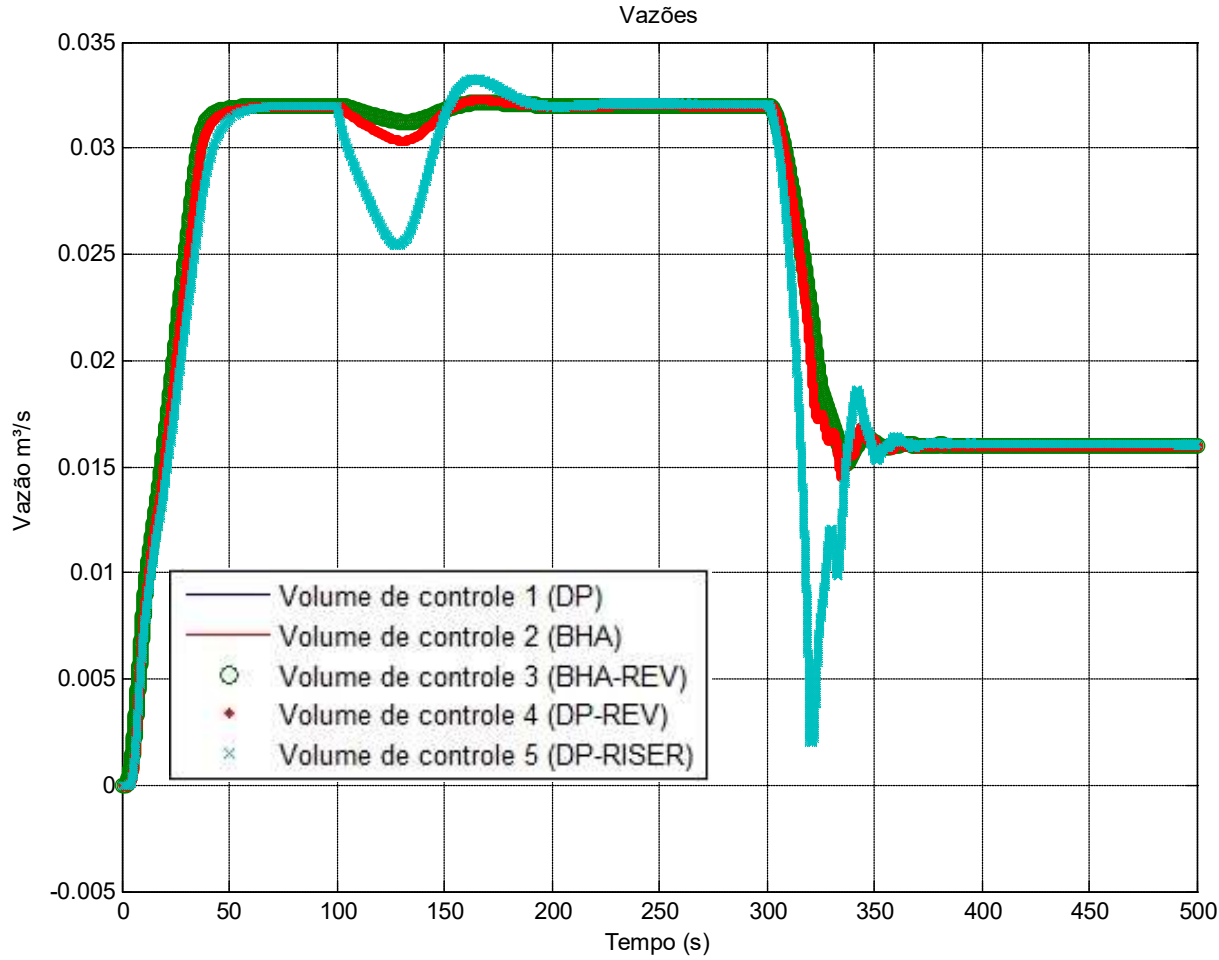

Figura 4.26 - Pressão nos vários volumes de controle para um controlador PID com $k_{P}=1 \cdot 5 \cdot 10^{-8}, k_{I}=1 \cdot 10^{-10}$ e $k_{D}=1 \cdot 10^{-7}$. 


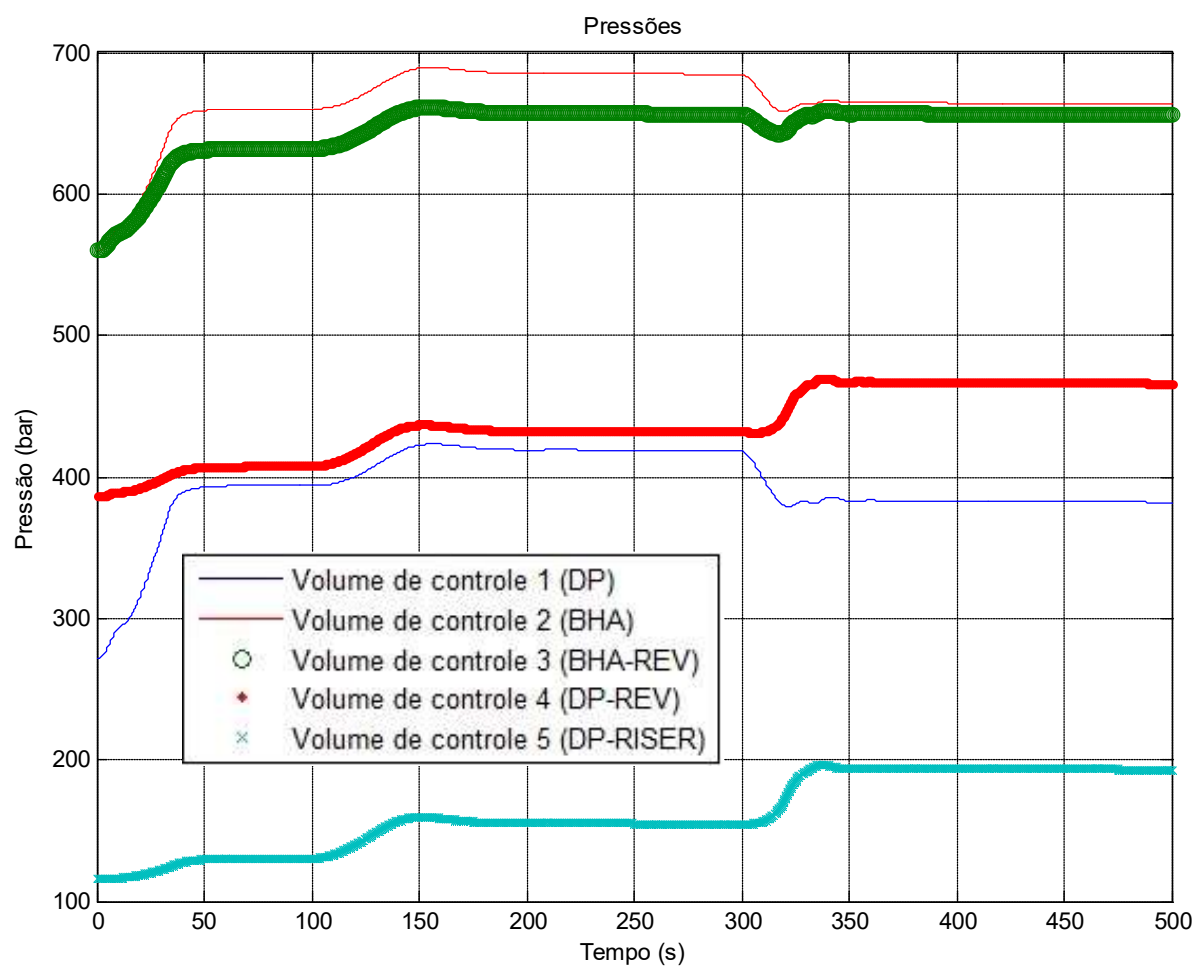

Figura 4.27 - Vazão nos vários volumes de controle para um controlador PID

$$
\operatorname{com} k_{P}=1 \cdot 5 \cdot 10^{-8}, k_{I}=1 \cdot 10^{-10} \text { e } k_{D}=1 \cdot 10^{-7} \text {. }
$$

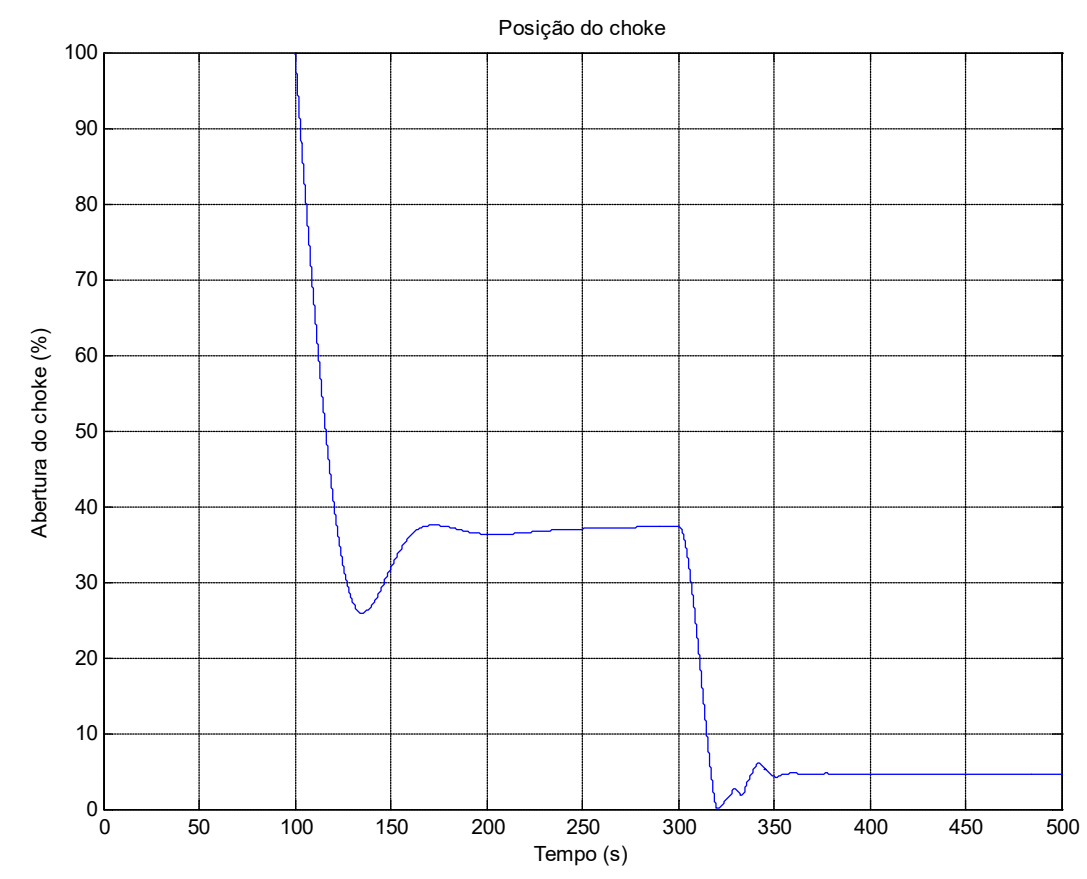

Figura 4.28 - Posição do choke para um controlador PID $\operatorname{com} \mathbf{k}_{\mathbf{P}}=$

$$
1.5 \cdot 10^{-8}, k_{I}=1 \cdot 10^{-10} \text { e } k_{D}=1 \cdot 10^{-7} \text {. }
$$




\section{2.}

\section{Mapa para o choke}

$\mathrm{Na}$ indústria automotiva atual os carros fazem uso da injeção eletrônica de combustível. A determinação do tempo de injeção de combustível dentro do cilindro do motor é feita com base em um mapa de injeção de combustível prédeterminado (Capelli, 2010). Na figura 4.29 o mapa de injeção eletrônica determina o tempo de injeção de combustível considerando a posição atual do acelerador e a rotação do motor.

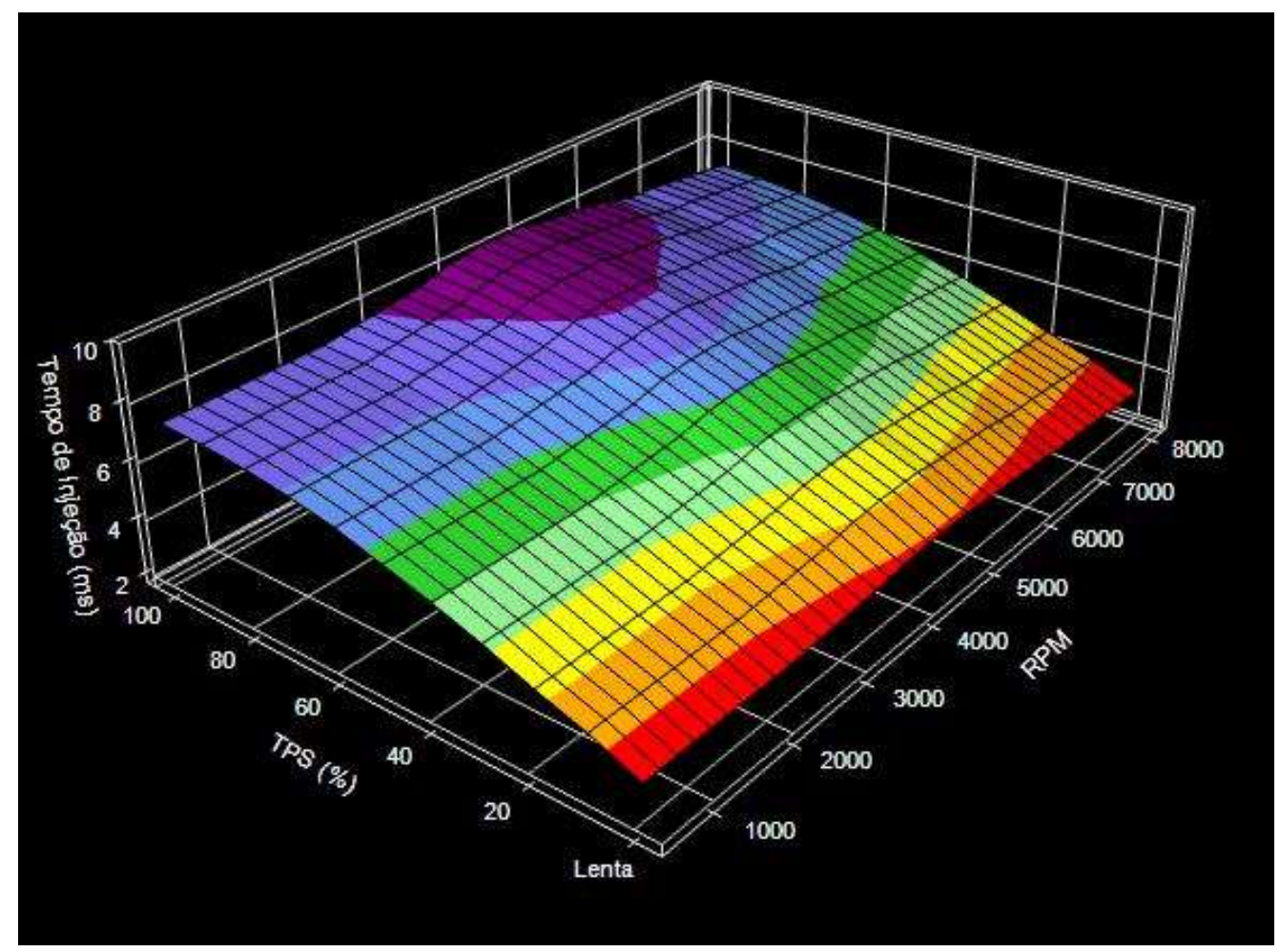

Figura 4.29 - Mapa de injeção de combustível de um carro.

A intenção do controlador mapa de choke é criar algo análogo ao mapa de injeção de um carro com injeção eletrônica, assumindo um comportamento em regime permanente. As condições de trabalho são previamente definidas para diversas situações, e aplicadas diretamente pelo controlador, não havendo necessidade de realizar cálculos da dinâmica interna do sistema durante a operação de controle.

Com objetivo de se verificar uma nova forma de controle, foi proposto utilizar um mapa para o choke. Esta ideia consiste em gerar um mapa de 3 variáveis: posição do choke, perda de carga localizada, e vazão. O controlador 
com mapa de choke deve considerar as condições do poço, incluindo dados de geometria e do fluido para determinação da perda de carga necessária no choke.

O controlador, com base no mapa feito previamente, busca a posição do choke necessária para atender a condição operacional solicitada. Como a atuação do controlador é na abertura do choke, as variáveis de entrada devem ser a vazão nele e sua perda de carga localizada. Para cálculo da pressão necessária no choke, a metodologia se baseia nas condições dinâmicas do poço. Como o mapa não é uma função, mas sim uma matriz de dados (100 por 100 nesta simulação), as variáveis de entrada vazão no choke e perda de carga necessária são interpoladas na matriz, o produto de saída é a posição do choke. Os dados da matriz foram levantados previamente, sendo referentes à posição do choke entre 1\% e 100\% com passo de $1 \%$ de abertura, e vazão de bombeio entre $2 \%$ e $200 \%$ com passo de $2 \%$ da vazão plena de bombeio da simulação. A figura 4.30 ilustra o mapa de choke desenvolvido para este trabalho.

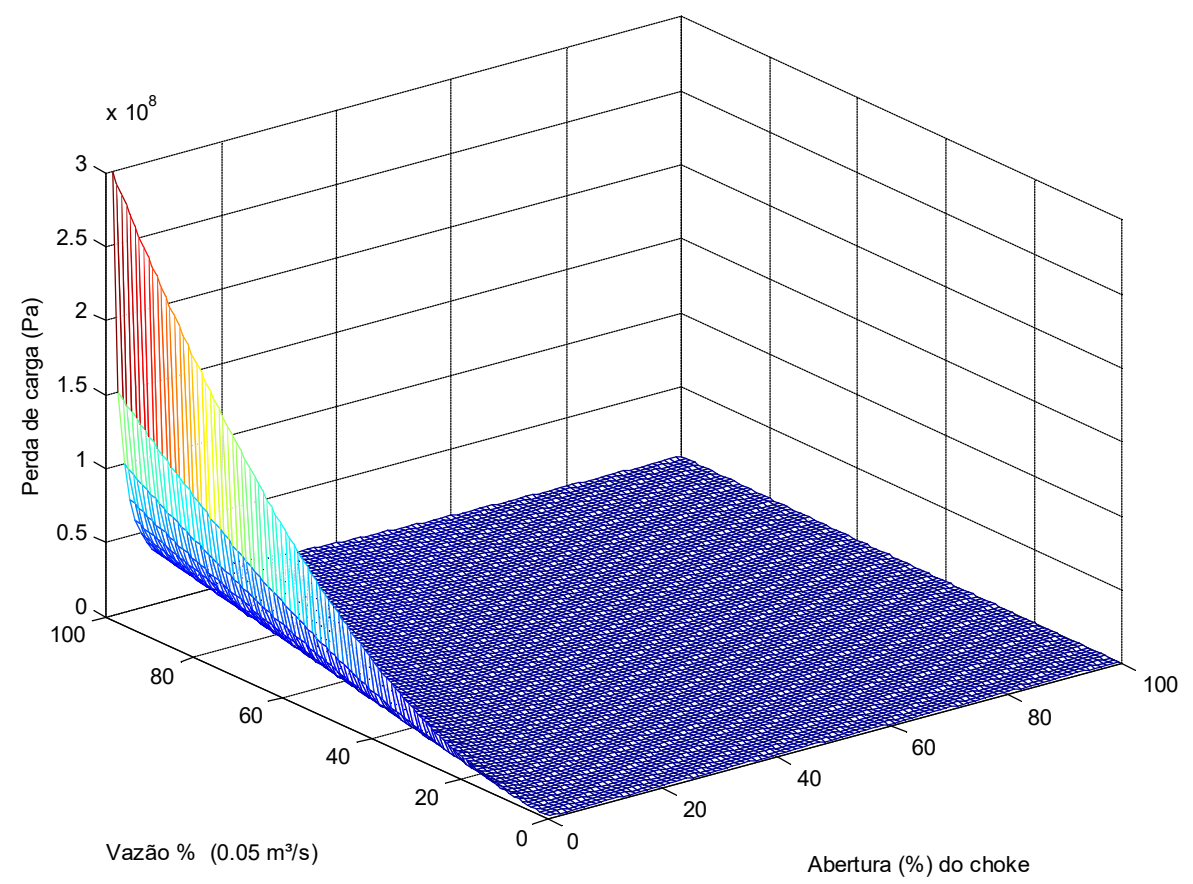

Figura 4.30 - Perda de carga localizada no choke em função da abertura e vazão - Mapa de choke. 
A taxa de variação do choke é feita na maior velocidade fisicamente possível no início da sua movimentação, com uma redução gradual da velocidade de abertura/fechamento ao se aproximar do ponto de referência (indicado pelo mapa do choke).

Para verificação da atuação do mapa de pressão, foi utilizada a simulação padrão para avaliação do controle, nas mesmas condições de geometria de poço e com as mesmas características de fluido. As figuras 4-31 a 4-33 mostram os resultados obtidos com um controle baseado em mapa de choke.

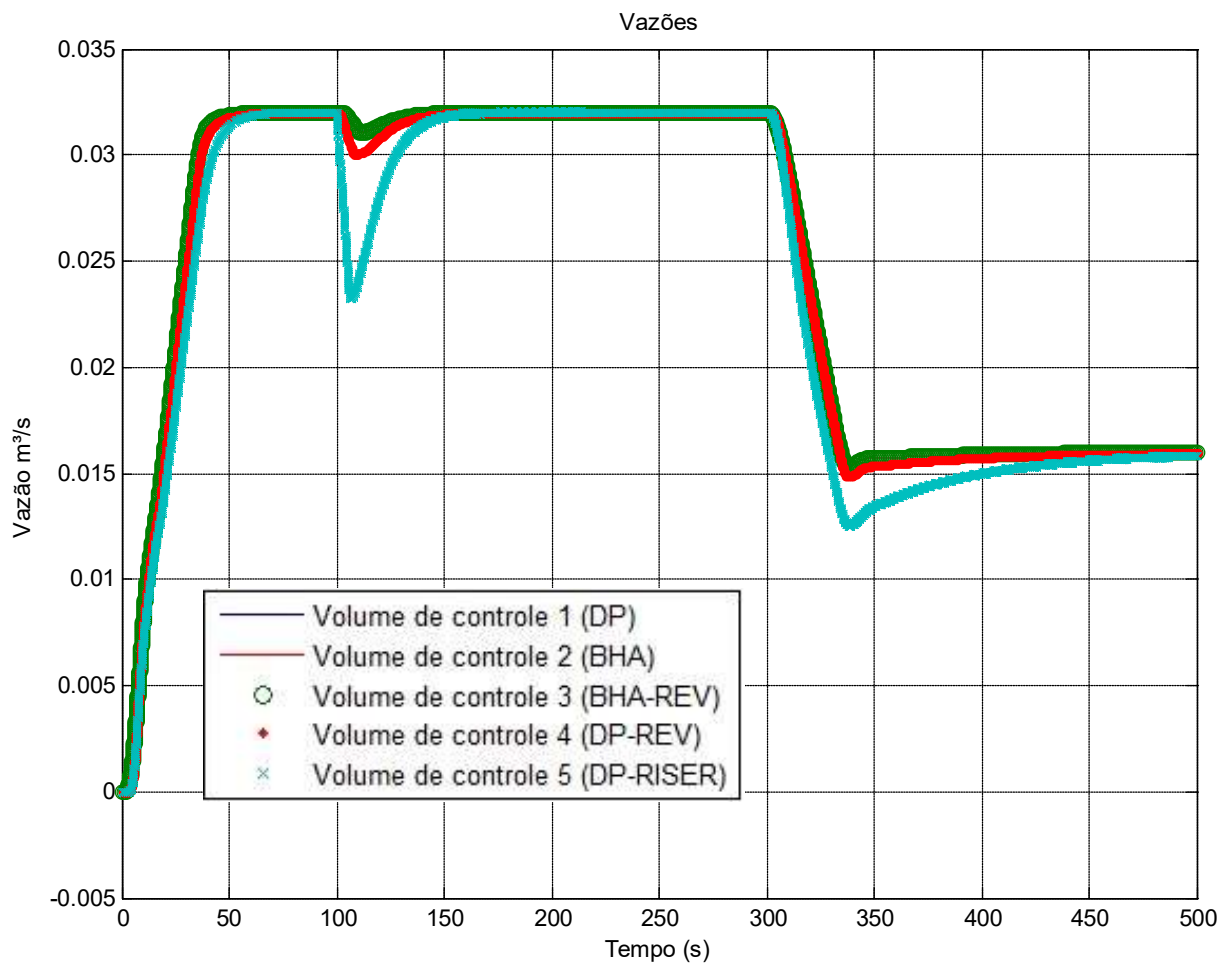

Figura 4.31 - Vazões para controlador com mapa de choke. 


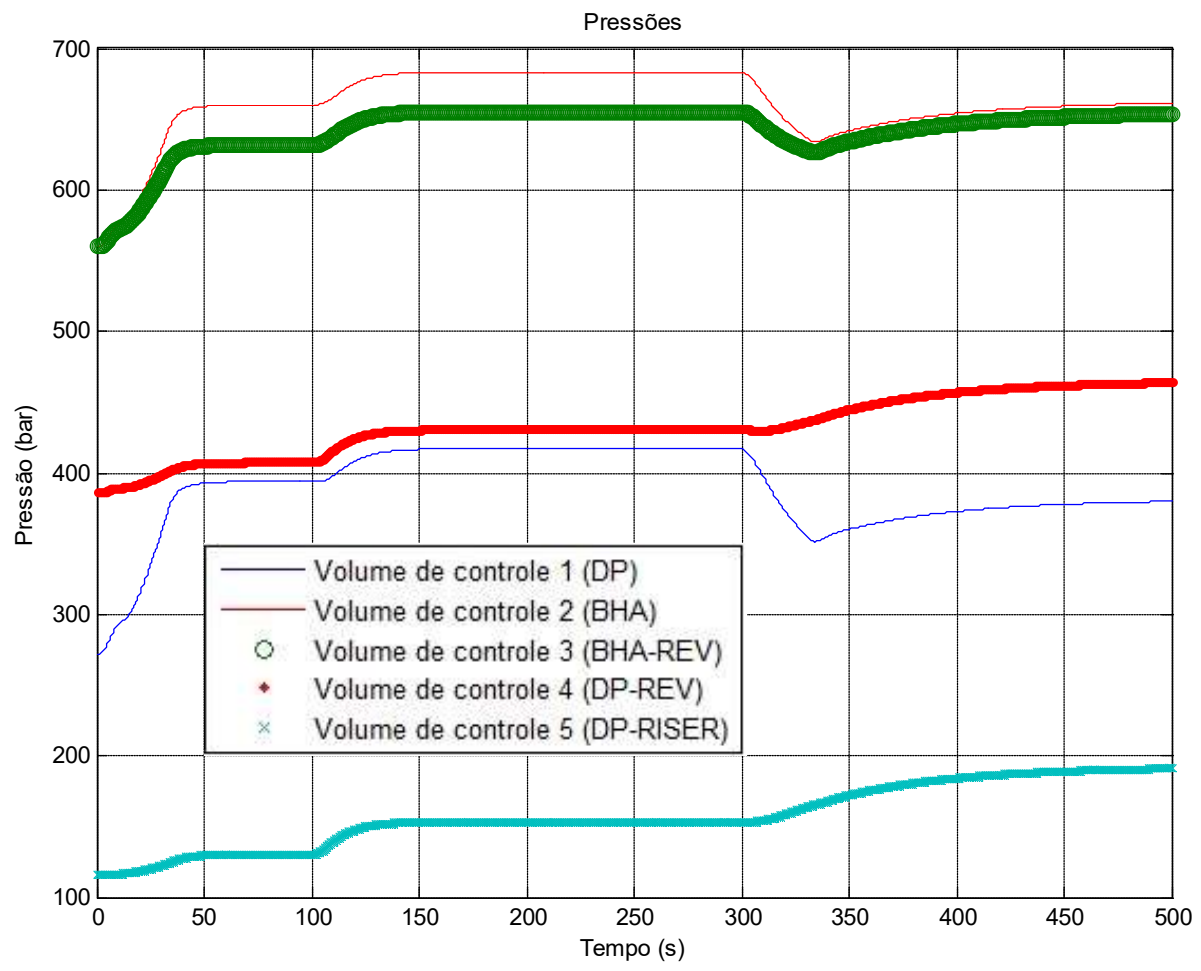

Figura 4.32 - Pressões para controlador com mapa de choke.

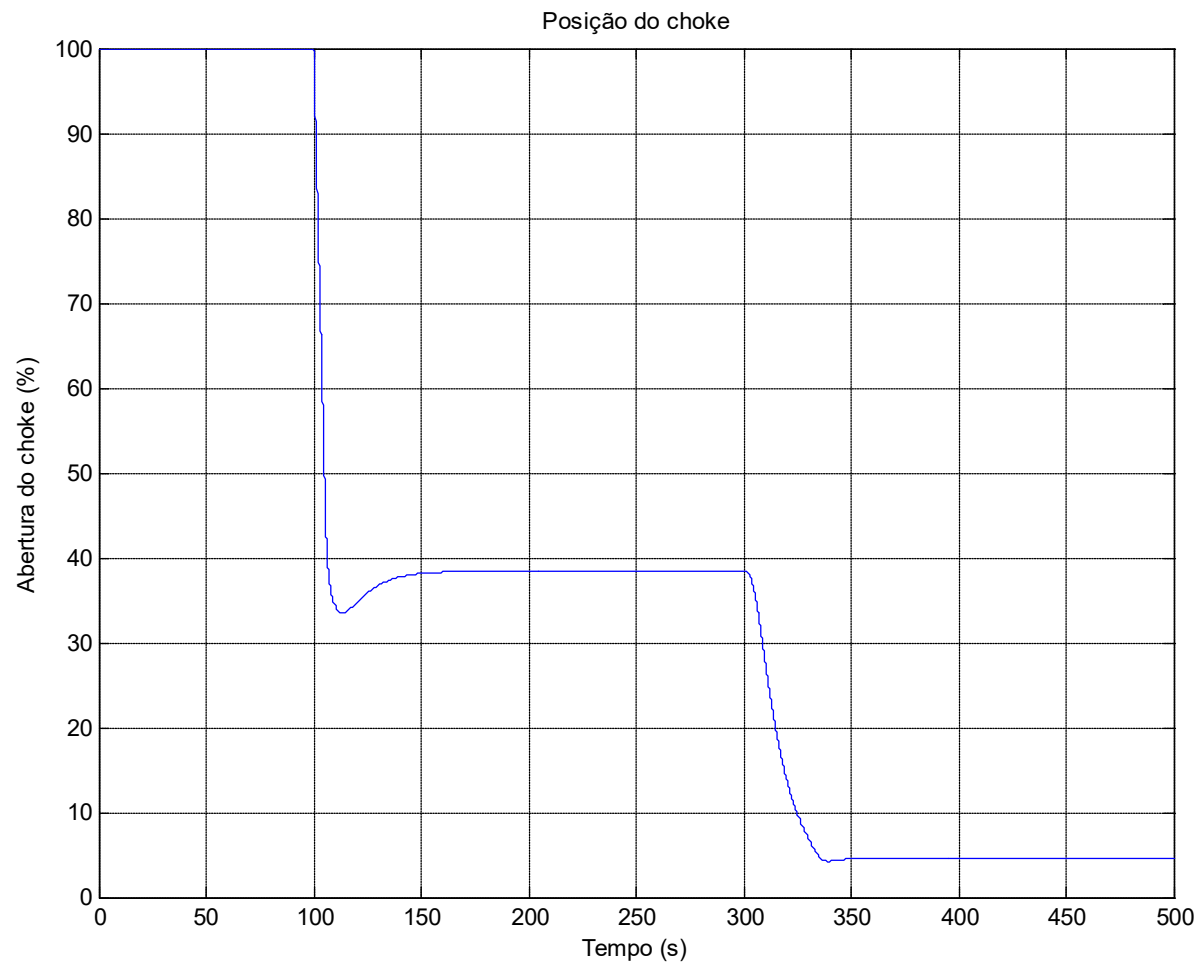

Figura 4.33 - Posição do choke para controlador com mapa de choke. 
Os resultados da simulação indicam um menor tempo de subida na pressão do volume de controle objetivo usando o controlador mapa de choke do que com o controlador de referência PD. A análise da posição do choke indica que ele foi quase diretamente para a posição de estabilização, havendo um pequeno sobresinal por conta da redução da vazão momentânea na saída do poço em decorrência de sua atuação. Para a segunda etapa da simulação, a resposta do controlador de mapa de choke foi mais lenta que do controlador PD de referência. Uma explicação para este fato é que o controlador de mapa de choke reage à inércia do sistema, ao contrário da primeira etapa de simulação (na qual foi aplicado um degrau de pressão). A demora na reação do sistema, i.e. na transmissão da pressão, faz o controlador atuar mais lentamente. Essa característica é indesejável para operação, visto que na conexão de novos drillpipes, para aprofundamento do poço, a vazão da coluna no poço tem que ser reduzida até zero e acelerada até a vazão de perfuração.

Uma limitação do controlador baseado em mapa de choke é que o mapa deve ser adequado e ajustado para cada operação de perfuração. Como é inviável testar previamente todos os fluidos de perfuração disponíveis, uma opção para viabilizar a operação seria testar o choke em diversas configurações de posição de abertura e vazão logo antes do início da perfuração da fase, como uma etapa de calibração. Este procedimento teria o inconveniente de gastar tempo da operação para calibração do sistema, e não poder gerar uma malha tão fina de dados, uma vez que o custo diário de uma sonda de perfuração offshore é da ordem de US\$500.000,00/dia (fonte: rigzone.com). Desse modo, este procedimento não seria recomendado.

Outro ponto de atenção de uso de um controlador de mapa de choke é que o mesmo seria calibrado para uma condição limpa do poço, ou seja, o fluido do poço se encontraria sem nenhum cascalho, ou pedaço de acessório do poço. Ao se iniciar a perfuração, a broca passa a gerar cascalhos que são transportados até a superfície. Os cascalhos gerados pela broca e por condições geomecânicas (pressão no poço acima ou abaixo dos limites de colapso do poço) possuem tamanhos variados, nem sempre de dimensões inferiores aos cortadores da broca. Cascalhos de tamanho excessivo podem interagir mecanicamente com o choke. Uma situação operacional comum é o entupimento parcial do choke com cascalho e eventuais pedaços de acessórios, como sapata, colar flutuante, e plug de 
cimentação, utilizados no poço. Para melhor lidar com estas perturbações, um controlador não linear seria muito mais eficiente, como discutido a seguir.

\section{3.}

Controlador Não Linear

Os resultados obtidos com o controlador PID e suas variantes indicam que uma abordagem linear para controle da pressão do fundo do poço com atuação no choke pode não ser a melhor solução. Um controlador que funcione com uma lógica não linear pode ter melhor resposta no controle da pressão no fundo em várias situações operacionais do poço, sem a necessidade de uso de ganhos escalonados ou um mapa de choke, cuja calibragem possui altos custos associados, como discutido anteriormente.

A análise do modelo hidráulico do sistema poço-MPD indica que o mesmo é um sistema não linear. Dos 3 componentes que descrevem a equação (2.2) para pressão no fundo, somente a pressão hidrostática pode ser determinada de maneira linear. A perda de carga no anular é definida após uma série de cálculos, que dependem do regime de fluxo do fluido em cada região do poço.

O modelo de choke desenvolvido para este simulador tem a perda de carga definida pela equação (2.31). Conforme pode ser verificado, diversas variáveis da equação, que são dependentes das variáveis de entrada do problema (vazão das bombas de lama e posição do choke) não são lineares. O coeficiente de descarga, $\alpha_{d}$, e a abertura do choke, $A$, são diretamente relacionáveis com a sua abertura.

Ao todo são feitas neste trabalho cinco abordagens de controle não linear. $\mathrm{O}$ controle não linear se baseia na compensação de um fator não linear definido sobre o controlador PD de referência. Foi assumido o controlador PD como referência devido aos resultados obtidos anteriormente. Como um fator de compensação é aplicado nesta formulação, é necessário alterar os ganhos proporcional e derivativo do controlador de referência por um valor médio de cada fator a ser compensado. A equação (4.4) mostra a forma de aplicação original dos ganhos do controlador, e a equação (4.5) mostra a forma alterada de ganho do controlador não linear.

$$
\dot{A}=K_{P} e(t)+K_{D} \frac{d}{d t} e(t)
$$




$$
\dot{A}=\left(K_{P} e(t)+K_{D} \frac{d}{d t} e(t)\right) * \frac{F A T O R}{F_{\text {FATOR }} \text { MÉDIO }}
$$

onde $\dot{A}$ é a variação da abertura do choke, $K_{P}$ o ganho proporcional, $K_{D}$ o ganho derivativo, e $e(t)$ o erro da variável selecionada com o valor de referência. FATOR é o fator a ser usado para correção do ganho, enquanto FATOR ${ }_{M E ́ D I O}$ é a correção média do ganho pelo valor médio do fator de correção a ser utilizado. Essa correção é necessária para não alterar a reposta do controlador quando o fator de correção for diferente da unidade, i.e. para normalizar a correção do controlador. A correção permite avaliar a resposta do controlador para as mesmas condições do PD de referência adotado.

A primeira abordagem do controlador não linear é uma compensação pelo quadrado do coeficiente de descarga e abertura. Juntamente com a equação (4.2), verifica-se que é necessário compensar os ganhos do controlador com o quadrado da abertura e do coeficiente de descarga. O coeficiente de descarga, para as faixas de vazão simuladas (operação de perfuração e conexão), possui um valor médio de 0,05 , enquanto a abertura média considerada (A) é de 0,25 , com base na posição do choke original. Com isso, os ganhos do controlador PD foram alterados pelo inverso de 0,00015625 , e são multiplicados pelos valores do quadrado do coeficiente de descarga e da abertura do choke do momento, normalizando assim o fator não linear de correção do controlador. Para cada abordagem de controle não linear, é necessário ajustar os ganhos do controlador PD com os valores médios considerados para promover esta normalização. A tabela 4.2 mostra os ganhos utilizados para cada abordagem de controle não linear feita, incluindo suas respectivas normalizações pelos FATOR $R_{M E ́ D I O}$ de cada formulação. As cinco abordagens não lineares são descritas nas seções a seguir. 
Tabela 4-2 - Equações e fatores dos controladores não lineares.

\begin{tabular}{|c|c|c|c|}
\hline Fator & $\begin{array}{l}K_{P} \\
/ F A T O R_{M E ́ D I O}\end{array}$ & $\begin{array}{l}K_{D} \\
/ F A T O R_{M E ́ D I O}\end{array}$ & $\dot{A}$ \\
\hline $\begin{array}{c}\text { PD } \\
\text { Original }\end{array}$ & $1,5 e-08$ & $1 \mathrm{e}-07$ & $K_{P} e(t)+K_{D} \frac{d}{d t} e(t)$ \\
\hline$\alpha_{D}^{2} A^{2}$ & $9,6 \mathrm{e}-05$ & $6,4 \mathrm{e}-04$ & $\left(K_{P} e(t)+K_{D} \frac{d}{d t} e(t)\right) * \frac{\alpha_{D}^{2} A^{2}}{\overline{\alpha_{D}^{2}} \overline{A^{2}}}$ \\
\hline$\alpha_{D}^{2} A$ & $2,4 \mathrm{e}-05$ & $1,6 \mathrm{e}-04$ & $\left(K_{P} e(t)+K_{D} \frac{d}{d t} e(t)\right) * \frac{\alpha_{D}^{2} A}{\overline{\alpha_{D}^{2}} \bar{A}}$ \\
\hline$\alpha_{D}^{2}$ & $6,0 \mathrm{e}-06$ & $4,0 \mathrm{e}-05$ & $\left(K_{P} e(t)+K_{D} \frac{d}{d t} e(t)\right) * \frac{\alpha_{D}^{2}}{\overline{\alpha_{D}^{2}}}$ \\
\hline $8^{*} \alpha_{D}^{2}$ & $4,8 \mathrm{e}-05$ & $3,2 \mathrm{e}-04$ & $\left(K_{P} e(t)+K_{D} \frac{d}{d t} e(t)\right) * \frac{\alpha_{D}^{2}}{\overline{\alpha_{D}^{2}}}$ \\
\hline$\alpha_{D} A$ & $1,2 \mathrm{e}-06$ & $8,0 \mathrm{e}-06$ & $\left(K_{P} e(t)+K_{D} \frac{d}{d t} e(t)\right) * \frac{\alpha_{D} A}{\overline{\alpha_{D}} \bar{A}}$ \\
\hline $3 * \alpha_{D} A$ & $3,6 \mathrm{e}-06$ & $2,4 \mathrm{e}-05$ & $\left(K_{P} e(t)+K_{D} \frac{d}{d t} e(t)\right) * \frac{\alpha_{D} A}{\overline{\alpha_{D}} \bar{A}}$ \\
\hline$A$ & $6,0 \mathrm{e}-08$ & $4,0 \mathrm{e}-07$ & $\left(K_{P} e(t)+K_{D} \frac{d}{d t} e(t)\right) * \frac{A}{\bar{A}}$ \\
\hline $5 * A$ & $3,0 \mathrm{e}-07$ & $2,0 \mathrm{e}-06$ & $\left(K_{P} e(t)+K_{D} \frac{d}{d t} e(t)\right) * \frac{A}{\bar{A}}$ \\
\hline
\end{tabular}

\subsection{1.}

Controlador NL compensado por $\alpha_{D}^{2} A^{2}$

Como abordagem inicial para compensação da não linearidade do sistema, o foco foi dado para o choke MPD. A primeira maneira de se compensar o ganho do controlador é o cancelamento do impacto da abertura do choke e do coeficiente de descarga. Com esta ação, é esperado com a compensação por estes termos que a resposta do controlador seja linearizada. A intenção é que a compensação deixe o 
desempenho do controlador independente da posição do choke e de seu coeficiente de descarga.

As figuras 4.34 a 4.36 mostram uma simulação com controle PD compensado com o quadrado do coeficiente de descarga e da abertura do choke.

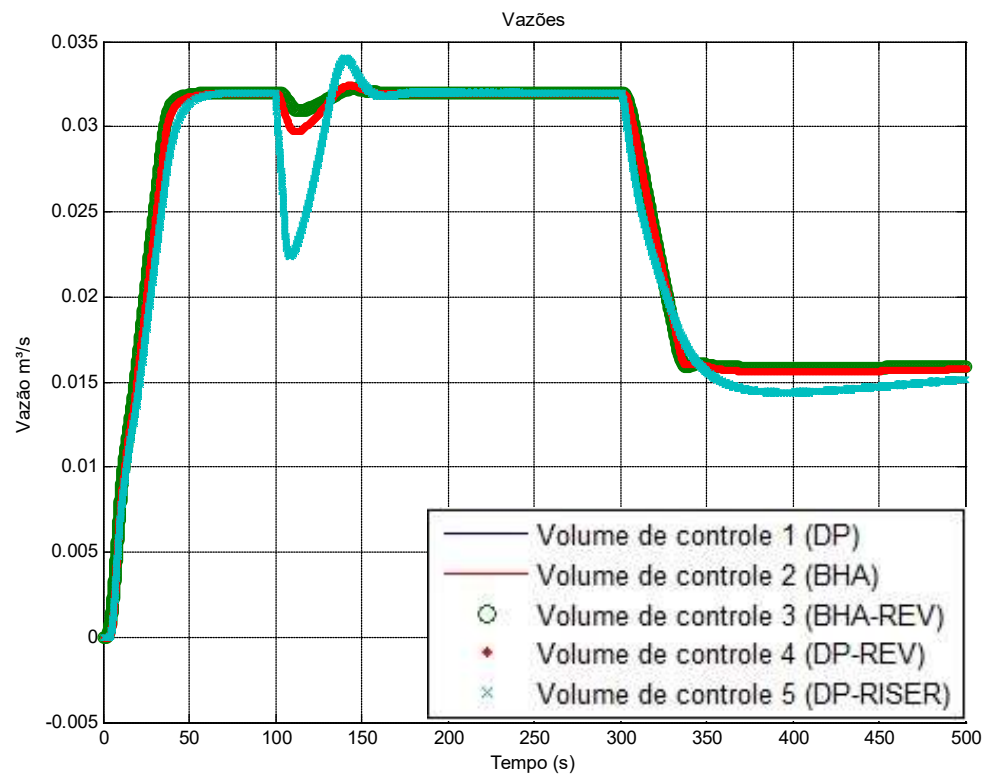

Figura 4.34 - Vazões nos vários volumes de controle para um controlador NL compensado por $\alpha_{\mathrm{D}}^{2} A^{2}$.

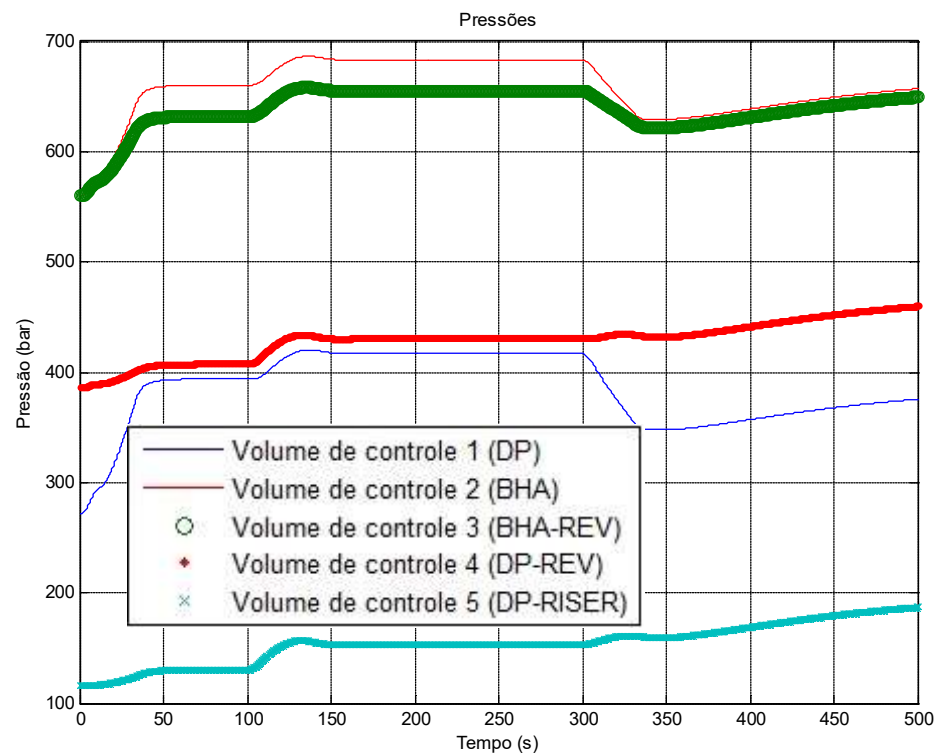

Figura 4.35 - Pressões nos vários volumes de controle para um controlador NL compensado por $\alpha_{D}^{2} A^{2}$. 


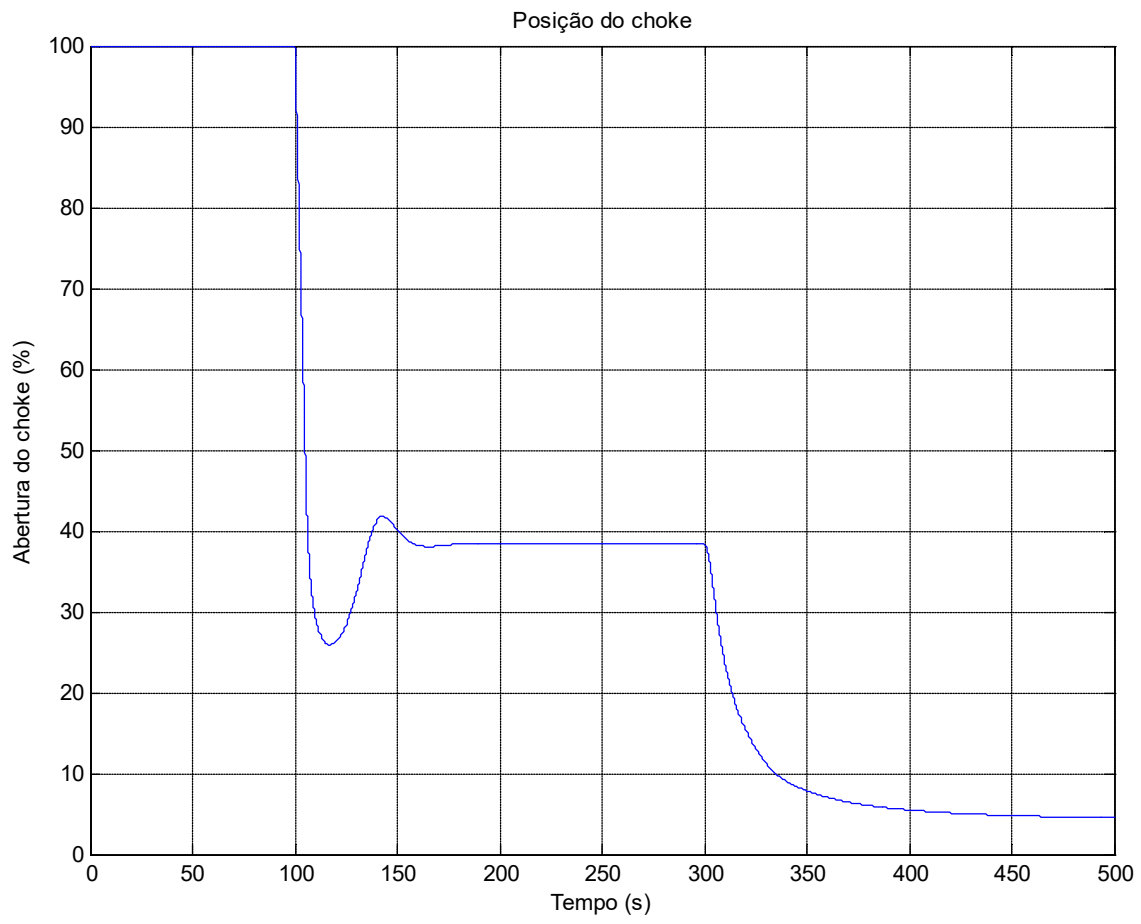

Figura 4.36 - Posição do choke para um controlador NL compensado $\operatorname{por} \alpha_{D}^{2} A^{2}$.

Os resultados indicam que o controlador NL obteve uma resposta semelhante ao controlador PD para a primeira etapa de simulação, porém uma resposta mais lenta para a segunda etapa. Como na segunda etapa da simulação o choke se fecha até $5 \%$, a compensação no ganho do controlador será 25 vezes maior do que a compensação média. Nesta situação, o ganho do controlador fica atenuado, provocando uma maior queda na pressão e um maior tempo para controle de pressão adequado no volume de controle BHA-Revestimento. O desempenho apresentado por esta opção de controle não linear se mostra inferior ao controle PD.

\subsection{2.}

\section{Controlador NL compensado por $\alpha_{D}^{2} A$}

Uma segunda abordagem para controle não linear foi a consideração somente do coeficiente de descarga como termo quadrático, e o termo de abertura de choke como linear. Os ganhos do controlador PD foram alterados com relação à primeira abordagem de forma a compensar a diferença entre o termo médio 
quadrático e linear da abertura do choke, normalizando o fator de correção não linear (NL) e permitindo uma comparação direta (e justa) com o controle linear PD de referência. As figuras 4.37 a 4.39 mostram os resultados da simulação.

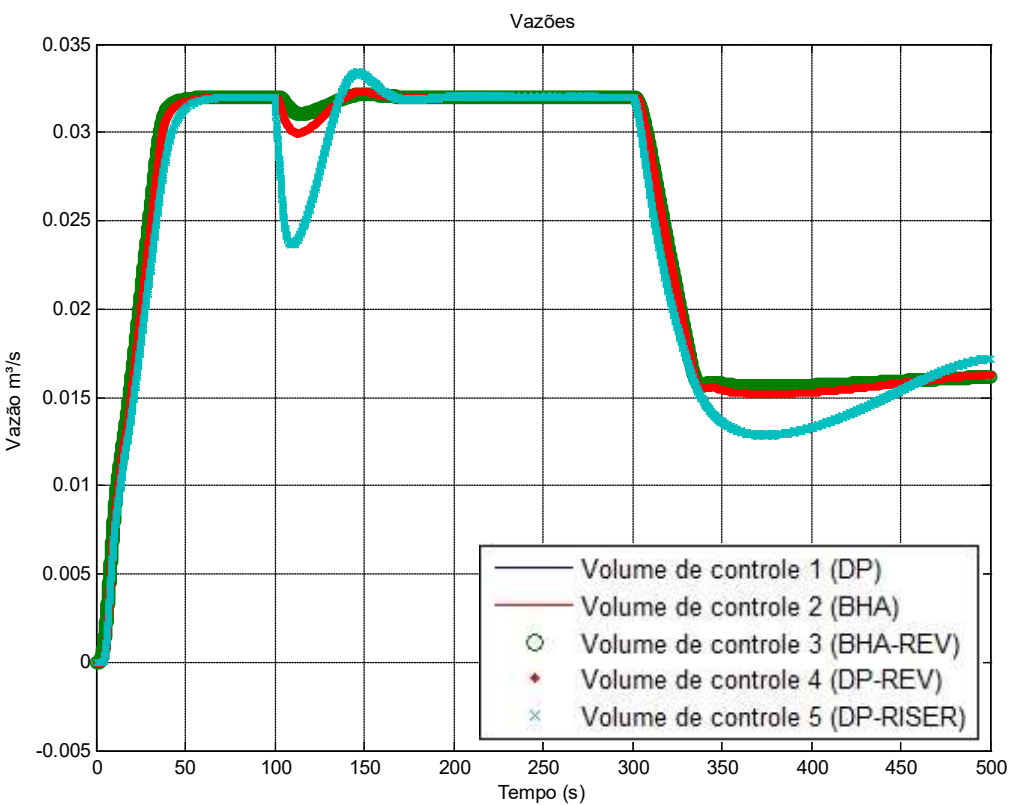

Figura 4.37 - Vazões nos vários volumes de controle para um controlador NL compensado por $\alpha_{D}^{2} A$.

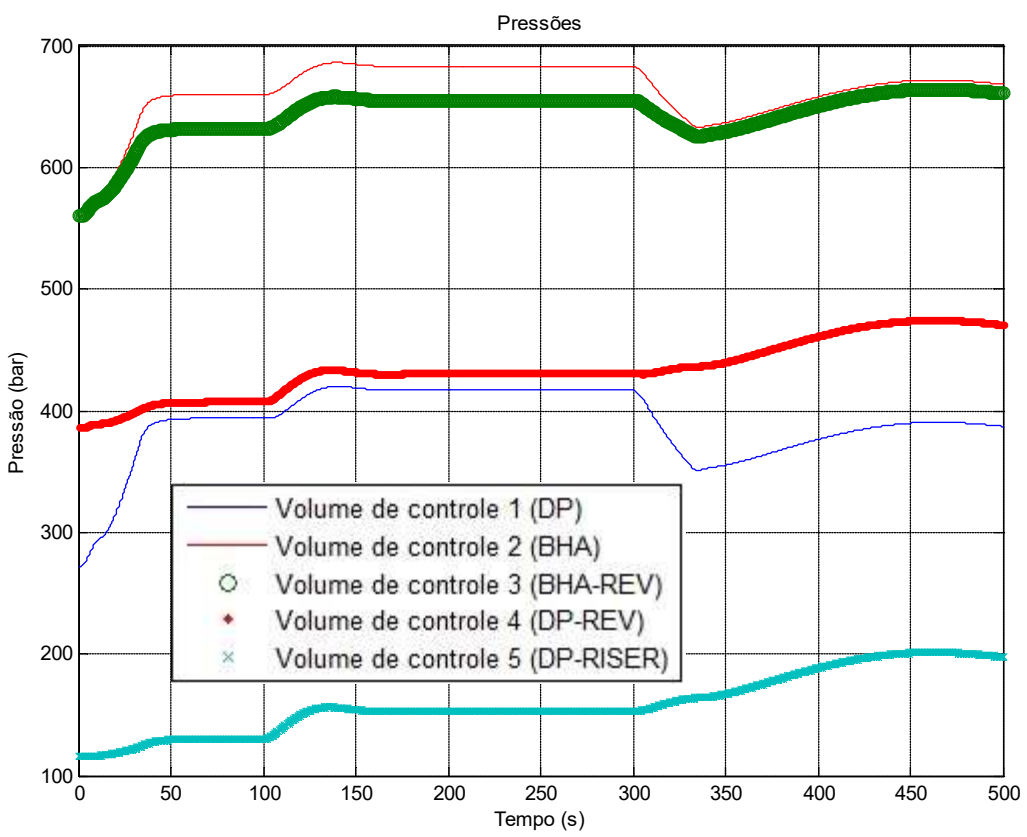

Figura 4.38 - Pressões nos vários volumes de controle para um controlador NL compensado por $\alpha_{D}^{2} A$. 


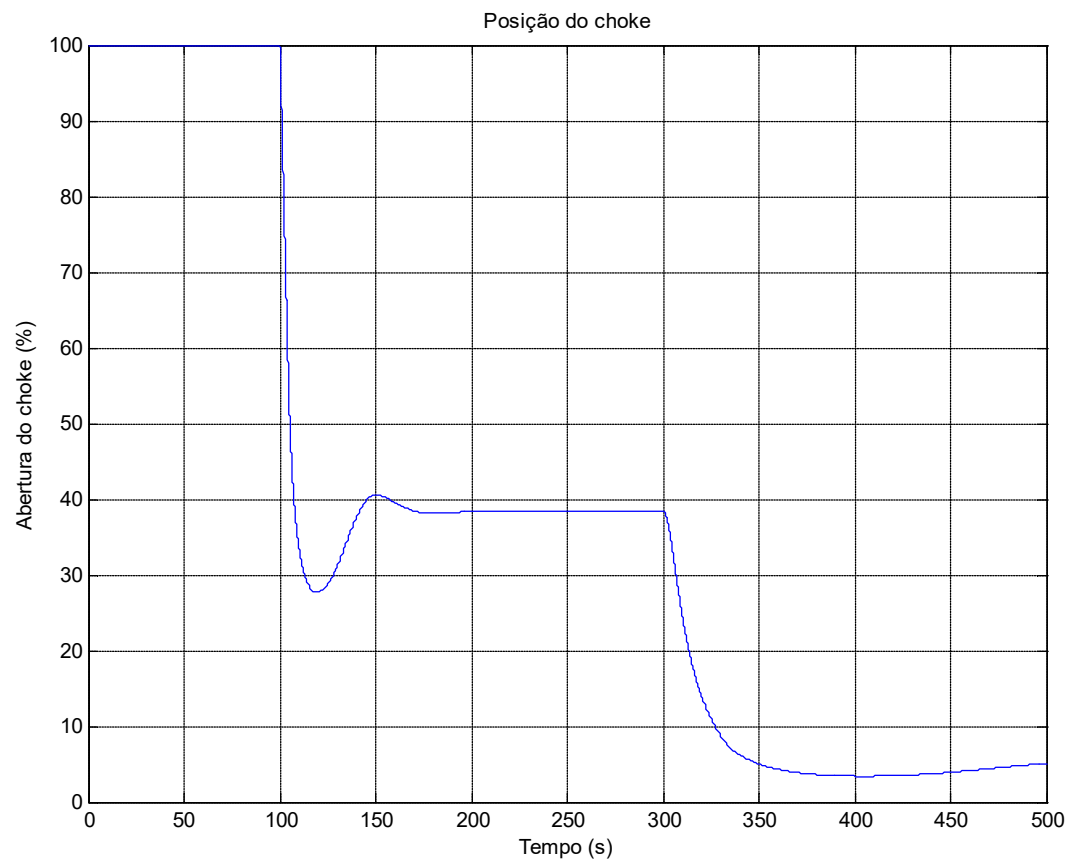

\section{Figura 4.39 - Posição do choke para um controlador NL compensado por $\alpha_{D}^{2} A$.}

Com relação ao primeiro controlador NL, verifica-se uma melhora no tempo da resposta da segunda etapa da simulação, pois a pressão no volume de controle objetivo (BHA-revestimento) tem um desvio da pressão de referência em um menor intervalo de tempo. Em relação ao controlador PD, a resposta verificada é mais lenta, indicando que uma nova abordagem deveria ser feita.

Foram feitas simulações para os controladores não lineares (NL) compensados por $\alpha_{D}^{2} A^{2}$ e $\alpha_{D}^{2} A$ com ganhos ampliados do controlador PD, porém os resultados não apresentam melhora significativa com relação às simulações anteriores.

\subsection{3.}

\section{Controlador NL compensado por $\alpha_{D}^{2}$}

A terceira abordagem considerou somente o coeficiente de descarga. De forma semelhante às outras abordagens, os ganhos do controlador foram ajustados para o coeficiente de descarga médio considerado. A simulação feita segue nas figuras 4.40 a 4.42 . 


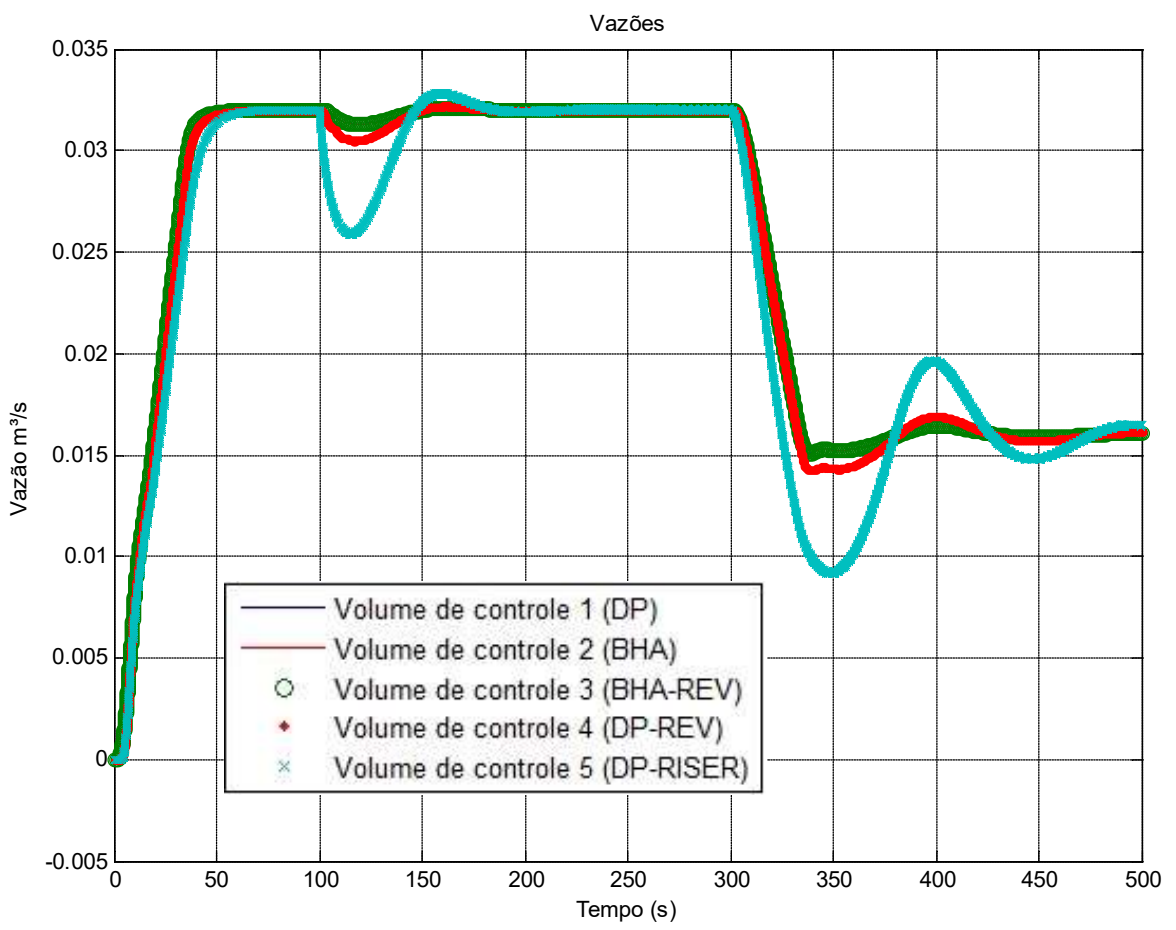

Figura 4.40 - Vazões nos vários volumes de controle para um controlador NL compensado por $\alpha_{D}^{2}$.

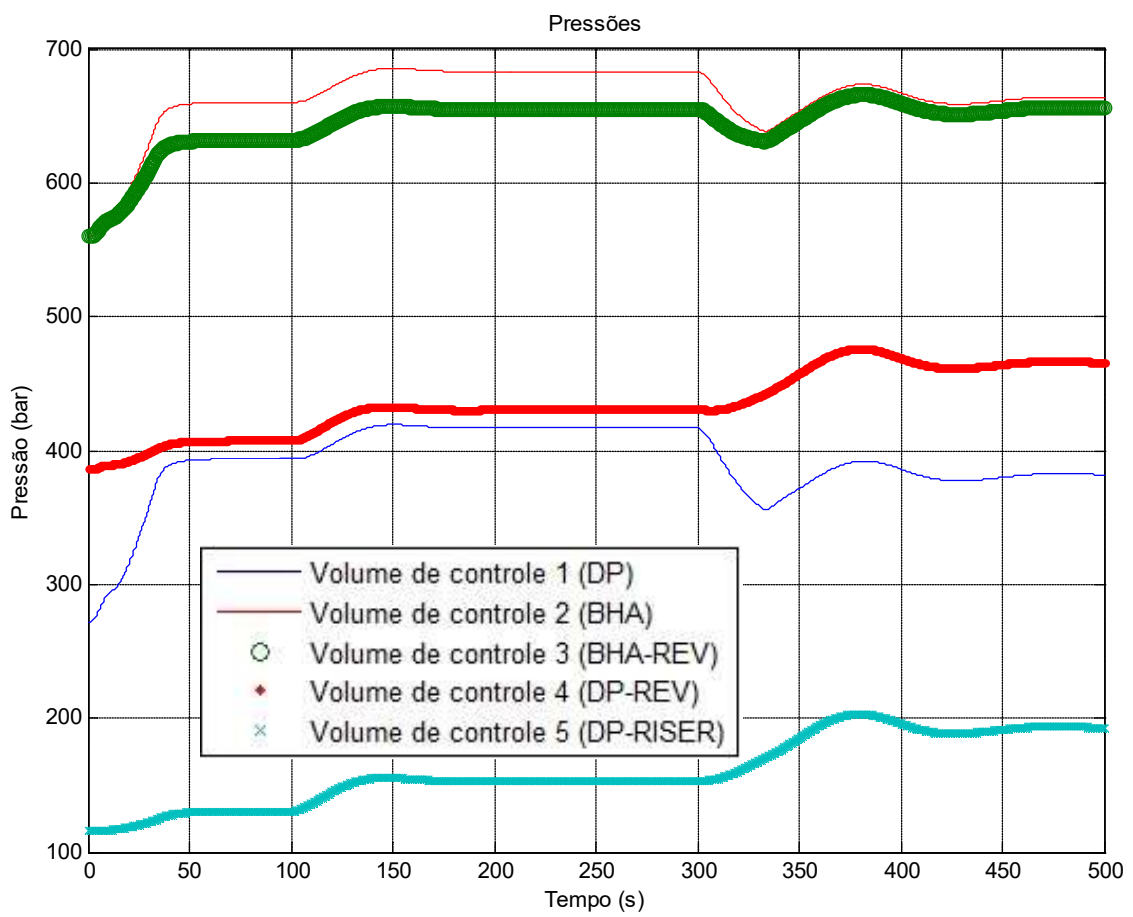

Figura 4.41 - Pressões nos vários volumes de controle para um controlador NL compensado por $\alpha_{D}^{2}$. 


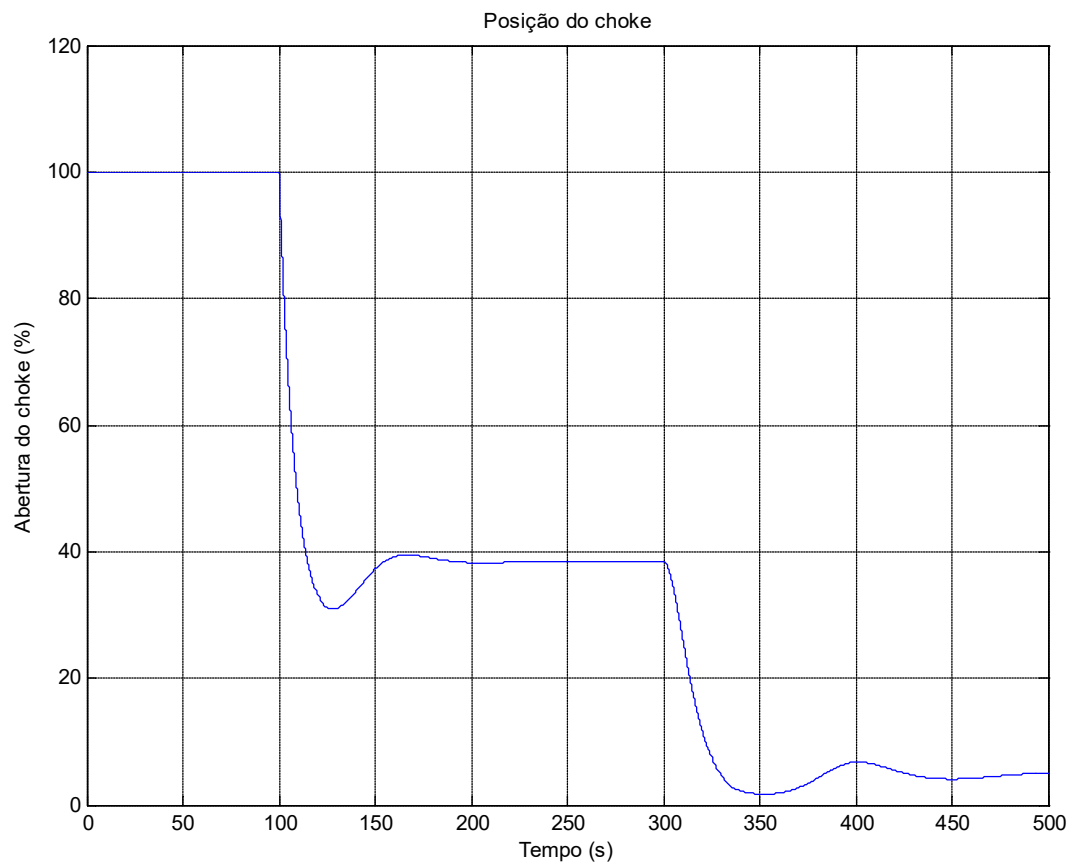

Figura 4.42 - Posição do choke para um controlador NL compensado $\operatorname{por} \alpha_{\mathrm{D}}^{2}$

Os resultados obtidos apresentam melhora com relação à segunda abordagem de controle NL, principalmente na segunda etapa da simulação. Observando o comportamento do choke no tempo, se verifica que ele na segunda etapa possui uma resposta lenta com relação à redução da vazão, confirmada pela queda de pressão no volume de controle BHA-Revestimento. Para acelerar a resposta do choke, foram feitas novas simulações com aumento dos ganhos PD do controlador. $\mathrm{O}$ fator de aumento dos ganhos que apresentou melhor resposta foi de 8 vezes. As figuras 4.43 a 4.45 mostram o resultado da simulação com os ganhos ampliados dessa forma. 


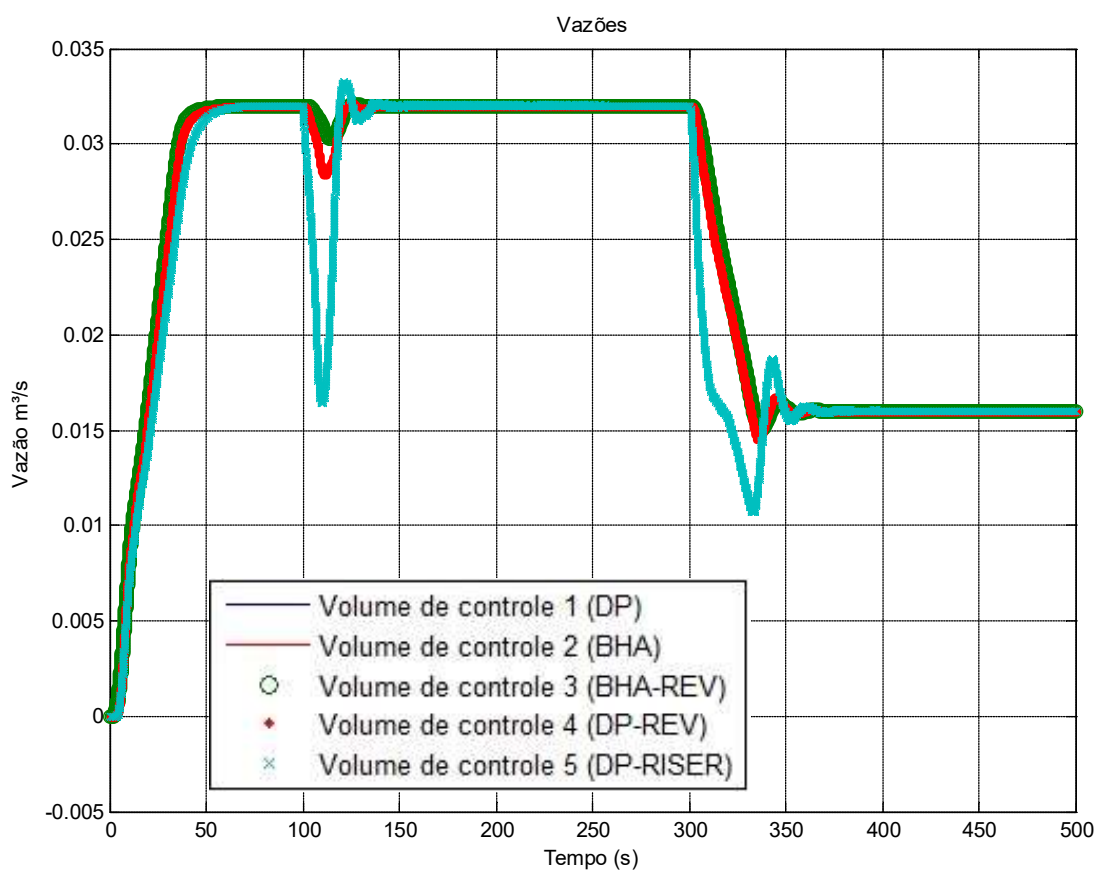

Figura 4.43 - Vazões nos vários volumes de controle para um controlador NL compensado por $\alpha_{\mathrm{D}}^{2}$, para ganhos ampliados em 8 vezes.

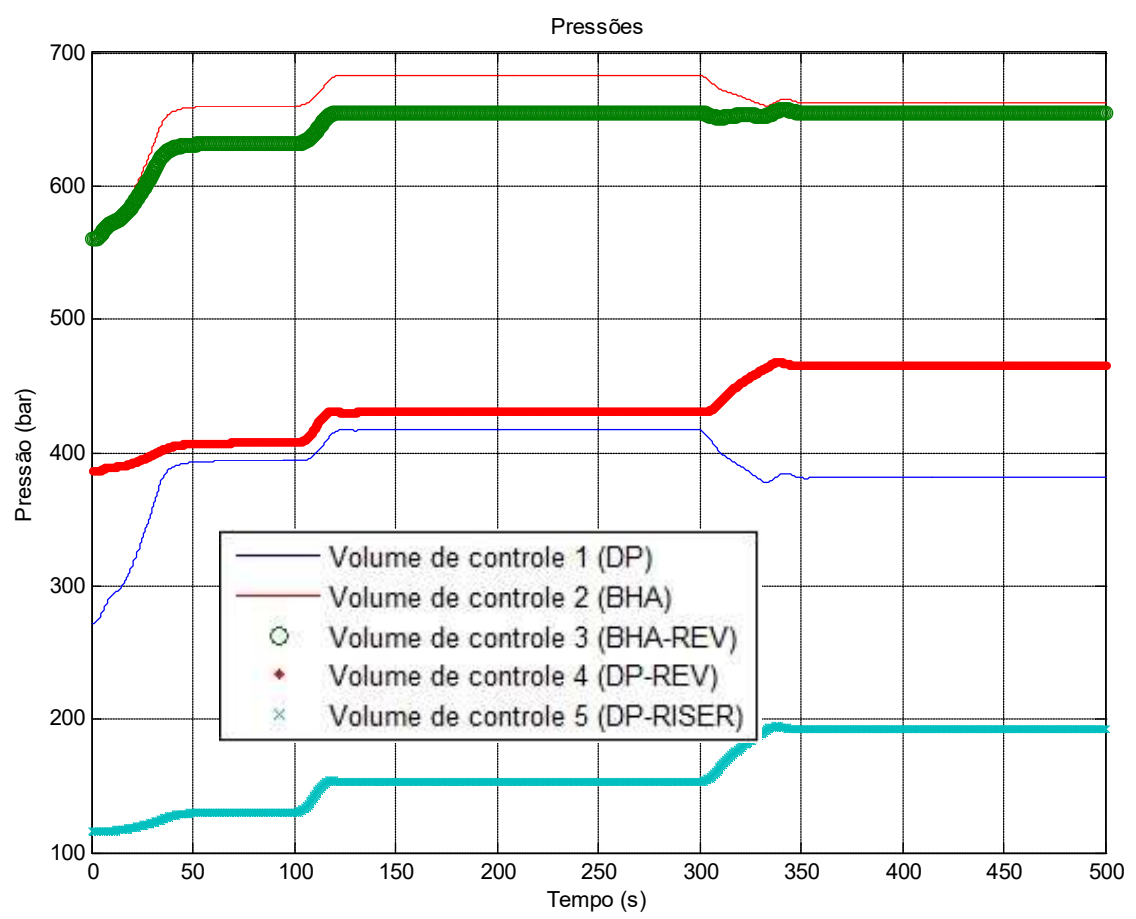

Figura 4.44 - Pressões nos vários volumes de controle para um controlador NL compensado por $\alpha_{\mathrm{D}}^{2}$, para ganhos ampliados em 8 vezes. 


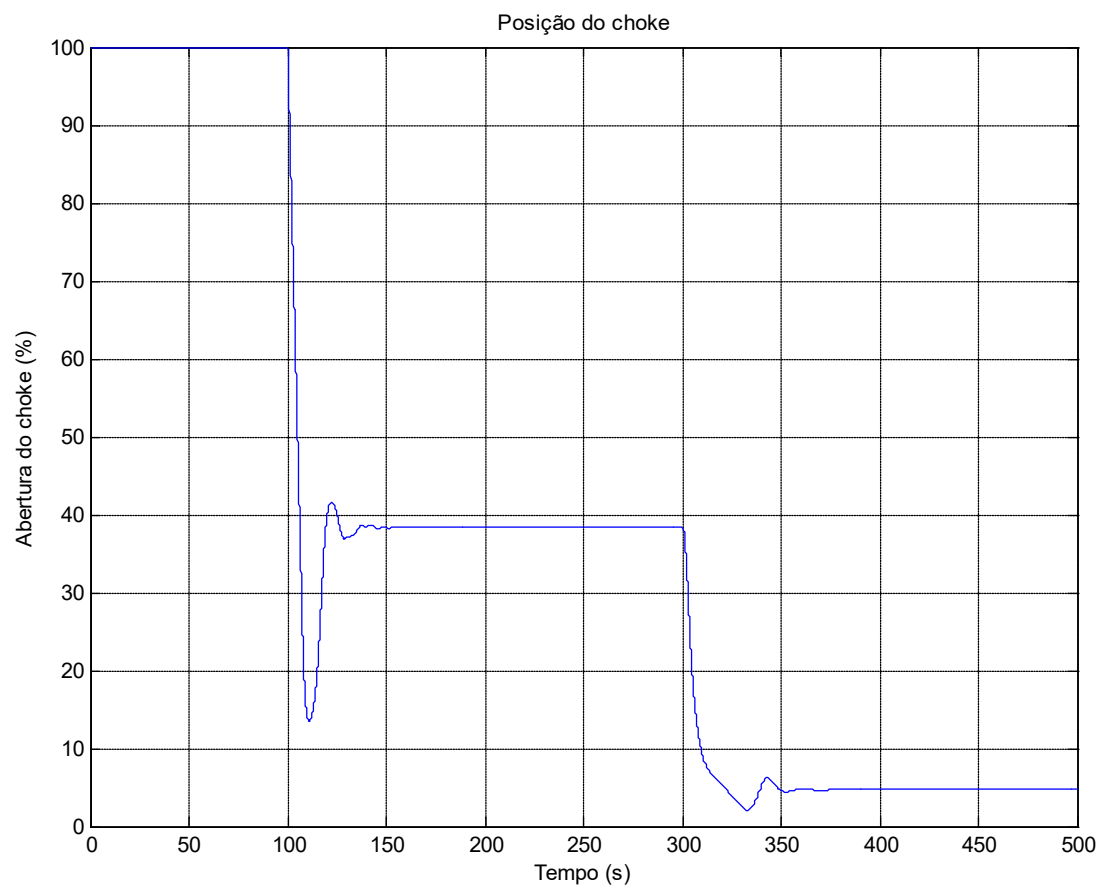

Figura 4.45 - Posição do choke para um controlador NL compensado por $\alpha_{D}^{2}$, para ganhos ampliados em 8 vezes.

Verifica-se que a resposta da pressão apresenta melhora na segunda etapa da simulação, sofrendo menor desvio da pressão de referência quando comparado com o controlador de referência PD e o controlador NL com ganhos menores.

\subsection{4.}

\section{Controlador NL compensado por $\alpha_{D} A$}

Como quarta abordagem para o controle NL foi considerada uma compensação linear do coeficiente de descarga e da abertura do choke. Os ganhos utilizados foram ajustados seguindo o ganho médio estabelecido para cada parâmetro, para normalizar o fator de correção, como feito anteriormente.

Conforme se pode verificar nas figuras 4.46 a 4.48, a pressão do fundo do poço atinge o valor de referência, primeira etapa da simulação, e sofre desvio da pressão durante a redução da vazão das bombas de lama (segunda etapa) em intervalos de tempo semelhantes ao controlador NL compensado com o quadrado do coeficiente de descarga, na primeira estimativa de ganhos. 


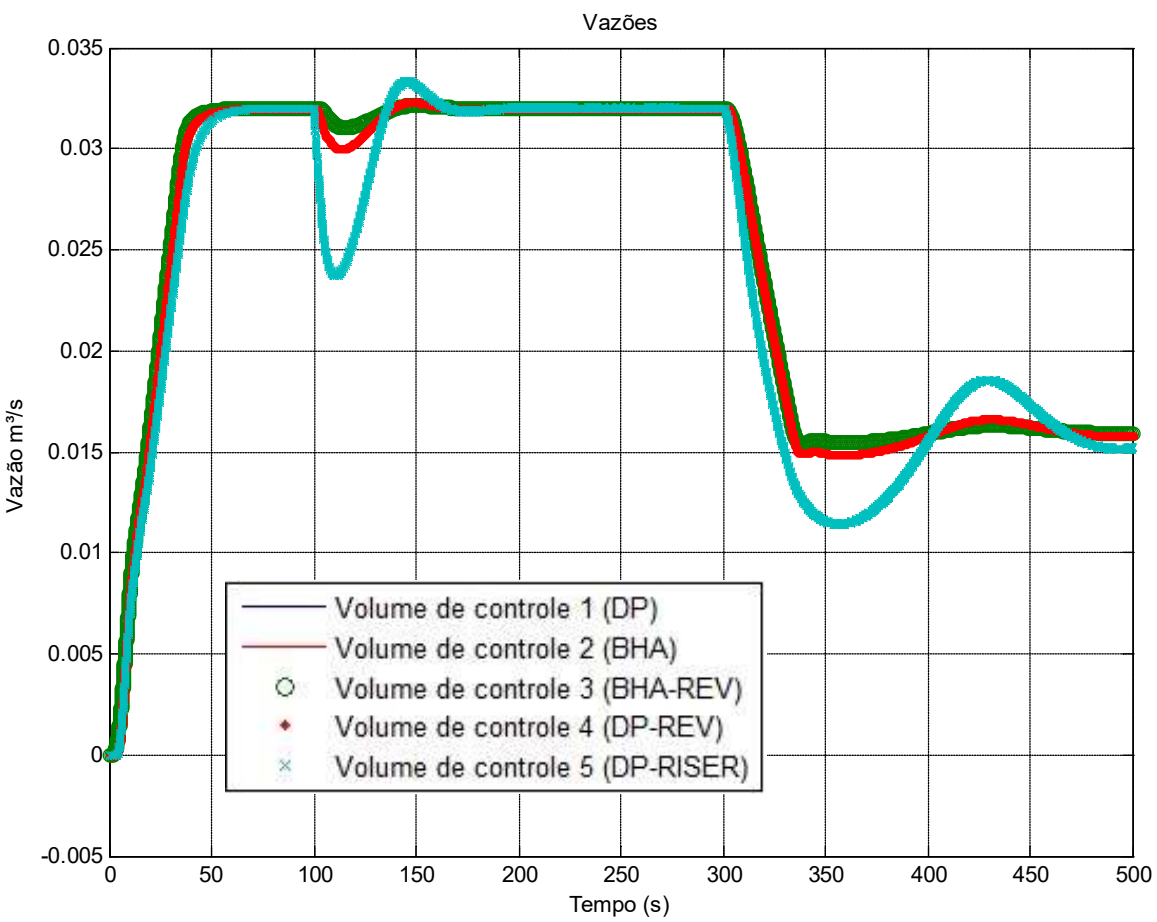

Figura 4.46 - Vazões nos vários volumes de controle para um controlador NL compensado por $\alpha_{D} A$.

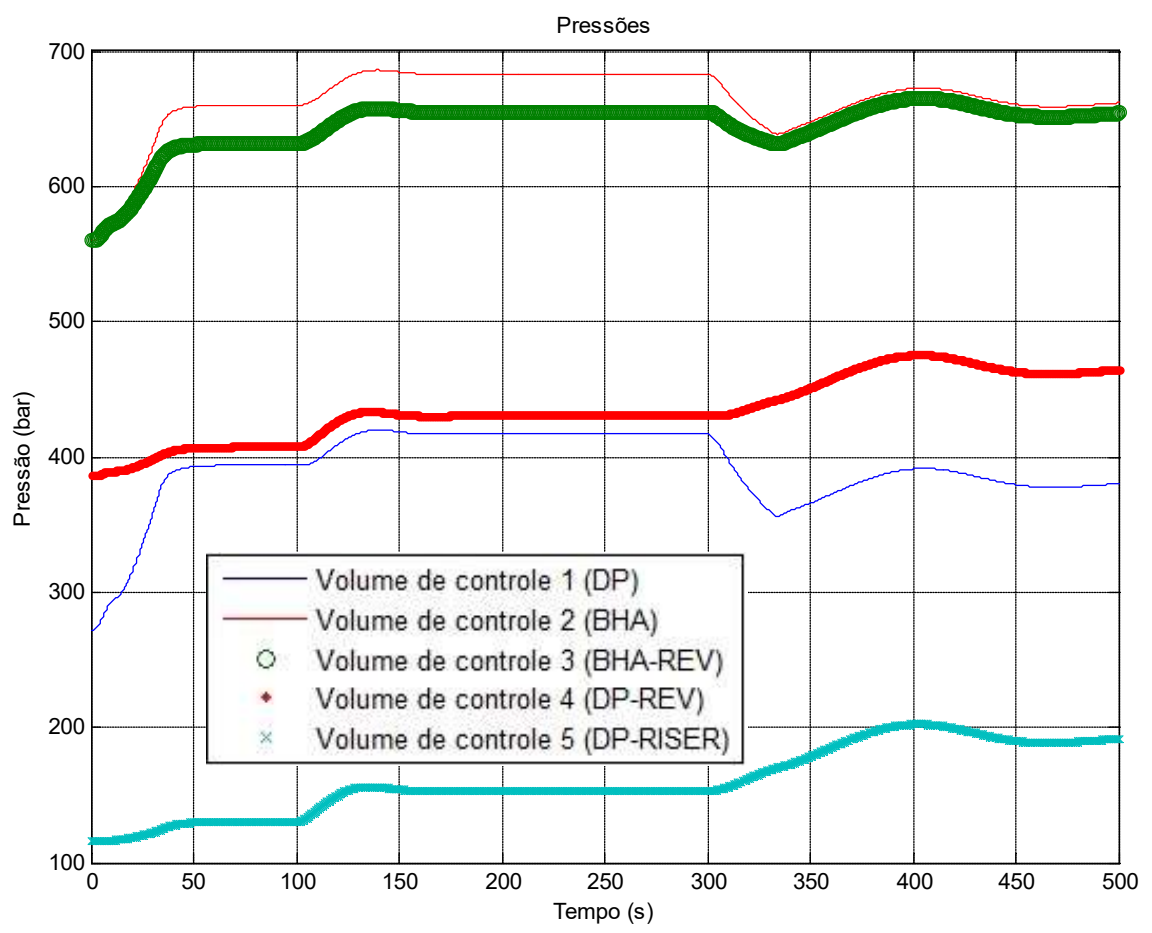

Figura 4.47 - Pressões nos vários volumes de controle para um controlador NL compensado por $\alpha_{D} A$. 


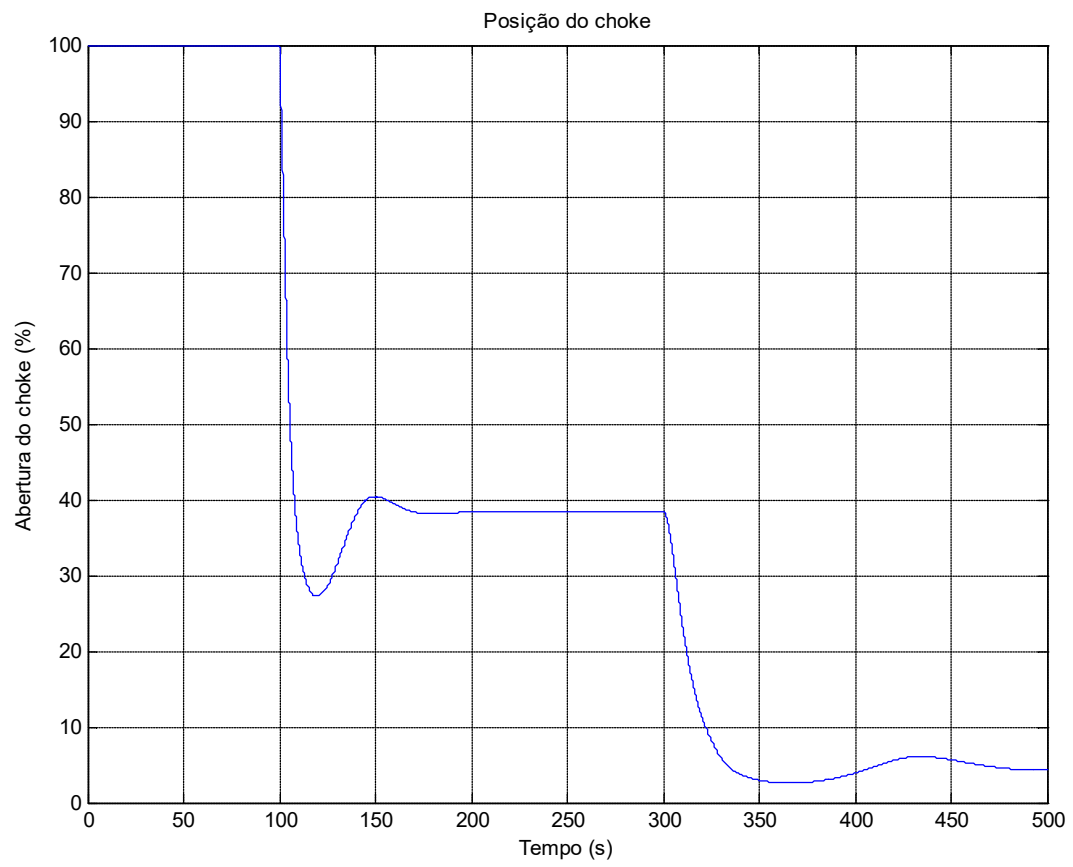

Figura 4.48 - Posição do choke para um controlador NL compensado por $\alpha_{D} A$.

Foi assumida a mesma estratégia do controlador NL compensado pelo quadrado do coeficiente de descarga, realizando aumento nos ganhos dos controladores até obtenção do melhor resultado após diversas simulações. As figuras 4.49 a 4.51 mostram os resultados obtidos com ganhos 3 vezes superiores aos originalmente propostos. 


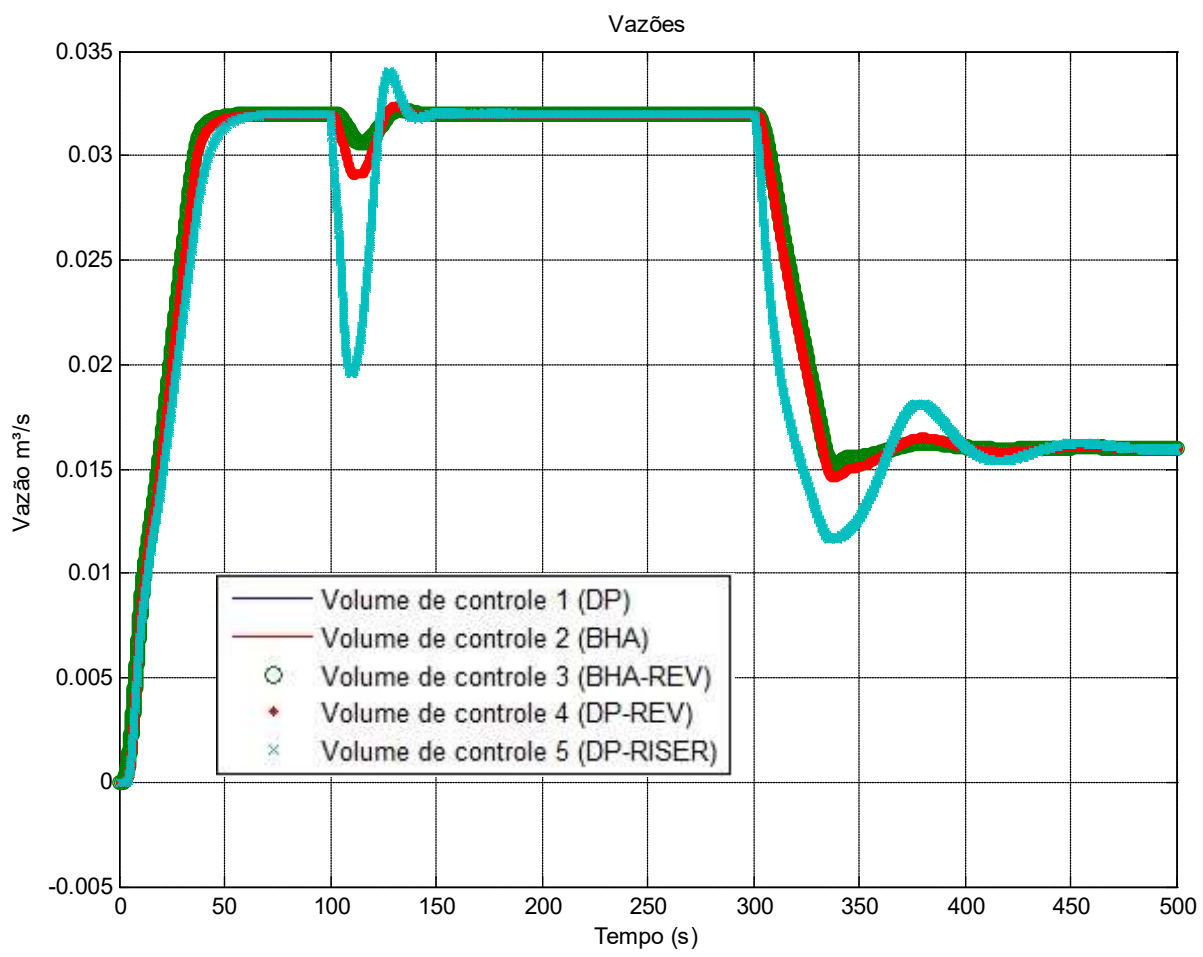

Figura 4.49 - Vazões nos vários volumes de controle para um controlador NL compensado por $\alpha_{D} A$, com ganhos ampliados em 3 vezes.

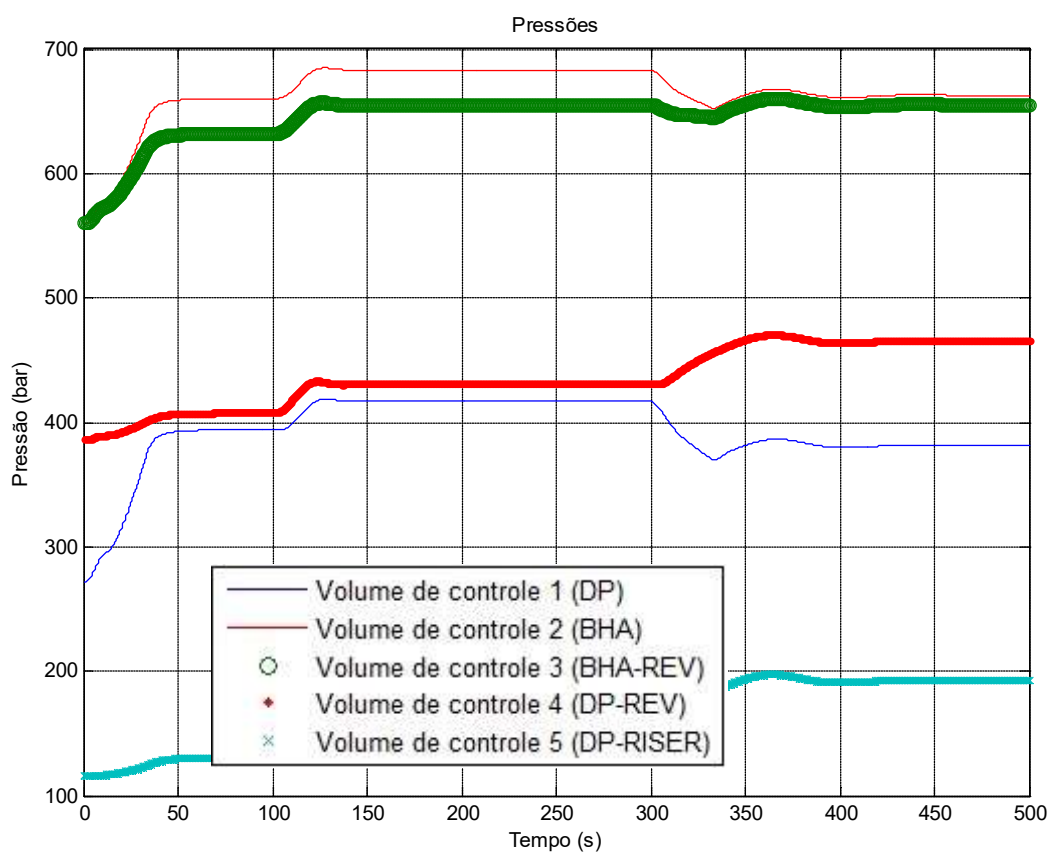

Figura 4.50 - Pressões nos vários volumes de controle para um controlador NL compensado por $\alpha_{D} A$, com ganhos ampliados em 3 vezes. 


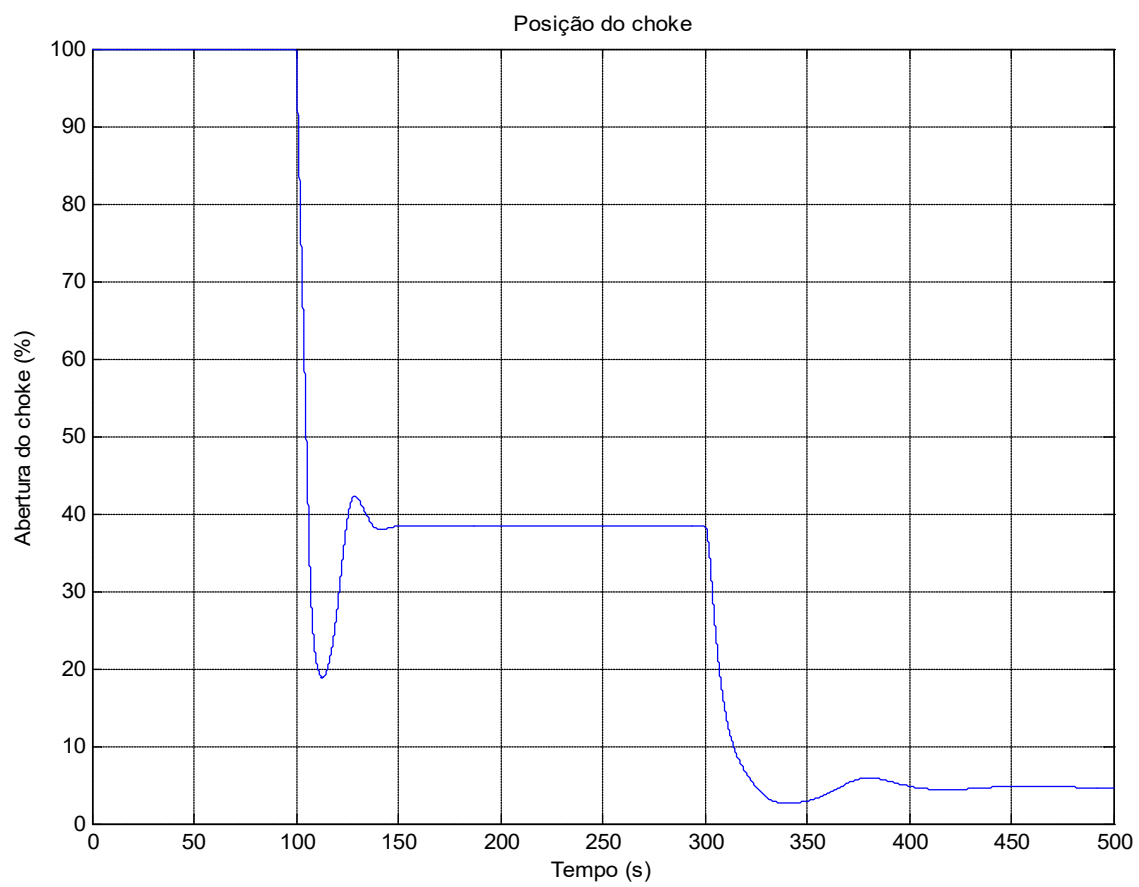

\section{Figura 4.51 - Posição do choke para um controlador NL compensado por $\alpha_{D} A$, com ganhos ampliados em 3 vezes.}

Com relação às simulações anteriores, observou-se que os resultados com ganho ampliado obtiveram resultados inferiores aos do controlador NL compensado pelo quadrado do coeficiente de descarga, porém superiores aos resultados obtidos a partir do controlador $\mathrm{PD}$ de referência. $\mathrm{O}$ aumento dos ganhos do controlador PD trouxe um maior sobre-sinal na primeira etapa da simulação, o que limitou o seu aumento e consequente melhora de desempenho na segunda etapa.

\subsection{5.}

\section{Controlador NL compensado por $A$}

A quinta e última abordagem para aplicação de um controle NL foi a compensação linear da abertura do choke. Esta abordagem é a mais simples, e se trata de um valor diretamente medido durante uma operação com sistema MPD. Os ganhos iniciais foram compensados de acordo com o valor médio considerado da abertura do choke, para normalizar o fator de correção. As figuras 4.52 a 4.54 mostram os resultados da simulação. 


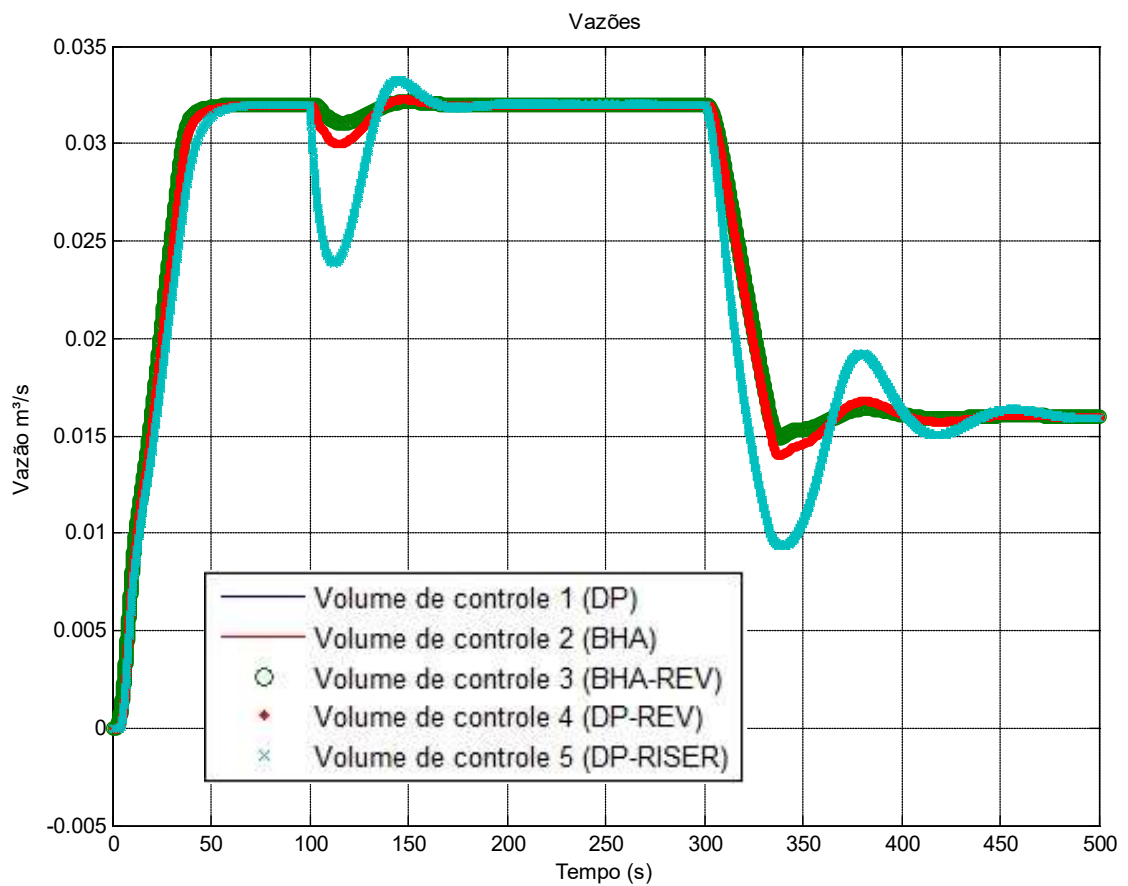

Figura 4.52 - Vazões nos vários volumes de controle para um controlador NL compensado por A.

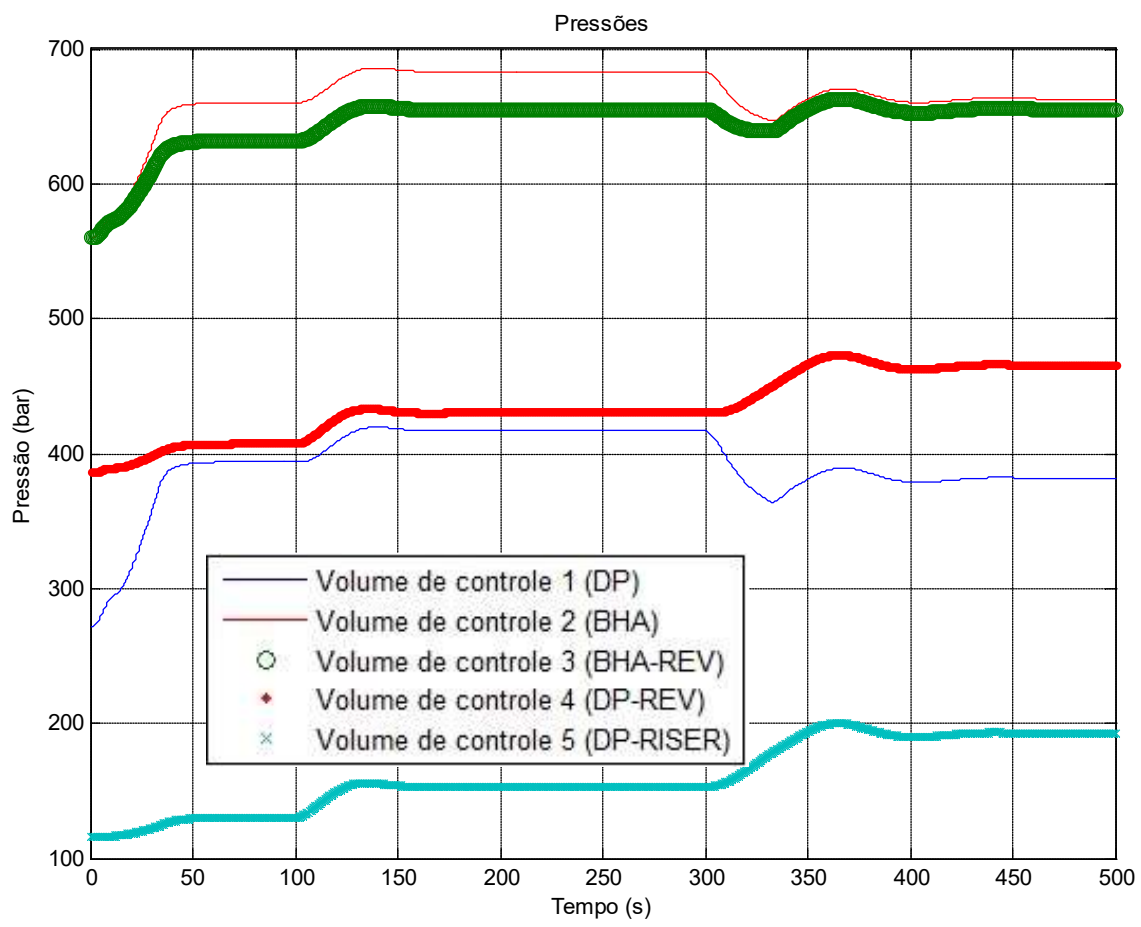

Figura 4.53 - Pressões nos vários volumes de controle para um controlador NL compensado por A. 


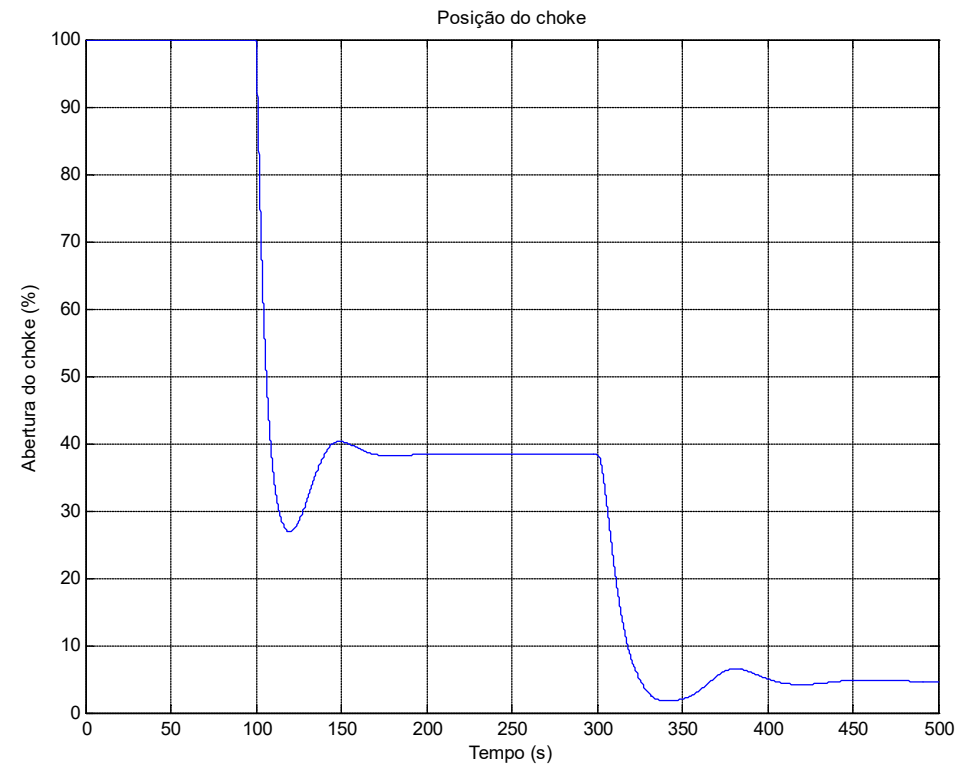

Figura 4.54 - Posição do choke para um controlador NL compensado por A.

Os resultados da simulação indicam melhor desempenho geral em comparação ao controlador PD e aos demais controladores, mesmo sem alteração dos ganhos. Aumentando-se o ganho como em 4.3.3 e 4.3.4, a melhor taxa de alteração dos ganhos identificada foi com um fator de 5 vezes. As figuras 4.55 a 4.57 mostram os resultados obtidos.

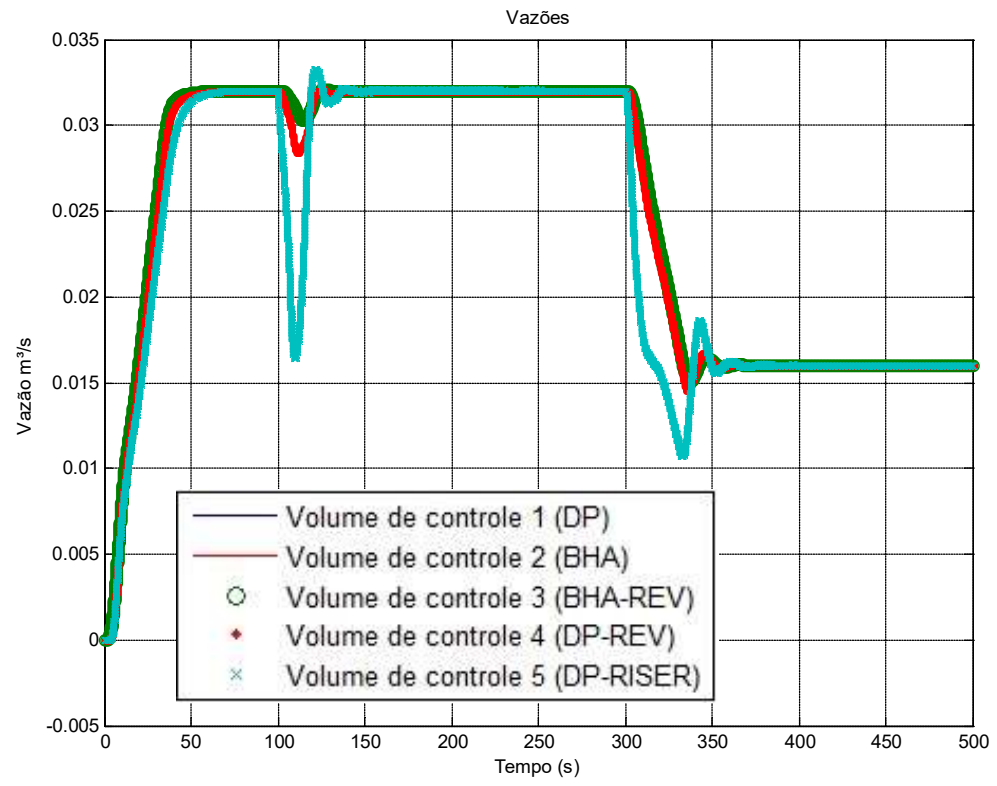

Figura 4.55 - Vazões nos vários volumes de controle para um controlador NL compensado por A, com ganhos ampliados em 5 vezes. 


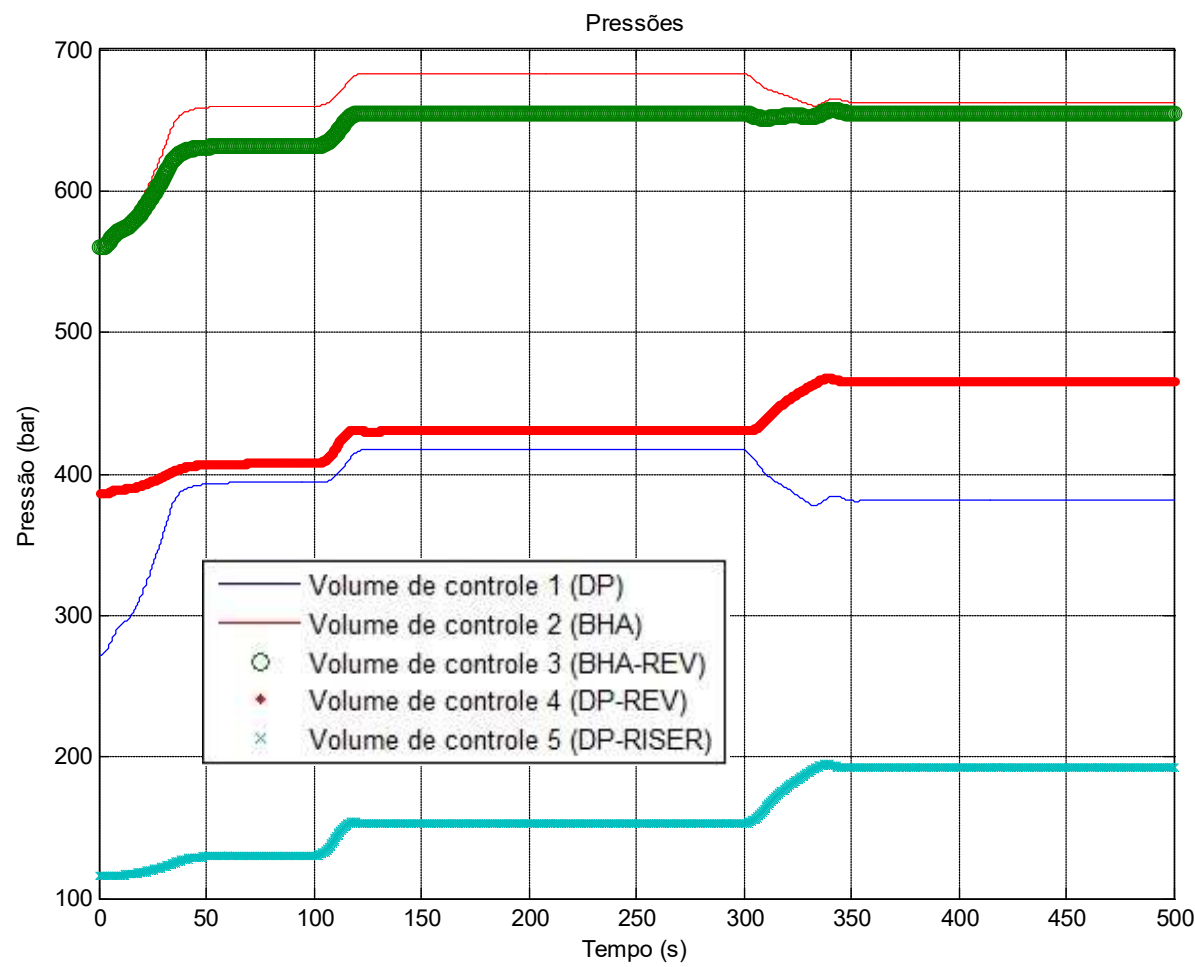

Figura 4.56 - Pressões nos vários volumes de controle para um controlador NL compensado por $A$, com ganhos ampliados em 5 vezes.

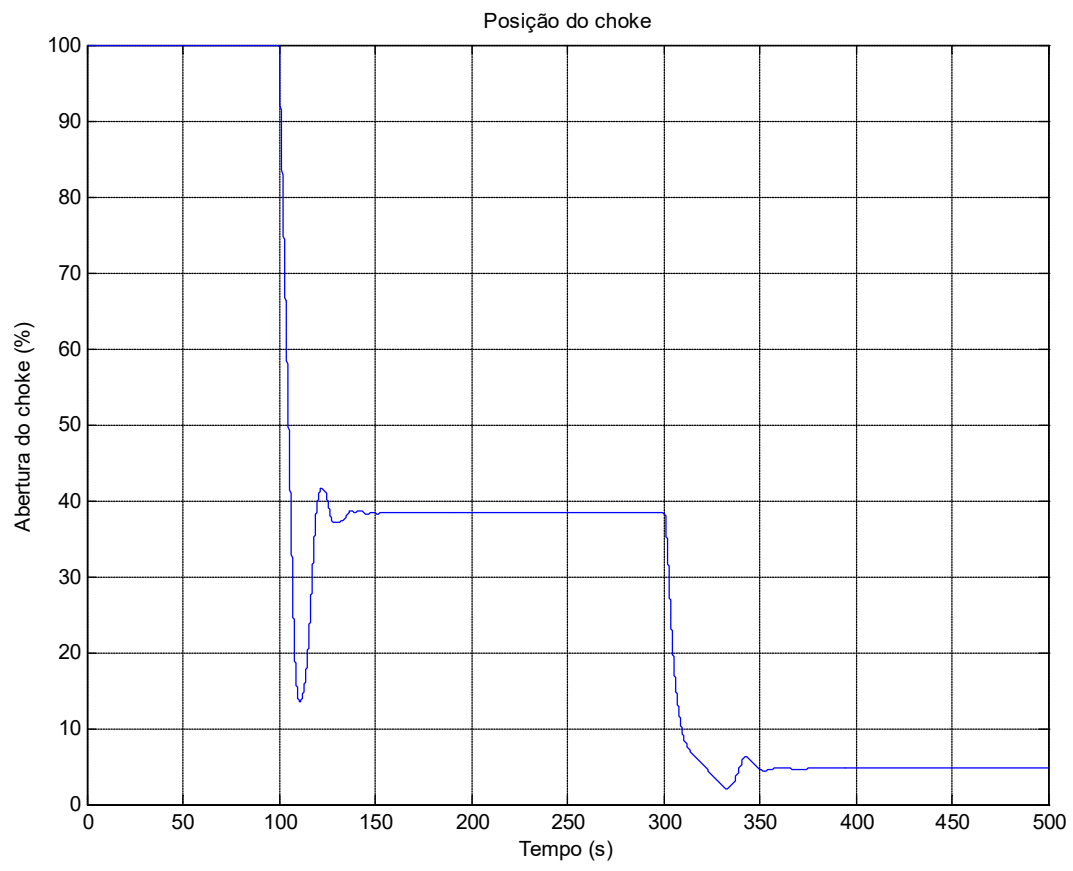

Figura 4.57 - Posição do choke para um controlador NL compensado por $A$, com ganhos ampliados em 5 vezes. 
Os resultados obtidos com o controlador NL compensado pela abertura do choke A se mostram superiores aos demais controladores utilizados anteriormente. Na primeira etapa da simulação, o tempo de subida é inferior às demais simulações com outros controladores NL. A segunda etapa da simulação é a menos sensível à redução da vazão.

Das cinco abordagens para controle não linear da pressão no anular do poço através da atuação do choke, a que apresentou melhores resultados foi a abordagem com compensação direta da área A. Como a resposta do controlador possui compensação não linear, foi possível ampliar os ganhos PD do controlador de referência sem provocar instabilidade na segunda etapa da simulação, que trabalha com o choke em uma região mais sensível.

No próximo capítulo, os resultados obtidos são analisados mais a fundo, e simulações de robustez do controlador proposto a perturbações são realizadas e discutidas. 
5

\section{Análise dos Resultados e Robustez dos Controladores}

\section{1.}

Avaliação dos resultados

Uma maneira direta de avaliação dos controladores é a comparação entre os resultados das simulações. Foram considerados os controladores PD (referência), mapa choke, e controlador NL compensado pela abertura do choke A (o melhor dos cinco controladores NL propostos no capítulo anterior). A tabela 5.1 mostra os resultados obtidos nas duas etapas de simulação. Na primeira etapa, foram considerados sobre-sinal máximo, tempo de subida, e tempo de acomodação do controlador. Na segunda etapa, foi considerado o tempo em que o controlador trabalha abaixo da tolerância da pressão de referência, e a queda de pressão. Como critério de estabilização e tolerância, foi considerada a variação em um intervalo entre 1 bar da pressão de referência. O tempo de subida considerado foi o tempo para a pressão atingir o limite inferior da tolerância de pressão.

Tabela 5-1 - Resultados objetivos dos controladores

\begin{tabular}{|c|c|c|c|c|c|}
\hline Controlador & \multicolumn{3}{|c|}{$1^{\text {a }}$ etapa simulação } & \multicolumn{2}{c|}{$2^{\text {a } \text { etapa simulação }}$} \\
\cline { 2 - 6 } & $\begin{array}{c}\text { Tempo de } \\
\text { subida (s) }\end{array}$ & $\begin{array}{c}\text { Sobre-sinal } \\
\text { máximo } \\
(\text { bar) }\end{array}$ & $\begin{array}{c}\text { Tempo de } \\
\text { acomodação } \\
(\mathbf{s})\end{array}$ & $\begin{array}{c}\text { Tempo fora } \\
\text { tolerância } \\
(\mathrm{s})\end{array}$ & $\begin{array}{c}\text { Queda de } \\
\text { pressão } \\
\text { (bar) }\end{array}$ \\
\hline PD & 42 & 2 & 70 & 33 & 14 \\
\hline Mapa & 40 & 0 & 40 & +200 & 19 \\
\hline NL (A) & 19 & 0 & 19 & 33 & 4 \\
\hline
\end{tabular}

Os resultados numéricos indicam o melhor desempenho do controlador NL compensado por A. Conforme verificado nos resultados do capítulo 4, ganhos muitos agressivos no controlador PD causam sobre-sinal na primeira etapa da simulação, e instabilidade na segunda etapa. Assim, os ganhos no controlador PD precisaram ser limitados, para estabilidade da resposta do controlador.

O controlador de mapa de choke apresentou um resultado intermediário para a primeira etapa da simulação, porém resulta no pior resultado na segunda etapa, 
quando o controlador não consegue retornar a pressão da zona objetivo para dentro da tolerância da pressão de referência em um intervalo de 200s (limite estabelecido para a simulação). Uma explicação para este comportamento é a característica do sistema não linear: o controlador, ao buscar a posição do choke ideal para um cenário de vazões transientes no poço, acaba alterando o sistema e reduzindo a vazão ao longo dele, momentaneamente gerando uma maior contrapressão na jusante do sistema de circulação do poço. Este comportamento se intensifica em situações de redução de vazão das bombas de lama, cenário que ocorre durante as conexões do drillpipe. No entanto, para aumento de pressão de referência ou aumento de vazão, o comportamento do controlador do mapa de choke não é prejudicial ao seu desempenho.

O controlador NL compensado pela abertura A mostrou os melhores resultados de controle. Os ganhos mais agressivos reduziram, em relação aos outros controladores estudados, o tempo de subida da primeira etapa da simulação em mais de $50 \%$. O tempo fora da tolerância na segunda etapa da simulação se manteve, porém com uma menor queda de pressão, o que acarretaria em menores riscos operacionais em uma operação com MPD, visto que uma estreita janela operacional limitaria a faixa de variação de pressão possível no fundo do poço sem consequências danosas.

\section{2.}

Avaliação dos controladores com perturbações

Durante a perfuração de uma nova fase de um poço com retorno para a superfície, todo o cascalho gerado pela broca ao perfurar as novas formações deve ser transportado para os tanques na superfície. Caso o cascalho gerado não retorne para a superfície, o poço ficará com limpeza ruim, podendo ocorrer problemas operacionais como: prisão de coluna, perda do retorno hidráulico, arraste elevado, fundo falso, entre outros. Por este motivo, a hidráulica de cada fase do poço é projetada para garantir a limpeza adequada do poço. Além dos cascalhos, também retornam para a superfície pedaços dos acessórios da fase anterior (e.g. sapata, plug de cimentação), e cimento do final da fase anterior.

Todo este material transportado pelo fluido de perfuração deve passar pelo choke em um poço MPD. Como o choke possui uma área mais restrita do que o 
espaço anular do poço e das linhas de retorno aos tanques na superfície, é situação comum o entupimento parcial dos chokes MPD.

O entupimento parcial de um choke MPD gera uma maior perda de carga localizada nele, pois a área de fluxo é reduzida. A maior perda de carga localizada no choke acaba por perturbar a condição de equilíbrio do sistema, aumentando a pressão em todo o espaço anular do poço, funcionando como uma perturbação do sistema de controle. Em muitos casos, o entupimento parcial do choke é reduzido ou até eliminado quando ele é aberto, ao menos, parcialmente com relação à posição de entupimento parcial. Em outras situações, o choke deve ser isolado do sistema, enquanto outro choke assume o controle do poço, devendo ser aberto e limpo manualmente. A figura 5.1 mostra um elemento de vedação da cabeça rotativa recuperado como detrito no choke MPD de uma operação offshore.

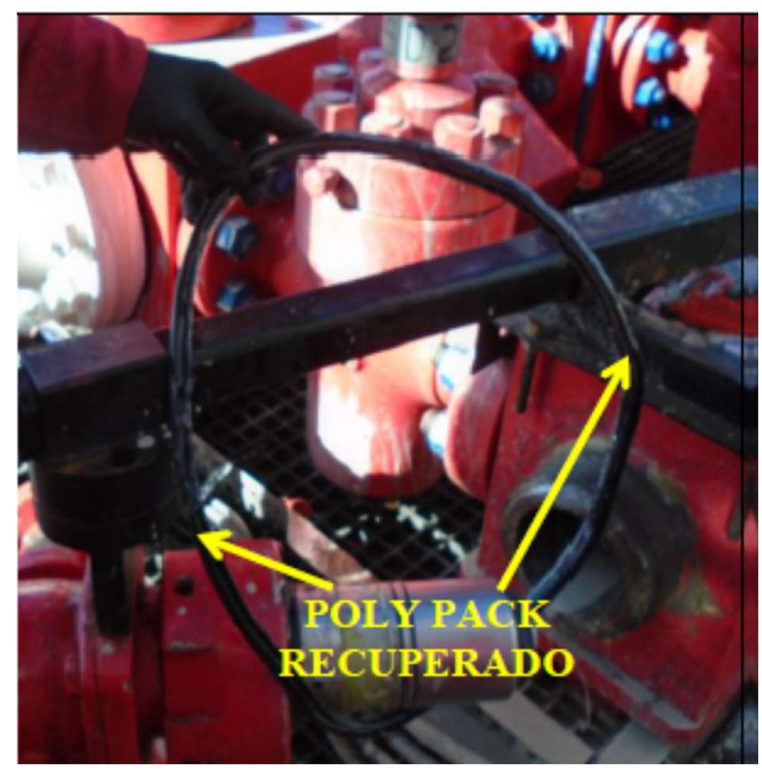

Figura 5.1 - Elemento recolhido de um choke MPD após limpeza.

Uma lógica de controle para choke MPD deve ser robusta o suficiente para contornar o problema de seu entupimento parcial. Os três controladores desenvolvidos, o controlador PD (referência), controlador de mapa de choke, e controlador não linear compensado pela abertura do choke A, foram testados para uma situação de entupimento parcial.

A simulação de teste seguiu a mesma sequência utilizada para verificação de desempenho dos controladores, até o instante de 250s. Neste momento, foi aplicado um entupimento parcial do choke, simulado reduzindo instantaneamente 
a sua área efetiva para um percentual de $50 \%$ da sua abertura física. O controlador então age abrindo o choke, para tentar compensar o efeito deste entupimento parcial. O entupimento parcial é eliminado na simulação no momento em que o choke atinge uma abertura superior a 50\%. Vale observar que no momento em que houver liberação do entupimento parcial, há uma súbita queda de pressão no choke, pois o mesmo se encontra numa posição mais aberta do que o necessário, situação em que o controlador deve reagir rapidamente para impedir a perda de pressão no anular do poço.

As figuras 5.2 a 5.4 mostram o desempenho do controlador PD usado como referência nas simulações de controle, para a perturbação imposta (entupimento parcial) em $t=250$ s.

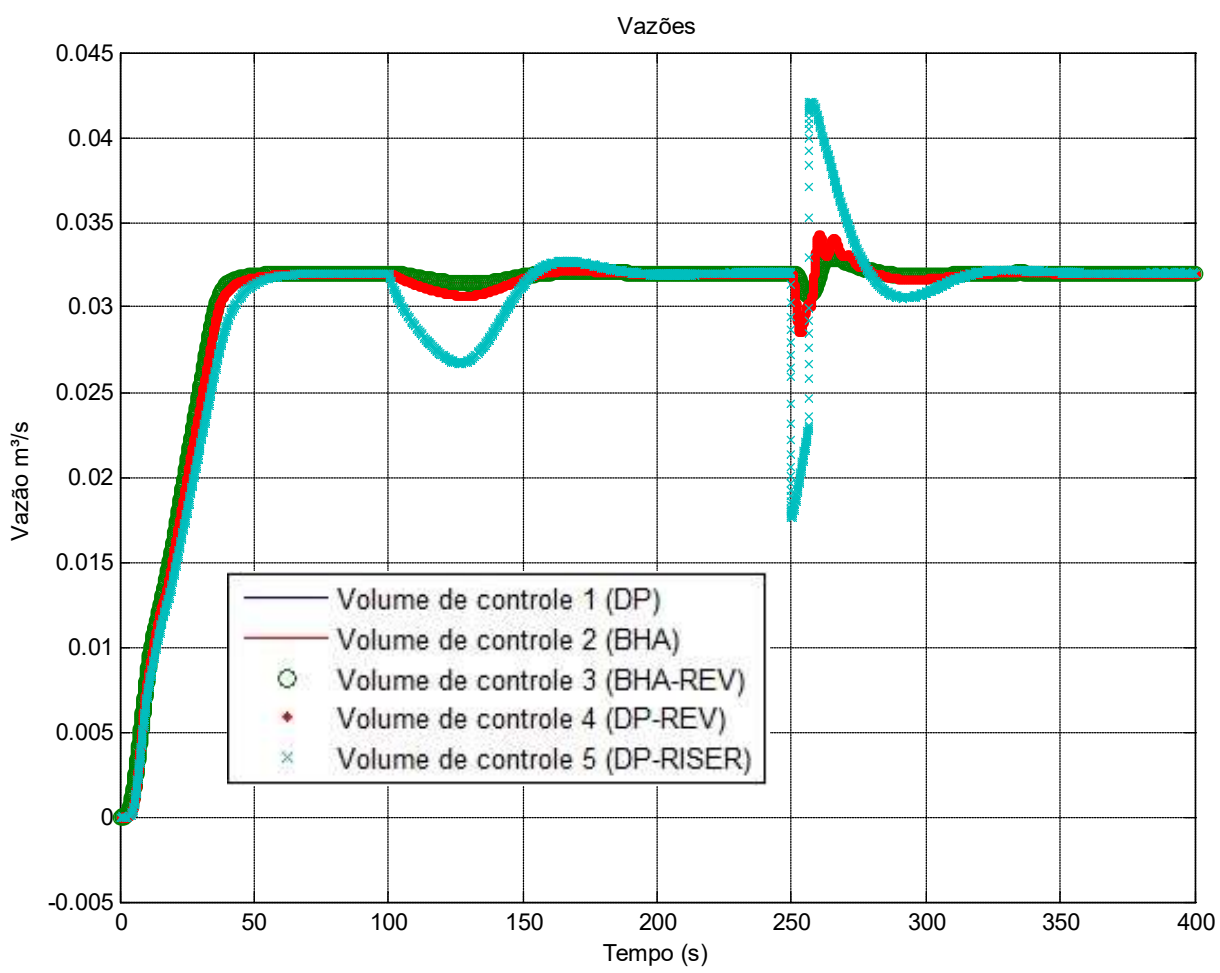

Figura 5.2 - Variação de vazão para controlador PD com perturbação no instante $t=250 \mathrm{~s}$. 


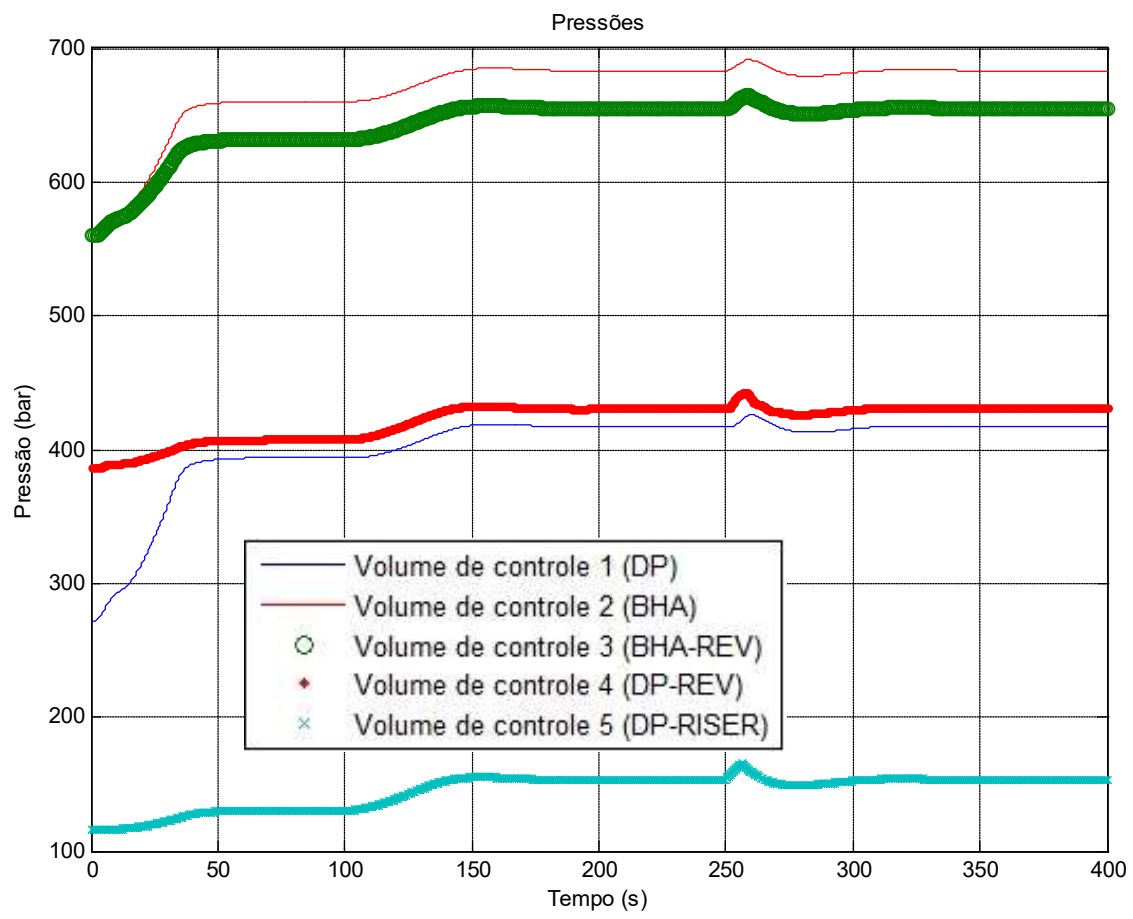

Figura 5.3 - Variação de pressão para controlador PD com perturbação no instante $t=250 \mathrm{~s}$.

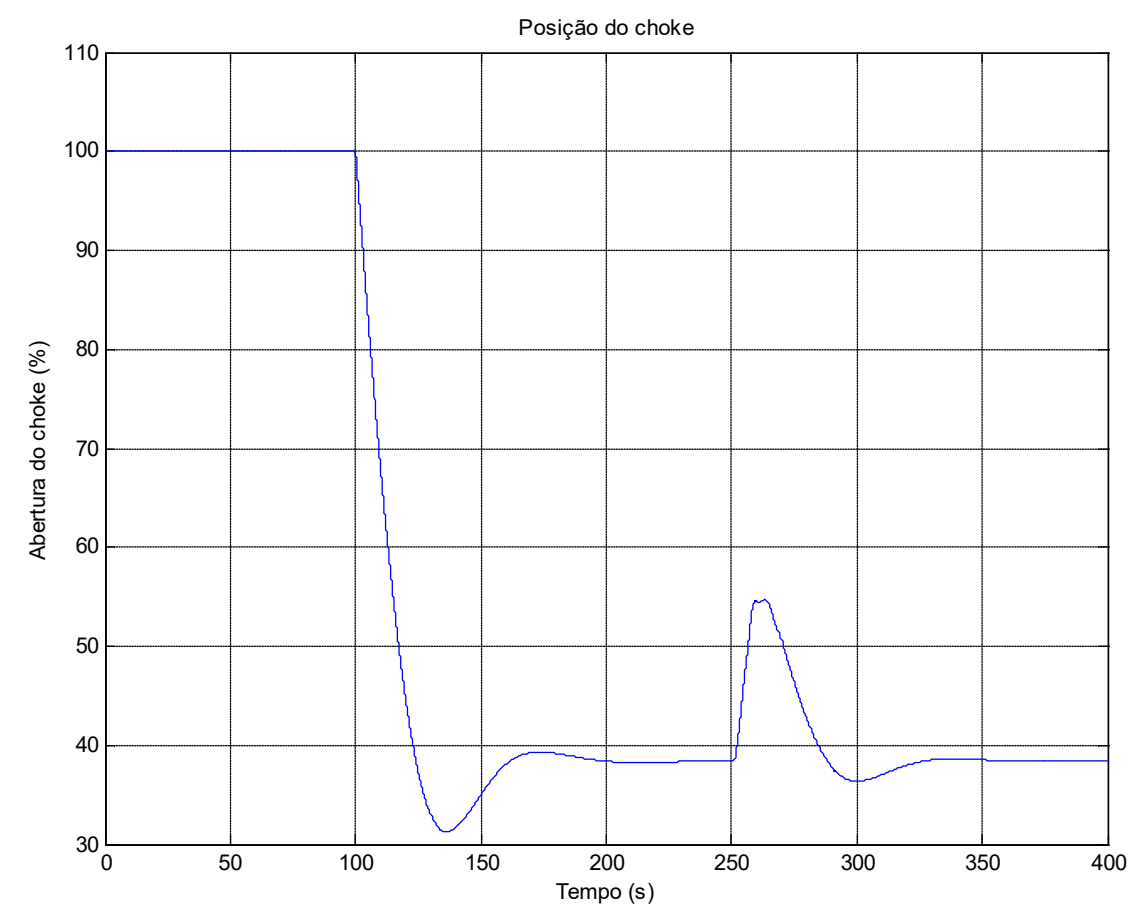

Figura 5.4 - Posição do choke do controlador PD com perturbação no instante $t=250 s$. 
Conforme verificado, o controlador PD se mostrou robusto para a perturbação imposta. A resposta se mostra coerente com o tempo de reação do controlador PD na situação de mudança de pressão de referência (instante 100s). Os desvios de pressão verificados entre o entupimento do choke até a liberação da pressão e retorno para normalidade ficaram entre +10 bar e $-4 \mathrm{bar}$, com tempo fora de uma tolerância assumida de 50s para compensação.

As figuras 5.5 a 5.7 mostram a reposta do controlador de mapa de choke para a perturbação por entupimento parcial em $\mathrm{t}=250 \mathrm{~s}$.

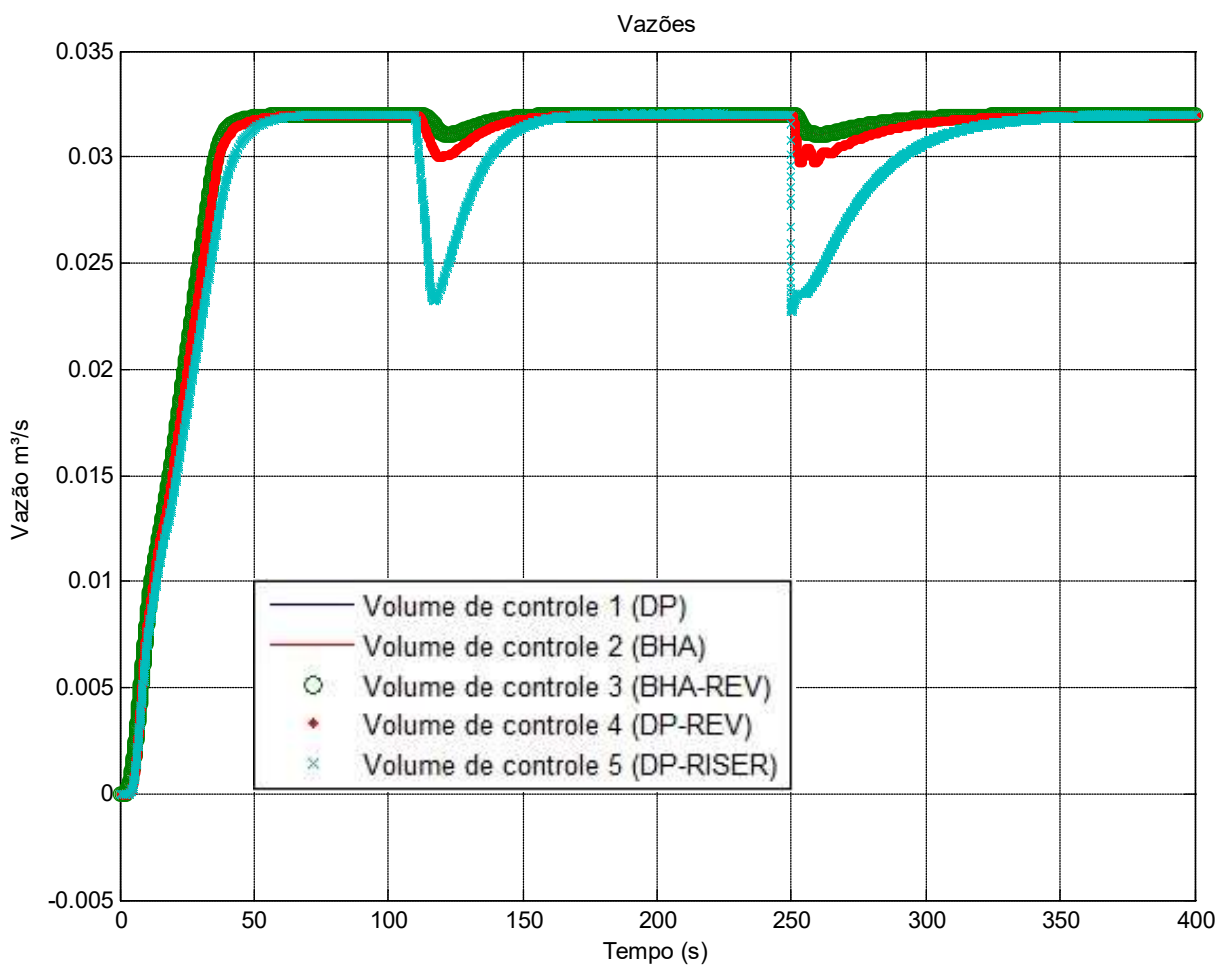

Figura 5.5 - Variação de vazão para controlador com mapa de choke com perturbação em $t=250 s$. 


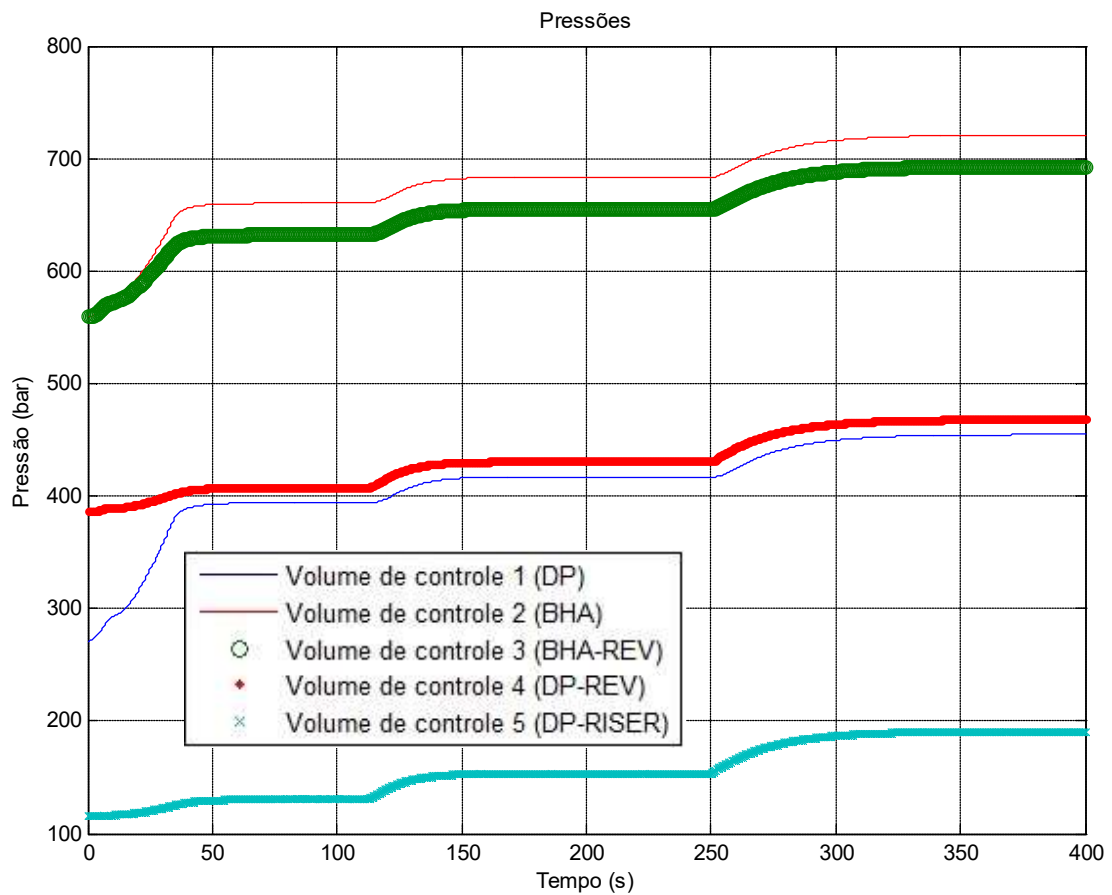

Figura 5.6 - Variação de pressão para controlador mapa de choke com perturbação em $t=250 \mathrm{~s}$.

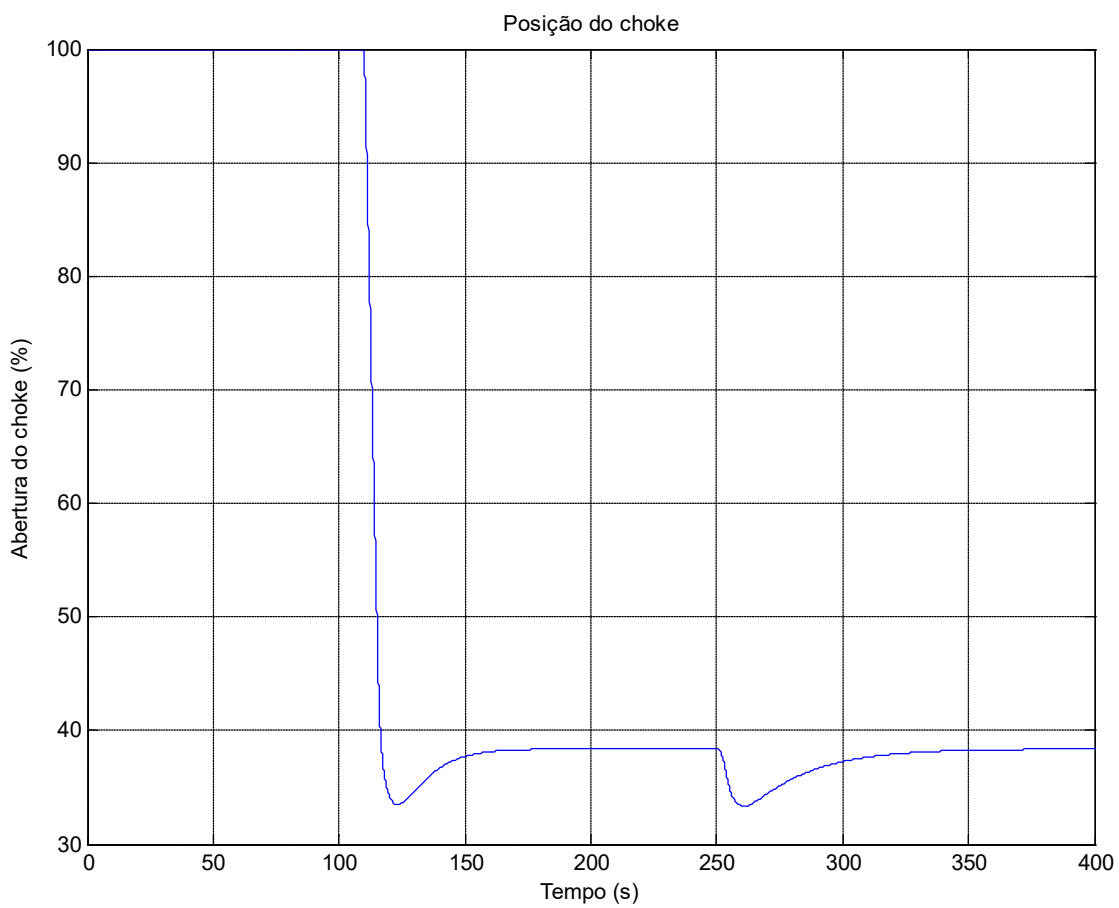

Figura 5.7 - Posição do choke do controlador mapa de choke com perturbação em $t=250$ s. 
O controlador baseado em mapa de choke não se mostra robusto para a perturbação. Como o mapa é fixo, qualquer mudança no choke irá provocar desvio entre a referência do mapa de abertura para a área efetiva de fluxo de passagem do choke. Assim, a abertura indicada pelo mapa não é mais válida para a geração da perda de carga de referência, indicando que um mapa fixo de choke não é robusto para uso de um controlador em cenário MPD.

As figuras 5.8 a 5.10 mostram os resultados para a simulação com o controlador NL compensado por A de uma perturbação por entupimento parcial em $\mathrm{t}=250 \mathrm{~s}$.

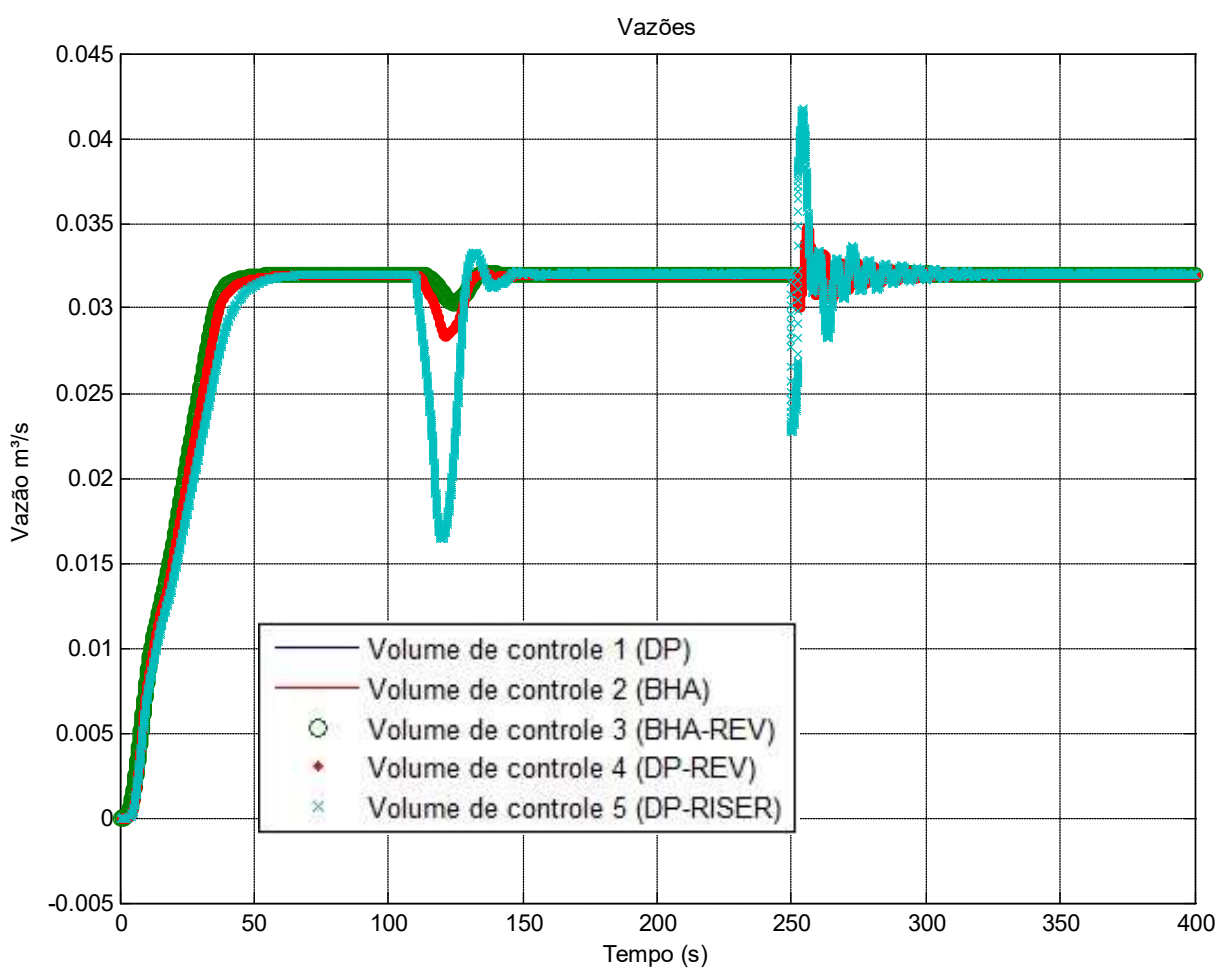

Figura 5.8 - Variação de vazão para o controlador NL compensado por A com perturbação em $t=250$ s. 


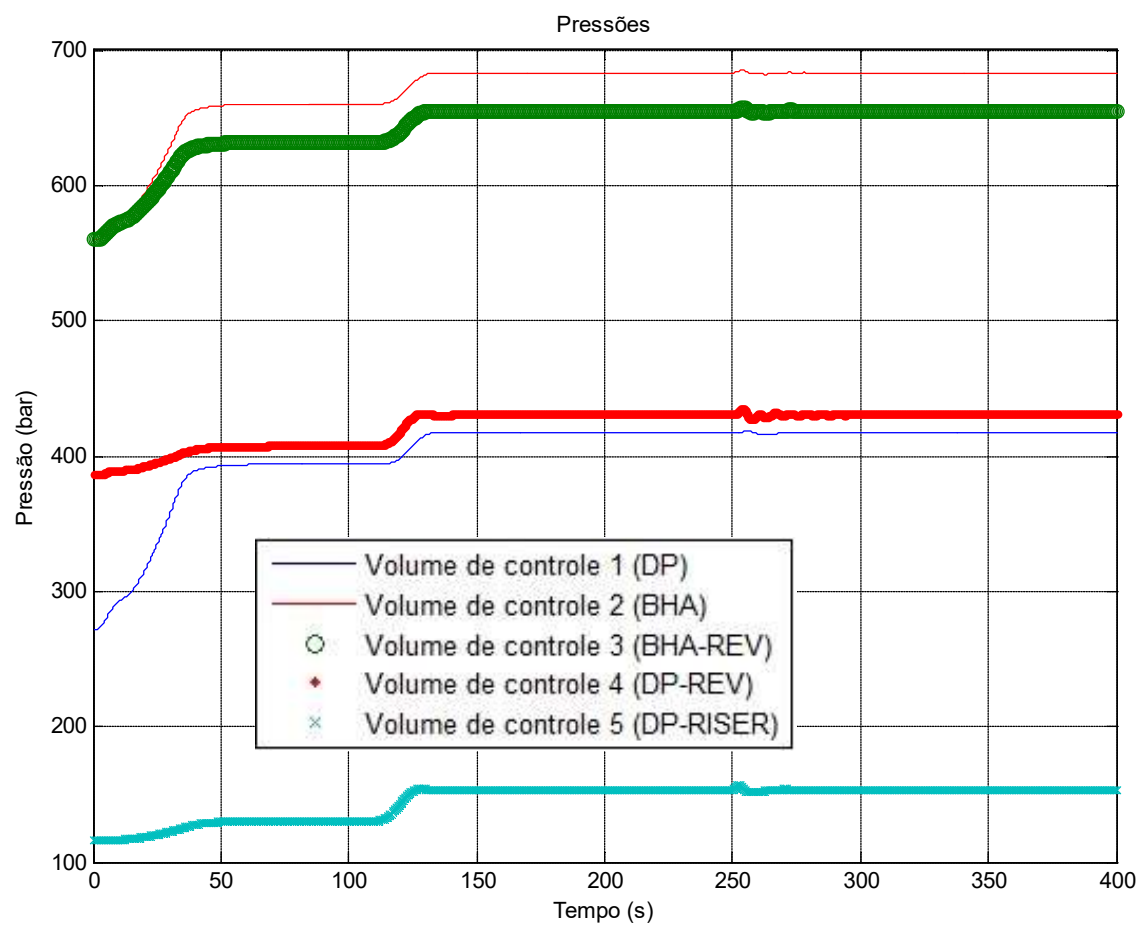

Figura 5.9 - Variação de pressão para o controlador NL compensado por A com perturbação em $\mathbf{t}=\mathbf{2 5 0 s}$.

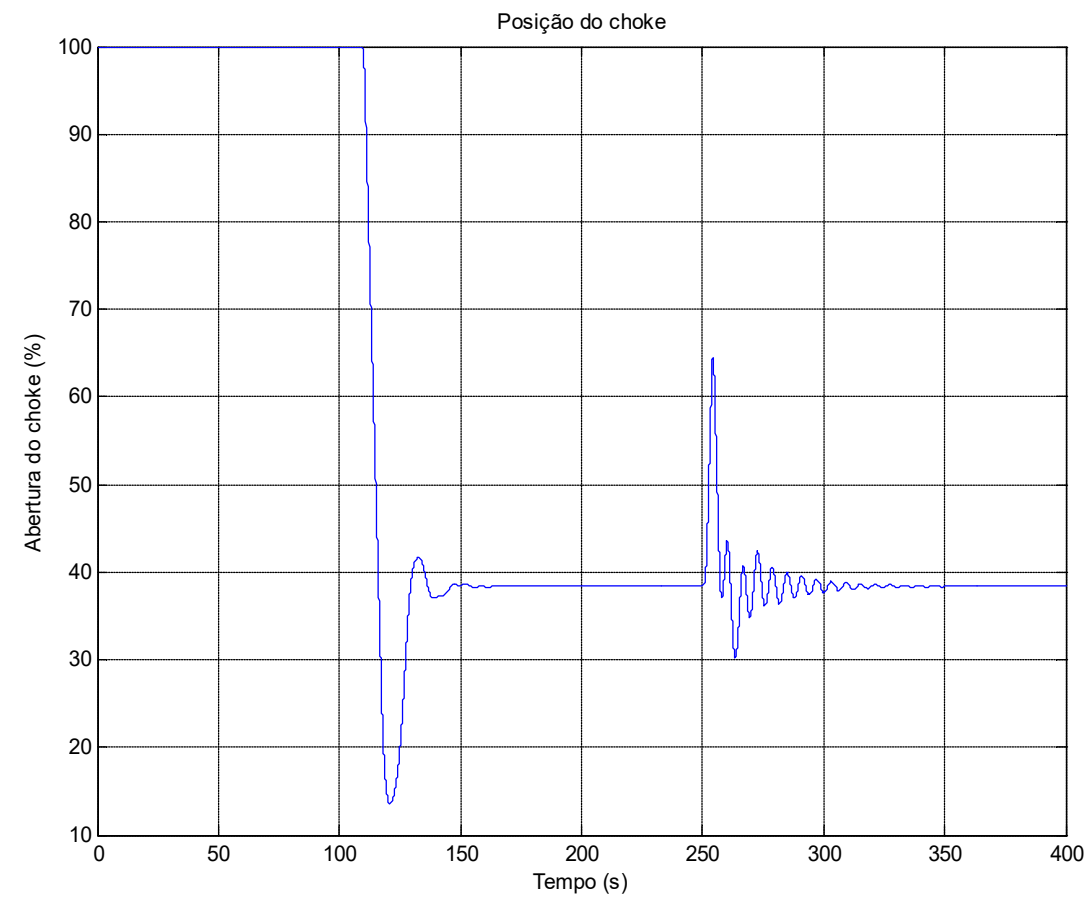

Figura 5.10 - Posição do choke para o controlador NL compensado por A com perturbação em $t=250$ s. 
O controlador não linear conseguiu alcançar a robustez observada pelo controlador PD, porém com menor desvio da pressão de referência e com menor tempo de resposta. Como os ganhos do controlador não linear são maiores do que os ganhos do controlador PD, é possível um menor desvio da resposta, pois um erro menor é capaz de provocar uma reação mais rápida do controlador, porém sem comprometer a estabilidade e sem causar sobre-sinal significativo de pressão. Os desvios de pressão verificados entre o entupimento do choke até a liberação da pressão e retorno para normalidade ficaram entre +3 bar e -2 bar, com intervalo de tempo relativamente curto de cerca de $15 \mathrm{~s}$.

O teste de perturbação indicou que entre os controladores testados somente os controladores PD e não linear possuem robustez para contornar uma situação comum na perfuração de poços MPD. O controlador de mapa de choke fixo se mostrou incapaz de contornar a situação de perturbação, justamente por possuir um referencial fixo, indicando que esta abordagem é ineficiente para um cenário de perfuração onde as condições de perfuração podem ser alteradas.

\section{3. \\ Comparação entre modelo dinâmico e modelo quase-estático}

Os modelos de controle desenvolvidos nas sessões anteriores consideram a dinâmica do sistema hidráulico (modelo dinâmico) para estimar a pressão no fundo a ser controlada, a qual será realimentada. Utilizando o controlador de referência PD foi feita uma simulação, vide figuras 5.11 a 5.13, considerando o cálculo das perdas de carga no sistema de acordo com a vazão da bomba, mas sem considerar a dinâmica do sistema. Ou seja, assume-se neste caso que a pressão no fundo do poço (a qual é usada na realimentação do controlador) é instantaneamente modificada por variações de pressão no choke, uma hipótese simplista que degrada o desempenho do controle.

Vale notar que a forma de cálculo de pressão do modelo quase-estático é a forma normalmente utilizada no controle da pressão de poços em que o MPD é aplicado. Para regime permanente, não existe diferença no resultado do cálculo de pressão entre o modelo quase-estático e o modelo dinâmico. A diferença entre o cálculo de pressão dos modelos se apresenta durante os transientes de pressão e vazão no sistema, como esperado. Isso impacta no cálculo da pressão na 
superfície necessário para ajuste da pressão no fundo de referência, e consequentemente a pressão efetiva no ponto de controle.

A simulação consiste no mesmo procedimento da primeira etapa das simulações anteriores de avaliação dos controladores: verificação do sistema estável estaticamente, 0 a $1 \mathrm{~s}$; aceleração das bombas até a vazão de perfuração, 1 a $33 \mathrm{~s}$; verificação da estabilidade do sistema, 33 a $100 \mathrm{~s}$; aumento da pressão de referência no fundo (25 bar), instante de $100 \mathrm{~s}$; e verificação da resposta do controlador. Os dados geométricos do poço e as características do fluido seguem o modelo padrão de simulação usado neste trabalho.

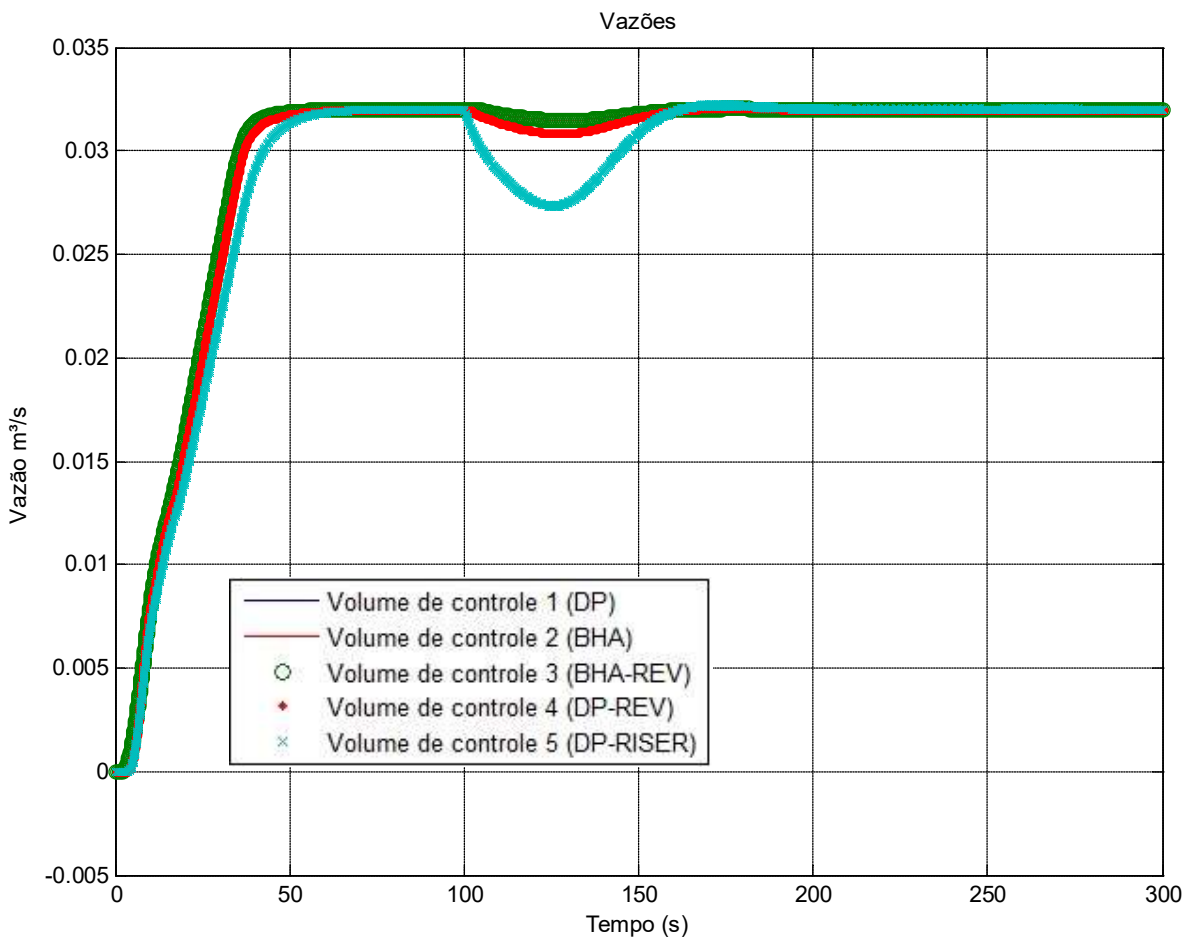

Figura 5.11 - Vazões para um simulador $P D \operatorname{com} k_{P}=1.5 \cdot 10^{-8}$ e $k_{D}=$ $1 \cdot 10^{-7}$, assumindo comportamento quase-estático. 


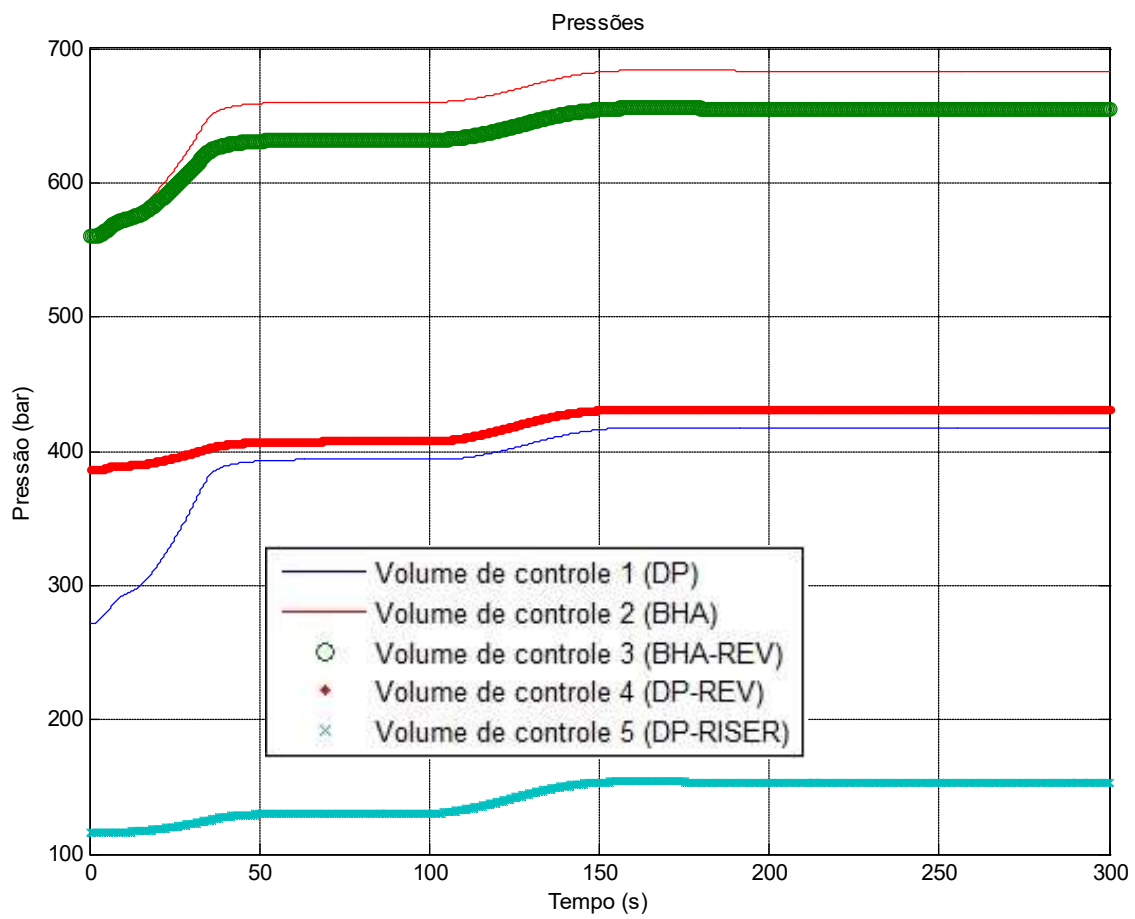

Figura 5.12 - Pressões para um simulador $P D \operatorname{com} k_{P}=1.5 \cdot 10^{-8}$ e $k_{D}=$ $1 \cdot 10^{-7}$, assumindo comportamento quase-estático.

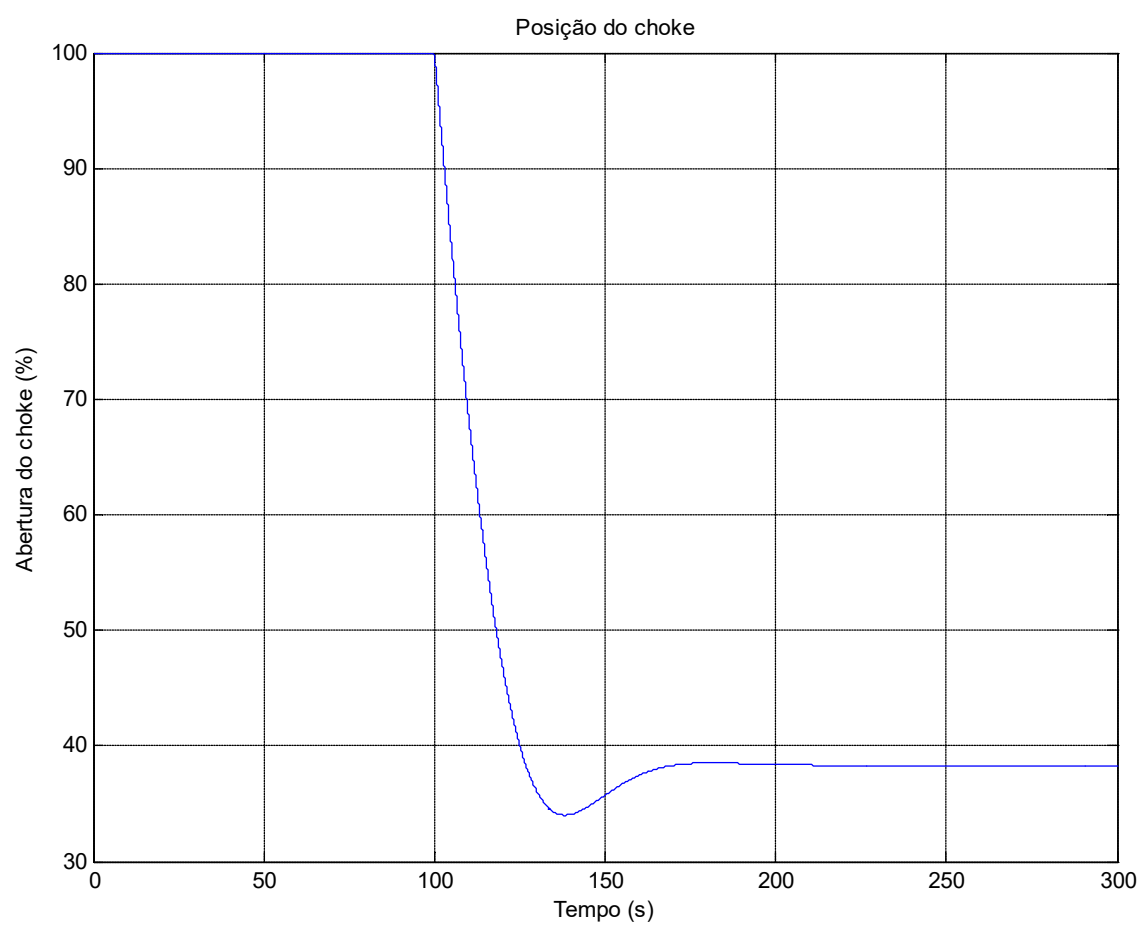

Figura 5.13 - Posição do choke para um simulador PD $\operatorname{com} k_{P}=$ $1.5 \cdot 10^{-8}$ e $k_{D}=1 \cdot 10^{-7}$, assumindo comportamento quase-estático. 
Em comparação com os resultados do controlador que considera a dinâmica do sistema na realimentação, figuras 4.23 a 4.25, a desconsideração da dinâmica das vazões no controlador provoca um atraso na sua resposta e consequentemente um pior desempenho do mesmo, visto que a pressão no fundo demora mais tempo para atingir o seu valor de referência. $\mathrm{O}$ atraso na resposta do controlador se deve ao fato que a ação do choke afeta a vazão na saída do poço, consequentemente diminuindo a perda de carga no anular. A redução da fricção do anular, apesar de ser observada no modelo dinâmico, é desconsiderada no modelo estático, por ser considerado um transiente.

Uma forma de mitigar o atraso na transmissão da pressão para o fundo do poço seria a variação do ponto de referência de forma mais lenta, com menor degrau de pressão entre passos. Com isso, a variação da vazão seria menor, acarretando em uma menor variação da perda de carga ao longo do poço. Para os casos em que a variação da vazão é aplicada, no caso do controlador apresentar atraso o ideal é que a taxa de alteração seja mais suave do que a taxa utilizada nas simulações.

Apesar de os objetivos de controle usando uma realimentação baseada em modelo quase-estático serem atendidos com um controlador PD, deve-se observar que em algumas situações operacionais durante a perfuração de poços a demora de um controlador para atingir uma nova referência de pressão pode gerar problemas que acarretam em tempo não produtivo, como influxos ou perdas para formação devido a eventual fratura. O ideal de um controlador de um choke MPD é que o mesmo considere a dinâmica interna do sistema para atuar de forma mais rápida, sabendo que transientes de alta pressão na superfície não significam necessariamente sobre-pressurização da pressão do fundo. Ou seja, a realimentação deve utilizar a pressão no fundo do poço estimada dinamicamente a partir das simulações, como feito nas seções anteriores, ao invés de usar valores quase-estáticos calculados em regime permanente.

\section{4 .}

Avaliação dos controladores NL

Dentre os controladores não lineares, os que se mostraram mais efetivos foram os controladores compensados por A e pelo quadrado do coeficiente de 
descarga. Note que a atuação no choke provoca uma variação da perda de carga localizada no mesmo. Como a perda de carga é sensível ao inverso da abertura do choke ao quadrado, vide equação (2.31), o ganho do controlador PD terá uma atuação não linear. Para evitar instabilidades, um controlador linear como o PD deve ser calibrado na região não linear mais sensível do choke, acarretando em uma resposta mais lenta do que o possível em outras regiões de operação. O uso de controladores não lineares, como os 5 propostos nesta dissertação, pode melhorar (ou piorar) o desempenho em comparação com o PD. Isto pode ser avaliado pelo comportamento das curvas de perda de carga do choke multiplicadas pelo fator de compensação dos controladores não lineares para a variação de abertura, como mostrado na figura 5.14.

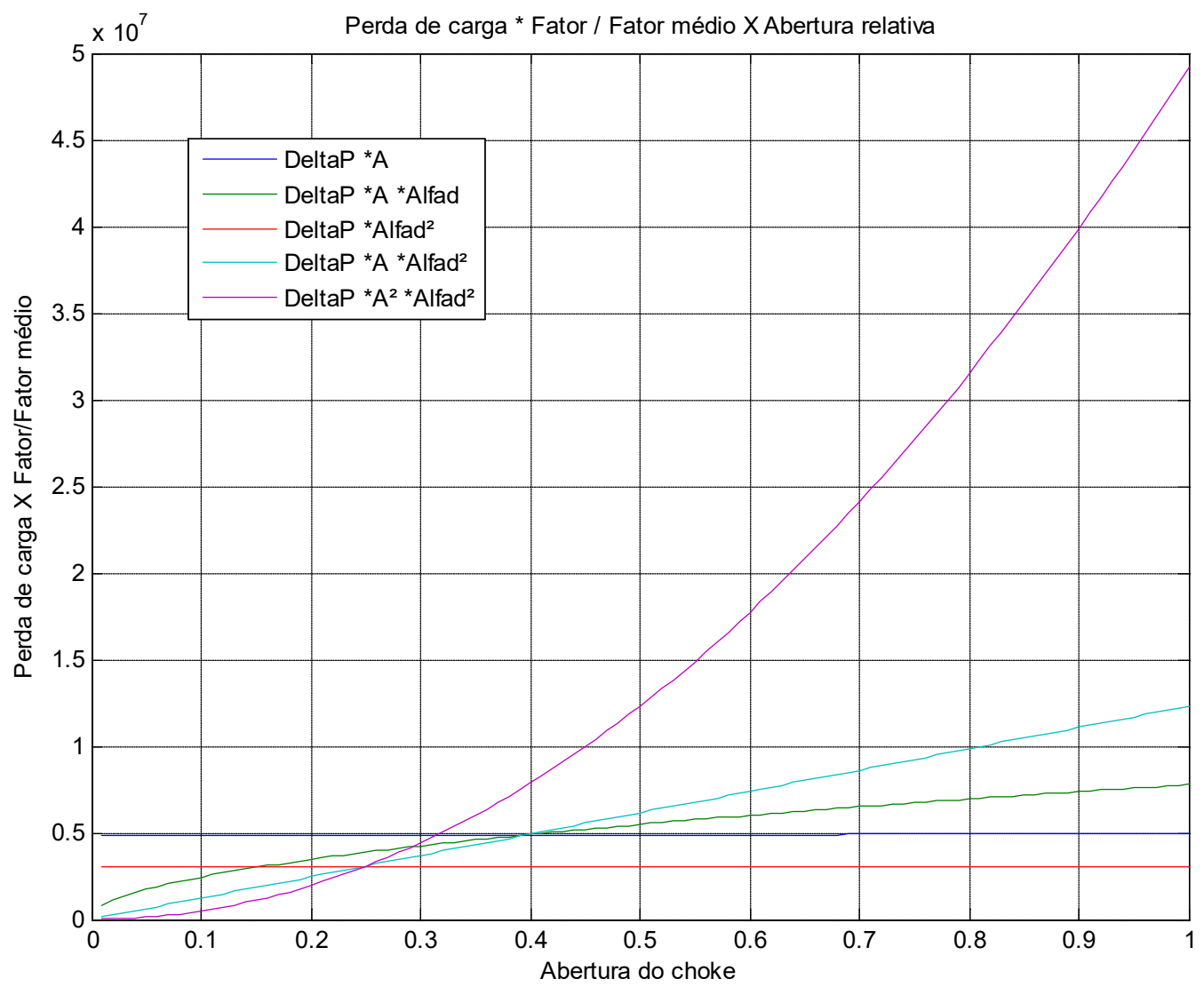

Figura 5.14 - Curvas da perda de carga compensada por fator no controlador não linear.

Conforme pode ser verificado nas 2 curvas da figura descrevendo retas horizontais, as perdas de carga compensadas pela abertura do choke A (linha azul 
escura) e pelo coeficiente de descarga do choke ao quadrado (linha vermelha) se tornam constantes, sendo capazes de linearizar a atuação no sistema para qualquer condição de operação. Isso significa que a perda de carga no choke é inversamente proporcional à abertura, visto que:

$$
\begin{aligned}
& \Delta p_{\text {choke }} * A=\text { Constante } \\
& \Delta p_{\text {choke }}=\frac{\text { Constante }}{A}
\end{aligned}
$$

No caso do controlador NL compensado pela abertura A, a constante é equivalente a $5 \cdot 10^{6}$ para o modelo simulado. A investigação dos parâmetros da equação (2.31) de perda de carga do choke indica que o mesmo é proporcional ao inverso do quadrado do coeficiente de descarga e do quadrado da área do choke. O coeficiente de descarga é definido pela equação (2.32), a partir do qual nota-se que a abertura do choke A pode ser inserida em sua equação:

$$
\alpha_{d}=\left(2,28+64 \frac{2 L}{A d^{2}}\right)^{-1 / 2} \operatorname{para} A=\frac{d_{0}}{d}
$$

A figura 5.15 mostra que a curva da perda de carga do choke em relação à sua abertura é praticamente a mesma que a curva do inverso de sua abertura, adotada no controlador NL. Como o controlador NL compensado pelo quadrado do coeficiente de descarga também apresentou bons resultados no controle da pressão, foi adicionada a curva do inverso do quadrado do coeficiente de descarga para comparação. Os resultados explicam o melhor rendimento desses dois controladores NL: ambos reproduzem muito bem as curvas de perda de carga no choke, funcionando como um compensador de suas não linearidades. 


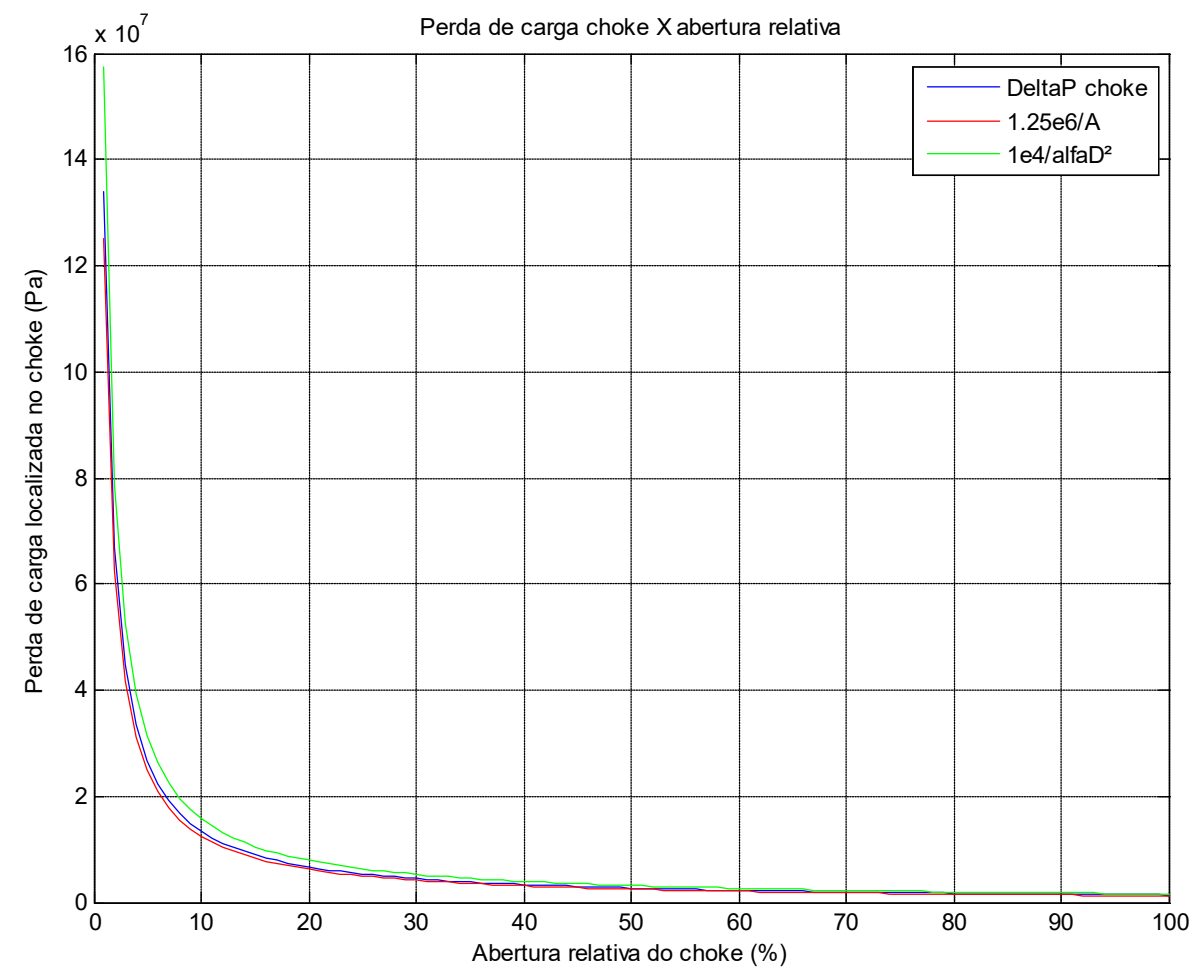

Figura 5.15 - Curvas comparativas da perda de carga do choke (DeltaP) e de fatores de compensação dos controladores NL baseados em A e em $\alpha_{d}^{2}$, em relação à abertura relativa.

Considerando uma variação de pressão lenta, e que a parcela derivativa dos controladores é desprezível, a figura 5.15 implica no fato que, para um dado erro e ganho proporcional $\mathrm{K}_{\mathrm{p}}$, a taxa de abertura comandada ao choke será uma constante, pois

$$
\frac{d A}{d t}=K_{p} * \text { erro } * \frac{A}{\bar{A}}=\text { Constante }
$$

compensando assim as não linearidades do choke, onde $\bar{A}$ é a abertura média definida para ele.

O erro na equação acima é a diferença entre a pressão desejada e a atual do fundo, logo

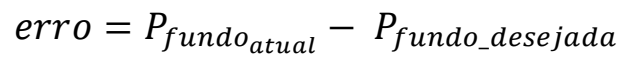

Como em uma situação de mudança lenta de pressão a pressão no fundo será dada pela equação (2.2), assumindo a mesma pressão hidrostática e as 
mesmas perdas de carga por fricção no anular, o erro passa a ser definido como a diferença da perda de carga localizada no choke para a posição desejada e a posição atual:

$$
\text { erro }=\frac{5 \cdot 10^{6}}{A}-\frac{5 \cdot 10^{6}}{A_{\text {desejado }}}
$$

O fator de $5 \cdot 10^{6}$ é referente à figura 5.14, que correlaciona a perda de carga do choke multiplicada por sua abertura. Combinando as equações 5.4 e 5.6:

$$
\frac{d A}{d t}=K_{p} \cdot 5 \cdot 10^{6} \cdot\left(\frac{1}{A}-\frac{1}{A_{\text {desejado }}}\right) \cdot \frac{A}{\bar{A}}=5 \cdot 10^{6} \cdot K_{p} \cdot \frac{A_{\text {desejado }}-A}{A_{\text {desejado }} * \bar{A}}
$$

Como a variação é constante para qualquer $\mathrm{A}$, à medida que o erro vai diminuindo, $\frac{d A}{d t}$ também diminui, mas de forma linear. Com a linearização da resposta do controlador, maiores ganhos podem ser utilizados sem afetar a estabilidade do sistema nas regiões mais sensíveis do choke, pois a reposta não linear do choke foi linearizada pela lei de controle NL.

Assumindo as mesmas premissas de transiente lento da pressão, pode-se observar na equação (5.8) que um controlador sem compensação não linear terá uma resposta não linear:

$$
\frac{d A}{d t}=K_{p} \cdot 5 \cdot 10^{6} \cdot\left(\frac{1}{A}-\frac{1}{A_{\text {desejado }}}\right)=5 \cdot 10^{6} \cdot K_{p} \cdot \frac{A_{\text {desejado }}-A}{A_{\text {desejado }} \cdot A}
$$

A figura 5.16 ilustra as curvas de resposta de um controlador linear e de um controlador não linear para abertura do choke, considerando que a abertura desejada é de $50 \%$. Valores de abertura do choke abaixo da desejada provocam uma abertura da válvula, enquanto valores acima provocam o fechamento da mesma. A figura ilustra a linearização da resposta do controlador para o caso NL, melhorando o desempenho em zonas sensíveis do choke, ao contrário do controle linear, que tem altos problemas de sensibilidade especialmente para aberturas menores que $20 \%$. 


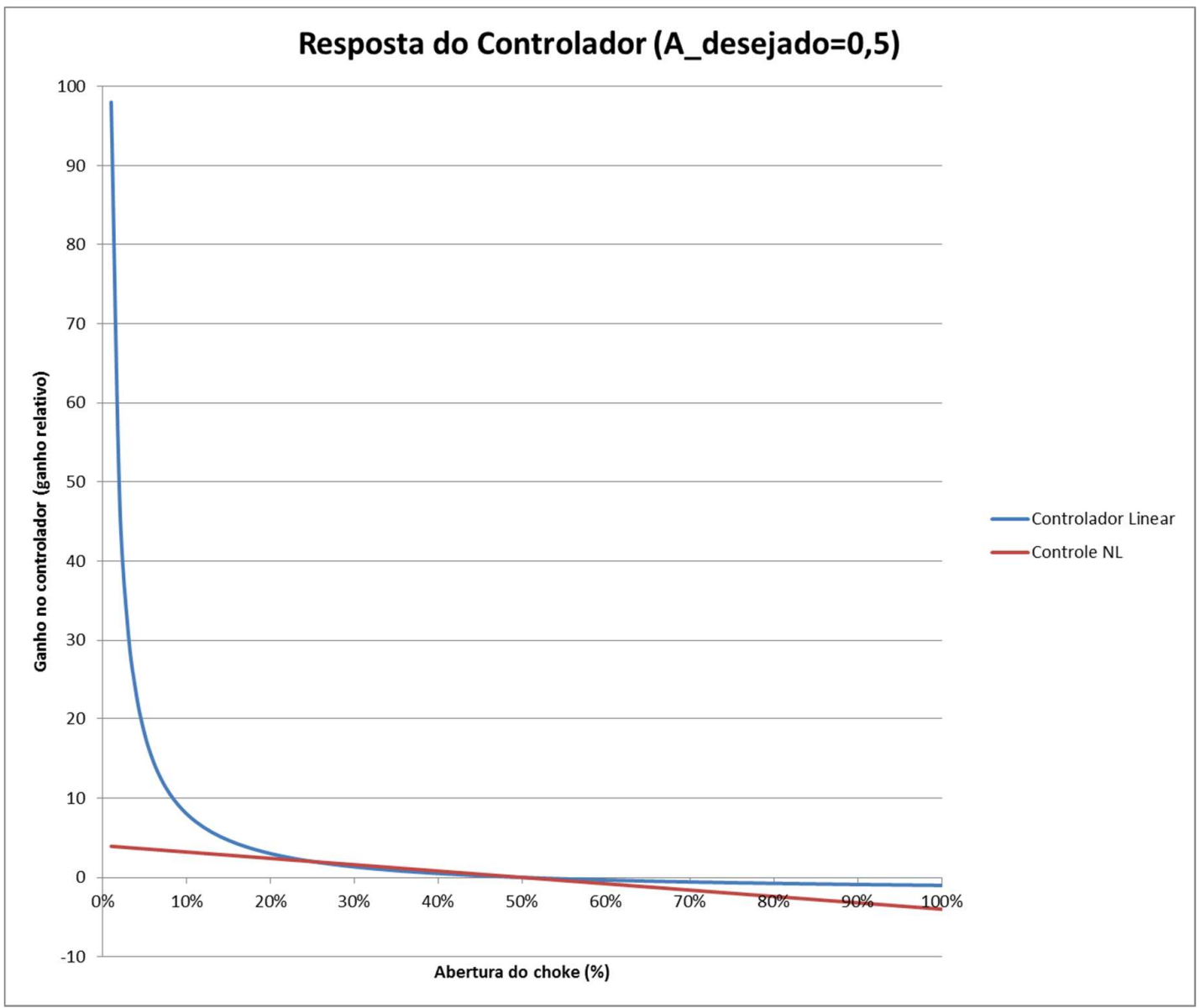

Figura 5.16 - Curvas de respostas dos controladores NL e linear na velocidade de abertura do choke.

Vale observar que as deduções encontradas nesse trabalho valem para o modelo hidráulico do mesmo. Para outros modelos de choke, seria necessário definir uma lei de controle que consiga linearizar a sua resposta com o erro da pressão na zona objetivo. A curva da constante da válvula do choke poderia servir como referência para a lei de controle NL, de forma análoga à adotada nessa dissertação. 


\section{6 Conclusões}

O modelo hidráulico desenvolvido neste trabalho mostra a importância da consideração de fluidos de diferentes reologias na distribuição da pressão em um poço, assim como o comportamento não linear dos componentes de pressão. A simplificação do modelo hidráulico por um fluido ideal incompressível demonstra erros consideráveis na estimativa de pressão no poço em comparação com outros tipos de fluido. Além da reologia, pode ser verificado que a dinâmica de atuação do choke e variações na vazão no poço causam variações de pressão que não são consideradas em uma modelagem quase-estática.

Dadas as múltiplas faixas operacionais do sistema (vazão e abertura no choke), conclui-se que não é eficiente implementar um sistema linearizado, pois o mesmo geraria um erro considerável na estimativa das condições do sistema. A decisão de trabalho com um sistema não linear facilitou o ajuste e avaliação das técnicas de controle.

As abordagens feitas para controle da pressão no poço com MPD mostram que a não linearidade do sistema e a dinâmica da transmissão da vazão e pressão representam desafios. No controle PID, e suas derivações, a não linearidade do sistema acarreta em dificuldades na seleção de ganhos adequados do controlador. Os ganhos do controlador obtidos pela metodologia de Ziegler-Nichols não apresentam desempenho satisfatório.

O não atendimento do controle da pressão pelos controladores P e PI não significa que os mesmos não são aptos ao controle de choke MPD. Em operações com estes controladores, uma alternativa seria a alteração dos ganhos do controlador conforme situação operacional, i.e. o uso de ganhos escalonados, o que é uma prática comum em alguns sistemas disponíveis no mercado. A desvantagem desta opção é que o sistema automatizado passaria a ser mais dependente do operador, e não da lógica de controle. Uma explicação para o pior desempenho dos controladores P e PI nas simulações é que a saída do controle foi baseada na taxa de mudança de velocidade do choke, que acaba por provocar um 
efeito integrativo do controle. Parte das lógicas de controle de choke disponíveis no mercado se baseia na posição do choke e não na sua taxa de alteração, eliminando o efeito integrativo do controlador e justificando o controle adequado da pressão pelos controladores P e PI nestes casos.

Os resultados das simulações indicam que a não linearidade do choke é a que possui maior impacto no controle adequado da pressão do sistema. A aplicação de um controlador não linear com compensação das características do choke na lei de controle, conforme proposto neste trabalho, permitiu o uso de parâmetros mais agressivos para controle da pressão do poço, em comparação com o controlador PD de referência, gerando melhores resultados no controle da pressão do sistema. Um fato notável do controlador não linear proposto é sua relativa facilidade de implementação. A outra proposta do trabalho para nova forma de controle, o controlador fixo baseado em mapa de características do choke e do sistema, não se mostrou robusto para um entupimento parcial do choke, problema operacional comum durante a perfuração MPD, não justificando a continuidade do seu desenvolvimento.

Uma das dificuldades do controle da pressão do poço com MPD é a medição da pressão no seu fundo. As ferramentas disponíveis no mercado não fornecem informações na taxa e confiabilidade necessárias para o uso direto no controlador do sistema. Este fato é um empecilho para que fornecedores de controladores de choke MPD passem a considerar os efeitos da dinâmica do poço, limitando a modelagem hidráulica do sistema para uma modelagem quaseestática, o que de fato limita a real efetividade dos sistemas atuais. Em formações competentes, as alterações na pressão do poço são desprezíveis, porém em formações frágeis a dinâmica do sistema durante os transientes pode causar impactos na operação de perfuração.

Neste trabalho, por outro lado, não apenas foram inseridas não linearidades no controlador, mas também o valor de realimentação da pressão no fundo do poço foi simulado e estimado dinamicamente. Deste modo, o controlador não linear proposto que obteve melhor desempenho (baseado em A) é pouco sensível às não linearidades do choke (pois elas são compensadas), é robusto em relação a perturbações (como entupimento parcial do choke por detritos, um evento comum), e possui resposta consideravelmente mais rápida que a de controladores 
baseados em modelos quase-estáticos (pois a dinâmica do sistema é simulada, estimada e realimentada).

O controle da pressão no poço se mostrou dependente do modelo hidráulico e técnica de controle empregada. Quanto mais elaborado o modelo hidráulico, melhor foi o desempenho observado no controle da pressão. O controlador que melhor resposta obteve foi o que conseguiu linearizar a resposta ao erro do sistema apresentando-se como alternativa para implementações futuras.

\section{1 .}

\section{Trabalhos Futuros}

Como desenvolvimento futuro deste trabalho, duas frentes são possíveis: a primeira é o aprimoramento do modelo hidráulico; a segunda é o desenvolvimento adicional das técnicas de controle do sistema.

O modelo hidráulico desenvolvido limitou o uso de somente um fluido no sistema de cada vez, e somente dois tipos de fluido possíveis. O ajuste da não linearidade das equações de perda de carga para os fluidos de Bingham e Herschell-Buckley trariam maior abrangência sobre os fluidos de perfuração. $O$ uso de mais de um tipo de fluido no sistema possibilitaria as simulações de troca de fluido e circulação de influxos no poço.

Além disso, o modelo de perda de carga do choke foi adaptado de um modelo teórico; a inserção de dados de testes de válvulas e a inclusão da dinâmica de pressão dentro do choke aproximaria o modelo hidráulico ainda mais da realidade.

A implementação de um observador tipo filtro de Kalman estendido no controle permitiria avaliar a implementação da dinâmica do sistema na resposta do controlador na presença de ruidos significativos dos sensores. A técnica de controle não linear, com compensação pelas caraterísticas da válvula escolhida como compensação pela abertura $\mathrm{A}$, poderia servir de referência na avaliação de outras técnicas de controle como lógica fuzzy e controle adaptativo.

Outra possibilidade de trabalho futuro é a implementação das técnicas de controle em uma planta de testes de um poço real, conforme é feito por alguns fornecedores de controladores de choke MPD. 


\section{7 Referências Bibliográficas}

AZIZ, I. A. A., MOHAMMAD, M. B., SAPIDIH, F. B., SYAFEEQ, M., AMIR, B. E., VAN HUNG, L., ROJAS, F., TANG, J., RICHARDS, D., RUBIANTO, I., BRAHMANTO, E., MPD Application on ERD Well in Offshore Peninsular Malaysia - Reducing Cyclical Fatigue Forces across the Weak Formations by Managing the ECD 168951-MS SPE Conference Paper - 2014.

BOURGOYNE, T. A., MILLHEIM, K. K., CHENEVERT, M. E., YOUNG, F. S., Applied Drilling Engineering, 1985.

CAPELLI, A., Eletrônica Automotiva, 2010.

FERNANDES, A. A., GOZZI, D. S., NOGUEIRA, E. F., TERRA, F. S., VANNI, G. S. FRAZÃO, R. S., MPD/MCD Offshore Application on a Dynamic Positioning Rig, 173825-MS SPE Conference Paper, 2015.

FOSSLI, B., SANGESLAND, S., Controlled Mud-Cap Drilling For subsea Applications: Well-Control Challenges in Deep Waters, SPE 91633, 2006.

FRINK, P., Managed Pressure Drilling - What's in a name? Drilling Contractor March/April, 2006.

GABALDON, O., CULEN, M., BACON, W., BRAND, P., Enhancing Well Control Through Managed Pressure Drilling, 25256-MS OTC Conference Paper, 2014.

GODHAVN, J.M., Control Requirements for high-end automatic MPD Operations, SPE/IADC 119442, 2009.

GOMES, F. J. A. D., Hidráulica, fluidos de potência: racionalização do uso do fator de fricção, I. Encontro Técnico sobre Informática na Perfuração, CAPER/87, Módulo 7, Salvador, Brasil, 1987. 
HAMOUDI, I, KARTOBI, K., VIEIRA, P., SAAD, M. A., TORRES, F., QUTOB, H., Drilling Hazard Mitigation Technology Enables Conventionally Undrillable Prospects To be Drilled With Reduced Nonproductive Time and Increased Operational Safety: Application of Solid Expandable Liners and Managed Pressure Drilling in Algeria Nezla Field, SPE/IADC 156907, 2012.

ISMAIL, Z., AZIZ, I. UMAR, L., NORDIN, N. A. B., ROJAS, F., TANG, J., ZAPATA, G. G., WAGUIH, A., SUBrotO, B., DOW, B., Automated Managed Pressure Drilling Allows Identification of New Reserves in a HPHT Exploration Well in SB field, offshore Malaysia, SPE/IADC 151518, 2012.

JELALI, M., KROLL, A., Hydraulic servo-systems: modelling, identification and control. (Advances in industrial control), 2003.

LANDET, I. S., MAHDIANFAR, H., AARSNES, U. J. F.; PAVlOV, A., STATOIL; AAMO, O. M., Modeling for MPD operations with experimental validation, SPE 150461, 2012.

MACHADO, J. C. V., Reologia e Escoamento de Fluidos, 2002.

MARTINS, A. L.; MARQUES DE SÁ, C. H.; AMARAL, M. S.; VILLASBOAS, M. B.; Programa Chip-Reo cálculos de hidráulica de perfuração utilizando diversos modelos reológicos, CT TEP 025/93, Ago 1993.

MATHEW, S. G., NASR, G. G., Optimized Drilling by improved Well Control Using MPD in Narrow Pressure Window, SPE 157075, 2012.

MATLAB® (The MathWorks Inc., 2000) User Manual, Mathworks, 2011.

MONTILVA, J, MOTA, J., POLETZKY, I. C., SATI, M., LOVORN, R., GRABLE, J., Next-Generation Managed Pressure Drillin System Enables HP/HT Horizontal Wells in Haynesville Shale SPE/IADC 151168, 2012.

NUNES, G. C., MEDIROS, J. L., ARAUJO, O. Q. F., Modelagem e Controle na Produção de Petróleo, 2010.

OGATA, K., Engenharia de Controle Moderno 5ª Ed, 2011. 
PEREIRA, C. E. G, An Experimental Work on Well Cementing Hydraulics, AADE Fluids Technical Conference and Exhibition, 2014, Houston, TX.

ROCHA, L. A., AZEVEDO, C. T., Projetos de poços de petróleo, 2007.

ROCHA, L. A., AZUAGA, D., ANDRADE, R., VIEIRA, J. L. B., SANTOS, O. L. A., Perfuração Direcional, 2002.

ROSS, N., SCAIFE, T., MACMILLAN, R., BERG, P. C., JENNER, J. W., Use of the continuous Circulation System on the Kvitebjørn Field, SPE/IADC 156899, 2012

ROTAVA, O, Aplicações Práticas em Escoamento de Fluidos, 2011.

SAEED, S., LOVORN, R., KNUDSEN, K. A., Automated Drilling Systems for MPD- The Reality, SPE/IADC 151416, 2012.

SANTOS, H., PEREZ, R., What have we been doing wrong in wellbore Stability?, 69493-MS SPE Conference Paper, 2001.

SANTOS, H., ROSA, F. S., CUNHA, J. C., Horizontal Underbalanced Drilling In Northeast Brazil: A Field Case History, 69490-MS SPE Conference Paper, 2001.

SCHEID, C. M., CALCADA, L.A., ROCHA D., ARANHA, P. E. ARAGAO, A. F. L., MARTINS, A. L., Prediction Of Pressure Losses In Drilling Fluid Flows In Circular And Annular Pipes And Accessories, Latin American and Caribbean Petroleum Engineering Conference, Cartagena de Indias, Colombia, SPE 122072-MS, 2009.

SHARMA, D., AGARWAL, C., LOBO, M., CHAKRABORTY, B., BRICKELL, N., PATHAK, M., LANG, C., Use of Managed Pressure Drilling Technology Helped in Achieving Well Objectives: A Case Study of an Offshore HTHP Well in India, 173817-MS SPE Conference Paper, 2015.

SIAHAAN, H. B., VEFRING, E. H., NIKOLAOU, M., GRAVDAL, J. E., Evaluation of Coordinated Control During Back Pressure MPD Operations, SPE 169205-MS, 2014.

THOMAS, J. E., Fundamentos de engenharia de Petróleo, 2001. 
THOROGOOD, J.L., Automation in Drilling: Future Evolution and Lessons from Aviation, SPE/IADC 151257, 2012.

UMAR, L., AZIAN, I., AZREE, N., ALI, A.R.M., WAGUIH, A., ROJAS, F., FEY, S., SUBROTO, B., DOW, B., GARCIA, G., Demonstrating the Value of Integrating FPWD Measurements With Managed Pressure Drilling To Safely Drill Narrow Mud Weight Windows in HP/HT Environment, SPE/IADC 156888, 2012.

WISE, K. A, Develop next generation MPD technology; Enabling operation by the driller as a Best Practice drilling operation, IADC Dubai conference, 2015. www.rigzone.com/data/dayrates/

ZIEGLER, J.G AND NICHOLS, N. B. Optimum settings for automatic controllers, 1942. 


\section{8 \\ Anexos}

\section{1.}

Dados para simulação

Dados geométricos do poço e coluna de perfuração:

Tabela 8-1 - Dimensões dos elementos do poço

\begin{tabular}{|l|c|c|c|}
\hline \multicolumn{1}{|c|}{ Elemento } & $\begin{array}{c}\text { ID } \\
\text { (polegadas) }\end{array}$ & $\begin{array}{c}\text { OD } \\
\text { (polegadas) }\end{array}$ & $\begin{array}{c}\text { Comprimento } \\
(\mathrm{m})\end{array}$ \\
\hline Drillpipe & 4,63 & - & 4700 \\
\hline BHA & 3 & - & 300 \\
\hline Anular poço revestido - BHA & 8,6 & 8 & 300 \\
\hline Anular poço revestido - drillpipe & 8,6 & 5,5 & 2700 \\
\hline Anular riser - drillpipe & 19,25 & 5,5 & 2000 \\
\hline
\end{tabular}

Propriedades do fluido de perfuração, em unidades SI:

Modelo reológico: Potência;

Densidade: $1092.4 \mathrm{~kg} / \mathrm{m}^{3}$;

Módulo de compressibilidade: 6,6 *10 ${ }^{9} \mathrm{~Pa}$;

Viscosidade plástica:0,057 Pa.s;

Limite de escoamento: 11,97 Pa;

Fator K: 0,04;

Fator N: 0,5. 


\section{2.}

\section{Matrizes linearizadas do sistema}

Código Matlab para montagem das matrizes do sistema linearizado:

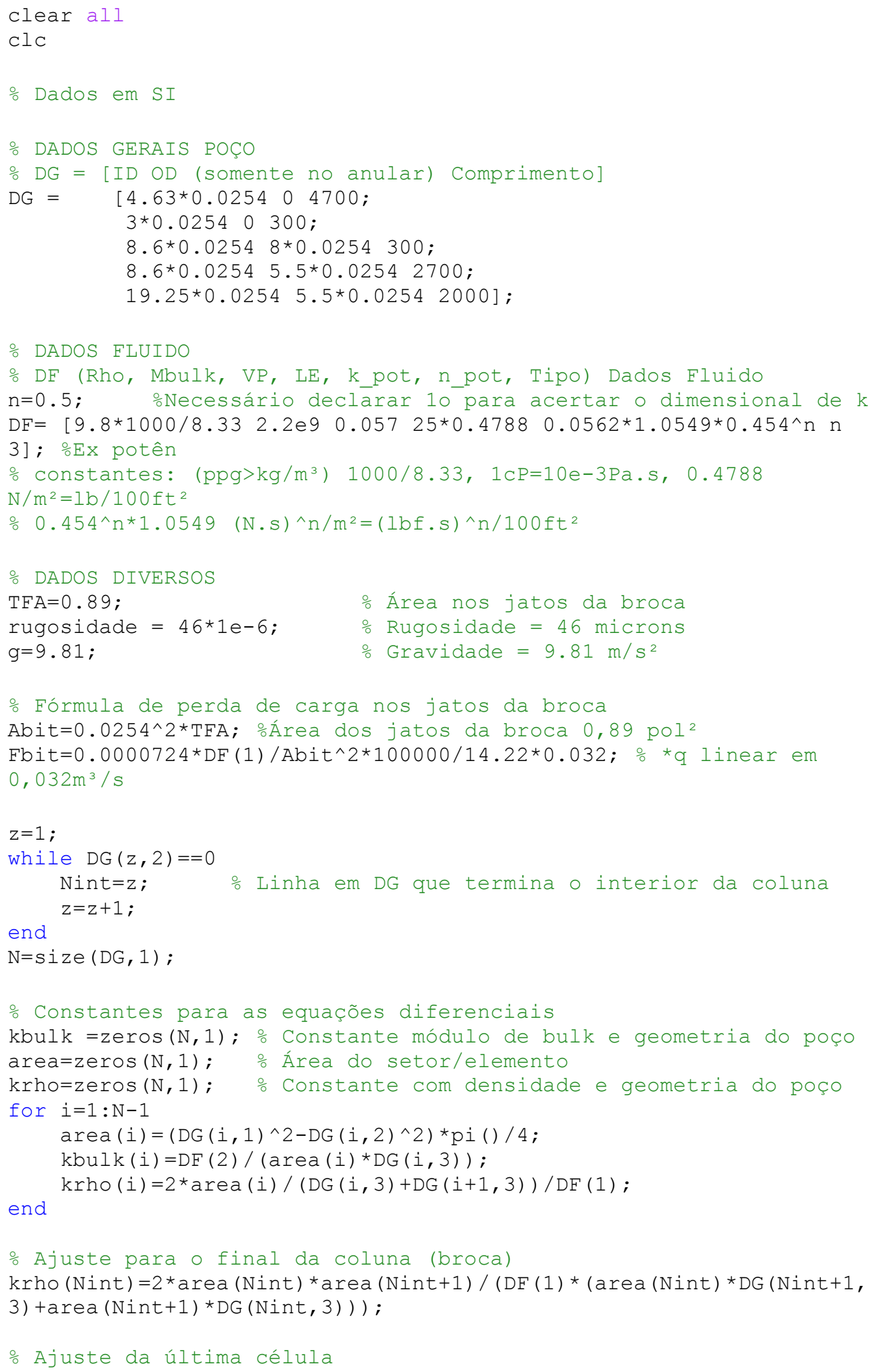




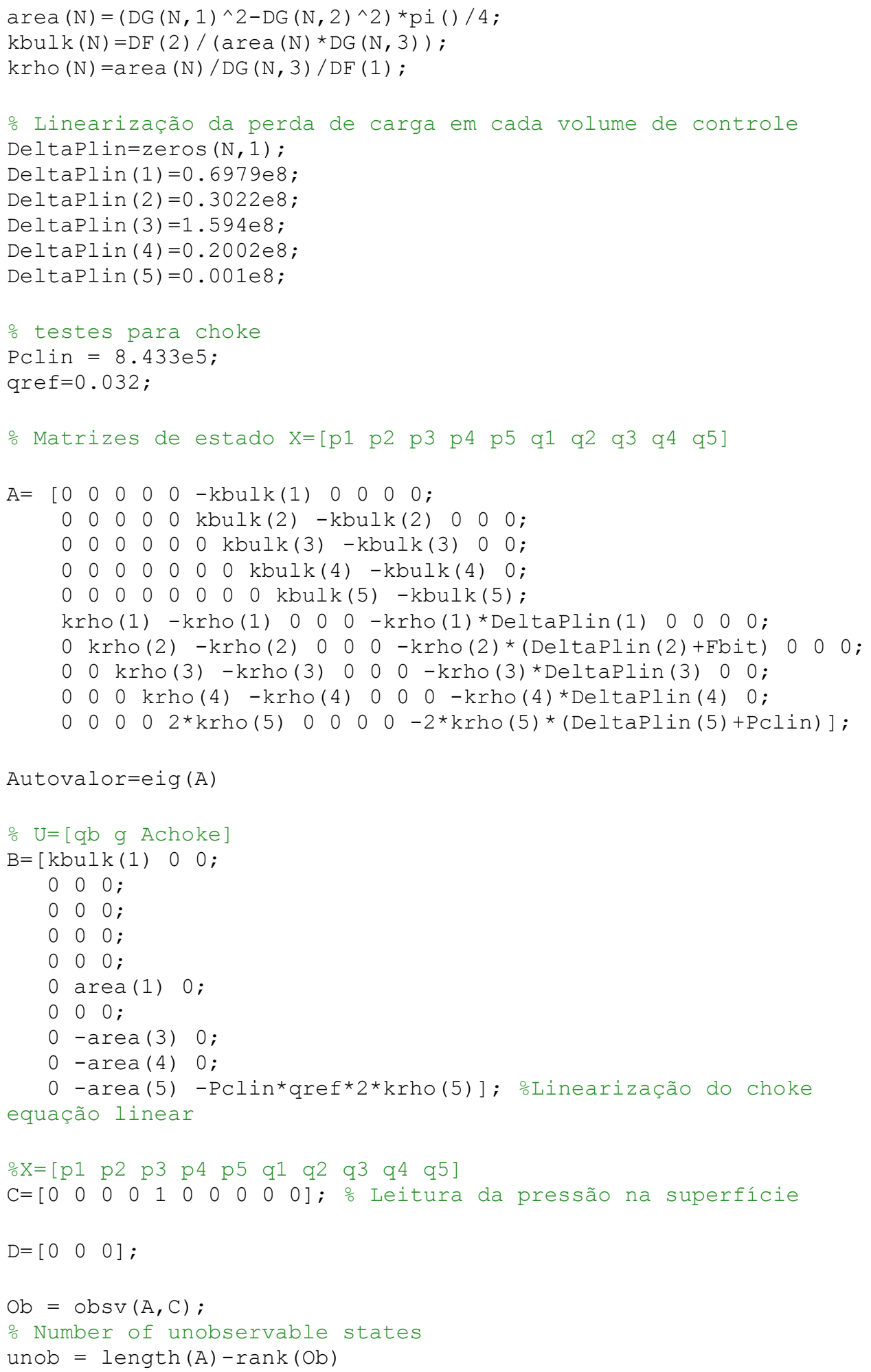

